\title{
Identifizierung der für die Agonisten-induzierte Phosphorylierung und Internalisierung relevanten Serine und Threonine in der C-terminalen Domäne des humanen Prostaglandin $E_{2}$ Rezeptors, Subtyp EP4
}

\author{
Dissertation \\ zur Erlangung des Doktorgrades \\ der Mathematisch-Naturwissenschaftlichen Fakultäten \\ der Georg-August-Universität zu Göttingen
}

vorgelegt von

Matthias Rehwald

aus Homberg

Göttingen 2003 
D 7

Referent :

Prof. Dr. K. von Figura

Korreferent :

Prof. Dr. R. Hardeland

Tag der mündlichen Prüfung : 7. Mai 2003 


\section{INHALTSVERZEICHNIS}

VERZEICHNIS DER ABBILDUNGEN................................................... XI

VERZEICHNIS DER TABELLEN.......................................................... XIV

VERZEICHNIS DER ABKÜRZUNGEN............................................... XV

VERZEICHNIS DER AMINOSÄUREN UND IHRER ABKÜRZUNGEN.......... XVIII

Zusammenfassung ...................................................................... 1

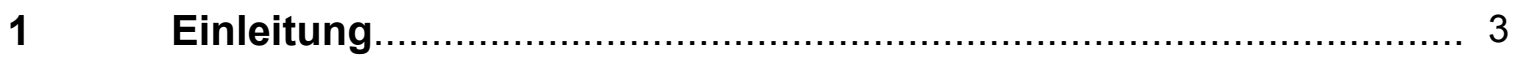

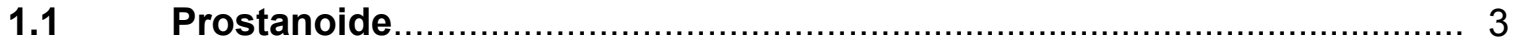

1.2 Plasmamembranständige Prostanoidrezeptoren................................... 3

1.2.1 Klassifikation der Prostanoidrezeptoren................................................ 5

1.2.2 Strukturelle Gemeinsamkeiten der Prostanoidrezeptoren............................. 5

1.3 Signaltermination der G-Protein-gekoppelten Rezeptoren..................... 8

1.3.1 Komponenten der Agonisten-induzierten Desensitisierung und

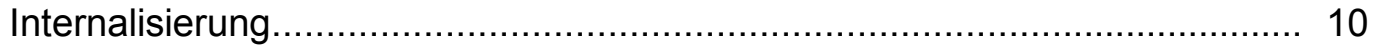

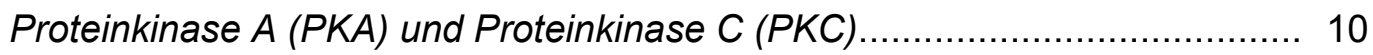

G-protein-coupled receptor kinase (GRK) ............................................ 11

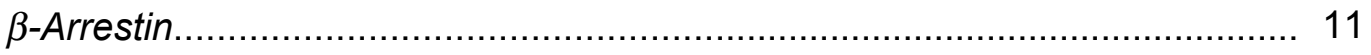

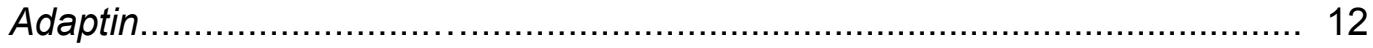

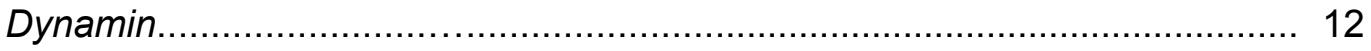

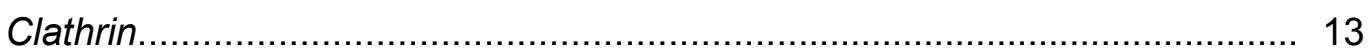

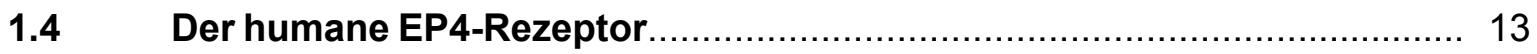

1.4.1 Struktur des humanen EP4-Rezeptors.................................................. 13

1.4.2 Physiologische Bedeutung des EP4-Rezeptors........................................ 15

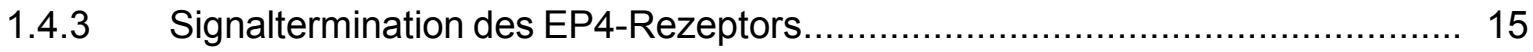

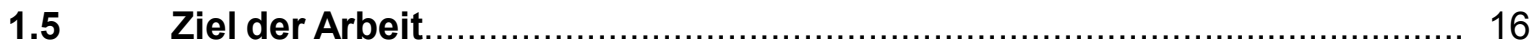

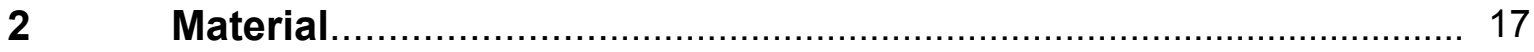

2.1 Chemikalien und Biochemikalien.................................................. 17

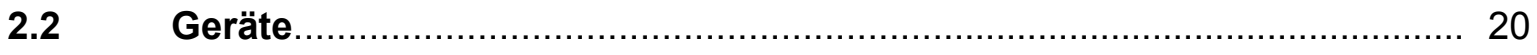

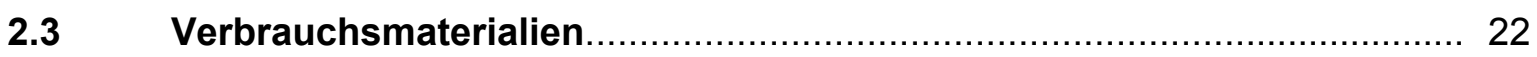

$2.4 \quad$ Reinigungs- und Isolierungssysteme ............................................. 22

2.5 Chemilumineszenz-Nachweissystem............................................... 23

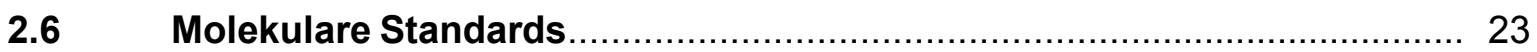

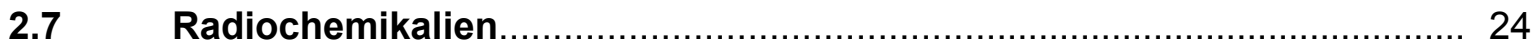

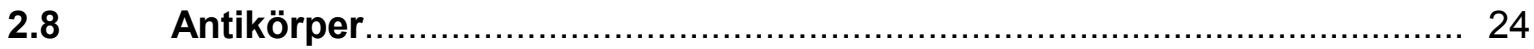




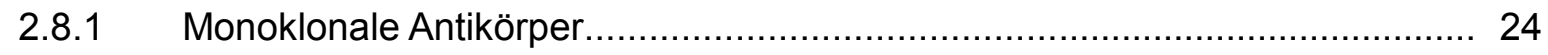

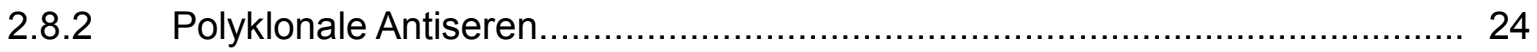

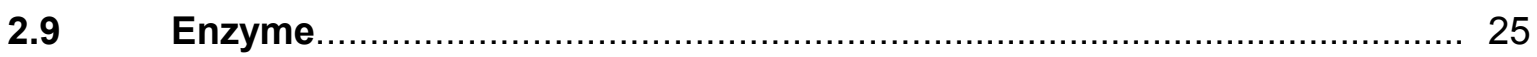

2.9.1 Restriktionsenzyme mit Erkennungssequenz und Spaltstelle (-)................. 25

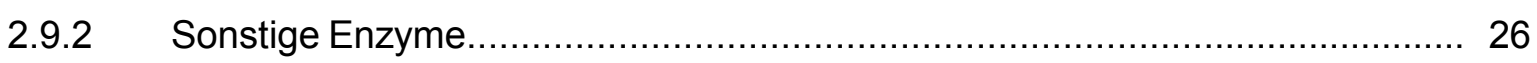

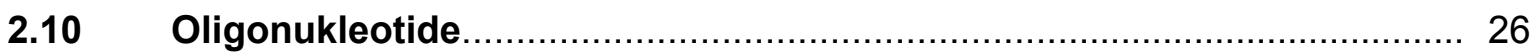

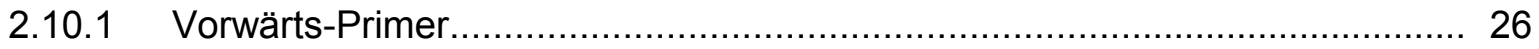

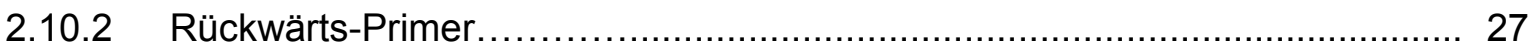

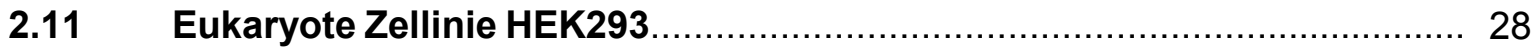

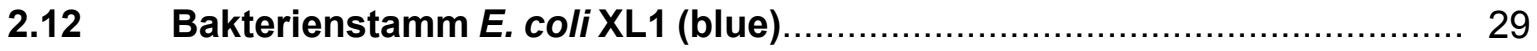

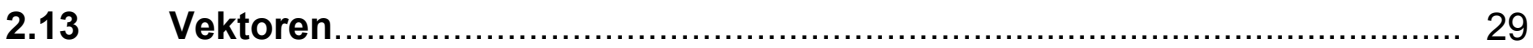

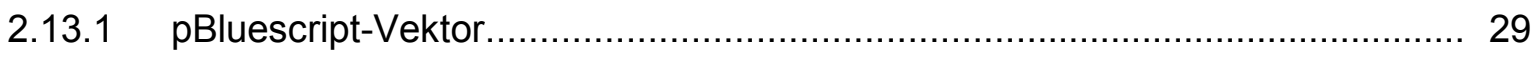

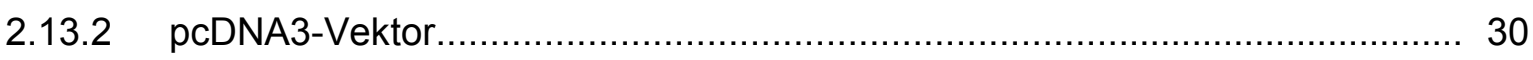

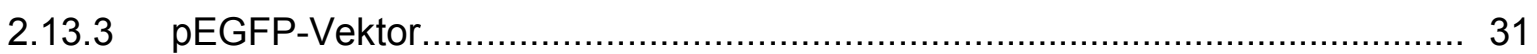

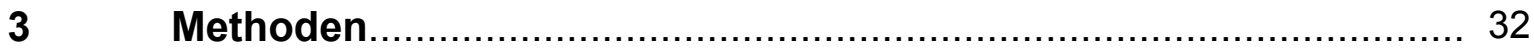

\section{ALLGEMEINE MOLEKULARBIOLOGISCHE METHODEN}

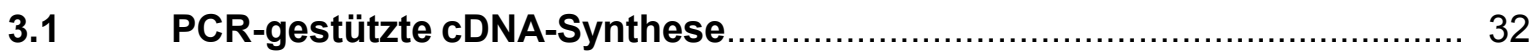

3.1.1 Puffer und Lösungen............................................................................. 32

3.1.2 Prinzip der Polymerasekettenreaktion (PCR) ............................................ 32

3.1.3 Amplifizierung von Rezeptor-cDNA mit der PowerScript DNA-Polymerase..... 33

3.1.4 Verlängerung des translatierten Bereichs einer cDNA-Sequenz um eine für eine Peptid- oder Restriktionsenzym-Erkennungsstelle-codierenden

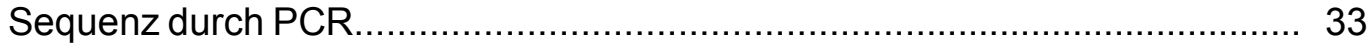

3.1.5 Prinzip der sequenzgerichteten Mutagenese ........................................... 34

3.2 Agarose-Gelelektrophorese von DNA ............................................. 35

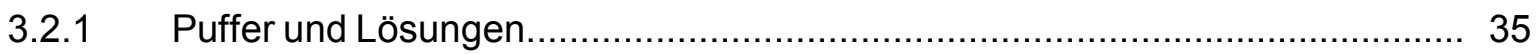

3.2.2 Auftrennung von DNA auf Agarose-Gelen................................................. 36

3.2.3 Semiquantitative Bestimmung der DNA-Menge in Agarose-Gelen................. 36

3.3 Reinigung von DNA aus Agarose-Gelen........................................... 36

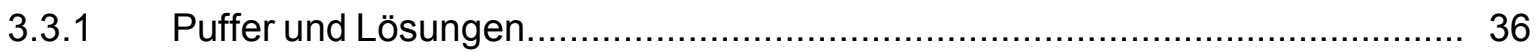

3.3.2 Isolierung der DNA-Fragmente.............................................................. 37

3.4 Klonierung der gereinigten cDNA-Fragmente in einen Vektor................ 37

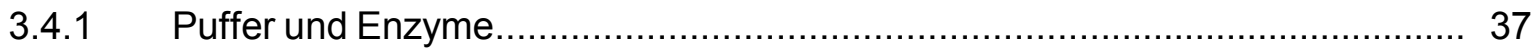


3.4.2 Vorbereitung der cDNA-Fragmente (5'- und 3'-hEP4-Fragmente) und der Vektoren (pBluescript und pcDNA3).

3.4.3 Ligation der cDNA-Fragmente in die Vektoren (pBluescript und pcDNA3).

3.5 Herstellung kompetenter E. coli XL1 (blue) Zellen für die Elektroporation. 38

3.5.1 Puffer und Lösungen....................................................................... 38

3.5.2 Vorbereitung der E. coli XL1 (blue) Zellen.............................................. 39

3.5.3 Herstellung einer Glycerolkultur von E. coli XL1 (blue) Zellen....................... 39

3.6 Transformation kompetenter E.coli XL1 (blue) Zellen.............................. 39

3.6.1 Puffer und Lösungen..................................................................... 39

3.6.2 Transformation durch Elektroporation.................................................. 40

3.7 Isolierung von Plasmid-DNA im Mini-Maßstab.................................. 41

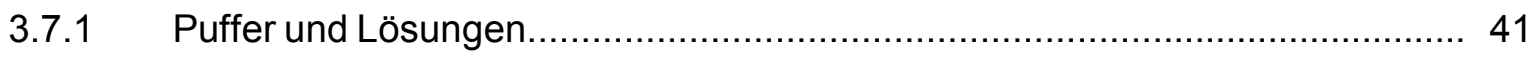

3.7.2 Präparation von Plasmid-DNA im Mini-Maßstab........................................ 42

3.7.3 Photometrische Quantifizierung der gereinigten Plasmid-DNA.................... 42

3.8 Isolierung von Plasmid-DNA im Maxi-Maßstab................................. 43

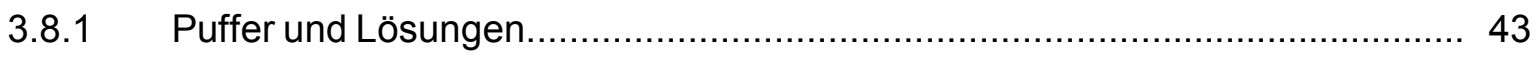

3.8.2 Isolierung der Plasmid-DNA durch Affinitätschromatographie im Maxi-

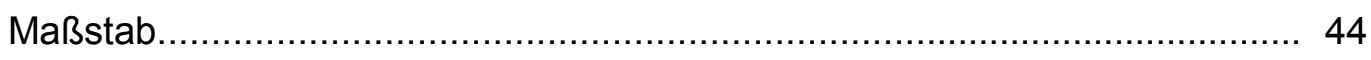

3.9 Charakterisierung der Plasmide durch Restriktionsenzymspaltung....... 44

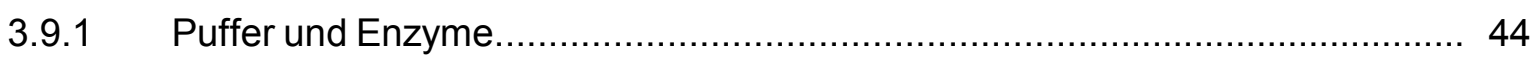

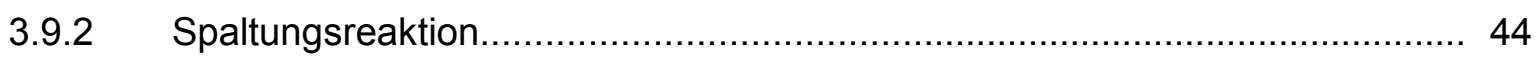

3.10 Charakterisierung der Plasmide durch Sequenzierung........................ 45

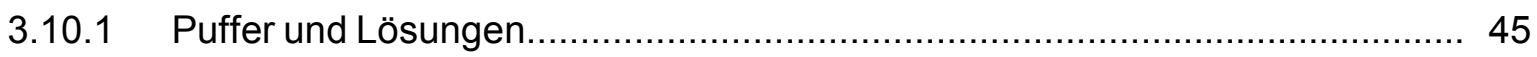

3.10.2 Vorbereitung der Polyacrylamid (PAA)-DNA-Sequenziergele....................... 46

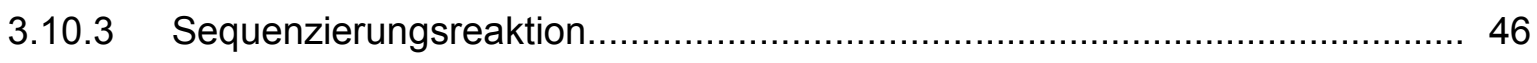

3.10.4 Aufreinigung der Proben................................................................. 47

3.10.5 Automatische Sequenzierung und EDV-gestützte Auswertung.................... 47

SYNTHESE DER MUTIERTEN REZEPTORPROTEINE

3.11 Modifikationen der humanen EP4-Rezeptor-cDNA .............................. 47

3.11.1 Verlängerung des translatierten Bereichs der hEP4-Rezeptor-cDNA um eine für das FLAG-Epitop codierende Sequenz.

3.11.2 Sequenzgerichtete Mutagenese der FLAG-hEP4-Rezeptor-cDNA zum Einführen der SnaB I-Restriktions-Erkennungssequenz. 
3.12 Einfügen der Mutationen zur Substitution der Serine und Threonine in der für die C-terminalen Domäne codierenden 3'-Sequenz der FLAG-hEP4 wt-R-cDNA.

3.12.1 Amplifizierung des 5' um die Kpn I-Restriktions-Erkennungssequenz verlängerten 3'-cDNA-Fragments der FLAG-hEP4-Rezeptor-cDNA und Einfügen der ST335-338A-Mutationen.

3.12.2 Synthese der C-terminalen Sequenz der FLAG-hEP4-R-cDNA mit der Substitution aller Serine und Threonine. 50

3.12.3 Klonierung der gereinigten Fragmente in pBluescript. 52

3.13 Klonierung der gesamten FLAG-hEP4 wt-Rezeptor- sowie der mutierten Rezeptor-cDNAs in den pcDNA3-Vektor............................. 54

3.13.1 Puffer und Enzyme........................................................................ 54

3.13.2 Vorbereitung der cDNA-Fragmente und Ligation....................................... 54

\section{ZELLBIOLOGISCHE UND BIOCHEMISCHE METHODEN}

3.14 Eukaryote Expression der gentechnisch modifizierten Rezeptorproteine in HEK293-Zellen.......................................................... 55

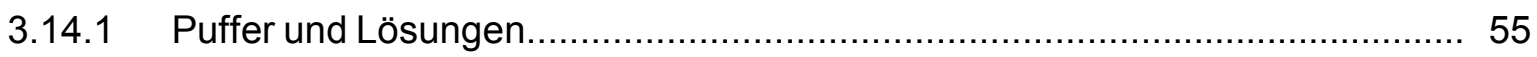

3.14.2 Kultivierung von HEK293-Zellen........................................................ 56

3.14.3 TransienteTransfektion von HEK293-Zellen mit der modifizierten Calcium-Phosphat-Methode.............................................................. 56

3.14.4 Selektion stabil transfizierter HEK293-Zellen.......................................... 57

3.14.5 Kryolagerung der stabilen Zellklone in flüssigem Stickstoff.......................... 58

3.15 Präparation von Gesamt-RNA aus stabil transfizierten HEK293-

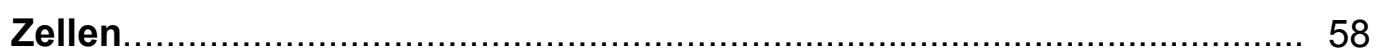

3.15.1 Puffer und Lösungen....................................................................... 58

3.15.2 Isolierung von Gesamt-RNA aus stabil transfizierten HEK293-Zellen............ 59

3.16 cDNA-Synthese durch reverse Transkription...................................... 60

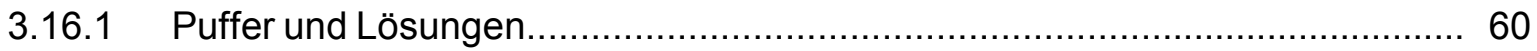

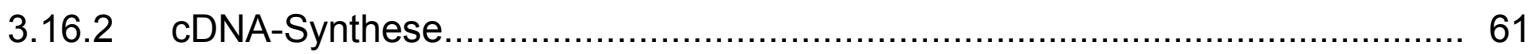

3.17 PCR-gestützte Analyse zur Identifikation der stabil transfizierten HEK293-Zellen............................................................................ 61

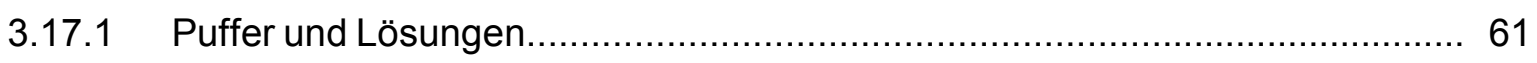

3.17.2 Amplifizierung spezifischer cDNA-Fragmente........................................ 61

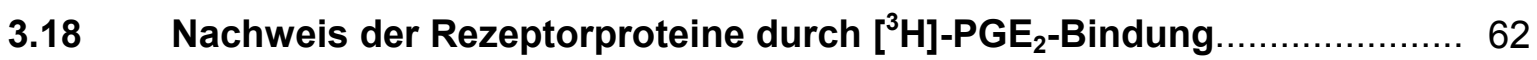

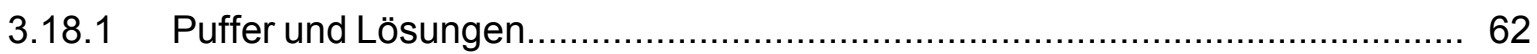

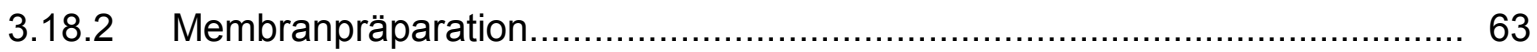




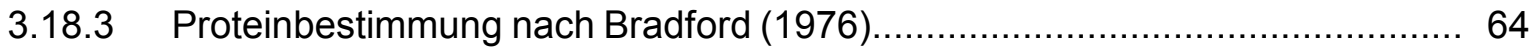

3.18.4 Nachweis der $\left[{ }^{3} \mathrm{H}\right]-\mathrm{PGE}_{2}$-Bindung in Membranen..................................... 64

3.19 Immunologischer Nachweis der Rezeptorproteine durch

Westernblot-Analyse..................................................................... 64

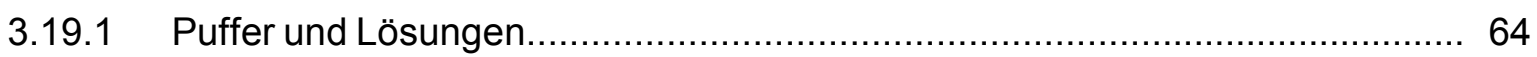

3.19.2 Immunpräzipitation der Rezeptorproteine .................................................. 67

3.19.3 Vorbereitung der Proben für die SDS-Polyacrylamid-Gelelektrophorese........ 68

3.19.4 Vorbereitung der Polyacrylamidgele für die SDS-PAGE............................. 68

3.19.5 Trennung der Membranproteine durch SDS-PAGE.....................................6 69

3.19.6 Fixierung mit Coomassie-Blue-Fixierlösung und Trocknung der Gele für den Nachweis der metabolisch [ $\left.{ }^{32} \mathrm{P}\right]$-ortho-Phosphat markierten Rezeptorproteine.

3.19.7 Transfer der getrennten Proteine auf PVDF-Membranen durch

Elektroblotting für den immunologischen Nachweis der

Rezeptorproteine

3.19.8 Nachweis der geblotteten Proteine durch Ponceau S-Färbung.................... 70

3.19.9 Immunologischer Nachweis der Rezeptorproteine durch Immunperoxidase-Färbung der geblotteten Proteine.

3.20 Charakterisierung der Bindungseigenschaften der modifizierten Rezeptorproteine im Vergleich mit dem nativen Rezeptorprotein.......... 71

3.20.1 Puffer und Lösungen................................................................... 71

3.20.2 Bestimmung der Affinität und der maximalen Bindungskapazität der verschiedenen Rezeptorproteine durch Sättigungsbindungsstudien

3.21 Nachweis der funktionellen Eigenschaften der Rezeptorproteine

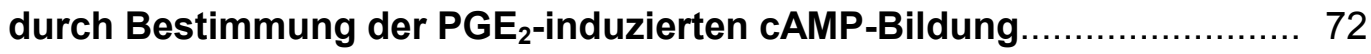

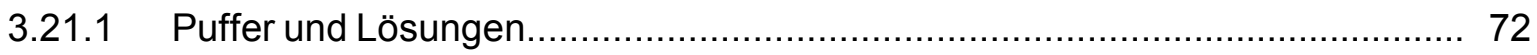

3.21.2 Präparation von Membranen der Rezeptor exprimierenden HEK293Zellen.

3.21.3 Nachweis der Dosis-abhängigen cAMP-Bildung an Membranen Rezeptorexprimierender HEK293-Zellen........................................................ 75

3.21.4 Kinetik der Forskolin-abhängigen cAMP-Bildung in intakten Zellen................. 75

3.21.5 Bestimmung der cAMP-Konzentration durch Radioimmunoassay (RIA)........ 76

3.22 Untersuchung der Desensitisierung der in HEK293-Zellen stabil exprimierten Rezeptorproteine .................................................. 76

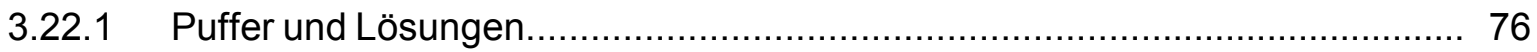


3.22.2 Bestimmung der Desensitisierung der $\mathrm{PGE}_{2}$-abhängigen cAMP-Bildung nach Vorstimulation der Rezeptor-exprimierenden HEK293-Zellen mit $\mathrm{PGE}_{2}$

3.22.3 Kinetik der $\mathrm{PGE}_{2}$-induzierten cAMP-Bildung nach Vorstimulation der Rezeptor exprimierenden HEK293-Zellen mit $\mathrm{PGE}_{2}$.

3.22.4 Kinetik der ONO604-induzierten cAMP-Bildung nach Vorstimulation der Rezeptor-exprimierenden HEK293-Zellen mit ONO604 und verzögerter Gabe von IBMX.

3.22.5 Bestimmung der Konzentrations-abhängigen cAMP-Bildung nach Vorstimulation mit $\mathrm{PGE}_{2}$

3.23 Nachweis der Internalisierung der Rezeptorproteine durch einen Oberflächen-ELISA (Enzzyme-ḷinked İmmunosorbent Á Assay)................. 79

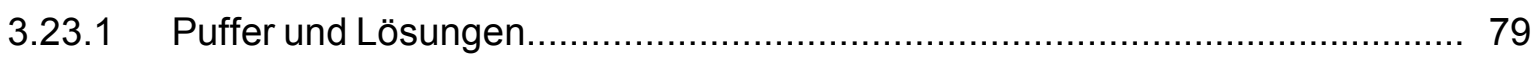

3.23.2 Stimulation der Rezeptor exprimierenden HEK293-Zellen und Antikörperbindung 80

3.23.3 Vorbereitung der ELISA-Platte....................................................... 80

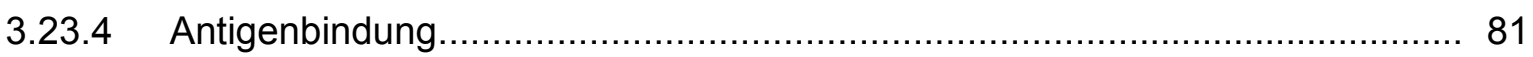

3.23.5 Nachweis der Rezeptorproteine durch einen Sekundärantikörper, Streptavidin-Peroxidase und eine Farbreaktion mit ABTS......................... 81

3.24 Bestimmung der Internalisierung aufgrund der Reduktion der

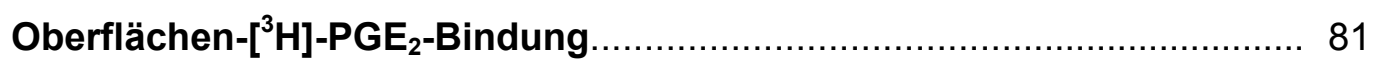

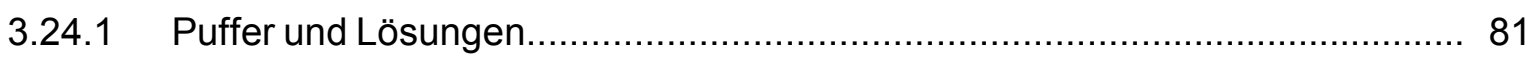

3.24.2 Nachweis der Internalisierung durch Bestimmung des nach Stimulation internalisierten $\left[{ }^{3} \mathrm{H}\right]-\mathrm{PGE}_{2}$.

3.25 Nachweis der Plasmamembranlokalisation und der Internalisierung der in den HEK293-Zellen stabil exprimierten Rezeptorproteine durch Immunfluoreszenz-Mikroskopie.............................................. 83

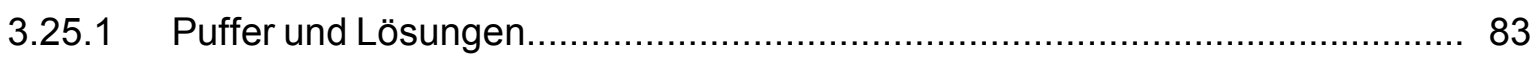

3.25.2 Kultivierung und Stimulation der Rezeptor-exprimierenden HEK293-Zellen.... 85

3.25.3 Plasmamembranmarkierung der HEK293-Zellen....................................... 85

3.25.4 Fixierung, Permeabilisierung und Blockierung der HEK293-Zellen................. 85

3.25.5 Nachweis der FLAG-markierten Rezeptorproteine und Gegenfärbung der biotinylierten Plasmamembran. 86

3.25.6 Einbettung der HEK293-Zellen für die Visualisierung der markierten Rezeptorproteine am konfokalen Laser-Scan-Mikroskop. 86 
3.26 Metabolische [ $\left.{ }^{32} \mathrm{P}\right]$-ortho-Phosphat-Markierung zur Bestimmung der Agonisten-induzierten Phosphorylierung der in HEK293-Zellen stabil exprimierten Rezeptorprteine ............................................... 87

3.26.1 Puffer und Lösungen..................................................................... 87

3.26.2 Metabolische $\left[{ }^{32} \mathrm{P}\right]$-ortho-Phosphat-Markierung und Stimulation der Rezeptor- exprimierenden HEK293-Zellen.............................................. 88

3.26.3 Auftrennung und Visualisierung der markierten Rezeptorproteine................. 88

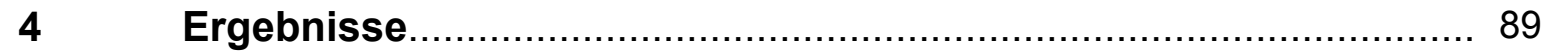

4.1 Einfügen der SnaB I-Restriktionsschnittstelle in die FLAG-hEP4Rezeptor-cDNA durch sequenzgerichtete Mutagenese. 89

4.1.1 Überprüfung der sequenzgerichteten Mutagenese durch Restriktions-

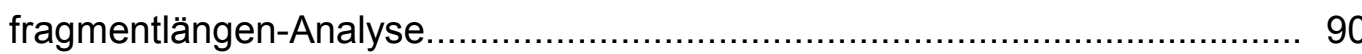

4.2 Synthese der mutierten FLAG-hEP4-Rezeptor-cDNA zur Substitution aller Serine und Threonine durch Alanine mittels sequenzgerichteter Mutagenese.

4.2.1 Einfügen der ST335-338A-Mutationen und Anfügen einer 5' der SnaB IRestriktionsschnittstelle gelegenen Kpn I-Restriktionserkennungssequenz in hEP4 CT.

4.2.2 Einfügen der ST369-382A-Mutationen in pBluescript hEP4 CT ST335-338A und Eliminierung der durch S372A-Substitution neu entstehenden Sty I-

Schnittstelle 92

4.2.3 Einfügen der ST428-443A-Mutationen in pBluescript hEP4 CT ST335-338; 369-382A.

4.2.4 Einfügen der ST354-366; 400-405A-Mutationen in pBluescript hEP4 CT ST335-338; 369-382; 428-443A. 96

4.2.5 Einfügen der ST448-484A-Mutationen in pBluescript hEP4 CT ST335-382; 400-443A. 96

4.2.6 Einfügen der ST389-394A-Mutationen in pBluescript hEP4 CT ST335-382; 400-484A und Eliminierung der durch T394A-Substitution neu entstehenden Dra II-Schnittstelle.

4.2.7 Synthese des pBluescript hEP4 CT ST335-405A und des pBluescript hEP4 CT ST428-484A

4.2.8 Synthese des pBluescript hEP4 CT ST335-354; 389-484A und des pBluescript hEP4 CT ST335-382A.

4.2.9 Synthese der FLAG-hEP4 S379A- und der FLAG-hEP4 ST335-377, 382484A-Rezeptor-cDNA. 
4.3 Klonierung der verschiedenen mutierten 3'-Fragmente und des 5'Fragmentes der FLAG-hEP4 Rezeptor-cDNA in den Expressionvektor pcDNA3.

4.4 Stabile Expression des FLAG-hEP4 wt-Rezeptors und der verschiedenen mutierten FLAG-hEP4-Rezeptoren

4.5 Charakterisierung der in HEK293-Zellen stabil exprimierten FLAGhEP4-Rezeptorproteine. 108

4.5.1 Immunologischer Nachweis der stabil exprimierten FLAG-hEP4 wt- und der mutierten FLAG-hEP4-Rezeptorproteine durch SDS-PAGE und Western-Blot-Analyse. 108

4.5.2 Untersuchung der Plasmamembranlokalisation der verschiedenen stabil exprimierten FLAG-hEP4-Rezeptorproteine durch ImmunfluoreszenzMikroskopie.

4.5.3 Bestimmung der Affinität und der maximalen Bindungskapazität der verschiedenen stabil exprimierten FLAG-hEP4-Rezeptoren für $\mathrm{PGE}_{2}$ durch Sättigungsbindungsstudien.

4.5.4 Nachweis der Funktionalität der verschiedenen in HEK293-Zellen stabil exprimierten FLAG-hEP4 Rezeptoren an Membranen.

4.5.5 Bestimmung der EC50-Werte der verschiedenen FLAG-hEP4-Rezeptoren für die $\mathrm{PGE}_{2}$-stimulierte cAMP-Bildung an Membranen.

4.6 Untersuchung der Phosphorylierung des FLAG-hEP4-Rezeptors und der verschiedenen mutierten Rezeptorproteine.

4.6.1 Untersuchung der durch $\mathrm{PGE}_{2}$-Stimulation induzierten Phosphorylierung des FLAG-hEP4 wt-Rezeptors.

4.6.2 Untersuchung der durch $\mathrm{PGE}_{2}$ induzierten Phosphorylierung des FLAGhEP4 wt-Rezeptors und der mutierten Rezeptorproteine.

4.7 Untersuchung der Desensitisierung des FLAG-hEP wt- und des FLAG-hEP4 ST335-484A-Rezeptors in stabil transfizierten HEK293-

Zellen.

4.7.1 Untersuchung der Desensitisierung der $\mathrm{PGE}_{2}$-induzierten cAMP-Bildung des FLAG-hEP4 wt- und des FLAG-hEP4 ST335-484A-Rezeptors nach Vorstimulation mit $\mathrm{PGE}_{2}$.

4.7.2 Kinetik der $\mathrm{PGE}_{2}$-induzierten cAMP-Bildung des FLAG-hEP4 wt- und des FLAG-hEP4 ST335-484A-Rezeptors nach Vorstimulation und verzögerter Gabe von IBMX und Kinetik der Forskolin-induzierten cAMP-Bildung an ganzen Zellen. 
4.7.3 Kinetik der cAMP-Bildung des FLAG-hEP4 wt- und des FLAG-hEP4 ST335484A-Rezeptors nach Vorstimulation mit dem EP4-Rezeptor-spezifischen, synthetischen Agonisten ONO604 und verzögerter Gabe von IBMX.

4.7.4 Untersuchung der Verschiebung der Dosis-Wirkungskurven für die $\mathrm{PGE}_{2}$ stimulierte cAMP-Bildung des FLAG-hEP4 wt- und des FLAG-hEP4 ST335484A-Rezeptors

4.8 Untersuchung der Internalisierung des in HEK293-Zellen stabil transfizierten FLAG-hEP4 wt- und der verschiedenen mutierten FLAG-hEP4-Rezeptoren 129

4.8.1 Untersuchung der Internalisierung der verschiedenen FLAG-hEP4-

Rezeptoren anhand der reduzierten FLAG-M2-mAk-Oberflächenbindung durch ELISA.

4.8.2 Untersuchung der Internalisierung der verschiedenen FLAG-hEP4Rezeptoren durch Bindungsstudien mit $\left[{ }^{3} \mathrm{H}\right]-\mathrm{PGE}_{2}$.

4.9 Untersuchung der Internalisierung der verschiedenen FLAG-hEP4Rezeptoren durch Immunfluoreszenz-Mikroskopie. 135

4.10 Untersuchung der Rezeptor/ $\beta$-Arrestin-Colokalisation nach AgonistenExposition der die FLAG-hEP4-Rezeptoren exprimierenden HEK293Zellen durch Immunfluoreszenz-Mikroskopie.

5 Diskussion. 146

5.1 Eliminierung potentieller Phosphorylierungsstellen in der C-terminalen Domäne des hEP4-R durch sequenzgerichtete Mutagenese.

5.2 Stabile Expression der verschiedenen FLAG-hEP4-Rezeptorproteine in HEK293-Zellen und Überprüfung der Funktionalität der verschiedenen FLAG-hEP4-Rezeptorproteine. 149

5.2.1 Expression der hEP4-Rezeptoren in HEK293-Zellen.................................... 149

5.2.2 Subzelluläre Lokalisation der hEP4-Rezeptoren in HEK293-Zellen................ 150

5.2.3 Bedeutung der eingefügten Mutationen für die Ligandbindung...................... 150

5.2.4 Einfluß der Mutationen in der C-terminalen Domäne des hEP4-R für die Signaltransduktion des Rezeptors.................................................. 151

Kopplungsspezifität.................................................................... 151

Kopplungskontrolle.......................................................................... 152

5.3 Agonisten-induzierte Phosphorylierung des FLAG-hEP4 wt-Rezeptors und der verschiedenen mutierten Rezeptorproteine. 152

5.3.1 Identifizierung der an der $\mathrm{PGE}_{2}$-induzierten Phosphorylierung des 
FLAG-hEP4 wt-Rezeptors beteiligten Kinasen

5.3.2 $\mathrm{PGE}_{2}$-induzierte Phosphorylierung der verschiedenen mutierten FLAGhEP4-Rezeptorproteine.

5.4 Desensitisierung des FLAG-hEP4 wt-Rezeptors und des FLAG-hEP4 ST335-484A-Rezeptors

5.4.1 Desensitisierung des hEP4 wt-Rezeptors und des hEP4 ST335-484ARezeptors nach Vorstimulation mit $\mathrm{PGE}_{2}$ 156

5.4.2 Fehlende Unterschiede in der Kinetik der $\mathrm{PGE}_{2}$-induzierten cAMP-Bildung in hEP4 wt-Rezeptor oder hEP4 ST335-484A-Rezeptor exprimierenden HEK293-Zellen nach Prästimulation mit $\mathrm{PGE}_{2}$

5.4.3 Fehlende Rechtsverschiebung der Dosis-Wirkungskurve des hEP4 wt-R. 158

5.5 Internalisierung und $\beta$-Arrestin-Rekrutierung des FLAG-hEP4 wtRezeptors und der verschiedenen mutierten Rezeptoren. 159

5.5.1 Internalisierung der verschiedenen FLAG-hEP4-Rezeptoren. 160

5.5.2 Untersuchung der Rezeptor/ $\beta$-Arrestin-Colokalisation der verschiedenen Rezeptorproteine durch Immunfluoreszenz-Mikroskopie. 162

5.6 Schlußfolgerung. 164 


\section{VERZEICHNIS DER ABBILDUNGEN}

Abb. 1: Prostanoid-Synthese....................................................................... 4

Abb. 2: Schematische Darstellung der durch Ligandbindung und Rezeptoraktivierung ausgelösten Signalkaskaden der G-Proteingekoppelten Rezeptoren.

Abb. 3: Schematische Darstellung der Entkopplung des Rezeptors vom G-Protein durch $\beta$-Arrestin und anschließende Internalisierung 10

Abb. 4: Hypothetische Struktur des humanen EP4-Rezeptors................................... 14

Abb. 5: Restriktionskarte von pBluescript SK-.................................................. 29

Abb. 6: Restriktionskarte von pcDNA3 .................................................................. 30

Abb. 7: Restriktionskarte von pEGFP................................................................. 31

Abb. 8: Synthese des pcDNA3 FLAG hEP4 wt-Rezeptors mit der eingefügten SnaB I-Restriktionserkennungssequenz. 90

Abb. 9: Charakterisierung der isolierten Plasmid-DNA des pcDNA/Amp FLAG-hEP4- und des pcDNA3 FLAG-hEP4 wt-Rezeptors durch Spaltung mit den Restriktionsenzymen Hind III, SnaB I und Xba I....... 91

Abb. 10: Synthese des pBluescript hEP4 CT ST335-338A........................................ 93

Abb. 11: Synthese des pBluescript hEP4 CT ST335-338; 369-382A......................... 94

Abb. 12: Synthese des pBluescript hEP4 CT ST335-338; 369-382; 428-443A............ 95

Abb. 13: Synthese des pBluescript hEP4 CT ST335-382; 400-443A....................... 97

Abb. 14: Synthese des pBluescript hEP4 CT ST335-382; 400-484A......................... 98

Abb. 15: Synthese des pBluescript hEP4 CT ST335-484A ....................................... 100

Abb. 16: Synthese des pBluescript hEP4 CT ST335-405A und des pBluescript hEP4 CT ST428-484A................................................... 101

Abb. 17: Synthese des pBluescript hEP4 CT ST335-354; 389-484A .......................... 102

Abb. 18: Synthese des pBluescript hEP4 CT ST335-382A ....................................... 103

Abb. 19: Synthese des pcDNA3 FLAG-hEP4 S379A.............................................. 104

Abb. 20: Synthese des pcDNA3 FLAG-hEP4 S335-377; 382-484A......................... 105

Abb. 21: Überprüfung der Klonierung der verschiedenen Rezeptor-cDNAs in den Expressionsvektor pcDNA3 ........................................................... 107

Abb. 22: Westernblotanalyse der in HEK293-Zellen stabil exprimierten Rezeptorproteine

Abb. 23: Plasmamembranlokalisation der verschiedenen, in den HEK293-Zellen stabil exprimierten FLAG-hEP4-Rezeptoren.

Abb. 24: Nachweis der $\mathrm{PGE}_{2}$ - und der Forskolin-induzierten cAMP-Bildung der die verschiedenen Rezeptoren exprimierenden HEK293-Zellen. 
Abb. 25: Phosphorylierung des FLAG-hEP4 wt-Rezeptors durch PGE 2 , Forskolin und PMA .

Abb. 26: Nachweis der Lokalisation der für die Agonisten-induzierte Phosphorylierung des FLAG-hEP4 wt-Rezeptors relevanten Ser und Thr in der C-terminalen Domäne

Abb. 27: $\mathrm{PGE}_{2}$-induzierte cAMP-Bildung in FLAG-hEP4 wt- und in FLAG-hEP4 ST335-484A-Rezeptor exprimierenden HEK293-Zellen mit und ohne Vorstimulation durch $\mathrm{PGE}_{2}$

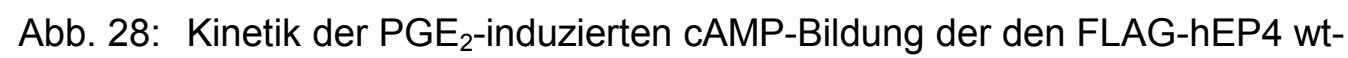
und FLAG-hEP4 ST335-484A-Rezeptor stabil exprimierenden HEK293Zellen nach verzögerter Gabe von IBMX...

Abb. 29: Kinetik der Forskolin-induzierten cAMP-Bildung der mit dem FLAG-hEP4 wt- und dem FLAG-hEP4 ST335-484A-Rezeptor stabil transfizierten HEK293-Zellen.

Abb. 30: Kinetik der cAMP-Bildung in FLAG-hEP4 wt- und FLAG-hEP4 ST335-484A-

Rezeptor exprimierenden HEK293-Zellen durch Stimulation mit dem EP4-R-spezifischen Agonisten ONO604 und verzögerter Gabe von IBMX....

Abb. 31: Konzentrationsabhängigkeit der $\mathrm{PGE}_{2}$-induzierten cAMP-Bildung in FLAG-hEP4 wt- und FLAG-hEP4 ST335-484A-Rezeptor exprimierenden HEK293-Zellen nach Vorstimulation mit $\mathrm{PGE}_{2}$

Abb. 32: Bestimmung der Agonisten-induzierten Internalisierung des FLAG-hEP4 wt- und des FLAG-hEP4 ST335-484A-Rezeptors durch Zell-Oberflächen-ELISA 130

Abb. 33: Bestimmung der Agonisten-induzierten Internalisierung des FLAG-hEP4 wt-Rezeptors und der mutierten Rezeptorproteine durch Zell-Oberflächen-ELISA ohne und nach Vorbehandlung der Zellen mit Saccharose......

Abb. 34: Bindung von $\left[{ }^{3} \mathrm{H}\right]-\mathrm{PGE}_{2}$ an die Oberflächen von FLAG-hEP4 wt- oder FLAG-hEP4 ST335-484A-Rezeptor exprimierenden HEK293-Zellen bei $4^{\circ} \mathrm{C}$ und bei $37^{\circ} \mathrm{C}$.

Abb. 35: Internalisierung der verschiedenen Rezeptorproteine durch Bestimmung des intrazellulären $\left[{ }^{3} \mathrm{H}\right]-\mathrm{PGE}_{2}$ ohne und nach Vorbehandlung der Zellen mit Saccharose.

Abb. 36: Internalisierung des FLAG-hPE4 wt-Rezeptors in stabil transfizierten HEK293-Zellen nach $\mathrm{PGE}_{2}$-Stimulation

Abb. 37: Plasmamembranlokalisation des FLAG-hPE4 ST335-484A-Rezeptors nach $\mathrm{PGE}_{2}$-Stimulation. 
Abb. 38: $P E_{2}$-induzierte Internalisierung des FLAG-hEP4 S379A-, FLAG-hEP4 ST335-382A- und FLAG-hEP4 ST335-405A-Rezeptors in stabil exprimierenden HEK293-Zellen.

Abb. 39: Plasmamembranlokalisation des FLAG-hEP4 ST335-377; 382-484A-, FLAG-hEP4 ST335-354; 382-484A- und FLAG-hEP4 ST428-484A-

Rezeptors nach $\mathrm{PGE}_{2}$-Stimulation. 140

Abb. 40: Nachweis der cytosolischen $\beta$-Arrestin-Lokalisation in HEK293Zellen.

Abb. 41: Translokation und Colokalisation von $\beta$-Arrestin mit dem FLAG-hEP4 wtRezeptors nach $\mathrm{PGE}_{2}$-Stimulation ohne und nach Vorbehandlung der Zellen mit Saccharose dargestellt durch ImmunfluoreszenzMikroskopie 143

Abb. 42: Fehlende $\beta$-Arrestin-Translokation und -Colokalisation mit dem FLAG-hEP4 ST335-484A-, FLAG-hEP4 S335-405A-, FLAG-hEP4 ST428-484A-, FLAGhEP4 ST335-354; 389-484A-Rezeptor und dem FLAG-hEP4 ST335-377; 382-484A-R nach $\mathrm{PGE}_{2}$-Stimulation dargestellt durch ImmunfluoreszenzMikroskopie

Abb. 43: $\beta$-Arrestin-Translokation und -Colokalisation mit dem FLAG-hEP4 ST335-

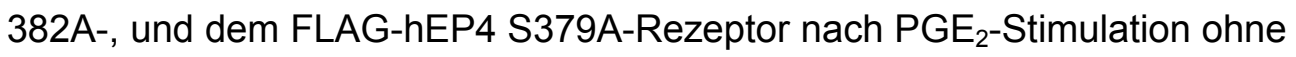
und nach Vorbehandlung der Zellen mit Saccharose. 


\section{VERZEICHNIS DER TABELLEN}

Tab. 1: Einteilung der Prostanoidrezeptoren

Tab. 2: Durchführung der sequenzgerichteten Mutagenese zum Einfügen der SnaB I-Schnittstelle in die FLAG-hEP4-R-cDNA.

Tab. 3: PCR-Reaktionen zur Synthese der für die C-terminale Domäne codierenden Sequenz der FLAG-hEP4-R-cDNA mit der Substitution aller Serine und Threonine.

Tab. 4: Restriktionsansätze zur Generierung der verschiedenen hEP4 CT-cDNAFragmente. 51

Tab. 5: Restriktionsansätze zur Generierung der verschiedenen pBluescript hEP4 CT Vektor-Fragmente.

Tab. 6: Ligationsansätze zur Synthese der verschiendenen C-terminalen cDNAFragmente.

Tab. 7: $\quad K_{d}$-Werte und maximale Bindungskapazität der verschiedenen in HEK293Zellen stabil exprimierten FLAG-hEP4-Rezeptoren.

Tab. 8: $\quad$ EC50-Werte der $\mathrm{PGE}_{2}$-stimulierten cAMP-Bildung der verschiedenen in HEK293-Zellen stabil exprimierten FLAG-hEP4-Rezeptoren. 


\section{VERZEICHNIS DER ABKÜRZUNGEN}

ABTS

Amp

APS

ATP

BES

bp

BS

BSA

cDNA

$\mathrm{Ci}$

cAMP

cpm

Cy3

CT

DABCO

DEPC

DMEM

DMSO

DNA

dNTP

DP-R

DTT

E. coli

EDTA

ELISA

EP1-R

EP2-R

EP3-R

EP4-R

FCS

FITC

FP-R

G-418

GFP

GPCR
2,2'-Azino-di-[3-ethylbenzthioazylin-sulfonat (6)]

Ampicillin

Ammoniumpersulfat

Adenosintriphosphat

$\mathrm{N}, \mathrm{N}$-bis[2-Hydroxyethyl]-2-aminoethansulfonsäure

Basenpaare

Bovines Serum

Bovines Serum Albumin

complementary (komplementäre) DNA

Curie

cyclisches Adenosin-3',5'-monophosphat

counts per minute (Zerfälle pro Minute)

Cyanin-Farbstoff

C-Terminus

Diazobicyclooctan

Diethylpyrocarbonat

Dulbecco's Modifiziertes Eagle Medium

Dimethylsufoxid

Desoxyribonukleinsäure

Desoxyribonukleosidtriphosphate

Prostaglandin $\mathrm{D}_{2}$-Rezeptor

Dithiothreitol

Escherichia coli

Ethylendiamintetraacetat

Enzyme-linked Immunosorbent Assay

Prostaglandin $\mathrm{E}_{2}$-Rezeptor Subtyp 1

Prostaglandin $\mathrm{E}_{2}$-Rezeptor Subtyp 2

Prostaglandin $\mathrm{E}_{2}$-Rezeptor Subtyp 3

Prostaglandin $\mathrm{E}_{2}$-Rezeptor Subtyp 4

Fetal Calf Serum (Fötales Kälberserum)

Fluoresceinisothiocyanat

Prostaglandin $\mathrm{F}_{2 \alpha}$-Rezeptor

Geneticin-Sulfat

Green-Fluorenscent-Protein

G-protein-coupled receptor (G-Protein-gekoppelter Rezeptor) 


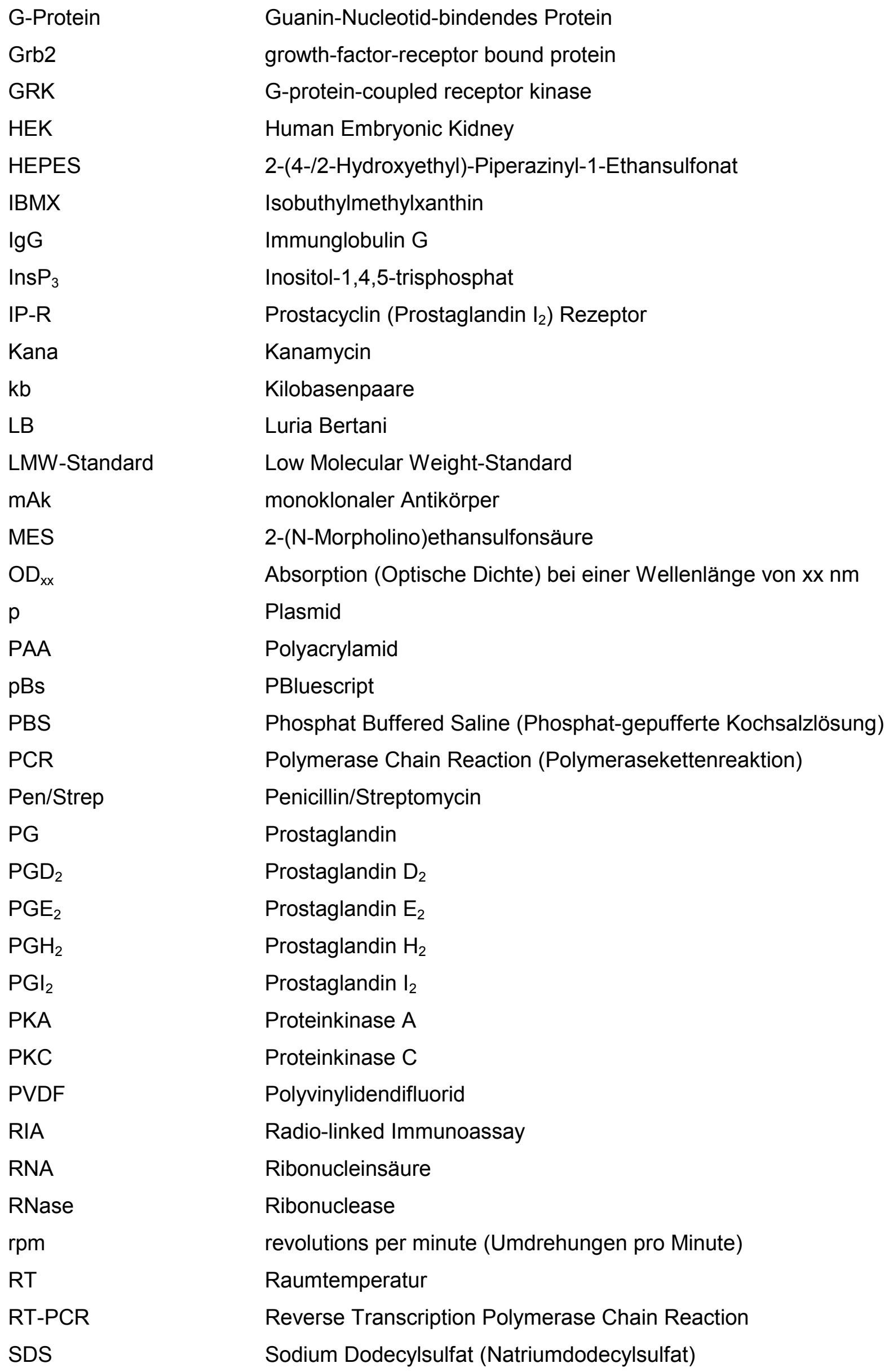


SDS-PAGE

SH3-domäne

Stlsg

TAE

TBE

TCA

TEMED

Tetra

TP-R

Tris

$\mathrm{TXA}_{2}$

$U$

UV

$\mathrm{v} / \mathrm{v}$

wt

$w / v$
SDS-Polyacrylamid-Gelelektrophorese

Src-homology 3 Domäne

Stammlösung

Tris-Acetat-EDTA-Puffer

Tris-Borat-EDTA

Trichloressigsäure

$\mathrm{N}, \mathrm{N}, \mathrm{N}^{\prime}, \mathrm{N}^{\prime}$-Tetramethylethylendiamin

Tetracyclin

Thromboxan $\mathrm{A}_{2}$-Rezeptor

Tri-(hydroxymethyl)-aminomethan

Thromboxan A2

Units (enzymatische Aktivität)

Ultraviolett

volume per volume (Volumen pro Volumen)

Wildtyp

weight per volume (Gewicht pro Volumen) 


\section{VERZEICHNIS DER AMINOSÄUREN UND IHRER ABKÜRZUNGEN}

$\begin{array}{lll}\text { A } & \text { Ala } & \text { Alanin } \\ \text { C } & \text { Cys } & \text { Cystein } \\ \text { D } & \text { Asp } & \text { Asparaginsäure } \\ \text { E } & \text { Glu } & \text { Glutaminsäure } \\ \text { F } & \text { Phe } & \text { Phenylalanin } \\ \text { G } & \text { Gly } & \text { Glycin } \\ \text { H } & \text { His } & \text { Histidin } \\ \text { I } & \text { lle } & \text { Isoleucin } \\ \text { K } & \text { Lys } & \text { Lysin } \\ \text { L } & \text { Leu } & \text { Leucin } \\ \text { M } & \text { Met } & \text { Methionin } \\ \text { N } & \text { Asn } & \text { Asparagin } \\ \text { P } & \text { Pro } & \text { Prolin } \\ \text { Q } & \text { Gln } & \text { Glutamin } \\ \text { R } & \text { Arg } & \text { Arginin } \\ \text { S } & \text { Ser } & \text { Serin } \\ \text { T } & \text { Thr } & \text { Threonin } \\ \text { V } & \text { Val } & \text { Valin } \\ \text { W } & \text { Trp } & \text { Tryptophan } \\ \text { Y } & \text { Tyr } & \text { Tyrosin } \\ \end{array}$




\section{Zusammenfassung}

Ausgangsbefunde und Aufgabenstellung: Der humane Prostaglandin $\mathrm{E}_{2}$ Rezeptor, Subtyp EP4 (hEP4-R), ist ein in der Plasmamembran lokalisierter G-Protein-gekoppelter Rezeptor, der an ein $\mathrm{G}_{\mathrm{s}}$-Protein koppelt und nach Ligandbindung eine Erhöhung des intrazellulären cAMP-Spiegels induziert. Für diesen Rezeptor konnte eine Agonisten-induzierte Desensitisierung gezeigt werden, die möglicherweise durch eine G-Protein-gekoppelter Rezeptor-Kinasen (GRK) vermittelte Phosphorylierung des Rezeptors an Serinen und Threoninen in den intrazellulären Domänen initiiert wird. Die Agonisten-induzierte Phosphorylierung des Rezeptors konnte auf Serine und Threonine in der C-terminalen Domäne des Rezeptors eingegrenzt werden. Innerhalb der C-terminalen Domäne des hEP4-R sind 38 Serine und Threonine lokalisiert, die alle für die Agonisten-induzierte Phosphorylierung und die daran anschließende Desensitisierung und Internalisierung des Rezeptors relevant sein könnten.

Ziel dieser Arbeit war, die Serine und Threonine in der C-terminalen Domäne des hEP4-R zu identifizieren, die an der Agonisten-induzierten Phosphorylierung, Desensitisierung und Internalisierung des humanen EP4-Rezeptors beteiligt sind.

Eliminierung der potentiellen Phosphorylierungsstellen: Durch PCR-gestützte, sequenzgerichtete Mutagenese wurden die in der C-terminalen Domäne des hEP4-R lokalisierten Serine und Threonine teilweise oder vollständig gegen Alanine ausgetauscht. Folgende, für mutierte EP4-Rezeptoren codierende cDNAs wurden synthetisiert: hEP4 ST335-484A-R, in dem alle Serine und Threonine in der C-terminalen Domäne durch Alanine ersetzt waren, sowie hEP4 ST335-405A-, hEP4 ST428-484A-, hEP4 ST335-354; 389-484A-, hEP4 ST335-382A-, hEP4 S379A- und hEP4 ST335-377; 382-484A-R, in denen die Serine und Threonine zwischen den angegeben Aminosäuren durch Alanine ersetzt waren.

Expression, Ligandbindung und Signaltransduktion: Die cDNAs für die verschiedenen Rezeptorproteine wurden in HEK293-Zellen stabil transfiziert. Wildtyp- und alle mutierten Rezeptorproteine wurde synthetisiert und korrekt prozessiert und in die Plasmamembran eingebaut. Die Substitution einzelner oder mehrerer Serine und Threonine in der C-terminalen Domäne des hEP4-Rezeptors hatte ebenfalls keine Auswirkung auf die Affinität der Rezeptoren für $\mathrm{PGE}_{2}$ und führte zu keiner Veränderung der Ligand-induzierten G-Protein-Aktivierung und Signaltransduktion im Vergleich mit dem Wildtyp EP4-R.

Phosphorylierung: Der hEP4 wt-R wurde Agonisten-abhängig, wahrscheinlich durch GRKs phosphoryliert. Nach Substitution aller in der C-terminalen Domäne lokalisierten Serine und Threonine wurde der Rezeptor nach Agonisten-Exposition nicht mehr phosphoryliert, was die Lokalisation der Phosphorylierungsstellen in der C-terminalen Domäne des Rezeptors bestätigte. Als potentielle Hauptphosphorylierungsstellen konnten Serine und Threonine zwischen den Serinen 359 und 382 identifiziert werden, jedoch konnte eine residuale 
Phosphorylierung von Serinen und Threoninen, die distal von Serin 382 lokalisiert waren, nicht ausgeschlossen werden

Desensitisierung: Eine Agonisten-induzierte Desensitisierung des hEP4 wt-R konnte in stabil transfizierten HEK293-Zellen nicht nachgewiesen werden, so daß die Relevanz der identifizierten Phosphorylierungsstellen für die Agonisten-induzierte Desensitisierung nicht überprüft werden konnte. Dies war möglicherweise auf die hohe Rezeptorexpression in dem gewählten System zurückzuführen, bei dem ein geringer Teil nicht desensitierter Rezeptoren ausreichen würde, um die nachgeschaltete Signalkette noch immer maximal zu aktivieren.

Internalisierung: Der hEP4 wt-R wurde Agonisten-abhängig internalisiert und war nach der Internalisierung mit $\beta$-Arrestin colokalisiert. Die Agonisten-induzierte Internalisierung des hEP4-R wurde durch Substitution der Serine und Threonine in der C-terminalen Domäne des Rezeptors aufgehoben. Die in dem identifizierten Hauptphosphorylierungsbereich lokalisierten Serine und Threonine Ser359-Ser382 waren für die Internalisierung des hEP4-R weder hinreichend noch notwendig. Die für die Internalisierung des hEP 4-R notwendigen Serine und Threonine waren distal von Serin 382 lokalisiert, wobei der internalisierte hEP4-R nach Substitution von Ser359-Ser382 nicht mehr mit $\beta$-Arrestin colokalisiert war. Die Internalisierung des hEP4-R wurde durch Behandlung der Rezeptor-exprimierenden HEK293-Zellen mit hyperosmolaren Saccharosekonzentrationen inhibiert, was auf eine Clathrin-vermittelte Internalisierung hindeutete.

Schlußfolgerung: Für die, wahrscheinlich GRK-vermittelte, Agonisten-induzierte Phosphorylierung sind die Serine und Threonine zwischen Serin 359 und Serin 382 in der Cterminalen Domäne des hEP4-R notwendig. Die Relevanz dieser Serine und Threonine für die Agonisten-induzierte Desensitisierung des hEP4-R konnte jedoch in dem gewählten System nicht nachgewiesen werden. Die für die Agonisten-induzierte Internalisierung des hEP4-R relevanten Serine und Threonine sind mit den für die Phosphorylierung und möglicherweise Desensitisierung notwendigen nicht identisch und sind distal des Serin 382 lokalisiert, wobei eine der Internalisierung vorausgehende Phosphorylierung der Rezeptoren an diesen Positionen nicht ausgeschlossen werden kann. Der hEP4-R wird im Komplex mit $\beta$-Arrestin internalisiert, jedoch scheinen die im distalen Teil der C-terminalen Domäne gelegenen Serine und Threonine möglicherweise eine $\beta$-Arrestin-unabhängige Clathrinvermittelte Internalisierung zu ermöglichen. Die im proximalen Teil der C-terminalen Domäne lokalisierten Serine und Threonine des hEP4-R sind also wahrscheinlich für die Entkopplung des Rezeptors verantwortlich, während die im distalen Bereich lokalisierten Serine und Threonine für die Internalisierung relevant sind. 


\section{Einleitung}

\subsection{Prostanoide}

Prostanoide sind lokal gebildete autokrin oder parakrin wirkende Mediatoren. Sie sind Derivate der Arachidonsäure, die durch einen externen Stimulus durch die Phospholipase $\mathrm{A}_{2}$ aus Phospholipiden der Plasmamembran freigesetzt wird (Clark et al. (1991)). Durch Katalyse des bifunktionellen Enzyms Prostaglandin-H-Synthase (Cyclooxygenase und Peroxidase) entsteht aus der Arachidonsäure unter Einbau von molekularem Sauerstoff das Prostaglandin $\mathrm{H}_{2}\left(\mathrm{PGH}_{2}\right)$ (Smith und Marnett (1991)), aus dem durch Redoxreaktionen und Umlagerung des Endoperoxidrings die Prostanoide Prostaglandin $D_{2}\left(P \mathrm{D}_{2}\right)$, Prostaglandin $E_{2}\left(P E_{2}\right)$, Prostaglandin $F_{2 \alpha}\left(P F_{2 \alpha}\right)$ sowie Prostacyclin $\left(P G_{2}\right)$ und Thromboxan $A_{2}\left(T_{X} A_{2}\right)$ gebildet werden (Abb. 1) (Samuelsson (1978)).

Die freigesetzten Prostanoide können verschiedene Funktionen modulieren; so wurde die durch PGF ${ }_{2 \alpha}$ induzierte Gefäßkonstriktion gezeigt (Morita et al. (1994)), während Prostacyclin die Gefäßdilatation (Williams et al. (1994); Baxter et al. (1995)) induzieren kann. Für PGE 2 wurde ein anaboler Effekt auf den Knochenmetabolismus (Machwate et al. (2001)) und die Regulation von Entzündungsreaktionen in der Leber (Peters et al. (1990)) beschrieben, während für $\mathrm{PGD}_{2}$ eine Rolle an der Schlafinduktion nachgewiesen wurde (Hayaishi (1991); Urade und Hayaishi (1999)). Thromboxan $\mathrm{A}_{2}$ bewirkt die Kontraktion vaskulärer und respiratorischer glatter Muskulatur (Samuelsson 1978; Coleman und Sheldrick (1989)) und stimuliert die Thrombocytenaggregation (Okuma et al. (1996)), die durch $\mathrm{PGI}_{2}$ inhibiert wird (Armstrong et al. (1989); Hirata et al. (1994)).

Prostanoide übertragen ihre Signale auf Zielzellen über Prostanoidrezeptoren, die zur Klasse der an heterotrimere G-Proteine gekoppelten Rezeptoren (GPCR) mit sieben Transmembrandomänen gehören (Giles et al. (1991); Narumiya et al. (1993); Coleman et al. (1994)). $\mathrm{PGI}_{2}$ kann darüber hinaus über die Bindung an nukleäre Hormonrezeptoren, sogenannte Peroxisom Proliferator-aktivierte Rezeptoren (PPAR $\gamma$ und $\delta$ ) die AdipocytenProliferation modulieren (Reginato et al. (1998); Hatae et al. (2001)).

\subsection{Plasmamembranständige Prostanoidrezeptoren}

Die plasmamembranständigen Prostaniodrezeptoren bilden eine Subfamilie innerhalb der Rhodopsin-Typ-Rezeptorfamilie. Sie besitzen eine extrazelluläre N-terminale Domäne, sieben Transmembrandomänen, drei extrazelluläre und drei intrazelluläre Schleifen und eine intrazelluläre C-terminale Domäne (Dohlman et al. (1991)). 


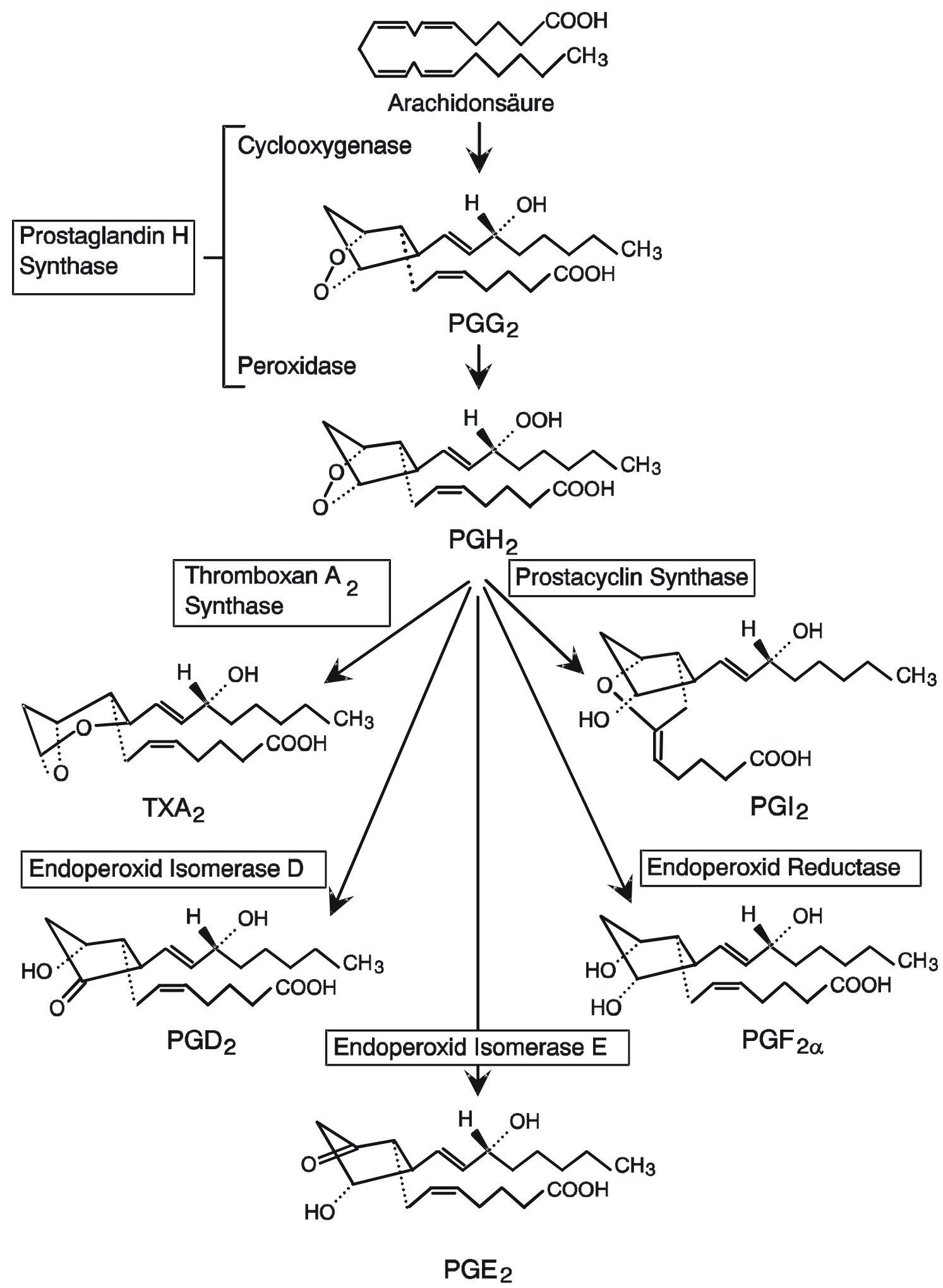

Abb. 1: Prostanoid-Synthese. Die Bildung der Prostanoide erfolgt nach Freisetzung von Arachidonsäure aus der Zellmembran. Nach Ring- und Peroxidbildung durch die Cyclooxygenase werden die einzelnen Prostanoide durch spezifische Synthasen (Prostacyclin-Synthase, Endoperoxid-Isomerase D, Endoperoxid-Isomerase E, EndoperoxidReduktase, und Thromboxan $\mathrm{A}_{2}$-Synthase) gebildet. $\mathrm{TXA}_{2}$ : Thromboxan $\mathrm{A}_{2}, \mathrm{PGI}_{2}$ : Prostacyclin, $\mathrm{PGD}_{2}$ : Prostaglandin $\mathrm{D}_{2}, \mathrm{PGF}_{2 \alpha}$ : Prostaglandin $\mathrm{F}_{2 \alpha}, \mathrm{PGE}_{2}$ : Prostaglandin $\mathrm{E}_{2}$. 
Sie sind an heterotrimere G-Proteine gekoppelt, die die Bildung sekundärer Botenstoffe wie CAMP und $\mathrm{InsP}_{3} / \mathrm{Ca}^{2+}$ modulieren und so extrazelluläre Signale in intrazelluläre umwandeln (Boege et al. (1991); Narumiya et al. (1993)).

\subsubsection{Klassifikation der Prostanoidrezeptoren}

Die Prostanoidrezeptoren wurden anhand ihrer Spezifität für natürliche und synthetische Agonisten und Antagonisten sowie biochemisch durch ihre Kopplung an verschiedene G-Proteine klassifiziert und in acht Gruppen unterteilt (Coleman et al. (1994)) (Tab. 1).

Danach existieren folgende Rezeptortypen: $\mathrm{PGD}_{2}$-Rezeptor (DP-R), PGF ${ }_{2 \alpha}$-Rezeptor (FP-R), $\mathrm{PGI}_{2}$-Rezeptor (IP-R), Thromboxan $\mathrm{A}_{2}$-Rezeptor (TP-R) und vier Subtypen von PGE ${ }_{2}$ Rezeptoren: EP1-R, EP2-R, EP3-R, EP4-R, die von verschiedenen Genen codiert werden und sich in ihrer Größe und in ihrer G-Protein-Kopplung unterscheiden.

Der DP-, EP2-, EP4- und der IP-Rezeptor sind $\mathrm{G}_{\mathrm{s}}$-gekoppelt und erhöhen somit den intrazellulären cAMP-Spiegel, der EP1-, FP-, IP- und der TP-Rezeptor sind $\mathrm{G}_{\mathrm{q}}$-gekoppelt und führen so zu einem Anstieg von $\mathrm{InsP}_{3}$ und $\mathrm{Ca}^{2+}$. Der EP3-Rezeptor ist $\mathrm{G}_{i}$-gekoppelt und hemmt die Hormon-stimulierte cAMP-Bildung. Für den TP-Rezeptor wurde darüberhinaus direkt (Offermanns et al. (1994); Djellas et al. (1999)), für den EP3-Rezeptor (Katoh et al. (1996); Hasegawa et al. (1997)) und den FP-Rezeptor (Pierce et al. (1999)) indirekt eine Kopplung an $\mathrm{G}_{12 / 13}$ mit einer Aktivierung von Rho nachgewiesen.

Spleißvarianten des bovinen EP3-Rezeptors zeigten eine Kopplung an verschiedene GProteine (Namba et al. (1993)). Für den ovinen FP-R und humanen TP-R wurden ebenfalls Spleißvarianten identifiziert (Pierce und Regan (1998); Narumiya et al. (1999)).

\subsubsection{Strukturelle Gemeinsamkeiten der Prostanoidrezeptoren}

Die Prostanoidrezeptoren zeigen untereinander eine Sequenzidentität von $20-30 \%$, die in den Transmembrandomänen sehr hoch, dagegen aber in den extrazellulären und intrazellulären Rezeptordomänen deutlich geringer ist. Die konservierten Aminosäuren innerhalb der Prostaniodrezeptoren sind für die räumliche Struktur sowie die Ausbildung der Ligandbindungstaschen und die Signaltransduktion von Bedeutung. So sind in den extrazellulären Domänen der Prostanoidrezeptoren Asn-X-Ser/Thr Konsensus-Sequenzen für N-Glykosylierungsstellen lokalisiert. Die N-Glykosylierung ist für den Transport und die korrekte Insertion in die Plasmamembran, sowie in einigen Fällen für die korrekte Faltung wichtig. So wurde eine Mutante des EP3 $\beta-R$, der die potentiellen Glykosylierungsstellen fehlten, im endoplasmatischen Retikulum retiniert (Böer et al. (2000)). 
Tab. 1: Einteilung der Prostanoidrezeptoren. In der Tabelle aufgeführt sind die Prostanoidrezeptoren, ihre natürlichen Liganden, die durch die Ligandenbindung aktivierten G-Proteine und das dadurch ausgelöste intrazelluläre Signal. DP-R, EP2-R, EP4-R und IP-R werden als relaxierende Rezeptoren bezeichnet und stimulieren die cAMP- Bildung; EP3-R wirkt als einziger der Prostanoidrezeptoren inhibierend auf die Hormon-stimulierte cAMPBildung; EP1-R, FP-R und TP-R gelten als kontrahierende Rezeptoren und führen zu einer Erhöhung des intrazellulären $\mathrm{Ca}^{2+}$-Spiegels. Die mit ${ }^{*}$ versehenen Prostanoidrezeptoren existieren in manchen Spezies in Spleißvarianten, welche auch andere Signalketten aktivieren können.

\begin{tabular}{|c|c|c|c|}
\hline Name & $\begin{array}{l}\text { Natürlicher } \\
\text { Ligand }\end{array}$ & $\begin{array}{l}\text { Aktiviertes } \\
\text { G-Protein }\end{array}$ & $\begin{array}{l}\text { Intrazelluläres } \\
\text { Signal }\end{array}$ \\
\hline DP-R & $\mathrm{PGD}_{2}$ & $\mathrm{G}_{\mathrm{s}}$ & cAMP $\uparrow$ \\
\hline EP1-R* & $\mathrm{PGE}_{2}$ & $\mathrm{G}_{\mathrm{q}}$ & $\operatorname{lnsP} P_{3} \uparrow, \mathrm{Ca}^{2+\uparrow}$ \\
\hline EP2-R & $\mathrm{PGE}_{2}$ & $\mathrm{G}_{\mathrm{s}}$ & $\mathrm{cAMP} \uparrow$ \\
\hline EP3-R* & $\mathrm{PGE}_{2}$ & $\mathrm{G}_{\mathrm{i}}$ & cAMP $\downarrow$ \\
\hline EP4-R & $\mathrm{PGE}_{2}$ & $\mathrm{G}_{\mathrm{s}}$ & $\mathrm{cAMP} \uparrow$ \\
\hline $\mathrm{FP}-\mathrm{R}^{*}$ & $\mathrm{PGF}_{2 \alpha}$ & $\mathrm{G}_{\mathrm{q}}$ & InsP ${ }_{3} \uparrow, \mathrm{Ca}^{2+\uparrow}$ \\
\hline IP-R & $\mathrm{PGI}_{2}$ & $\mathrm{G}_{\mathrm{s}}, \mathrm{G}_{\mathrm{q}}$ & $\mathrm{cAMP} \uparrow, \mathrm{InsP}_{3} \uparrow, \mathrm{Ca}^{2+\uparrow}$ \\
\hline $\mathrm{TP}-\mathrm{R}^{*}$ & $\mathrm{TXA}_{2}$ & $\mathrm{G}_{\mathrm{q}}$ & $\operatorname{lnsP}{ }_{3} \uparrow, \mathrm{Ca}^{2+\uparrow}$ \\
\hline
\end{tabular}

Weiterhin wurde für den in Astrozyten endogen exprimierten FP-Rezeptor gezeigt, daß die Behandlung der Zellen mit Tunicamycin, einem Inhibitor der N-Glykosylierung, zu einer gestörten Rezeptorfunktion führte (Kitanaka et al. (1994)). Die Elimination der Glykosylierungsstellen im hIP-R führte zu einem geringeren Transport in die Plasmamembran und einer reduzierten Ligandbindung der plasmamembranständigen Rezeptoren (Zhang et al. 2001)), was auch für den TP-R gezeigt wurde (Walsh et al. (1998); Chiang et al. (1998)).

In der ersten und zweiten extrazellulären Schleife sind zwei Cysteine konserviert, die durch Ausbildung einer Disulfidbrücke zur Stabilisierung der funktionellen Proteinstruktur beitragen können (Probst et al. (1992); D’Angelo et al. (1996), Chiang et al. (1996), Dorn II. et al. (1997), Narumiya et al. (1999)). Das im hochkonservierten Trp-Cys-Phe-Element in der zweiten extrazellulären Schleife lokalisierte Cys ist die am höchsten konservierte Aminosäure in den extrazellulären Domänen der Prostanoidrezeptoren (Abramowitz et al. (1995)). Allerdings schien im Kaninchen-EP3-R die Ausbildung dieser Disulfidbrücke für die Faltung eines funktionellen Rezeptorproteins nicht essentiell zu sein (Audoly und Breyer (1997b)). 
Die Ligandbindung der Prostanoidrezeptoren findet innerhalb der Plasmamembran an den hydrophoben Transmembrandomänen statt, die aus 22 bis 28 zumeist unpolaren Aminosäuren gebildeten werden. Innerhalb der Prostanoidrezeptoren sind in der III., IV., VI. und VII. Transmembrandomäne vier Proline hochkonserviert, von denen vermutet wird, daß sie für die Bildung der Bindungstasche relevant sein könnten (Probst et al. (1992)). Weiterhin wurde nach Substitution einzelner Aminosäuren in den Transmembrandomänen für den EP3 $\alpha-R$ (Huang und Tai (1995)), den Maus-IP-R (Kobayashi et al. (1997)), den KaninchenEP3-R (Audoly und Breyer (1997a)) und den humanen FP-R (Neuschäfer-Rube et al. 2003) eine verringerte Ligandbindung gezeigt. Eine eindeutige Zuordnung einzelner hydrophiler Aminosäuren in den Transmembrandomänen als Interaktionspartner für die Hydroxyl- und Ketogruppen der Prostanoide ist bislang aber noch nicht möglich.

Spezifisch für die Prostanoidrezeptoren ist die polare, positiv geladene Aminosäure Arginin in der VII. Transmembrandomäne, die tief in der lipophilen Membran liegt. Diese Aminosäure ist in allen Prostanoidrezeptoren konserviert (Coleman et al. (1994); Abramovitz et al. (1995)). Es wird vermutet, daß dieses Arginin über eine ionische Wechselwirkung oder durch Ausbildung von Wasserstoffbindungen mit der Carboxylgruppe der Prostanoide die Ligandbindung unterstützt (Funk et al. (1993); Chang et al. (1997); Audoly und Breyer (1997a)).

Eine in allen G-Protein-gekoppelten Rezeptoren (GPCR) hoch konservierte intrazelluläre Sequenz ist das an die III. Transmembrandomäne anschließende DRY-Motiv, welches einen Einfluß auf die Struktur und die Signaltransduktion (Rasmussen et al. (1999)), sowie die Signaltermination (Bennett et al. (2000); Hüttenrauch et al. (2002)) hat. Diesem DRY-Motiv entspricht ein ERC-Motiv innerhalb der meisten Prostanoidrezeptoren, wobei im EP2- und im EP4-R ein ERY-Motiv konserviert ist. Das Arginin ist in allen GPCR vorhanden.

Unmittelbar am Ende der VII. Transmembrandomäne ist das in Prostanoidrezeptoren konservierte DPXXY-Motiv zu finden, das für die Kopplung des Rezeptors an das G-Protein von Bedeutung ist. Der Austausch des Asp im DPXXY-Motiv des mEP3 $\alpha-R$ (Satoh et al. (1999)) oder des Kaninchen-EP3-R (Audoly und Breyer (1997a)) veränderte die Affinität des Rezeptors zum Liganden nicht wesentlich, führte aber zu einer Reduktion der Kopplung des Rezeptors an das G-Protein.

Weiterhin befinden sich im proximalen Teil der C-terminalen Domäne des EP2-, EP4-, FPund der IP-R zwei Cysteine, die palmitoyliert werden können, sodaß durch deren Membranverankerung eine vierte cytoplasmatische Schleife gebildet werden kann, die an der Signaltransduktion beteiligt sein könnte (Bouvier et al. (1995); Morello et al. (1996); Böhm et al. (1997)). Die Membranverankerung über ein in der C-terminalen Domäne lokalisiertes Cys, die zu einer verminderten G-Protein-Aktivierung führte, wurde für den IP-R gezeigt (Hayes et al. (1999)). Die für die Palmitoylierung postulierte Konsensus-Sequenz 
Leu-X-Cys-(X)n-Arg/Lys ca. 11-16 Aminosäuren nach der VII. Transmembrandomäne ist in den Prostanoidrezeptoren jedoch nicht vorhanden (Narumiya et al. (1999)).

Zusätzlich sind in den intrazellulären Schleifen und der C-terminalen Domäne der verschiedenen Rezeptoren Serine und Threonine lokalisiert, denen durch Phosphorylierung ihrer Seitenketten eine Bedeutung in der Entkopplung des Rezeptors von der intrazellulären Signalkette zukommt. Bisher konnte eine Beteiligung der C-terminalen Domäne an der Entkopplung von der intrazellulären Signalkette für den IP- (Smyth et al. 1998), den TP(Spurney (1998)), den EP3 $\alpha$ - (Negishi et al. (1993)) und den EP4-Rezeptor (Bastepe und Ashby (1997)) gezeigt werden.

\subsection{Signaltermination der G-Protein-gekoppelten Rezeptoren}

Nach der Ligandbindung an den Rezeptor kommt es zu einer Konformationsänderung des Rezeptors in seine aktivierte Form, die eine Interaktion mit dem G-Protein ermöglicht. Diese Interaktion führt zum Austausch des an die $\alpha$-Untereinheit gebundenen GDP zu GTP, wodurch das G-Protein in die $\alpha$ - und die $\beta \gamma$-Untereinheit dissoziiert und die $\alpha$-Untereinheit verschiedene Effektoren aktiviert oder inhibiert.

Die Signaltermination der G-Protein-gekoppelten Rezeptoren kann entweder durch die Entfernung des Liganden vom Rezeptor an der Zelloberfläche oder durch eine Entkopplung des Ligand-besetzten Rezeptors von seiner intrazellulären Signalkette erfolgen. Damit der Ligand sich vom Rezeptor lösen kann, muß er aus dem Gleichgewicht entfernt werden, was durch Diffusion und daraus resultierender Verdünnung in das umgebende Medium erfolgen kann. Die Entfernung des Liganden aus dem Gleichgewicht kann weiterhin durch extrazellulären enzymatischen Abbau oder durch Aufnahme in die Zelle beschleunigt werden. Dieser letzte Weg könnte für die Prostaglandine relevant sein, für die ProstaglandinTransporter identifiziert wurden, durch die die Prostaglandine in die Zelle aufgenommen werden, in der sie dann metabolisiert werden. Prostaglandin-Transporter wurden für $\mathrm{PGD}_{2}$ $\mathrm{PGE}_{2}$ und $\mathrm{PGF}_{2 \alpha}$ beschrieben (Kanai et al. (1995); Lu et al. (1996); Chan et al. (1998)).

Auch in Gegenwart des Liganden kann bei vielen GPCR durch intrazelluläre kovalente Modifikationen des Rezeptors die Signaltransduktion terminiert werden. Dabei werden die Rezeptorproteine zunächst signalabhängig entweder durch „second messenger“-abhängige Kinasen (siehe 1.3.1) oder durch den Ligand-besetzten Rezeptor selbst aktivierte Kinasen (G-protein-coupled receptor kinase (GRKs)) (siehe 1.3.1) an intrazellulären Domänen phosphoryliert. Während durch GRKs nur Ligand-besetzte, aktivierte Rezeptoren homolog phosphoryliert werden können, kann eine Rezeptorphosphorylierung durch „secondmessenger"-abhängige Kinasen auch ohne Aktivierung des Substratrezeptors (heterolog) durch Aktivierung eines anderen Rezeptors in derselben Zelle erfolgen (Abb. 2). 


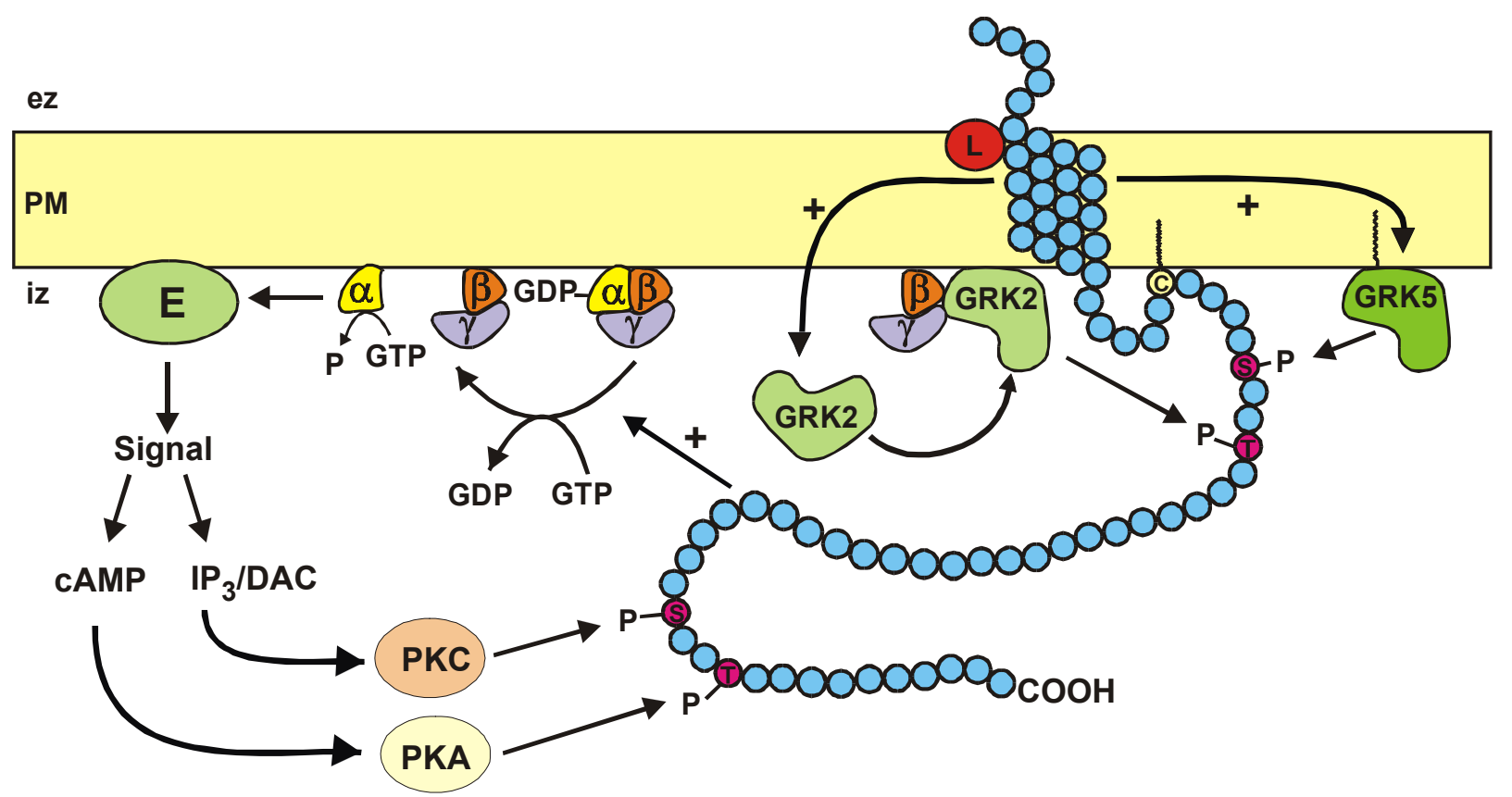

Abb. 2: Schematische Darstellung der durch Ligandbindung und Rezeptoraktivierung ausgelösten Signalkaskaden der G-Protein-gekoppelten Rezeptoren. Dargestellt sind die VII. Transmembrandomäne und die C-terminale Domäne des Rezeptors mit gebundenem Liganden ( $L$ ) und der aktivierte Effektor $(E)$. Weitere Einzelheiten siehe Text.

Die Phosphorylierung der Rezeptorproteine ermöglicht die Interaktion mit einem Protein, dem $\beta$-Arrestin (Lohse et al. (1992)) (siehe 1.3.1), das die Kopplung des Rezeptors an sein G-Protein sterisch inhibiert. Diese Entkopplung wird als Desensitisierung bezeichnet (Abb. 3). $\beta$-Arrestin markiert gleichzeitig den Rezeptor für die auf die Entkopplung folgende Internalisierung.

Durch die Bindung des Adaptorproteins Adaptin (siehe 1.3.1) an $\beta$-Arrestin wird die Internalisierung eingeleitet. Nach Kopplung von $\beta$-Arrestin und Adaptin an Clathrin (siehe 1.3.1) folgt die Invagination der Plasmamembran und die Dynamin-vermittelte Abschnürung eines Vesikels, die in einer Entfernung des Rezeptors von der Zelloberfläche resultiert (Abb. 3). Der Rezeptor wird internalisiert und in einem intrazellulären Kompartiment vom Liganden getrennt und dephosphoryliert. Der dephosphorylierte Rezeptor kann zur Plasmamembran zurücktransportiert (Resensitisierung) oder aber, vor allem bei lang anhaltender AgonistenExposition der Zelle, abgebaut werden (Down-Regulation). 


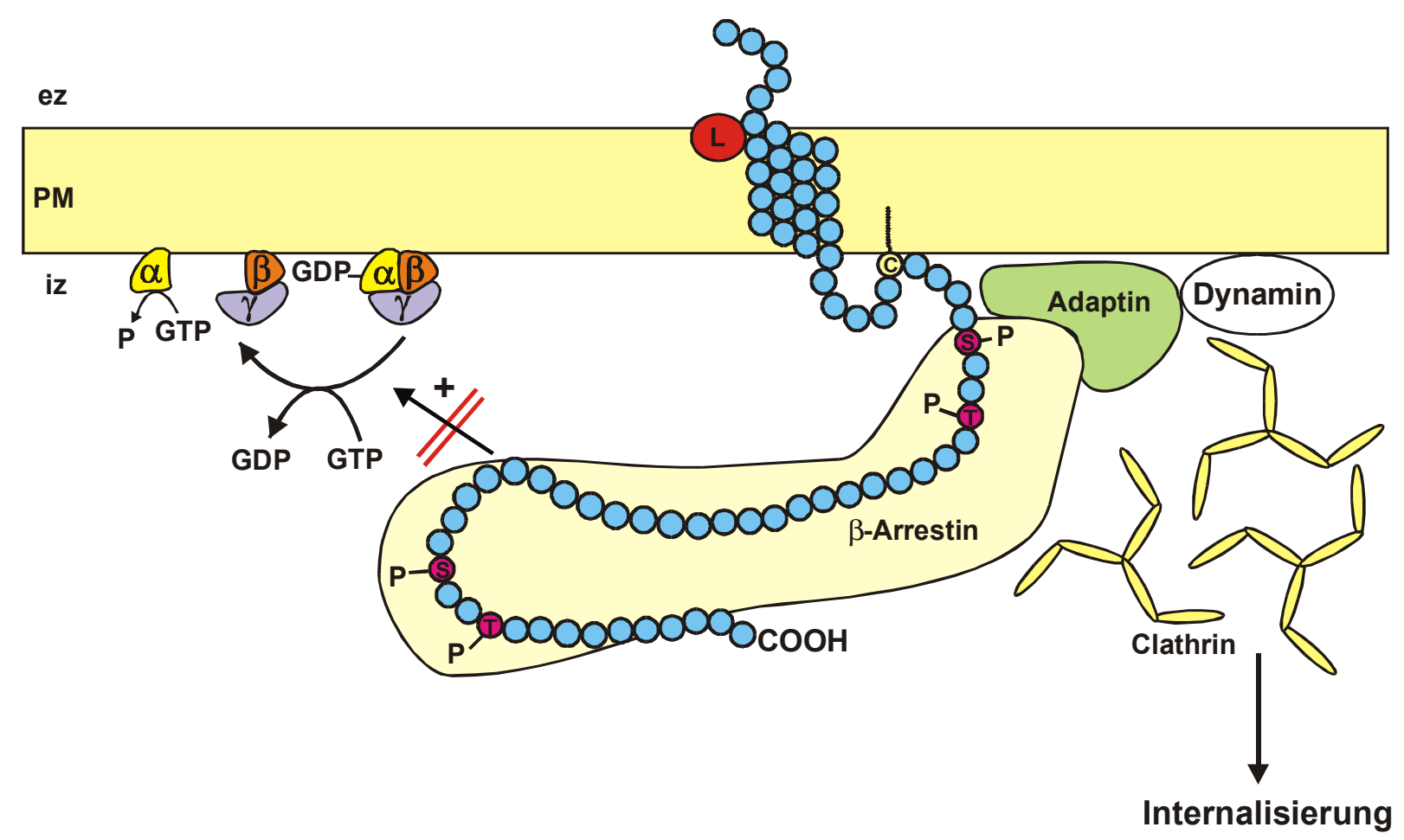

Abb. 3: Schematische Darstellung der Entkopplung des Rezeptors vom G-Protein durch $\beta$-Arrestin und anschließende Internalisierung. Dargestellt sind die VII. Transmembrandomäne mit gebundenem Ligand und die phosphorylierte C-terminale Domäne des Rezeptors, sowie die an der Internalisierung beteiligten Proteine. Weitere Einzelheiten siehe Text.

\subsubsection{Komponenten der Agonisten-induzierten Desensitisierung und Internalisierung}

An der Desensitisierung G-Protein-gekoppelter Rezeptoren sind verschiedene Proteine beteiligt, deren Zusammenspiel zur Entkopplung und Internalisierung des Rezeptors führt. Die einzelnen Komponenten der Entkopplung und Internalisierung werden durch den Rezeptor selbst oder durch Komponenten der intrazellulär ausgelösten Signalkaskade aktiviert. Die Hauptkomponenten, denen eine Bedeutung in der Desensitisierung und Internalisierung nachgewiesen wurde, sind im folgenden dargestellt.

Proteinkinase A (PKA) und Proteinkinase C (PKC)

PKA und PKC sind „second messenger"-abhängige (PKA durch CAMP und PKC durch Diacylglycerol (DAG)) cytosolische Kinasen, die Serine und Threonine, die sich innerhalb einer spezifischen Konsensus-Sequenz befinden, phosphorylieren können (Böhm et al. (1997), Ferguson (2001)). Sie werden in vielen Geweben exprimiert und sind an verschiedenen Signalwegen beteiligt. PKA und PKC können einen Rezeptor phosphorylieren, auch wenn der Rezeptor nicht Ligand-besetzt ist und so nur als Substrat dient. PKA und PKC sind an der heterologen Desensitisierung beteiligt. 
G-protein-coupled receptor kinase (GRK)

"G-protein-coupled receptor kinases“ (GRK) sind cytosolische oder membranassoziierte Kinasen, die in verschiedenen Geweben exprimiert werden (Lefkowitz (1993), Böhme et al. (1997), Ferguson (2001)). Bisher konnten sieben verschiedene GRKs identifiziert werden, die einen Rezeptor nach der notwendigen Membranassoziation phosphorylieren können (Stoffel et al. (1997)). Die Membranassoziation wird durch Elemente in der C-terminalen Domäne gewährleistet. GRK1 und GRK7, die nur in der Retina exprimiert werden, verfügen über ein CAAX-Motiv, durch das sie über eine lichtinduzierte Farnesylierung an der Membran verankert werden. GRK2 und GRK3 sind ubiquitär exprimierte, cytosolisch lokalisierte Kinasen, die über eine $G_{\beta \gamma}$-Bindungs- und eine „pleckstrin-homology“-Domäne innerhalb der C-terminalen Domäne verfügen, über die es zu einer $G_{\beta \gamma^{-}}$und Phosphoinositid-abhängigen Membranverankerung kommt. Im Gegensatz dazu sind GRK4, die im Testis exprimiert wird, und GRK6, die ubiquitär exprimiert wird, palmitoyliert und permanent an der Plasmamembran verankert. Die Membranverankerung von der ubiquitär exprimierten GRK5 wird möglicherweise durch elektrostatische Interaktionen über einen basischen Bereich in der C-terminalen Domäne mit Phospholipiden der Membran gewährleistet (Krupnick und Benovic (1998); Penn et al. (2000)).

Die GRKs haben eine vergleichbare strukturelle Organisation. Sie verfügen über eine gering konservierte N-terminale-Domäne, in der die Rezeptor-Bindungsdomäne lokalisiert ist. Innerhalb der Rezeptor-Bindungsdomäne liegt die konservierte „regulator of G-Protein signaling homology"-Domäne (RGS-Domäne), über die die Aktivität der G-Proteine moduliert werden kann. Der N-terminalen Domäne folgt die katalytische Domäne (Böhm et al. (1997)), an die sich ein 66 Aminosäuren-umfassender konservierter Bereich anschließt. Die Cterminale Domäne, die zur Membranassoziation der GRKs dient, ist in der Peptidsequenz und Größe sehr variabel.

Die Membranverankerung der cytosolischen Kinasen und die Aktivierung werden durch einen aktivierten Rezeptor induziert, wobei für die Aktivierung Phosphatidylinisitol-bisphosphat (GRK2 und 3) oder $G_{\beta \gamma}$ erforderlich ist. Nach der Membranassoziation phosphorylieren die GRKs ausschließlich Serine und Threonine, wobei sie im Gegensatz zu PKA und PKC keine Konsensus-Sequenz benötigen. Die aktivierten GRKs können nur Ligand-besetzte Rezeptoren phosphorylieren.

\section{$\beta$-Arrestin}

$\beta$-Arrestin ist ein monomeres cytosolisches Protein, von dem bisher vier Typen identifiziert wurden: Visual-Arrestin und C-Arrestin sind hauptsächlich in der Retina lokalisiert, wohingegen $\beta$-Arrestin1 und $\beta$-Arrestin2 in vielen Geweben exprimiert werden (Böhm et al. 
(1997)). Für $\beta$-Arrestin wurden in verschiedenen Geweben Spleißvarianten identifiziert (Parruti et al. (1993); Sterne-Marr et al. (1993)).

$\beta$-Arrestin besitzt eine $\mathrm{N}$-terminale und eine $\mathrm{C}$-terminale regulatorische Domäne, die für die Struktur wichtig sind. Weiterhin verfügen sie N-terminal über eine Erkennungsstelle für den Aktivierungsgrad des Rezeptors, der eine Phosphorylierungs-Erkennungsstelle folgt. Innerhalb der C-terminalen Domäne ist eine Rezeptor-Bindungsdomäne lokalisiert und, in $\beta$ Arrestin1, eine primäre Phosphorylierungsstelle (Ser 412), über deren Phosphorylierung die Affinität zu Clathrin reduziert werden kann. Weiterhin befinden sich ein ClathrinBindungsmotiv (LIEF) und ein RXR-Bindungsmotiv für $\beta 2$-Adaptin in diesem Bereich (Luttrell und Lefkowitz (2002)). $\beta$-Arrestin bindet hauptsächlich an phosphorylierte Rezeptoren, kann jedoch auch mit einer deutlich geringeren Affinität an nicht-phosphorylierte Ligand-besetzte Rezeptoren binden (Böhm et al. (1997)).

\section{Adaptin}

Adaptin ist ein heterotetrameres Protein, das sich aus zwei großen Untereinheiten $(\alpha, \gamma, \delta$, oder $\varepsilon$ und $\beta 1-\beta 4)$ zusammensetzt, die nicht-kovalent über eine $\mu$-Untereinheit $(\mu 1-\mu 4)$ und eine kleine $\sigma$-Untereinheit $(\sigma 1-\sigma 4)$ assoziiert sind. Bisher konnten vier Adaptin-Komplexe identifiziert werden, AP1-4 (Adaptor-Protein 1-4), von denen AP2 an der Clathrin-vermittelten Endocytose beteiligt ist. Die Bindung von Adaptin an $\beta$-Arrestin erfolgt über ein Motiv in der C-terminalen Domäne von $\beta$-Arrestin (Laporte et al. (1999)). Die Interaktion mit Clathrin erfolgt über ein Clathrin-Bindungsmotiv in der $\beta$-Untereinheit (Galluser und Kirchhausen (1993)). Die $\alpha$-Untereinheit des Adaptin kann mit Dynamin interagieren (Wang et al. (1995), das eine regulatorische Funktion in der Endocytose übernimmt (Zhang et al. (1996), Ahn et al. (2002)). Die Bindung des Adaptin-Komplex an das Zielprotein kann auch über DileucinMotiv im Zielprotein erfolgen.

\section{Dynamin}

Dynamin ist ein monomeres Protein von dem bisher zwei Isoformen identifiziert wurden, wobei Dynamin I im Nervengewebe und Dynamin II in vielen Geweben exprimiert wird. Dynamin besitzt eine GTPase-Aktivität, durch die eine Oligomerisierung in Ring- oder Spiralstrukturen und die daraus resultierende Abschnürung von Vesikeln von der Plasmamembran ermöglicht wird (Hinshaw und Schmid (1995); Ahn et al. (2002)). Die GTPase-Domäne mit drei hochkonservierten GTP-Bindungsstellen ist im N-terminalen Bereich des Proteins lokalisiert, der die mögliche Assemblierungs-Domäne folgt. Weiterhin verfügt Dynamin über eine „pleckstrin-homology“-Domäne, die an Phosphoinositide der Plasmamembran bindet und so für die Membranlokalisation relevant ist. In der C-terminalen Domäne ist eine GTPase-Effektor-Domäne (GED), die die GTP-abhängige Oligomerisierung 
beschleunigt (Warnock et al. (1996)) und eine Prolin-reiche Domäne, an die regulatorische Proteine mit einer „Src-homology-3“-Domäne binden können (Grabs et al. (1997)), lokalisiert. Die Interaktion von Dynamin mit Clathrin und dem AP2-Komplex sowie die Oligomerisierung kann von Amphiphysin, Grb2, PLC $\gamma$ und Endophilin über diese Domäne reguliert werden (Eccleston et al. (2002); Claing et al. (2002)). Darüber hinaus können $\mathrm{PIP}_{2}$ und $\mathrm{G}_{\beta \gamma}$ die GTPase-Aktivität von Dynamin und damit die Abschnürung positiv und negativ modulieren (Lin und Gilman (1996)).

\section{Clathrin}

Clathrin besteht aus drei schweren und drei leichten Polypeptidketten, die die sogenannte Triskelion-Struktur ausbilden. Diese Triskelions formen korbähnliche konvexe Netzwerke auf der cytosolischen Seite der Plasmamembran mit den assoziierten Rezeptoren, die dann durch Invagination zu cytosolischen Clathrin-coated-Vesikeln werden. Anschließend folgt die Dynamin-vermittelte Abschnürung der Vesikel von der Plasmamembran und eine darauffolgende Fusion mit Lysosomen oder cytosolischen Transportkompartimenten.

\subsection{Der humane EP4 Rezeptor}

\subsubsection{Struktur des humanen EP4-Rezeptors}

Die von der cDNA abgeleitete Aminosäuresequenz des humanen EP4-Rezeptors (Abb. 4) besteht aus 488 Aminosäuren. Das anhand der Peptidsequenz errechnete Molekulargewicht beträgt ca. $54 \mathrm{kDa}$. Innerhalb dieser Sequenz befinden sich zwei Asn an Position 7 in der Nterminalen Domäne und an Position 177 in der zweiten extrazellulären Schleife, die potentielle N-Glykosylierungsstellen sind. Weiterhin sind an Position 92 in der ersten und an Position 170 in der zweiten extrazellulären Schleife zwei Cysteine vorhanden, die durch Ausbildung einer Disuldfidbrücke den Rezeptor stabilisieren können, wobei Cys 170 in dem koservierten Trp-Cys-Phe-Element (Position 169-171) liegt. Im Gegensatz zu den meisten Prostanoidrezeptoren, die statt des unter allen GPCR konservierten DRY-Motives, ein ERCMotiv haben, trägt der EP4-R in Position 116-118 ein ERY-Motiv in der zweiten cytoplasmatischen Schleife. In den Transmembrandomänen IV (Position 154), VI (Position 287) und VII (Position 326) sind drei der vier konservierten Proline vorhanden. 


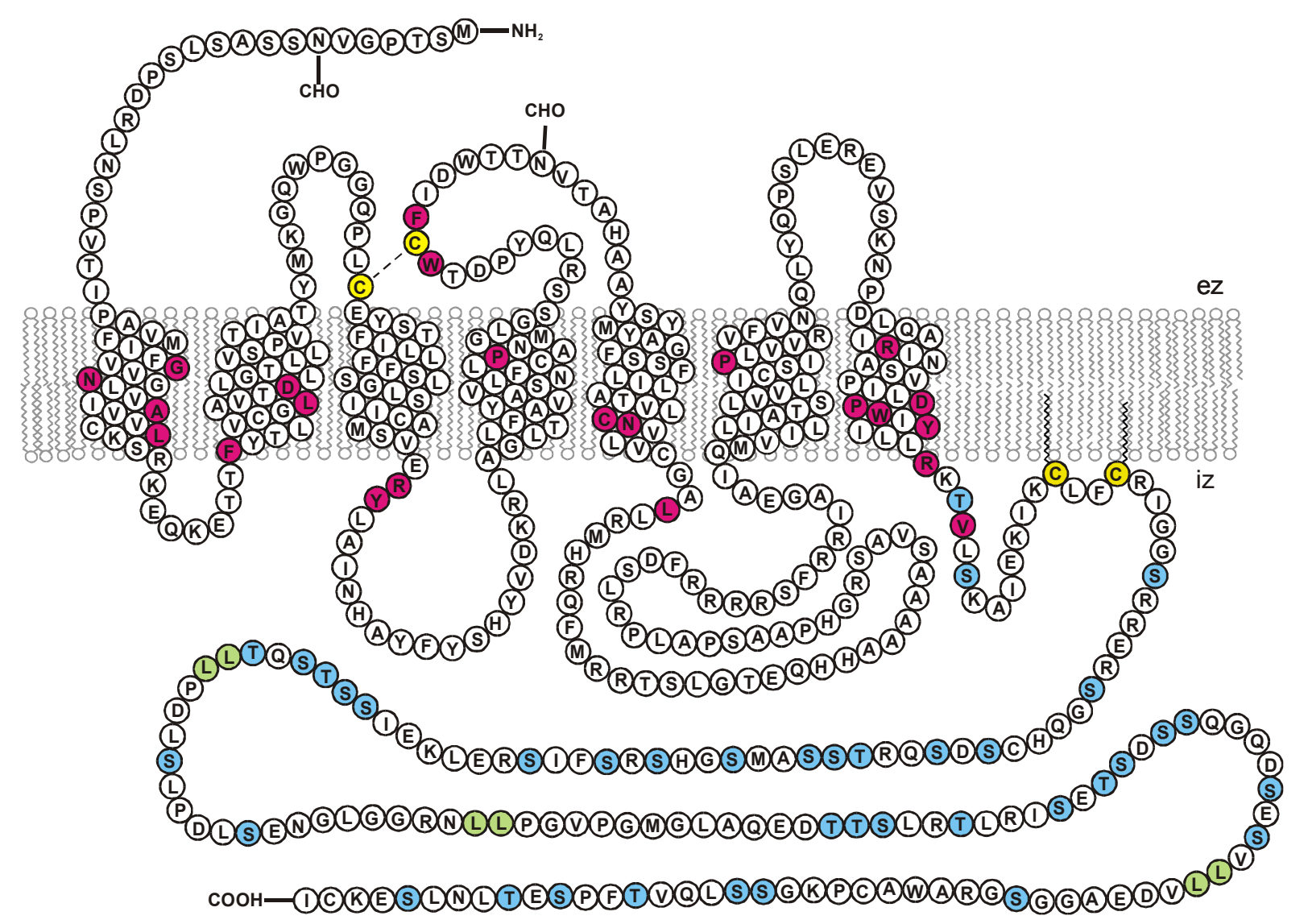

Abb. 4: Hypothetische Struktur des humanen EP4-Rezeptors. Gezeigt ist die hypothetische Struktur des humanen Prostaglandin $\mathrm{E}_{2}$-Rezeptors, Subtyp EP4 mit seinen sieben Transmembrandomänen, der extrazellulären $\mathrm{N}$ - und der intrazellulären $\mathrm{C}$ terminalen Domäne und den drei extrazellulären und den drei intrazellulären Schleifen. Die mit $-\mathrm{CHO}$ versehenen Aminosäuren bilden potentielle N-Glykosylierungsstellen. Serine und Threonine in der C-terminalen Domäne, die als potentielle Phosphorylierungsstellen dienen können sind blau, die Dileucin-Motive grün, Aminosäuren, die in allen Prostanoidrezeptoren konserviert sind, rot markiert. Cysteine, die extrazellulär eine Disulfidbrücke bilden können, sind gelb und durch eine Linie verbunden; die gelb markierten Cysteine 346 und 349 in der C-terminalen Domäne sind möglicherweise palmitoyliert und können somit in der Membran verankert sein.

Die VII. Transmembrandomäne wird wahrscheinlich von den Aminosäuren 311 bis 332 gebildet, innerhalb der sich an Position 316 das hochkonservierte Arginin befindet und in der an Position 325-329 das DPXXY-Motiv lokalisiert ist. Die C-terminale Domäne des EP4-R wird von den Aminosäuren 333-488 gebildet. Die C-terminale Domäne ist die mit Abstand größte innerhalb der Prostanoidrezeptoren. Innerhalb der 156 Aminosäuren sind an Position 346 und 349 zwei Cysteine lokalisiert, die als potentielle Palmitoylierungsstellen dienen können. Weiterhin beinhaltet die C-terminale Sequenz 38 Serine und Threonine, denen durch Phosphorylierung ihrer Seitenketten eine Rolle in der Entkopplung des Rezeptors von der Signalkette und der Internalisierung des Rezeptors zukommen kann. Darüber hinaus verfügt der EP4-R über eine sehr große dritte intrazelluläre Schleife, in der weitere Serine und Threonine lokalisiert sind, die eine 
mögliche Bedeutung in der Entkopplung und Internalisierung haben können. Zusätzlich sind auch drei Dileucin-Motive (LL 395-96; LL 452-53; LL 414-15) in der C-terminalen Domäne vorhanden, die als Bindungsmotive für Adaptin ein Rolle in der Internalisierung spielen können (Gabilondo et al. (1997), Fan et al. (2001)).

\subsubsection{Physiologische Bedeutung des EP4-Rezeptors}

Der EP4-Rezeptor konnte bisher in vielen verschiedenen Geweben nachgewiesen werden, in denen er eine Vielzahl verschiedener Funktionen übernehmen kann. Bisher wurde eine Beteiligung des EP4-Rezeptors an Fieberreaktionen (Narumiya et al. 1999), an der intestinalen Sekretion während Entzündungen (Belley und Chadee (1999)) und an der Regulation von Nierenfunktionen (Breyer und Breyer (2000)) nachgewiesen. Die Beteiligung des Rezeptors am Knochenmetabolismus wurde gezeigt (Machwate et al. (2001)) und $\mathrm{PGE}_{2}$ hemmt die Akut-Phase-Reaktion über den EP4-R in der Leber (Fennekohl et al. 2000). In EP4-R knock-out Mäusen kam es nicht mehr zum Verschluß des Ductus arteriosus und führte zum Tod neonataler Tiere (Segi et al. (1998)).

\subsubsection{Signaltermination des EP4-Rezeptors}

Die Desensitisierung des EP4-Rezeptors wurde zuerst von Nishigaki et al. (1996) beschrieben. Sie zeigten, daß bei repetitiver Stimulation mit $\mathrm{PGE}_{2}$ die maximale, Agonisteninduzierte cAMP-Bildung in der zweiten Stimulationsphase reduziert war, jedoch die halbmaximale Stimulation der cAMP-Bildung nicht beeinflußt wurde. Weiterhin konnte nach Trunkierung der C-terminalen Domäne des EP4-Rezeptors ab Aminosäure 350 ein Verlust der Agonisten-induzierten Desensitisierung dieses Rezeptors nachgewiesen werden (Bastepe und Ashby (1999)), was eine Beteiligung der C-terminalen Domäne an der Desensitisierung vermuten läßt. Die Relevanz der C-terminalen Domäne für die Desensitisierung wurde durch die Charakterisierung eines nach $\mathrm{PGE}_{2}$-Stimulation desensitisierbaren Hybrid-Rezeptors unterstützt, der aus dem nicht desensitisierbaren Ratten-EP3 $\beta-R$ und der C-terminalen Domäne des humanen EP4-Rezeptors bestand (Neuschäfer-Rube et al. 1997b).

Innerhalb der intrazellulären Domänen sind für PKA und PKC aufgrund ihrer KonsensusSequenz Ser 222 und Ser 259 (PKA) und Ser 360, Ser 372, Ser 429, Thr 431 und Ser 484 (PKC) als potentielle Phosphorylierungsstellen lokalisiert, jedoch sind die PKA-Stellen für die Desensitisierung und Internalisierung irrelevant, da sie nicht in der C-terminalen Domäne lokalisiert sind. 


\subsection{Ziel der Arbeit}

Ziel dieser Arbeit war es, die 38 potentiellen Phosphorylierungsstellen in der C-terminalen Domäne des humanen EP4-Rezeptors durch sequenzgerichtete Mutagenese auszutauschen und die Serine und Threonine zu identifizieren, die für die Agonisten-abhängige Phosphorylierung von Bedeutung sind. Weiterhin sollte die Agonisten-abhängige Desensitisierung anhand der reduzierten cAMP-Bildung durch $\beta$-Arrestin-induzierte Entkopplung und die durch den Verlust der Phosphorylierung resultierende Eliminierung der Internalisierung der mutierten Rezeptoren mit dem Wildtyp-Rezeptor verglichen werden. 


\section{Material}

\subsection{Chemikalien und Biochemikalien}

\begin{tabular}{|c|c|c|}
\hline $\begin{array}{l}\text { 2,2'-Azino-di-[3-ethylbenzthioazylin- } \\
\text { sulfonat (6)] (ABTS) }\end{array}$ & Roche & Mannheim \\
\hline Acrylamid/Bisacrylamid-Lösung & Roth & Karlsruhe \\
\hline Agarose & Hybaid & Heidelberg \\
\hline Albumin Fraktion V (BSA) & Roth & Karlsruhe \\
\hline Ammoniumchlorid & Merck & Darmstadt \\
\hline Ammoniumpersulfat & BioRad & Hamburg \\
\hline Ampicillin & Sigma & Deisenhofen \\
\hline ATP (Dinatriumsalz) & Sigma & Deisenhofen \\
\hline Borsäure & Merck & Darmstadt \\
\hline Bovines Serum (BS) & Biochrom & Berlin \\
\hline Bromphenolblau & Sigma & Deisenhofen \\
\hline Calciumchlorid-Dihydrat & Merck & Darmstadt \\
\hline Coomassie-Brilliant-Blue R250 & Serva & Heidelberg \\
\hline Creatin-Phosphat & Roche & Mannheim \\
\hline Diazobicyclooctan (DABCO) & Sigma & Deisenhofen \\
\hline Desoxyribonukleotide & Roche & Mannheim \\
\hline Diethylpyrocarbonat (DEPC) & Sigma & Deisenhofen \\
\hline Dinatriumhydrogenphosphat & Sigma & Deisenhofen \\
\hline Dinatriumhydrogenphosphat-Dihydrat & Sigma & Deisenhofen \\
\hline Dithiothreitol (DTT) & Biomol & Hamburg \\
\hline Dimethylsulfoxid (DMSO) & Sigma & Deisenhofen \\
\hline Ethylendiamintetraacetat (EDTA) & Sigma & Deisenhofen \\
\hline Essigsäure & Roth & Karlsruhe \\
\hline Ethanol p. a. & Roth & Karlsruhe \\
\hline Ethidiumbromid & Sigma & Deisenhofen \\
\hline Fibronectin & Sigma & Deisenhofen \\
\hline Formamid & Roth & Karlsruhe \\
\hline Forskolin & Calbiochem & Bad Soden \\
\hline Gelatine & Serva & Heidelberg \\
\hline Glucose & Roth & Karlsruhe \\
\hline Glycerol & Roth & Karlsruhe \\
\hline Glycin & Roth & Karlsruhe \\
\hline
\end{tabular}


GTP

Harnstoff

Hefe-Extrakt

HEPES

Hydroluma

25-Hydroxycholesterol

Hyperfilm

Isobuthylmethylxanthin (IBMX)

Isopropanol

Kaliumchlorid

Kaliumdihydrogenphosphat

Kanamycin

LB-Agar

Leupeptin

Magermilchpulver

Magnesiumchlorid

Methanol

2-(N-Morpholino)ethansulfonsäure

(MES)

Mercaptoethanol
Mowiol 4-88
Nagellack
Natriumacetat
Natriumcarbonat
Natriumchlorid
Natriumcitrat
Natriumfluorid
Natriumhydrogencarbonat
Natriumdihydrogenphosphathydrat
Natriumhydroxid
Natriumdodecylsulfat (SDS)
Natriumperiodat
Natriumpyrophosphat
N-Biotin-Hydrazid
n-Butanol
Paraformaldehyd
Pefabloc

Sigma

Deisenhofen

Roth

Gibco BRL

Karlsruhe

Applichem

Eggenstein

Baker

Darmstadt

Sigma

Groß-Gerau

Amersham-Pharmacia

Deisenhofen

Calbiochem

Roth

Applichem

Merck

Serva

Gibco BRL

Biomol

Nestle

Merck

Roth

Biomol

Roth

Calbiochem

Jade

Merck

Merck

Merck

Merck

Sigma

Applichem

Merck

Merck

Serva

Sigma

Sigma

Pierce

Roth

Sigma

Biomol
Freiburg

Bad Soden

Karlsruhe

Darmstadt

Darmstadt

Heidelberg

Eggenstein

Hamburg

Frankfurt

Darmstadt

Karlsruhe

Hamburg

Karlsruhe

Bad Soden

Berlin

Darmstadt

Darmstadt

Darmstadt

Darmstadt

Deisenhofen

Darmstadt

Darmstadt

Darmstadt

Heidelberg

Deisenhofen

Deisenhofen

Frankfurt am Main

Karlsruhe

Deisenhofen

Hamburg 
Phorbol-12-myristat-13-acetat (PMA)

Oligo ( $\left.\mathrm{dT}_{12-18}\right)$

ONO604

o-Phosphorsäure (85\% v/v)

Ponceau S

Prostaglandin $\mathrm{E}_{2}\left(\mathrm{PGE}_{2}\right)$

Protein G-Sepharose

Natriumpyruvat

Salzsäure $(37 \%(w / v))$

Saponin

Sepharose 4B

Serva-Blue G Nr. 35050

Staurosporin

Streptavidin-Fluoresceinisothiocyanat

(FITC)-Konjugat

Streptavidin-Peroxidase-Konjugat

Sucrose

Tetracyclin

Trichloressigsäure (TCA)

$\mathrm{N}, \mathrm{N}, \mathrm{N}$ ',N'-Tetramethyl-ethylendiamin (TEMED)

Tris(hydroxymethyl)-aminomethan

Triton X-100

Trypsin-Inhibitor

Trypton

Tween 20

Wasserstoffperoxid

Ziegenserum

Zellkultur

(N,N-bis[2-Hydroxyethyl]-2-

aminoethansulfonsäure (BES)

Dulbecco's modifiziertes Eagle Medium

DMEM-Trockenpulver

Dulbecco's modifiziertes Eagle Medium

(DMEM) ohne Phosphat und Glutamat
Calbiochem

Bad Soden

Amersham-Pharmacia

Freiburg

ONO Pharmaceutical

Kyoto, Japan

Company

Roth

Karlsruhe

Sigma

Calbiochem

Amersham-Pharmacia

Serva

Roth

Sigma

Amersham-Pharmacia

Serva

Calbiochem

Amersham-Pharmacia

Dianova

Fluka

Sigma

Merck

Bio Rad

Merck

Darmstadt

Serva

Heidelberg

Biomol

Hamburg

Gibco BRL

Merck

Eggenstein

Darmstadt

Roth

Karlsruhe

Gibco BRL

Eggenstein

Sigma

Deisenhofen

Gibco BRL

Eggenstein

ICN

Eschwege 
Fötales Kälberserum (FCS)

Geneticin (G-418)-Sulfat

L-Glutamat 100 x Stammlösung

Penicillin/Streptomycin-Lösung

Poly-L-Lysin

Trypsin
Biochrom

Calbiochem

ICN

Gibco BRL

Sigma

Gibco BRL
Berlin

Bad Soden

Eschwege

Eggenstein

Deisenhofen

Eggenstein

\subsection{Geräte}

Automatische Pipettierhilfe, Gilson

Eppendorf

Hamburg

Typ P10, P20, P200, P1000

Automatische Pipettierhilfe,

Labsystems

Frankfurt am Main

Finnpipetten Digital

Automatische Pipettierhilfe,

Hirschmann

Eberstadt

pipetus akku

Automatische Pipettierhilfe,

Eppendorf

Hamburg

Typ Multipette plus

Automatischer DNA-Sequenzierer

$A B I$

Weiterstadt

Begasungsbrutschrank

Zapf Instruments

Sarstedt

Nu Aire IR Autoflow

ChemiDoc $^{\mathrm{TM}}$-System

BioRad

München

Dampfsterilisator Varioklav

$\mathrm{H}+\mathrm{P}$ Labortechnik

Oberschleißheim

Eismaschine

Ziegra

Isernhagen

Elektrophorese-System Mini Protean II

BioRad

München

Flachbettelektrophorese-Kammer

Flüssigkeitsscintillationszähler

Biometra

Göttingen

Beckmann / Coulter

München

Gene Pulser II Elektroporator

BioRad

München

Hettich-Zentrifugen Rotina 35 und

Hettich

Tuttlingen

Universal 16

Hettich-Rotoren 1617 und 1717

Hettich

Tuttlingen

High Voltage Power Pack P30

Biometra

Göttingen

Laborbrenner Gasprofi 1

Wartewig-Labortechnik

Göttingen

Laborwaage Sartorius

Sartorius

Göttingen

Magnetrührer mit Heizblock

Heidolph

Göttingen

MR 2002

Microplate-Reader MRX II

Dynex Technologies

Denkendorf

Mikroskop Wilovert S und Wilovert A

Hund

Wetzlar 
Mikrowellengerät

Molecular-Imager

pH-Meter inoLab pH Level 1

Quarzdestille DESTAMAT Bi 18 E

Röntgenfilmkasetten

Schüttelapparat 3006

Schüttelinkubator 3031

Scintillationszähler SM6000LL

Sicherheitswerkbank Nu Aire Class II

Sicherheitswerkbank Herasafe

Sicherheitsbrenner Fireboy eco

SIGMA Rotor 12154-H

SIGMA Zentrifuge $3 \mathrm{~K} 30$

Sorvall Rotor GSA

Sorvall Rotor SS 34

Sorvall Zentrifuge RC 5B plus

Spannungsgerät

Spectralphotometer Ultrospec 1000

Taumler Rocky 3D

Thermocycler 60/2

Thermocycler T3

Thermoshaker Schutron TS 2-24

Tischzentrifuge Biofuge pico

Transblot SD Semi-Dry Transfer Cell

Univac Vakuumpumpe

Univapo $150 \mathrm{H}$ beheizbare Zentrifuge mit Kühlfalle Unicryo $\mathrm{MC} 2 \mathrm{~L} 60^{\circ} \mathrm{C}$

UV-Leuchtkasten

Vakuum-Filtrationsanlage

Vortex Genie 2

Wasserbad ecoline $011 \mathrm{mit}$

Einhängethermostat A100

Wasserbad Haake D1

Wärmeschrank Modell 600
Deawoo

BioRad

WTW

Heraeus

Intas

GFL

GFL

Beckmann / Coulter

Zapf Instruments

Heraeus

Technorama

Sigma

Sigma

Du Pont Instruments

Du Pont Instruments

Du Pont Instruments

Biometra

Amersham-Pharmacia

Fröbel Labortechnik

Biomed

Biometra

Haep Labor Consult

Heraeus

BioRad

Uniquip Laborgeräte

Uniquip Laborgeräte

Schütt

Millipore

Scientific Industries

Lauda

Schütt

Memmert
Frankreich

München

Weilheim

Hanau

Göttingen

Burgwedel

Burgwedel

München

Sarstedt

Hanau

Wallisellen (Schweiz)

Osterode am Harz

Osterode am Harz

Bad Homburg

Bad Homburg

Bad Homburg

Göttingen

Freiburg

Lindau

Theres

Göttingen

Bovenden

Hanau

München

Martinsried

Martinsried

Göttingen

Neuisenburg

Bohemia, USA

Lauda-Königshofen

Göttingen

Schwabach 


\subsection{Verbrauchsmaterialien}

3MM-Filter

Cryo-Röhrchen, $2 \mathrm{ml}$

Einmachfolie Zellglas

Einmal-Spritzen, $2 \mathrm{ml}$

ELISA-Platten Microlon $96 \mathrm{~K}$

Faltenfilter

Glasdeckgläschen

GF 52-Filter

Petrischalen $100 \times 15 \mathrm{~mm}$

Pipettenspitzen

Polypropylen-Ria-Röhrchen, $4 \mathrm{ml}$

Polypropylenröhrchen, $15 \mathrm{ml}$ und $50 \mathrm{ml}$, Sarstedt steril

Objektträger

Polystyrol-Gewebekulturschalen,

$8,7 \mathrm{~cm}^{2}$ und $58 \mathrm{~cm}^{2}$

Polystyrol-Gewebekulturflasche, $25 \mathrm{~cm}^{2}$ und $75 \mathrm{~cm}^{2}$

6-Well-Gewebekulturplatte

24-Well-Gewebekulturplatte

Polystyrol-Röhrchen, $15 \mathrm{ml}$

PVDF-Membran

Schnappdeckel-Reaktionsgefäße, 1,5 ml

Schraubdeckel-Reaktionsgefäße

1,5 und $2 \mathrm{ml}$
Whatmann

Roth

Folia

Braun Melsungen

Greiner BIO-ONE

Schleicher und Schüll

Heinemann

Schleicher und Schüll

Sarstedt

Sarstedt

Sarstedt

Roth

Sarstedt

Sarstedt

Sarstedt

Sarstedt

Sarstedt

Millipore

Sarstedt

Sarstedt
Maidstone (England)

Karlsruhe

Wendelstein

Melsungen

Frickenhausen

Dassel

Duderstadt

Dassel

Nürnbrecht

Nürnbrecht

Nürnbrecht

Nürnbrecht

Kahlsruhe

Nürnbrecht

Nürnbrecht

Nürnbrecht

Nürnbrecht

Nürnbrecht

Neuisenburg

Nürnbrecht

Nürnbrecht

\subsection{Reinigungs- und Isolierungssysteme}

\section{Gesamt-RNA-Isolierung}

SV Total RNA Isolation System

Promega

Madison (USA)

DNA-Isolierung aus Agarose-Gelen 
Plasmid-Reinigung

Jetstar

GFX ${ }^{\mathrm{TM}}$ Micro Plasmid prep Kit

DNA-Sequenzierung

BigDye Ready Reaction Terminator

Cycle Sequencing Kit
Genomed

Amersham-Pharmacia

Applied Biosystems
Bad Oeynhausen

Freiburg

Weiterstadt

\subsection{Chemilumineszenz-Nachweissystem}

SuperSignal ${ }^{R}$ West Pico

Pierce

Rochford (USA)

Chemiluminescence substrate

\subsection{Molekulare Standards}

DNA-Längenstandard

Smart-Ladder

Proteinstandard

Protein LMW-Marker

$\left[{ }^{14} \mathrm{C}\right]$-methylierter Proteinstandard
Eurogentec

Seraing (Belgien)

MBI-Fermentas

Amersham-Pharmacia
St. Leon-Rot

Freiburg

\section{Low-molecular-weight-Standards (LMW-Standard)}

$\begin{array}{lc}\text { Protein } & \text { MW (kDa) } \\ \beta \text {-Galaktosidase } & 116 \\ \text { Bovines Serum Albumin } & 66,2 \\ \text { Ovalbumin } & 45 \\ \text { Lactat-Dehydrogenase } & 35 \\ \text { Restriktionsendonukleas Bsp 98I } & 25 \\ \beta \text {-Lactoglobulin } & 18,4\end{array}$




\section{$\left[{ }^{14} \mathrm{C}\right]$ methylierter Protein-Standard $\left({ }^{14} \mathrm{C}-\right.$ Standard $)$}

\section{Protein}

$\left[{ }^{14} \mathrm{C}\right]$-methyliertes Myosin

$\left[{ }^{14} \mathrm{C}\right]$-methylierte Phosphorylase $b$ *

$\left[{ }^{14} \mathrm{C}\right]$-methyliertes Bovines Serum Albumin

$\left[{ }^{14} \mathrm{C}\right]$-methyliertes Ovalbumin *

$\left[{ }^{14} \mathrm{C}\right]$-methylierte Carboanhydrase

$\left[{ }^{14} \mathrm{C}\right]$-methyliertes Lysozym

\section{MW (kDa)}

220

97,4

66

46

30

14,3

* $\left[{ }^{14} \mathrm{C}\right]$-methylierte Phosphorylase b kann zwei Banden mit einem Molekulargewicht von 97,4 kDa und $100 \mathrm{kDa}$ und $\left[{ }^{14} \mathrm{C}\right]$-methyliertes Ovalbumin kann zwei Banden mit einem Molekulargewicht von 46 kDa und 50 kDa aufweisen.

\subsection{Radiochemikalien}
cAMP- $\left[{ }^{125}\right.$ I] Biotrak Assay system
Amersham-Pharamcia
Freiburg
[ $\left.{ }^{3} \mathrm{H}\right]$-Prostaglandin $\mathrm{E}_{2}$
Amersham-Pharmacia
Freiburg
$\left[{ }^{32} \mathrm{P}\right]$-ortho-Phosphat
Amersham-Pharmacia
Freiburg

\subsection{Antikörper}

\subsubsection{Monoklonale Antikörper}

FLAG -M2-mAk

Kodak/Sigma

Stuttgart

\subsubsection{Polyklonale Antiseren}

Antiserum gegen die C-terminale wurde im Labor

Domäne des hEP4-R hergestellt

Cy3-gekoppelte Ziege-Anti-Maus-

Dianova

Hamburg

Immunglobuline $\mathrm{G}(\mathrm{H}+\mathrm{L})$

Peroxidase-gekoppelte Ziege-Anti-Maus- Biorad

München

Immunoglobuline $\mathrm{G}(\mathrm{H}+\mathrm{L})$

Peroxidase-gekoppelte-Ziege-anti-

Biorad

München

Kaninchen-Immunoglobuline $\mathrm{G}(\mathrm{H}+\mathrm{L})$

Biotin-gekoppelte Schaf-Anti-Maus

Amersham-Buchler

Braunschweig

Immunglobuline $\mathrm{G}(\mathrm{H}+\mathrm{L})$

Ziege-anti-Maus Immunglobuline $\mathrm{G}$

Dianova

Hamburg $(\mathrm{H}+\mathrm{L})$ 


\subsection{Enzyme}

\subsubsection{Restriktionsenzyme mit Erkennungssequenz und Spaltstelle (-)}

\begin{tabular}{|c|c|c|c|c|}
\hline Enzym & Erkennungssequenz & $\underline{\text { Puffer }}$ & & \\
\hline Dra II & RG-GNCCY & L & BioLabs & Schwalbach \\
\hline Hind III & A-AGCTT & B & Promega & Madison (USA) \\
\hline Kpn I & GGTAC-C & $J$ & Promega & Madison (USA) \\
\hline Sma I & CCC-GGG & $J$ & Promega & Madison (USA) \\
\hline SnaB I & TAC-GTA & B & Promega & Madison (USA) \\
\hline Sty I & C-CWWGG & $\mathrm{F}$ & Promega & Madison (USA) \\
\hline Xba I & T-CTAGA & $D$ & Promega & Madison (USA) \\
\hline
\end{tabular}

$\mathrm{N}=\mathrm{A}, \mathrm{C}, \mathrm{G}, \mathrm{T} \quad \mathrm{R}=\mathrm{A}, \mathrm{G} \quad \mathrm{Y}=\mathrm{C}, \mathrm{T} \quad \mathrm{W}=\mathrm{A}, \mathrm{T}$

Inkubationspuffer für die Enzyme

$\begin{array}{ccccccccc}\underline{\text { Puffer }} & \underline{\mathrm{A}} & \underline{\mathrm{B}} & \underline{\mathrm{C}} & \underline{\mathrm{D}} & \underline{\mathrm{F}} & \underline{\mathrm{J}} & \underline{\mathrm{L}} & \underline{\text { MULTI CORE }^{\mathrm{TM}}} \\ \mathrm{Tris} / \mathrm{HCl}(\mathrm{mM}) & 6 & 6 & 10 & 6 & 10 & 10 & 10 & - \\ \mathrm{MgCl}_{2}(\mathrm{mM}) & 6 & 6 & 10 & 6 & 10 & 7 & 10 & - \\ \mathrm{NaCl}(\mathrm{mM}) & 6 & 50 & 50 & 150 & 100 & & - & - \\ \mathrm{KCl}(\mathrm{mM}) & - & - & - & - & - & 50 & - & - \\ \text { DTE }(\mathrm{mM}) & - & - & - & - & - & - & 1 & \\ \text { DTT }(\mathrm{mM}) & 1 & 1 & 1 & 1 & 1 & 1 & - & 1 \\ \text { Tris-Acetat }(\mathrm{mM}) & - & - & - & - & - & - & - & 25 \\ \mathrm{~K}-\text { Acetat }(\mathrm{mM}) & - & - & - & - & - & - & - & 100 \\ \text { Mg-Acetat }(\mathrm{mM}) & - & - & - & - & - & - & - & 10 \\ \mathrm{pH}\left(\text { bei } 37^{\circ} \mathrm{C}\right) & 7,5 & 7,5 & 7,9 & 7,9 & 8,5 & 7,5 & 7,5 & 7,5\end{array}$

Die Restriktionsendonukleasen spalten nur unter bestimmten Pufferbedingungen. Für die Spaltung wurden die vom Hersteller empfohlenen Puffer eingesetzt, bei denen die Enzyme ihre volle Aktivität besitzen. In Spaltungsreaktionen mit mehreren Enzymen wurde der Puffer gewählt, in dem die jeweiligen Enzyme ihre höchste Aktivität hatten. Im MULTI CORE ${ }^{\text {TM }}$ Puffer der Firma Promega hatten bis auf Sty I alle Enzyme eine hohe Aktivität. Das Enzym Sma I hat ein Temperaturoptimum von $25^{\circ} \mathrm{C}$, so daß Reaktionen mit diesem Enzym in zwei Schritten mit den jeweiligen Temperaturen aufeinanderfolgend durchgeführt wurden. 


\subsubsection{Sonstige Enzyme}

PowerScript DNA-Polymerase

Taq DNA-Polymerase

T4 DNA-Ligase

Superscript ${ }^{\mathrm{TM}}$ II RNase $\mathrm{H}^{-}$Reverse

Transkriptase

Creatin-Kinase
PAN

Amersham-Pharmacia

GibcoBRL

Invitrogen

Roche
Aidenbach

Freiburg

Eggenstein

Karlsruhe

Mannheim

\subsection{Oligonukleotide}

Die Positionsangaben beziehen sich auf den Eintrag L25124 für die humane Prostaglandin $\mathrm{E}_{2}$-Rezeptorsequenz, Subtyp EP4 in der GenBank ${ }^{\mathrm{TM}} / \mathrm{EMBL}$ Data Bank Sequence Library in Heidelberg. Die Positionangaben der Primer SP6 und T7 beziehen sich auf den pBluescriptbzw. pcDNA3-Vektor.

\subsubsection{Vorwärts-Primer}

\begin{tabular}{|c|c|c|}
\hline Name & Sequenz & $\begin{array}{l}\text { Position in GenBank } \\
\text { Acc. No. L25124 }\end{array}$ \\
\hline \multirow{4}{*}{$\begin{array}{l}\text { Hind FLAG } \\
\text { EP4 } f\end{array}$} & 5'-gcggcgaagcttccaccatggactacaa & $\begin{array}{l}\text { Hind III-Erkennungssequenz } \\
\text { (unterstrichen), }\end{array}$ \\
\hline & ggacgacgacgacaagTCCACТССС & Kozak-Sequenz (kursiv), \\
\hline & GGGGTCAATTCGTCC & FLAG-Epitop codierende Sequenz (fett), \\
\hline & & hEP4-R Position: 589-612 \\
\hline \multirow{3}{*}{$\begin{array}{l}\text { EP4 SnaBI } \\
f\end{array}$} & 5'-GGATATATATCCTCCTACGTA & $\begin{array}{c}\text { SnaB I-Erkennungssequenz } \\
\text { (unterstrichen) }\end{array}$ \\
\hline & AGACAGTGCTC & mutierte Basen (fett), \\
\hline & & Position:1565-1596 \\
\hline \multirow{3}{*}{ SM $1 f$} & 5'-cggcggggtaccccgTCC $\underline{\text { TACGTA }}$ & $\begin{array}{c}\text { Kpn I- und SnaB I-Erkennungssequenz } \\
\text { (unterstrichen), }\end{array}$ \\
\hline & AGGCAGTGCTCGCTAAAGCAA & mutierte Basen (fett) \\
\hline & TAG & Position: 1585-1610 \\
\hline \multirow{3}{*}{ SM $2 f$} & 5'-ggcGGGGCCCGCAGGGAGCG & Dra II-Erkennungssequenz (unterstrichen), \\
\hline & CGCCGGACAGCACTGCGCAGA & mutierte Basen (fett), \\
\hline & CGCTCAAAGG & Position: 1639-1689 \\
\hline
\end{tabular}


5'-tccCCCGGGAGCTGAACGAGA Sma I-Erkennungssequenz (unterstrichen),

SM $4 \mathrm{f}$ TCGCCGCTGCAGCTCAAGCCC TCCTGCCAG

5'-GACGCCGCCGCACTGAGGG

SM $6 f$ CTTTGCGAATAGCAGAGGCCG

CAGACGCTGCACAGGGTCAG

5'-ACGCAGAGGCTGTCTTACTG

SM $7 f$ GTGGATGAGGCTGGTGGGGC

CGGCAGG

EP4 S379A 5'-CACTCTCGCGCCTTCATCTC

f CCGG

EP4 A379S 5'-CAGCTCGCTCCTTCATCGCC

f $\quad$ CGG

hEP4 $2 f$

5'-GGCGCGCTGCTCCGCATGC

AC

5'-GAACCCATCGCTTACTGGCT

T 7 TATCG mutierte Basen (fett),

Position: 1730-1777

mutierte Basen (fett),

Position: 1864-1923

mutierte Basen (fett),

Position: 1925-1971

mutierte Base (fett),

Position: 1711-1734

Position: 1711-1734

Position: 1207-1227

Position 5' des Polylinkers

pcDNA3 Position: 864-882

\subsubsection{Rückwärts-Primer}

pBluescript Position: 626-647

\begin{tabular}{|c|c|c|}
\hline Name & Sequenz & $\begin{array}{l}\text { Position in GenBank } \\
\text { Acc. No. L25124 }\end{array}$ \\
\hline EP4 Xba r & $\begin{array}{l}\text { 5'-gcggcgtctagaCTACTATATAC } \\
\text { ATTTTTCTGATAA }\end{array}$ & $\begin{array}{l}\text { Xba I-Erkennungssequenz (unterstrichen), } \\
\text { Position: } 2051-2032\end{array}$ \\
\hline $\begin{array}{c}\text { EP4 SnaBI } \\
r\end{array}$ & $\begin{array}{l}\text { 5'-GAGCACTGTCTIACGTAGG } \\
\text { AGGATATATATCC }\end{array}$ & $\begin{array}{c}\text { SnaB I-Erkennungssequenz (unterstrichen), } \\
\text { mutierte Basen (fett), } \\
\text { Position: } 1596-1565\end{array}$ \\
\hline$S M 3 r$ & $\begin{array}{l}\text { 5'-tccCCCGGGCGATGAAGGC } \\
\text { GCGAGCGTGGCCTGCCATAG } \\
\text { CAGCAGCTGCCCTTTGACT }\end{array}$ & $\begin{array}{l}\text { Sma II-Erkennungssequenz (unterstrichen), } \\
\text { mutierte Basen (fett), } \\
\text { Position: 1739-1681 }\end{array}$ \\
\hline
\end{tabular}




\begin{tabular}{|c|c|c|}
\hline \multirow{3}{*}{ SM 5r } & 5'-CTGCCTCCAAGGCCATTTT & Sty I-Erkennungssequenz (unterstrichen), \\
\hline & CAGCGAGGTCTGGCAGTGCG & mutierte Basen (fett), \\
\hline & AGGTCT & Position: 1820-1776 \\
\hline \multirow{4}{*}{ SM $6 r$} & 5'-TGTGCAGCGTCTGCGGCC & \\
\hline & TCTGCTATTCGCAAAGCCCT & mutierte Basen (fett), \\
\hline & CAGTGCGGCGGCGTCTTCCT & Position: 1916-1857 \\
\hline & GG & \\
\hline \multirow{3}{*}{ SM $7 r$} & 5'-CCGGCCCCACCAGCCTCA & \\
\hline & TCCACCAGTAAGACAGCCTC & mutierte Basen (fett), \\
\hline & TGCGTCCTGA & Position: 1967-1920 \\
\hline \multirow{4}{*}{ SM 8r } & 5'-gctctagaTTATTATATACATT & \multirow{4}{*}{$\begin{array}{c}\text { Xba I-Erkennungssequenz (unterstrichen) } \\
\text { mutierte Basen (fett), } \\
\text { Position: } 2052-1987\end{array}$} \\
\hline & TTTCTGCTAAGTTCAGTGCTTC & \\
\hline & AGCGGGAAATGCGACTTGC & \\
\hline & AGGGCGGCCCCCTT & \\
\hline \multirow{2}{*}{$\begin{array}{l}\text { EP4 ma } \\
\text { A379s r }\end{array}$} & 5'-GGCGATGAAGGAGCGAGC & \multirow{2}{*}{ Position: 1731-1708 } \\
\hline & GTGGCC & \\
\hline \multirow{2}{*}{$\begin{array}{l}\text { EP4 wt } \\
\text { S379A r }\end{array}$} & 5'-GGAGATGAAGGAGCGAGA & mutierte Base (fett), \\
\hline & GTGGCC & Position: 1731-1708 \\
\hline \multirow{2}{*}{$\begin{array}{c}\text { EP4 Xba r } \\
\text { mut }\end{array}$} & 5'-GGCGCGTCTAGATTATTAT & \multirow{2}{*}{ Position: 2051- 2029} \\
\hline & ATACATTTTTCTGCTAAGTT & \\
\hline \multirow{2}{*}{ SP 6} & 5'-GCGAGCTCTAGCATTTAGG & Position 3' des Polylinkers \\
\hline & TGACAC & pcDNA3 Position: 999-1016 \\
\hline
\end{tabular}

Alle Oligonukleotide wurden entweder von der Firma NAPS in Göttingen oder von der Firma MWG-Biotech AG in Ebersberg hergestellt.

\subsection{Eukaryote Zellinie HEK293}

Die HEK293-Zellinie ist eine humane Adenovirus-transformierte Nierenzellinie (ATCC Nr.CRL 1573). Die HEK293-Zellen wurden zur stabilen eukaryoten Expression der Rezeptorproteine verwendet und in DMEM mit $10 \% \quad(\mathrm{v} / \mathrm{v})$ FCS und $1 \%(\mathrm{v} / \mathrm{v})$ Penicillin/Streptomycin kultiviert. 


\subsection{Bakterienstamm E. coli XL1 (blue)}

E. coli XL 1 (blue) Stratagene Heidelberg

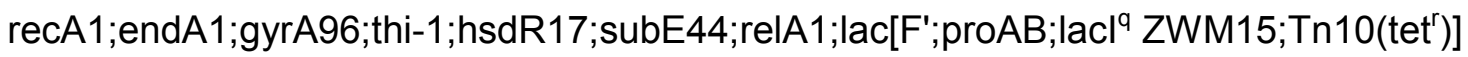

\subsection{Vektoren}

\subsection{1 pBluescript-Vektor}

Der pBluescript SK (-)-Vektor (pBS) von Stratagene (La Jolla, USA) wurde als Klonierungsvektor zur Synthese des 3'-cDNA-Fragmentes der hEP4-R-cDNA, in dem alle Serine und Threonine gegen Alanine substituiert waren, verwendet. Der Aufbau des Vektors ist in Abb. 5 gezeigt.

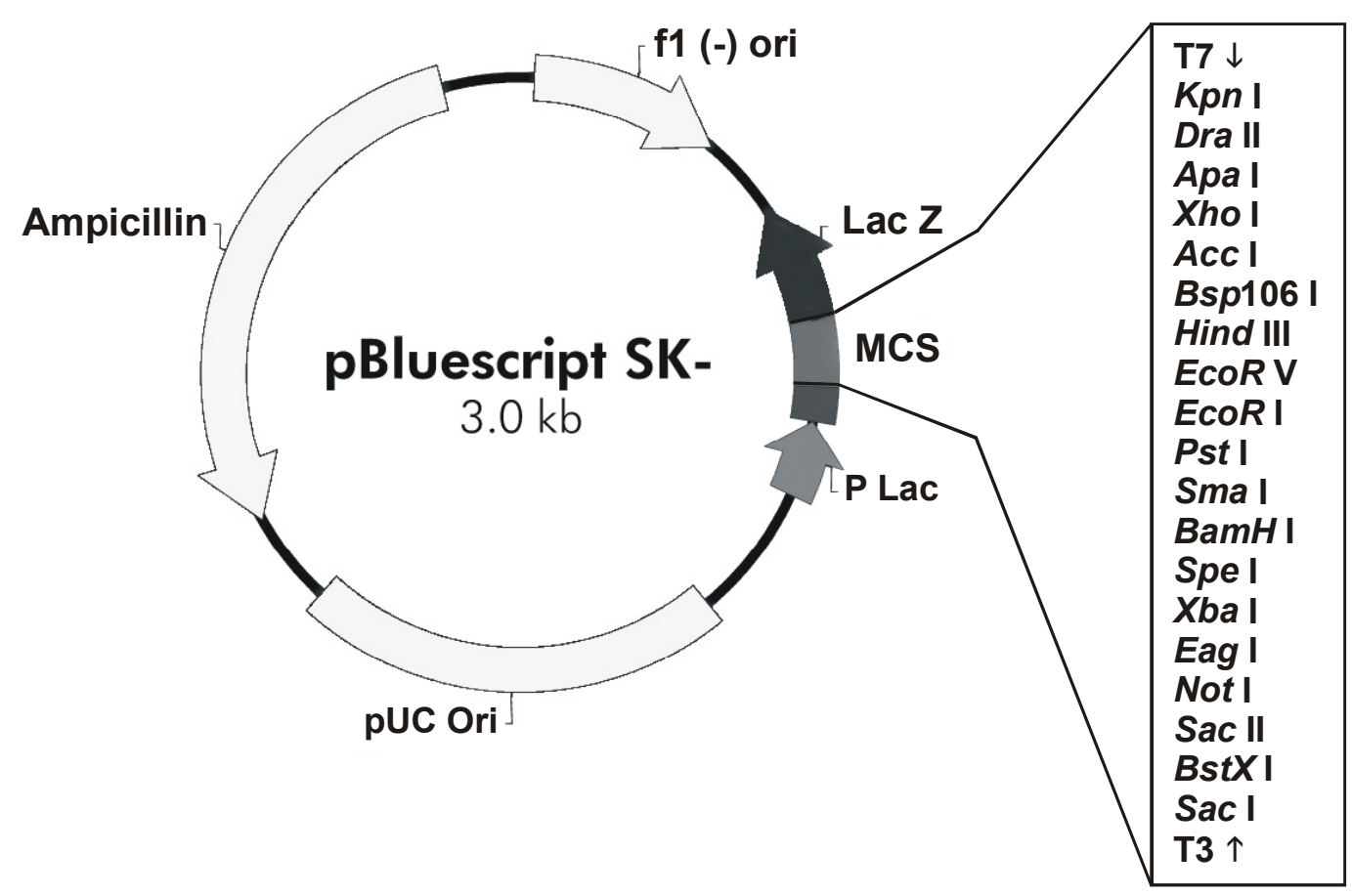

Abb. 5: Restriktionskarte von pBluescript SK-. Der Vektor besitzt die pUC19Replikationsstelle (pUC ori) und das Ampicillin-Resistenzgen für die Selektion transformierter Bakterien in Ampicillin-haltigen Medien. In das LacZ-Gen, das ein blau/weiß-Screening rekombinanter Bakterienklone ermöglicht, ist eine multiple Klonierungsstelle integriert, die vom T3- und T7-Promotor für die in vitro-Transkription flankiert wird und die die Sequenzen für den universalen Vorwärts- und Rückwärts-Primer enthält. 


\subsection{2 pcDNA3-Vektor}

Der pcDNA3-Vektor von Invitrogen (San Diego, USA) wurde zur stabilen eukaryoten Expression der verschiedenen Rezeptor-cDNAs verwendet. Die Aufbau des Vektors ist in Abb. 6 gezeigt.

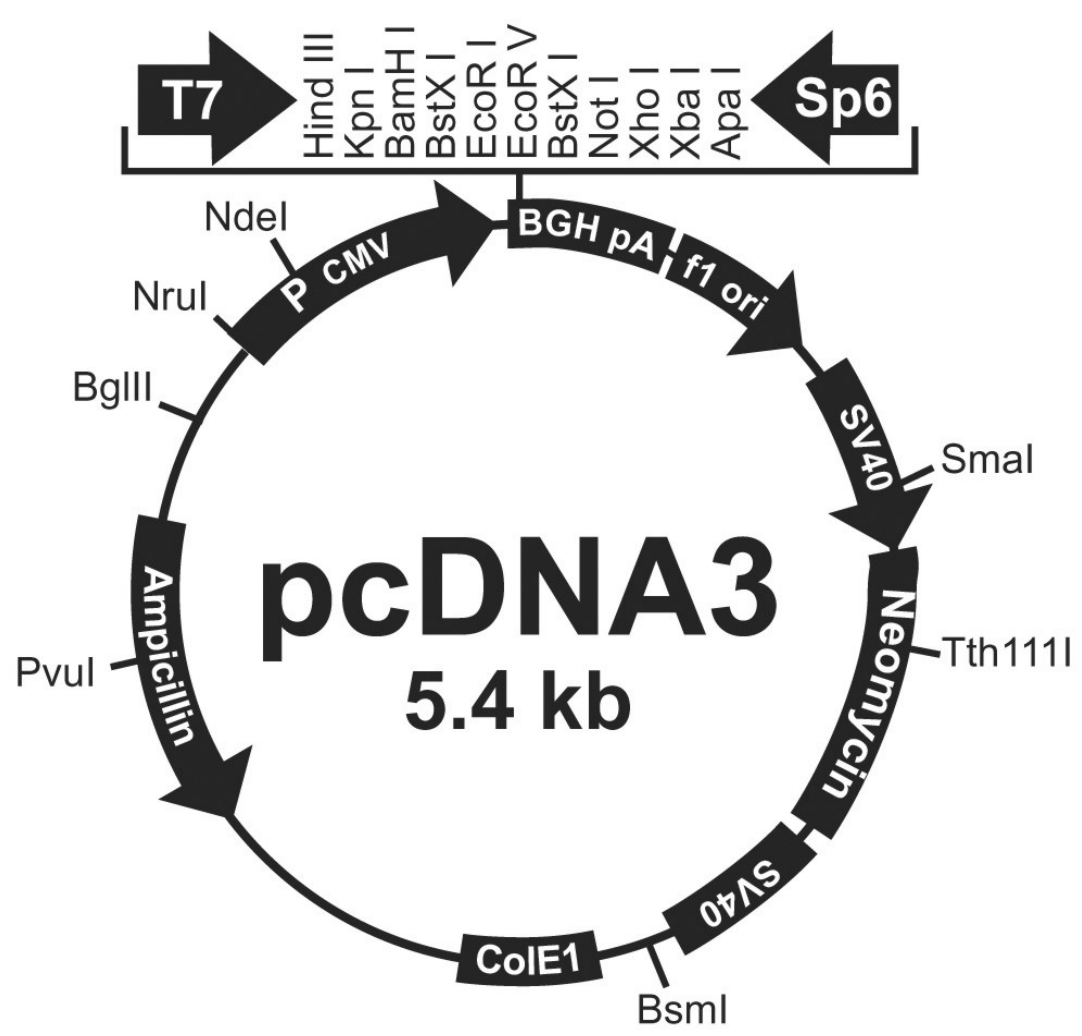

Abb. 6: Restriktionskarte von pcDNA3. Der Vektor eignet sich für die transiente und stabile Expression rekombinanter Proteine in eukaryoten Zellinien. Er besitzt für eine hohe Transkriptionsrate die Enhancer/Promotor-Sequenzen des frühen Gens des menschlichen Cytomegalie-Virus (CMV) und zur Stabilisierung der mRNA die Transkriptions-Terminationsund mRNA-Processierungs-Signale des Rinder-Wachstumshormon-Gens (BGH polyA). Das Plasmid verfügt darüberhinaus über eine multiple Klonierungsstelle. Für die Selektion und Vermehrung in E. coli wird von dem Plasmid ein Ampicillin-Resistenzgen und zur Selektion von Säugetierzellen, die das Plasmid stabil in ihr Genom aufgenommen haben, ein Neomycin-Resistenzgen codiert, welches den Zellen Resistenz gegenüber dem Antibiotikum Geneticin (G-418)-Sulfat verleiht. 


\subsection{3 pEGFP-Vektor}

Der pEGFP-Vektor der Firma Clontech diente zur Co-Transfektion der Rezeptorproteine mit $\beta$-Arrestin. Der pEGFP verfügt über die Sequenz für das „green-fluorescent-protein“ (GFP), das 3' an das zu exprimierende Protein angefügt werden kann. Dieses GFP ist ein 27 kDa großes monomeres Protein, das aus 238 Aminosäuren besteht. Es stammt aus der Qualle Aequorea victoria und eignet sich sowohl für in vivo- als auch in situ-Proteinlokalisationen durch Lichtemission nach Anregung mit UV- oder Blau-Licht. Die Fluoreszenz des GFPProteins ist speciesunabhängig, sehr stabil und eignet sich auch für Doppelmarkierungen mit anderen Fluoreszenzmarkern. Der Aufbau des pEGFP-Vektors ist in Abb. 7 gezeigt.

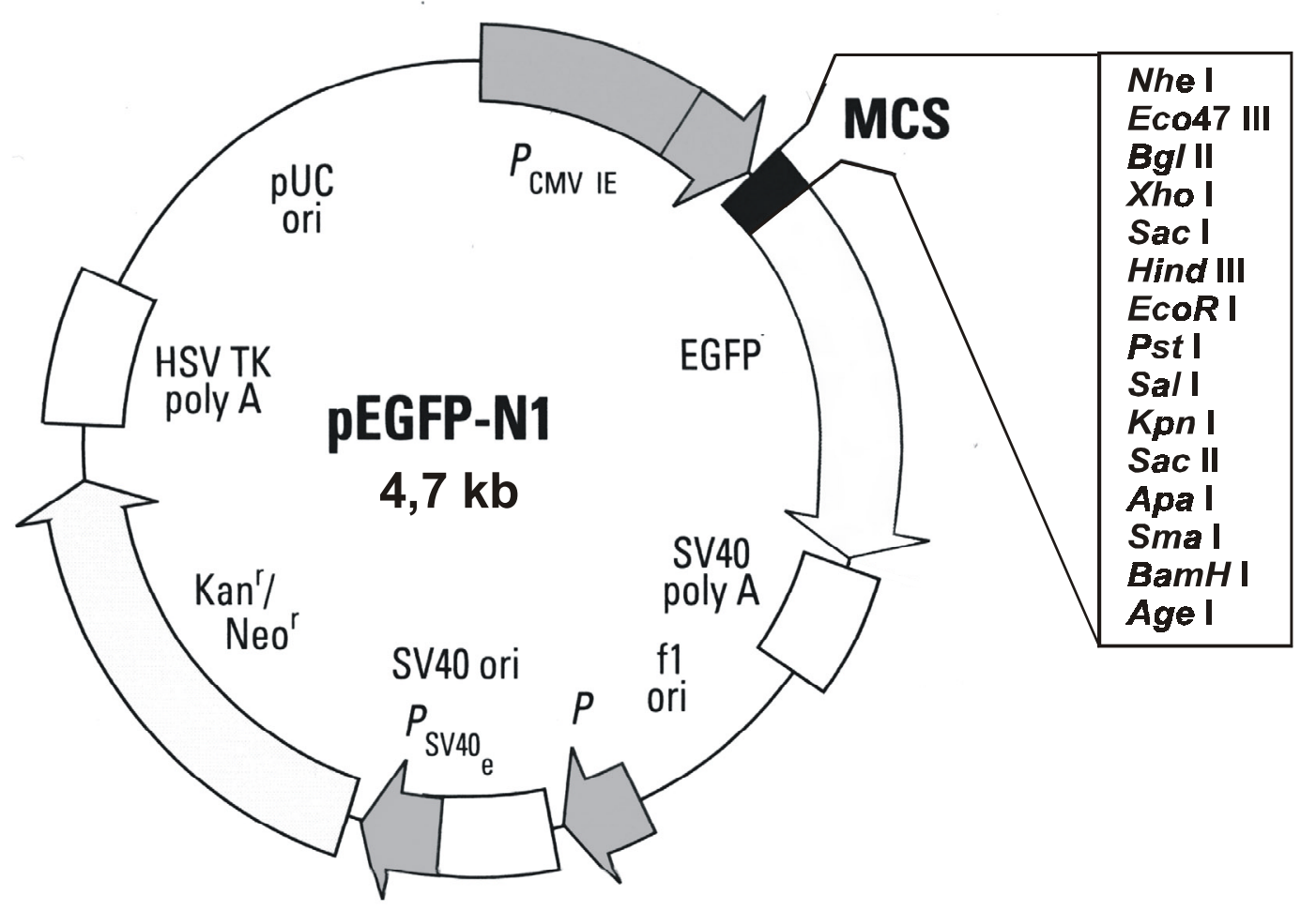

Abb. 7: Restriktionskarte von pEGFP. Der Vektor eignet sich für die transiente und stabile Expression rekombinanter Proteine in eukaryoten Zellinien. Der Vektor verfügt über den starken CMV-Promotor vor der multiplen Klonierungsstelle (MCS) und das SV40 Polyadenylierungssignal. Der Vektor besitzt den SV40-Origin für die Replikation in Säugerzellen, die das SV40-T-Antigen exprimieren. Eine Neomycin-Resistenz-Kassette, die den frühen SV40-Promoter beinhaltet, das Neomycin/Kanamycin-Resistenzgen $\left(\mathrm{Kan}^{r} / \mathrm{Neo}^{r}\right)$ von Tn5, sowie das Polyadenylierungssignal des Herpes simplex-Thymidinkinasegens (HSV TK poly A) erlauben eine Selektion stabil transfizierter eukaryoter Zellen durch G-418. Der bakterielle Promoter $P_{a m p}(P)$ 5' von dieser Kassette induziert die Kanamycinresistenz in $E$. coli. Der pEGFP-N1 verfügt über den pUC19 Replikationsursprung ( $p U C$ ori) für die Amplifizierung in E. coli. 


\section{Methoden}

\section{ALLGEMEINE MOLEKULARBIOLOGISCHE METHODEN}

Alle Puffer und Lösungen wurden, soweit nicht anders angegeben, mit entmineralisiertem $\mathrm{H}_{2} \mathrm{O}$ angesetzt, sterilfiltriert und bei $4^{\circ} \mathrm{C}$ gelagert.

\subsection{PCR-gestützte cDNA-Synthese}

\subsubsection{Puffer und Lösungen}

10 x PCR Puffer für PowerScript DNA-Polymerase

$\mathrm{KOH} \quad 500 \mathrm{mM}$

$\left(\mathrm{NH}_{4}\right)_{2} \mathrm{SO}_{4} \quad 160 \mathrm{mM}$

Tween-20 $0,1 \%(\mathrm{v} / \mathrm{v})$

$\mathrm{pH} 9,2$

Der Puffer war der Polymerase beigefügt.

$\underline{\mathrm{Mg}^{2+}-\text { Lösung }}$

$\mathrm{MgCl}_{2} \quad 50 \mathrm{mM}$

Die Lösung war der Polymerase beigefügt.

\section{OptiZyme-Enhancer $(5 \mathrm{x})$}

Die Lösung war der Polymerase beigefügt. Der Hersteller machte zur Zusammensetzung keine näheren Angaben. Die Lösung mußte vor der Verwendung auf $50^{\circ} \mathrm{C}$ erwärmt werden, bis sie komplett gelöst war.

\subsubsection{Prinzip der Polymerasekettenreaktion (PCR)}

Die Polymerase-Kettenreaktion (PCR = Polymerase Chain Reaction) erlaubt es, beliebige spezifische DNA-Abschnitte zu amplifizieren. Dazu werden zwei Oligonukleotide, die mit jeweils einem der DNA-Stränge auf beiden Seiten des zu amplifizierenden DNA-Abschnittes hybridisieren, ausreichende Mengen der vier Desoxyribonukleosidtriphosphate und eine hitzebeständige DNA-Polymerase benötigt.

Ein einzelner Zyklus besteht aus drei Schritten. Im ersten Schritt wird der DNA-Doppelstrang bei $95^{\circ} \mathrm{C}$ denaturiert, d. h. die beiden Stränge werden voneinander getrennt. Im zweiten Schritt wird dann der Reaktionsansatz auf ca. $45-70^{\circ} \mathrm{C}$ abgekühlt, um die Hybridisierung der in großem Überschuß vorhandenen Primer mit komplementären DNA-Sequenzen zu ermöglichen. Im dritten Schritt werden nun von diesen Startermolekülen ausgehend, an beiden Strängen komplementäre DNA-Stränge bei $72^{\circ} \mathrm{C}$ neu synthetisiert. Die $72^{\circ} \mathrm{C}$ entsprechen dem Temperaturoptimum der DNA-Polymerase. 
Dieser Zyklus wird im selben PCR Ansatz 20-40 mal wiederholt. Die Produkte des ersten Synthesedurchgangs sind heterogen in ihrer Größe; ihre Länge kann den Abstand zwischen den Primern überschreiten. Erst im zweiten Zyklus entstehen einzelsträngige DNAFragmente definierter Länge und nach dem zweiten Zyklus bilden sich DNA-Doppelstränge, deren Länge dem Abstand zwischen den Primern entspricht.

Das so synthetisierte Produkt definierter Länge dient als Matrize in den folgenden Zyklen, wodurch die Menge der amplifizierten DNA-Moleküle exponentiell zunimmt. Auch die in den ersten zwei Zyklen der PCR synthetisierten längeren Moleküle werden in den folgenden Zyklen immer wieder synthetisiert. Sie vermehren sich jedoch im Gegensatz zum Produkt definierter Länge nur linear und tragen im Vergleich zur exponentiell amplifizierten Zielsequenz nicht signifikant zur Masse der neu synthetisierten DNA bei.

Das zyklische Erhitzen und Abkühlen übernehmen „Thermocycler" oder Computergesteuerte Thermostate.

\subsubsection{Amplifizierung von Rezeptor-cDNA mit der PowerScript DNA-Polymerase}

Für einen $50 \mu \mathrm{l} \mathrm{PCR-Ansatz} \mathrm{wurden} 10$ ng zirkulärer Plasmid-cDNA, $5 \mu 10$ x PCR Puffer für PowerScript DNA-Polymerase, $5 \mu \mathrm{l} 2 \mathrm{mM}$ dATP, dGTP, dCTP, dTTP in $\mathrm{H}_{2} \mathrm{O}$, je 30 pmol Vorwärts- und Rückwärts-Primer, $1,5 \mu \mathrm{l} 50 \mathrm{mM} \mathrm{MgCl}$, $10 \mu \mathrm{l} 5$ x „Optizyme-Enhancer" und $2 \mathrm{U}$ PowerScript DNA-Polymerase gemischt und mit $\mathrm{H}_{2} \mathrm{O}$ auf $50 \mu$ aufgefüllt. Die PCR erfolgte im „Thermocycler" unter folgenden Bedingungen: 3 min $95^{\circ} \mathrm{C} ; 35 \times\left(1 \mathrm{~min} 95^{\circ} \mathrm{C}\right.$, $1 \min 55^{\circ} \mathrm{C}, 2 \min 72^{\circ} \mathrm{C}$ ); $10 \min 72^{\circ} \mathrm{C}$. Die Reaktionsprodukte wurden zur Analyse oder Reinigung in einem Agarose-Gel aufgetrennt (siehe 3.2).

\subsubsection{Verlängerung des translatierten Bereichs einer cDNA-Sequenz um eine für eine Peptid- oder Restriktionsenzym-Erkennungsstelle-codierenden Sequenz durch PCR}

Für die Verlängerung einer cDNA-Sequenz um eine für ein Peptid- oder eine Restriktionsenzym-Erkennungsstelle-codierende Sequenz am 5'-Bereich durch PCR wurden Primer verwendet, die um die einzufügende Sequenz verlängert waren. Dabei waren die 5'gelegenen Nukleotide des Vorwärts-Primers, die für eine Peptidsequenz- oder für eine Restriktionsenzym-Erkennungsstelle codieren, nicht komplementär zum 5'-Bereich der cDNA-Sequenz und die folgenden ca. 20 Nukleotide, der 3'-Bereich des Primers, waren komplementär zum 5'-Bereich der cDNA-Sequenz (5' überhängender Primer).

Mit diesem Vorwärts-Primer und dem flankierenden Rückwärts-Primer wurde eine PCR mit der zu verlängernden cDNA-Sequenz als Matrize durchgeführt. Im ersten Zyklus der PCRReaktion lagern sich die Primer nach der Denaturierung mit ihren komplementären 
Sequenzen an die DNA-Matrize an und die Polymerase synthetisiert die neuen DNAStränge. Durch diesen Schritt entsteht nur ein Strang, der die zusätzliche codierende Sequenz trägt. Im zweiten Zyklus der PCR-Reaktion werden nach der Denaturierung und Anlagerung der Primer ein DNA-Doppelstrang mit der zusätzlichen codierenden Sequenz und zwei DNA-Doppelstränge, von denen jeweils nur ein Strang die zusätzliche codierende Sequenz trägt, synthetisiert. Der DNA-Doppelstrang mit der zusätzlichen codierenden Sequenz wird von dem 3'-flankierenden Primer synthetisiert, der mit dem im ersten Zyklus synthetisierten Strang mit zusätzlicher codierender Sequenz hybridisiert. Von beiden DNADoppelsträngen, von denen nur jeweils ein Strang die zusätzliche codierende Sequenz trägt, wird einer, wie im ersten Zyklus beschrieben, synthetisiert, wobei der zweite an dem Syntheseprodukt des 3'-flankierenden Primers aus dem ersten Zyklus entsteht. Die Amplifizierung der cDNA-Sequenz mit der zusätzlichen codierenden Sequenz verläuft ab dem zweiten Zyklus exponentiell.

\subsubsection{Prinzip der sequenzgerichteten Mutagenese}

Die Methode der sequenzgerichteten Mutagenese („site directed mutagenesis“) wird häufig eingesetzt, um einzelne Basen in einem DNA-Abschnitt gezielt auszutauschen und somit eine gewünschte mutierte cDNA zu synthetisieren.

Es sind drei PCR-Reaktionen notwendig, um die mutierte Rezeptor-cDNA zu erhalten. In einer ersten PCR-Reaktion wird das 5'-Fragment der Rezeptor-cDNA mit einem VorwärtsPrimer, der 5' vor dem Startcodon des translatierten Bereichs der DNA des RezeptorWildtyps aufsetzt und einem Rückwärts-Primer, der die einzuführende Mutation etwa in der Mitte trägt, amplifiziert. Ein zu diesem Rückwärts-Primer komplementäres Oligonukleotid bildet den Vorwärts-Primer für die zweite PCR-Reaktion, mit der das 3'-Fragment der zu mutierenden Rezeptor-cDNA amplifiziert wird. Der Rückwärts-Primer der zweiten PCRReaktion liegt in 3'-Richtung des translatierten Bereichs der DNA-Matrize des RezeptorWildtyps. Die resultierenden Amplifikate (Megaprimer) enthalten nun eine komplementäre Sequenz, die die gewünschte Mutation trägt.

In einer dritten PCR lagern sich die Megaprimer mit ihren komplementären Enden zusammen, wobei die Hybride mit den 5'-überhängenden Enden in der Synthesereaktion zu einem Fragment der vollen Länge aufgefüllt werden. Im nächsten Zyklus lagern sich die flankierenden Primer an die Enden des die volle Länge umfassenden Fragmentes an und es wird amplifiziert.

Die sequenzgerichtete Mutagenese kann auch mit nur einer PCR-Reaktion durchgeführt werden, wenn das zu mutierende Nukleotid in der Nähe einer geeigneten Restriktionsschnittstelle liegt. Für diese sequenzgerichtete Mutagenese wird der Primer zum Einfügen der gewünschten Mutation so gewählt, daß er im 5'-Bereich vor der einzufügenden 
Mutation für eine Restriktionsenzym-Erkennungssequenz codiert, wobei der zweite für die PCR-Reaktion verwendete Primer, der auch eine Mutation tragen kann, ebenfalls 5 ' für eine Restriktionsenzym-Erkennungssequenz codiert. Im ersten Zyklus der PCR-Reaktion (siehe 3.1.2) werden die Mutationen tragenden Primern an ihrem 3'-Ende Matrizen-abhängig verlängert, so daß DNA-Stränge amplifiziert werden, die 5' der eingefügten Mutationen über eine Restriktionsenzym-Erkennungssequenz verfügen. Im zweiten Zyklus lagern sich an diese Ampifikate die entsprechenden Vorwärts- bzw. Rückwärts-Primer an, durch die ein DNA-Fragment amplifiziert wird, das 5' und 3' der eingefügten Mutationen Restriktionsschnittstellen enthält. Die Amplifizierung der cDNA-Sequenz, in die nur mit einem Primer eine Mutation eingefügt wurde, verläuft ab dem zweiten Zyklus exponentiell, während die Amplifizierung der cDNA-Sequenz, in der mit dem Vorwärts- und dem Rückwärts-Primer Mutationen eingefügt wurden, ab dem dritten Zyklus exponentiell verläuft. Über die flankierenden Restriktionsschnittstellen kann das Amplifikat anschließend in die ursprüngliche Matrizen-cDNA kloniert werden kann.

\subsection{Agarose-Gelelektrophorese von DNA}

DNA-Fragmente lassen sich in Agarose-Gelen elektrophoretisch trennen. Linearisierte DNAMoleküle haben in diesen Gelen Wanderungsgeschwindigkeiten, die umgekehrt proportional dem Logarithmus ihrer Molekulargewichte sind (Helling et al. 1974). Ihre Größe kann durch Vergleich mit Größenstandards ermittelt werden. Die Agarosekonzentration der Gele richtet sich nach der Größe der zu trennenden DNA-Fragmente. Für größere Fragmente $(>1,0 \mathrm{~kb})$ wurden $1 \%(w / v)$, für kleinere Fragmente $(<1,0 \mathrm{~kb}) 2 \%(\mathrm{w} / \mathrm{v})$ Agarose-Gele verwendet.

\subsubsection{Puffer und Lösungen}

$10 \times$ TAE-Puffer

$1000 \mathrm{ml}$

Tris

$0,5 \mathrm{M}$

$60,56 \mathrm{~g}$

Natriumacetat

$0,2 \mathrm{M}$

$16,4 \mathrm{~g}$

EDTA

$20 \mathrm{mM}$

$5,84 \mathrm{~g}$

Der Puffer wurde mit 100\%iger Essigsäure auf pH 8,0 eingestellt und autoklaviert.

Ethidiumbromid-Lösung

$10 \mathrm{ml}$

Ethidiumbromid

$10 \mathrm{mg} / \mathrm{ml}$

$100 \mathrm{mg}$ in TAE-Puffer

Die Lösung wurde bei $4^{\circ} \mathrm{C}$ gelagert. Für das Färbebad wurden $300 \mathrm{ml}$ TAE-Puffer mit $75 \mu \mathrm{l}$ dieser Lösung versetzt. 
Bromphenolblau-Probenpuffer

$100 \mathrm{ml}$

Bromphenolblau

$0,25 \%(w / v)$

$0,25 \mathrm{~g}$

Glycerol

$40 \%(\mathrm{v} / \mathrm{v})$

$40 \mathrm{ml} \mathrm{100 \%} \mathrm{Glycerol}$

$10 \times$ TAE-Puffer

$10 \%(\mathrm{v} / \mathrm{v})$

$10 \mathrm{ml} 10 \times$ TAE-Puffer

Der Puffer wurde bei Raumtemperatur gelagert.

\subsubsection{Auftrennung von DNA auf Agarose-Gelen}

Die zu analysierende Probe wurde mit 1/5 Volumen Bromphenolblau-Probenpuffer gemischt und in eine $5 \mathrm{~mm}$ breite Geltasche pipettiert. Zur Bestimmung der Fragmentlänge wurde in eine Spur der DNA-Längenstandard Smart-Ladder aufgetragen, bei dem die einzelnen DNA-Fragmente eine Größe von 10; $; ; 6 ; 5 ; 4 ; 3 ; 2,5 ; 2 ; 1,5 ; 1 ; 0,8 ; 0,6 ; 0,4$ und 0,2 kb aufwiesen.

Die DNA-Fragmente wurden in einem $10 \mathrm{~cm}$ langen Gel bei $80 \mathrm{~V}$ für ca. 90 min aufgetrennt, bis der Farbstoff Bromphenolblau die vordere Gelkante erreicht hatte. Danach wurde das Gel für $15 \mathrm{~min}$ in einem Ethidiumbromid-Färbebad inkubiert. Die DNA-Fragmente wurden auf einem Leuchtkasten bei $300 \mathrm{~nm}$ visualisiert und das Ergebnis durch ein Imager-System der Firma BioRad mit angeschlossenem Drucker dokumentiert.

\subsubsection{Semiquantitative Bestimmung der DNA-Menge in Agarose-Gelen}

Neben der Auftrennung von DNA erlaubt die Gelelektrophorese auch eine semiquantitative Bestimmung der DNA-Menge. Dazu konnte ebenfalls der DNA-Längenstandard SmartLadder genutzt werden. Bei der gewählten Auftragsmenge ( $5 \mu$ pro Geltasche) entsprachen die einzelnen Banden des Smart-Ladder-Standards 100, 80, 60, 50, 40, 30, 25, 20, 15, 100 , $80,60,40$ und 20 ng DNA.

\subsection{Reinigung von DNA aus Agarose-Gelen}

\subsubsection{Puffer und Lösungen}

Jetsorb-Suspension

Die Lösung war ohne nähere Angaben des Herstellers im Kit enthalten und wurde bei Raumtemperatur gelagert.

Waschpuffer A (hohe Salzkonzentration)

Die Lösung enthält konzentriertes Natriumperchlorat $\left(\mathrm{NaClO}_{4}\right)$, Tris-Borat-EDTASolubilisierer und Natriumacetat ohne nähere Konzentrationsangaben des Herstellers. Die Lösung wurde bei Raumtemperatur gelagert. 


\section{Waschpuffer B (niedrige Salzkonzentration)}

Die Lösung enthält Ethanol, $\mathrm{NaCl}$, EDTA und Tris/ $\mathrm{HCl}$ ohne nähere Konzentrationsangaben des Herstellers. Die Lösung wurde bei Raumtemperatur gelagert.

\subsubsection{Isolierung der DNA-Fragmente}

Die DNA-Fragmente wurden mit dem Jetsorb-Kit der Firma Genomed isoliert. Dazu wurde der gesamte PCR-Ansatz auf ein 1\% (w/v) Agarose-Gel aufgetragen. Nach der Elektrophorese und dem Anfärben des Gels im Ethidiumbromidbad wurden die DNA-Banden mit einem Skalpell präzise aus dem Gel ausgeschnitten, in ein Reaktionsgefäß überführt und ausgewogen. Zu je $100 \mathrm{mg}$ Gel wurden $300 \mu \mathrm{l}$ Waschpuffer A und $10 \mu \mathrm{l}$ Jetsorb-Suspension zur DNA-Bindung hinzugefügt. Das Gemisch wurde $15 \mathrm{~min}$ bei $50^{\circ} \mathrm{C}$ unter Schütteln inkubiert, 60 s bei 13000 rpm (16 000 x g) in der Tischzentrifuge Biofuge „pico“ zentrifugiert, das Sediment einmal mit Waschpuffer $A$ und zweimal mit Waschpuffer B gewaschen und anschließend für 5 min bei $50^{\circ} \mathrm{C}$ vollständig getrocknet. Zur Gewinnung der DNA wurde das Sediment für $10 \mathrm{~min}$ bei $50^{\circ} \mathrm{C}$ mit $20 \mu \mathrm{H}_{2} \mathrm{O}$ pro $100 \mathrm{mg}$ Gel inkubiert, $60 \mathrm{~s}$ bei $13000 \mathrm{rpm}$ (16 $000 \times \mathrm{g})$ in der Tischzentrifuge Biofuge „pico“ zentrifugiert und der DNA-haltige Überstand abgenommen.

\subsection{Klonierung der gereinigten cDNA-Fragmente in einen Vektor}

\subsubsection{Puffer und Enzyme}

Restriktionsenzyme und Puffer siehe 2.9.1

5 x T4 DNA-Ligase-Reaktionspuffer

Tris/ $/ \mathrm{HCl}$ $250 \mathrm{mM}$

$\mathrm{MgCl}_{2}$ $50 \mathrm{mM}$

ATP $5 \mathrm{mM}$

DTT $5 \mathrm{mM}$

Polyethylenglycol 8000 $25 \%(w / v)$

Der Puffer war der Ligase beigefügt und wurde bei $-20^{\circ} \mathrm{C}$ gelagert.

Zur Ligation wurde die T4 DNA-Ligase der Firma GibcoBRL verwendet.

\subsubsection{Vorbereitung der cDNA-Fragmente (5'- und 3'-hEP4-Fragmente) und der Vektoren (pBluescript und pcDNA3)}

Die cDNA-Fragmente eines PCR-Ansatzes wurden in einem 2\% (w/v) Agarose-Gel aufgetrennt und wie unter 3.3 beschrieben aus dem Agarose-Gel extrahiert. Zu den 
extrahierten cDNA-Fragmenten und dem jeweiligen Vektor wurden jeweils $1 \mu \mathrm{l}(10 \mathrm{U})$ der gewünschten Restriktionsenzyme und 2,5 $\mu \mathrm{l} 10$ x Puffer zugegeben und der Spaltansatz mit $\mathrm{H}_{2} \mathrm{O}$ auf $25 \mu \mathrm{l}$ aufgefüllt. Der Ansatz wurde für $2 \mathrm{~h}$ oder über Nacht bei $37^{\circ} \mathrm{C}$ inkubiert, mit $10 \mu$ Probenpuffer gemischt, die cDNA-Fragmente in einem 2\% (w/v) Agarose-Gel und die Vektoren in einem 1\% (w/v) Agarose-Gel aufgetrennt (siehe 3.2) und aus dem Gel isoliert (siehe 3.3).

\subsubsection{Ligation der cDNA-Fragmente in die Vektoren (pBluescript und pcDNA3)}

Die zuvor mit den jeweiligen Restriktionsenzymen geschnittenen cDNA-Fragmente sowie der jeweilige linearisierte Vektor wurden in einen Ligationsansatz eingesetzt. Für die Ligation wurden das cDNA-Fragment und der Vektor mit einem molaren Quotient Vektor:cDNAFragment 1:3, $4 \mu \mathrm{l} 5$ x T4 DNA-Ligase-Puffer, $1 \mu \mathrm{l}(1 \mathrm{U})$ T4 DNA-Ligase gemischt und das Endvolumen von $20 \mu \mathrm{l}$ mit $\mathrm{H}_{2} \mathrm{O}$ eingestellt.

Die Ligationsansätze wurde für $2 \mathrm{~h}$ bei $24^{\circ} \mathrm{C}$ inkubiert und sofort für die Transformation von E. coli XL1 (blue) Zellen verwendet (siehe 3.6) oder bis zur Transformation bei $-20^{\circ} \mathrm{C}$ gelagert.

\subsection{Herstellung kompetenter E. coli XL1 (blue) Zellen für die Elektroporation}

\subsubsection{Puffer und Lösungen}

Tetracyclin-Stammlösung

$100 \mathrm{ml}$

Tetracyclin

$5 \mathrm{mg} / \mathrm{ml}$

$500 \mathrm{mg}$

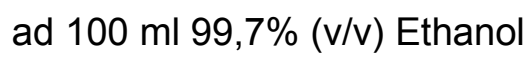

Die Tetracyclin-Stammlösung wurde sterilfiltriert und bei $-20^{\circ} \mathrm{C}$ gelagert.

LB-Tetra-Agar-Platten

$1000 \mathrm{ml}$

LB-Agar

$3,2 \%(w / v)$

$32 \mathrm{~g}$

Die Agar-Lösung wurde autoklaviert, nach Abkühlung auf ca. $46^{\circ} \mathrm{C}$ wurden $2,5 \mathrm{ml}$ Tetracyclin-Stammlösung zugegeben und $15 \mathrm{ml} /$ Petrischale ausplattiert. Die Platten wurden bei $4^{\circ} \mathrm{C}$ und, wegen der Lichtempfindlichkeit des Tetracyclins, unter Lichtausschluß gelagert.

$\underline{\text { LB-Tetra-Medium }}$

$1000 \mathrm{ml}$

Hefe-Extrakt

$0,5 \%(w / v)$

$5 \mathrm{~g}$

Trypton

$1 \%(w / v)$

$10 \mathrm{~g}$

$\mathrm{NaCl}$

$1 \%(w / v)$

$10 \mathrm{~g}$

Das LB-Medium wurde autoklaviert, nach Abkühlung auf $46^{\circ} \mathrm{C} 2,5 \mathrm{ml}$ der sterilfiltrierten Tetracyclin-Stammlösung zugegeben und das Medium bei $4^{\circ} \mathrm{C}$ gelagert. 
Elektroporationspuffer

$1000 \mathrm{ml}$

Glycerol

$10 \%(v / v)$

$100 \mathrm{ml} 100 \%$ Glycerol

\subsubsection{Vorbereitung der E. coli XL1 (blue) Zellen}

Es wurden $5 \mu$ einer Glycerolkultur von E. coli XL1 (blue) Zellen auf LB-Tetra-Agar-Platten ausgestrichen und über Nacht bei $37^{\circ} \mathrm{C}$ inkubiert. Danach wurde eine Kolonie in $5 \mathrm{ml} \mathrm{LB}-$ Tetra-Medium überführt und über Nacht bei $37^{\circ} \mathrm{C}$ geschüttelt. Anschließend wurden diese $5 \mathrm{ml}$ in $250 \mathrm{ml}$ LB-Tetra-Medium überführt und bei $37^{\circ} \mathrm{C}$ so lange geschüttelt, bis die Bakteriensuspension eine $\mathrm{OD}_{550 \mathrm{~nm}}$ von 0,5-1,0 (mittlere exponentielle Wachstumsphase) erreicht hatte. Die Zellen wurden sofort für $10 \mathrm{~min}$ im Eisbad abgekühlt.

Alle nachfolgenden Schritte wurden bei $4^{\circ} \mathrm{C}$ durchgeführt und die Zellen zwischen den einzelnen Schritten auf Eis gelagert. Nach einer Zentrifugation für 15 min bei 4000 rpm (2 $500 \times$ g, Hettrich-Zentrifuge) wurden die Zellen mit vorgekühltem Elektroporationspuffer einmal mit dem Ausgangsvolumen der ursprünglichen Zellsuspension, einmal mit 1/2 Volumen und einmal mit 1/20 Volumen Elektroporationspuffer gewaschen. Nach jedem Waschschritt folgte eine Zentrifugation für $15 \mathrm{~min}$ bei $4000 \mathrm{rpm}$ (2 $500 \mathrm{x} \mathrm{g}$, HettrichZentrifuge). Zum Ende des Waschvorganges wurde das Sediment in 1/500 Volumen der ursprünglichen Zellsuspension mit Elektroporationspuffer resuspendiert (Zellzahl ca. $10^{10} / \mathrm{ml}$ ). Es wurden jeweils $50 \mu \mathrm{l}$ der Zellsuspension in 1,5 ml-Reaktionsgefäße überführt, in flüssigem Stickstoff Schock-gefroren und bei $-70^{\circ} \mathrm{C}$ gelagert.

\subsubsection{Herstellung einer Glycerolkultur von E. coli XL1 (blue) Zellen}

Einer dicht gewachsenen E. coli-Bakterienkultur (nicht-transformiert oder transformiert) wurde $50 \%$ (v/v) Glycerol als Gefrierschutz zugesetzt. So können die Zellen bei $-70^{\circ} \mathrm{C}$ für mindestens 12 Monate gelagert werden, wobei häufiges Auftauen und Einfrieren vermieden werden sollte.

\subsection{Transformation kompetenter E. coli XL1 (blue) Zellen}

\subsubsection{Puffer und Lösungen}

SOB-Medium

$500 \mathrm{ml}$

Hefe-Extrakt

$0,5 \%(w / v)$

$2,5 \mathrm{~g}$

Trypton

$2 \%(w / v)$

$10 \mathrm{~g}$

$\mathrm{KCl}$

$2,7 \mathrm{mM}$

$0,1 \mathrm{~g}$

$\mathrm{NaCl}$

$10 \mathrm{mM}$

$0,3 \mathrm{~g}$

Das Medium wurde auf $\mathrm{pH} 7,0$ eingestellt, autoklaviert und bei $4^{\circ} \mathrm{C}$ gelagert. 
SOC-Medium

SOB-Medium

$\mathrm{MgCl}_{2}$

$20 \mathrm{mM}$

$10 \mu \mathrm{l} 2 \mathrm{M}$ Stlsg

Glucose

$20 \mathrm{mM}$

$10 \mu \mathrm{l} 2$ M Stlsg

Das Medium wurde unmittelbar vor Gebrauch angesetzt und im Wasserbad auf $37^{\circ} \mathrm{C}$ erwärmt.

Ampicillin-Stammlösung

$100 \mathrm{ml}$

Ampicillin

$0,5 \%(w / v)$

$500 \mathrm{mg}$

Die Lösung wurde sterilfiltriert und in Aliquots bei $-20^{\circ} \mathrm{C}$ gelagert.

Kanamycin-Stammlösung

$100 \mathrm{ml}$

Kanamycin

$0,5 \%(\mathrm{w} / \mathrm{v})$

$500 \mathrm{mg}$

Die Lösung wurde sterilfiltriert und in Aliquots bei $-20^{\circ} \mathrm{C}$ gelagert.

LB-Amp-Agar-Platten

$1000 \mathrm{ml}$

LB-Agar

$3,2 \%(w / v)$

$32 \mathrm{~g}$

Die Lösung wurde autoklaviert, nach Abkühlung auf ca. $46^{\circ} \mathrm{C}$ wurden $10 \mathrm{ml}$ AmpicillinStammlösung zugegeben und $15 \mathrm{ml} /$ Petrischale ausplattiert. Die Platten wurden bei $4^{\circ} \mathrm{C}$ gelagert.

LB-Kana-Agar-Platten

$1000 \mathrm{ml}$

LB-Agar

$3,2 \%(w / v)$

$32 \mathrm{~g}$

Die Lösung wurde autoklaviert, nach Abkühlung auf ca. $46^{\circ} \mathrm{C}$ wurden $10 \mathrm{ml}$ KanamycinStammlösung zugegeben und $15 \mathrm{ml} /$ Petrischale ausplattiert. Die Platten wurden bei $4^{\circ} \mathrm{C}$ gelagert.

\subsubsection{Transformation durch Elektroporation}

Um Plasmide in E. coli XL1 (blue) Zellen einzubringen, wurden $50 \mu$ le elektrokompetente Zellen während des Auftauens mit 1-2 $\mu$ l Ligationsansatz oder 1 ng zirkulärem Plasmid gemischt. Die Zellen wurden in die zuvor gekühlten Transformationsküvetten mit einem Elektrodenabstand von $2 \mathrm{~mm}$ pipettiert und mit einem Puls von $2500 \mathrm{~V}$, einem Widerstand von 200 Ohm und einer Kapazität von $25 \mu \mathrm{F}$ elektroporiert. Um das Absterben der Zellen zu minimieren, wurde sofort nach dem Puls $950 \mu$ auf $37^{\circ} \mathrm{C}$ erwärmtes SOC-Medium zu den Zellen gegeben und die Suspension $1 \mathrm{~h}$ bei $37^{\circ} \mathrm{C}$ im Schüttler inkubiert. Nach der Inkubation wurden 50-200 $\mu \mathrm{l}$ des Transformationsansatzes auf den LB-Amp-Platten bzw. LB-KanaPlatten ausgestrichen und über Nacht bei $37^{\circ} \mathrm{C}$ inkubiert. 
Da die E. coli XL1 (blue) Zellen Ampicillin-sensitiv sind und der pcDNA3- sowie der pBluescript-Vektor ein Antibiotika-Resistenzgen für Ampicillin enthalten, konnten nur transformierte (rekombinante) Bakterienklone auf den LB-Amp-Platten wachsen. Der pEGFP-Vektor besitzt ein Kanamycin-Resistenzgen und daher konnten die mit diesem Vektor transformierten Bakterienklone auf LB-Kana-Platten wachsen.

\subsection{Isolierung von Plasmid-DNA im Mini-Maßstab}

Bei dieser Methode werden die Bakterienzellen zunächst lysiert und die im Lysat befindliche Plasmid-DNA an eine Säulenmatrix gebunden. Nach mehrmaligem Waschen wird anschließend die DNA durch Absenken der Salzkonzentration eluiert.

Hier wurde der „GFX ${ }^{\mathrm{TM}}$ Micro Plasmid Prep Kit" von Amersham-Pharmacia verwendet. Alle Lösungen waren im Kit enthalten.

\subsubsection{Puffer und Lösungen}

LB-Amp-Medium $\quad 5 \mathrm{ml}$

LB-Medium $\quad 5 \mathrm{ml}$

Das Medium wurde bei $4^{\circ} \mathrm{C}$ aufbewahrt und unmittelbar vor der Verwendung mit $50 \mu \mathrm{l}$ Ampicillin-Stammlösung (siehe 3.6) versetzt.

LB-Kana-Medium

LB-Medium

Das Medium wurde bei $4^{\circ} \mathrm{C}$ aufbewahrt und unmittelbar vor der Verwendung mit $50 \mu \mathrm{l}$ Kanamycin-Stammlösung (siehe 3.6) versetzt.

Resuspendierungspuffer („Solution I")

$100 \mathrm{ml}$

Tris/ $/ \mathrm{HCl}$

$100 \mathrm{mM}$

EDTA

$10 \mathrm{mM}$

$372,3 \mathrm{mg}$

RNase A

$0,4 \mathrm{mg} / \mathrm{ml}$

$40 \mathrm{mg}$

Der Puffer hatte einen $\mathrm{pH}$-Wert von 7,5 und wurde bei $4^{\circ} \mathrm{C}$ gelagert.

Lysispuffer („Solution II")

$100 \mathrm{ml}$

$\mathrm{NaOH}$

$190 \mathrm{mM}$

$760 \mathrm{mg}$

SDS

$1 \%(w / v)$

$1 \mathrm{~g}$

Der Puffer wurde bei Raumtemperatur gelagert.

Neutralisationspuffer (,Solution III")

$100 \mathrm{ml}$

Natriumacetat

$3 \mathrm{M}$

$24,6 \mathrm{~g}$

Der Puffer hatte einen pH-Wert von 5,5 und wurde bei Raumtemperatur gelagert. 
Waschpuffer (,Wash Buffer")

$100 \mathrm{ml}$

Ethanol

$80 \%(\mathrm{v} / \mathrm{v})$

$80 \mathrm{ml}$

EDTA

$10 \mathrm{mM}$

$372,3 \mathrm{mg}$

Tris $/ \mathrm{HCl}$

$100 \mathrm{mM}$

$1,211 \mathrm{~g}$

Der Puffer hatte einen pH-Wert von 7,5 und wurde bei Raumtemperatur gelagert.

\subsubsection{Präparation von Plasmid-DNA im Mini-Maßstab}

Es wurde jeweils eine Bakterienkolonie von den Kulturplatten in $5 \mathrm{ml}$ LB-Amp-Medium für Bakterien, die mit dem pBluescript- oder pcDNA3-Vektor transformiert worden waren oder in $5 \mathrm{ml}$ LB-Kana-Medium für Bakterien, die mit dem pEGFP-Vektor transformiert worden waren, überführt und über Nacht unter Schütteln bei $37^{\circ} \mathrm{C}$ inkubiert. Danach wurden je $1,5 \mathrm{ml}$ der Bakteriensuspension in ein Reaktionsgefäß überführt, $30 \mathrm{~s}$ bei Raumtemperatur (RT) und 13000 rpm (16 $000 \times$ g) in der Tischzentrifuge Biofuge „pico“ zentrifugiert und der Überstand verworfen. Dieser Schritt wurde wiederholt und das entstandene Pellet in $300 \mu \mathrm{l}$ Resuspendierungspuffer resuspendiert. Die Zellen wurden durch Zugabe von $300 \mu \mathrm{l}$ Lysispuffer lysiert und die Suspension 10-15 mal invertiert. Danach wurden $600 \mu \mathrm{l}$ Neutralisationspuffer zugegeben und das Reaktionsgefäß mehrmals invertiert, bis sich eine gleichmäßige Suspension gebildet hatte; diese Suspension wurde für 5 min bei RT mit 13000 rpm (16 $000 \times g)$ zentrifugiert.

Der Überstand mit der Plasmid-DNA wurde auf die GFX-Säule gegeben, 1 min bei RT inkubiert und $1 \mathrm{~min}$ ebenfalls bei RT und $13000 \mathrm{rpm}(16000 \mathrm{xg})$ zentrifugiert. Das Eluat wurde verworfen, die Säule mit $400 \mu \mathrm{l}$ Waschpuffer gewaschen und $1 \mathrm{~min}$ bei $13000 \mathrm{rpm}$ (16 $000 \times$ g) zentrifugiert. Wiederum wurde das Eluat verworfen und die Säule in ein neues Reaktionsgefäß überführt. Die Säulenmatrix wurde mit $100 \mu \mathrm{l} \mathrm{H}_{2} \mathrm{O}$ überschichtet und 1 min bei RT inkubiert. Die Säule wurde dann bei $13000 \mathrm{rpm}(16000 \times \mathrm{g}$ ) für 2 min zentrifugiert und so die Plasmid-DNA eluiert.

\subsubsection{Photometrische Quantifizierung der gereinigten Plasmid-DNA}

Zur photometrischen Bestimmung wurden $10 \mu \mathrm{l}$ der Plasmid-DNA-Lösung in $500 \mu \mathrm{l} \mathrm{H}_{2} \mathrm{O}$ verdünnt, das Photometer gegen $\mathrm{H}_{2} \mathrm{O}$ geeicht und die Absorption bei $260 \mathrm{~nm}$ und bei $280 \mathrm{~nm}$ gemessen.

Die Konzentration der Plasmid-DNA im Eluat wurde nach folgender Formel berechnet:

DNA-Konzentration [ng/ $\mu \mathrm{l}]=\mathrm{E}_{260 \mathrm{~nm}} \times$ Verdünnungsfaktor $\times 50$

Die Reinheit wurde durch Quotientenbildung der $\mathrm{OD}_{260 \mathrm{~nm}}$ und $\mathrm{OD}_{280 \mathrm{~nm}}$ errechnet. Nur Plasmid-DNA mit einem 260/280 nm-Quotienten zwischen 1,8 und 2,0 wurde verwendet. 


\subsection{Isolierung von Plasmid-DNA im Maxi-Maßstab}

\subsubsection{Puffer und Lösungen}

Die Präparation wurde mit dem „Jetstar-Kit“ der Firma Genomed durchgeführt. Alle Lösungen waren im Kit enthalten.

\section{Lösung E1 (Resuspendierung)}

$100 \mathrm{ml}$

Tris

$50 \mathrm{mM}$

EDTA

$10 \mathrm{mM}$

$5 \mathrm{ml}$ (1 M Stlsg pH 8)

$2 \mathrm{ml}(0,5 \mathrm{M} \mathrm{Stlsg})$

$\mathrm{Zu}$ dem Puffer wurde lyophilisierte RNase in einer Endkonzentration von $100 \mu \mathrm{g} / \mathrm{ml}$ zugegeben. Er hatte einen $\mathrm{pH}-$ Wert von 8,0 und wurde bei $4^{\circ} \mathrm{C}$ gelagert.

Lösung E2 (Zelllyse)

$100 \mathrm{ml}$

$\mathrm{NaOH} 200 \mathrm{mM} 2 \mathrm{ml}(10 \mathrm{~N} \mathrm{NaOH})$

SDS

$1 \%(w / v)$

Der Puffer wurde bei Raumtemperatur gelagert.

Lösung E3 (Neutralisation)

$100 \mathrm{ml}$

Natriumacetat

$3,1 \mathrm{M}$

$31,41 \mathrm{~g}$

Der Puffer hatten einen $\mathrm{pH}-$ Wert von 5,5 und wurde bei Raumtemperatur gelagert.

Lösung E4 (Säulenäquilibrierung)

$100 \mathrm{ml}$

$\mathrm{NaCl}$

$\begin{array}{rr}600 \mathrm{mM} & 4,67 \mathrm{~g} \\ 100 \mathrm{mM} & 0,82 \mathrm{~g} \\ 0,15 \%(\mathrm{v} / \mathrm{v}) & 0,15 \mathrm{ml}\end{array}$

Natriumacetat

$0,15 \%(v / v)$

$0,15 \mathrm{ml}$

Der Puffer hatte einen pH-Wert von 5,0 und wurde bei Raumtemperatur gelagert.

Lösung E5 (Waschen der Säule)

$100 \mathrm{ml}$

$\mathrm{NaCl}$

$800 \mathrm{mM}$

$4,7 \mathrm{~g}$

Natriumacetat

$100 \mathrm{mM}$

$0,82 \mathrm{~g}$

Der Puffer hatte einen pH-Wert von 5,0 und wurde bei Raumtemperatur gelagert.

Lösung E6 (DNA-Elution)

$100 \mathrm{ml}$

$\mathrm{NaCl}$

$1250 \mathrm{mM}$

$7,3 \mathrm{~g}$

Tris/ $\mathrm{HCl}$

$100 \mathrm{mM}$

$10 \mathrm{ml}$ (1 M Stlsg)

Der Puffer hatte einen pH-Wert von 8,5 und wurde bei Raumtemperatur gelagert. 


\subsubsection{Isolierung der Plasmid-DNA durch Affinitätschromatographie im Maxi-Maßstab}

Es wurden $150 \mathrm{ml}$ LB-Amp-Medium mit $1 \mathrm{ml}$ Bakterienübernachtkultur angeimpft und bei $37^{\circ} \mathrm{C}$ über Nacht unter Schütteln inkubiert. Die Bakteriensuspension wurde anschließend bei Raumtemperatur $20 \mathrm{~min}$ bei $6000 \mathrm{rpm}$ (10 400 x g, Sorvall-Zentrifuge, SLA-1500-Rotor) sedimentiert. Das Sediment wurde in $10 \mathrm{ml}$ Lösung E1 resuspendiert, $10 \mathrm{ml}$ Lösung E2 zugegeben und die Bakterien 5 min bei Raumtemperatur lysiert. Danach wurde mit $10 \mathrm{ml}$ Lösung E3 neutralisiert, die Suspension durch Invertieren des Reaktionsgefäßes gemischt und für $10 \mathrm{~min}$ bei $15000 \mathrm{rpm}$ (27 $000 \times \mathrm{g}$, Sorvall-Zentrifuge, SS-34-Rotor) und $20^{\circ} \mathrm{C}$ zentrifugiert. Der Überstand wurde auf eine Säule gegeben, die zuvor mit $30 \mathrm{ml}$ Lösung E4 äquilibriert worden war. Anschließend wurde die Säule mit $60 \mathrm{ml}$ Lösung E5 gewaschen und die Plasmid-DNA mit $15 \mathrm{ml}$ Lösung E6 eluiert. Die Plasmid-DNA wurde mit 10,5 ml 99,7\% (v/v) Isopropanol versetzt und die präzipitierte Plasmid-DNA $45 \mathrm{~min}$ bei $15000 \mathrm{rpm}$ (27 $000 \times \mathrm{g}$, Sorvall Zentrifuge, SS-34-Rotor) und $4^{\circ} \mathrm{C}$ sedimentiert.

Das Pellet wurde durch Waschen mit 1,5 ml 70\% (v/v) Ethanol in ein 1,5 ml-Reaktionsgefäß überführt und resuspendiert. Nach erneutem Zentrifugieren für $15 \mathrm{~min}$ bei $4^{\circ} \mathrm{C}$ und $20000 \mathrm{rpm}$ (36 $700 \times$ g, SIGMA-Zentrifuge 3K30, Rotor 12154-H) wurde der Überstand verworfen, die DNA 10 min an der Luft getrocknet und in $500 \mu \mathrm{H}_{2} \mathrm{O}$ gelöst. Die Ausbeute betrug zwischen 0,5 und $3,0 \mu \mathrm{g} / \mu \mathrm{l}$ Plasmid-DNA.

\subsection{Charakterisierung der Plasmide durch Restriktionsenzymspaltung}

\subsubsection{Puffer und Enzyme}

Die Puffer und Enzyme wurden unter 2.9.1 beschrieben.

\subsubsection{Spaltungsreaktion}

Für einen $25 \mu \mathrm{l}$-Ansatz wurden ca. $100 \mathrm{ng}$ der isolierten Plasmid-DNA, $5 \mathrm{U}$ der jeweiligen Restriktionsenzyme und 2,5 $\mu$ des für die Enzymkombination optimalen 10 x Puffer gemischt, mit $\mathrm{H}_{2} \mathrm{O}$ auf $25 \mu \mathrm{l}$ aufgefüllt und für ca. $2 \mathrm{~h}$ bei $37^{\circ} \mathrm{C}$ inkubiert. Anschließend wurden $5 \mu$ l Bromphenolblau-Probenpuffer (siehe 3.2.1) hinzupipettiert, $15 \mu \mathrm{l}$ der Lösung auf ein $1 \%(w / v)$ Agarose-Gel aufgetragen, für ca. $90 \mathrm{~min}$ bei $80 \mathrm{mV}$ aufgetrennt, $15 \mathrm{~min}$ im Ethidiumbromidbad gefärbt (siehe 3.2) und die DNA mit dem ChemiDoc ${ }^{\mathrm{TM}}$-System der Firma BioRad visualisiert. 


\subsection{Charakterisierung der Plasmide durch Sequenzierung}

Die Sequenzierung von Doppelstrang-DNA der Plasmide wurde mit dem automatischen DNA-Sequenzierungsgerät der Firma ABI (Model 373 A) durchgeführt. Es wurde die „Big Dye Terminator Cycle Sequencing"-Methode entsprechend der Herstellervorschrift (Perkin Elmer) angewendet. Bei dieser Methode werden vier mit unterschiedlichen FluoreszenzFarbstoffen gekoppelte Didesoxyribonukleosidtriphosphate (ddATP, ddCTP, ddGTP, ddTTP) im Mangel mit nicht markierten Desoxyribonukleosidtriphosphaten gemischt. Die DNAMatrize wurde von einem Oligonukleotid, z. B. dem T7- oder Sp6-Primer, ausgehend an einem Strang durch zyklisches Denaturieren, Anlagern und Synthetisieren immer wieder abgeschrieben. Die so entstandenen, am 3'-Ende mit basenspezifischen Farbstoffen markierten Fragmente wurden elektrophoretisch in einem Acrylamidgel unter denaturierenden Bedingungen aufgetrennt und durch ihre Fluoreszenz im Gel nachgewiesen.

\subsubsection{Puffer und Lösungen}

$30 \%$ (w/v) Acrylamid-Stammlösung

$100 \mathrm{ml}$

Acrylamid

$29 \%(w / v)$

$29 \mathrm{~g}$

Bisacrylamid

$1 \%(w / v)$

$1 \mathrm{~g}$

Die Lösung wurde filtriert und in einer lichtgeschützten Flasche bei $4^{\circ} \mathrm{C}$ gelagert.

$10 \%(w / v)$ Ammoniumpersulfat-Lösung

$100 \mathrm{ml}$

Ammoniumpersulfat

$10 \%(w / v)$

$10 \mathrm{~g}$

Die Lösung wurde bei $4^{\circ} \mathrm{C}$ gelagert.

$10 \times$ TBE-Puffer (Tris-Borat-EDTA-Puffer)

$1000 \mathrm{ml}$

Tris

$0,9 \mathrm{M}$

$108,0 \mathrm{~g}$

Borsäure

$0,9 \mathrm{M}$

$55,0 \mathrm{~g}$

EDTA

$25 \mathrm{mM}$

$8,3 \mathrm{~g}$

Der Puffer wurde mit Borsäure auf $\mathrm{pH}$ 8,2 eingestellt und bei Raumtemperatur gelagert.

Natriumacetat-Puffer

$100 \mathrm{ml}$

Natriumacetat

$3 \mathrm{M}$

$24.6 \mathrm{~g}$

Der pH-Wert des Puffers wurde auf 4,6 eingestellt und der Puffer bei Raumtemperatur gelagert. 
EDTA-Lösung

$10 \mathrm{ml}$

EDTA

$25 \mathrm{mM}$

$875 \mathrm{mg}$

Der $\mathrm{pH}-$ Wert der Lösung wurde auf $\mathrm{pH}$ 8,0 eingestellt und die Lösung bei Raumtemperatur gelagert.

Formamid/EDTA-Lösung 5:1

$1 \mathrm{ml}$

Formamid

$83,3 \%(v / v)$

$833 \mu l$

25 mM EDTA-Lösung

$16,6 \%(\mathrm{v} / \mathrm{v})$

$166 \mu \mathrm{l}$

Die Lösungen wurden gemischt und bei $4^{\circ} \mathrm{C}$ gelagert.

\subsubsection{Vorbereitung der Polyacrylamid-(PAA)-DNA-Sequenziergele}

Die Glasplatten wurden mit einem Detergenz (Alconox) gewaschen, mit $\mathrm{H}_{2} \mathrm{O}$ gespült, mit Isopropanol nachbehandelt und danach getrocknet. Nach dem Trocknen wurden die Abstandhalter aufgelegt und die Glasplatten zusammengesetzt. Für das 4\% (w/v) PAA-Gel wurden $30 \mathrm{~g}$ Harnstoff, $8 \mathrm{ml}$ 30\% (w/v) Acrylamidlösung, 6,0 ml 10 x TBE-Puffer und 22,5 ml $\mathrm{H}_{2} \mathrm{O}$ eingesetzt. Der Harnstoff wurde durch Rühren und Erwärmen (nicht über $50^{\circ} \mathrm{C}$ ) gelöst und die Lösung danach durch einen 0,2 $\mu \mathrm{m}$-Filter filtriert und entgast. Die Lösung wurde in ein Becherglas überführt und die Polymerisationsreaktion durch Zugabe von $350 \mu 10 \%$ iger Ammoniumpersulfatlösung und $20 \mu \mathrm{l}$ TEMED gestartet. Die Lösung wurde sofort zwischen die vorbereiteten Glasplatten gegossen und der Kamm eingesetzt. Das Gel polymerisierte anschließend $2 \mathrm{~h}$ in horizontaler Lage.

\subsubsection{Sequenzierungsreaktion}

Die Sequenzierungsreaktion wurde wie folgt angesetzt:

$\begin{array}{ll}\text { Enzym/Puffer Gemisch } & 4 \mu \mathrm{l} \\ \text { (dNTP, ddNTP, Puffer, Polymerase) } & \\ \text { DNA-Matrize (Plasmid-DNA-Doppelstrang) } & 1 \mu \mathrm{g} \\ \text { Oligonukleotide } & 5 \mathrm{pmol} \\ \mathrm{H}_{2} \mathrm{O} & \text { ad } 20 \mu \mathrm{l}\end{array}$

Die Substanzen wurden kurz gemischt, zentrifugiert und anschließend für 25 Zyklen in einem Thermocycler mit folgendem Programm inkubiert:

Denaturierung: $30 \mathrm{~s}$ bei $96^{\circ} \mathrm{C}$; Anlagerung der Oligonukleotide: $15 \mathrm{~s}$ bei $50^{\circ} \mathrm{C}$; Kettenverlängerung: $4 \mathrm{~min}$ bei $60^{\circ} \mathrm{C}$. 


\subsubsection{Aufreinigung der Proben}

Nach Abschluß der Sequenzierungsreaktion wurde der Reaktionsansatz auf $4^{\circ} \mathrm{C}$ gekühlt und die DNA mit Ethanol gefällt, um überschüssige Didesoxyribonukleosidtriphosphate mit Fluoreszenzfarbstoffgruppen zu entfernen.

Hierzu wurden zu dem Reaktionsansatz $80 \mu \mathrm{l} \mathrm{H} \mathrm{H}_{2} \mathrm{O}, 10 \mu \mathrm{l} 3 \mathrm{M}$ Natriumacetat $(\mathrm{pH} \mathrm{4,6)}$ und $250 \mu \mathrm{l} 95 \%(\mathrm{v} / \mathrm{v})$ Ethanol (RT) gegeben und das Gemisch $15 \mathrm{~min}$ bei 13000 rpm (16 $000 \times$ g) in der Tischzentrifuge zentrifugiert. Danach wurde der Überstand entfernt, das Sediment mit $250 \mu \mathrm{l} 70 \%$ (v/v) Ethanol (RT) gewaschen und $5 \mathrm{~min}$ bei $13000 \mathrm{rpm}$ $(16000 \times g)$ zentrifugiert. Anschließend wurde das Ethanol abpipettiert und die DNA getrocknet. Die DNA wurde in $3 \mu$ Formamid/EDTA-Lösung 5:1 aufgenommen und 2 min bei $90^{\circ} \mathrm{C}$ denaturiert.

\subsubsection{Automatische Sequenzierung und EDV-gestützte Auswertung}

Auf das Sequenziergel wurden $3 \mu \mathrm{l}$ der DNA-Lösung aufgetragen und die Oligonukleotide elektrophoretisch der Größe nach aufgetrennt. Die vier unterschiedlichen FluoreszenzFarbstoffgruppen, die jeweils an das terminale Didesoxyribonukleotid eines bestimmten Oligonukleotids gekoppelt waren, wurden durch einen 40 mW Argon-Laser $(540$ nm, 570 nm, $595 \mathrm{~nm}$ und $625 \mathrm{~nm}$ ) angeregt. Die dadurch hervorgerufenen Fluoreszenzsignale wurden durch ein Detektorsystem des DNA-Sequenzierers anhand ihrer unterschiedlichen Emissionswellenlängen identifiziert und quantifiziert.

Die Auftragung der Proben auf Sequenziergele und die automatische Sequenzierung und Auswertung wurde von Herrn A. Nolte am Institut für Biochemie und Molekulare Zellbiologie der Universität Göttingen durchgeführt.

\section{SYNTHESE DER MUTIERTEN REZEPTOR-cDNA}

\subsection{Modifikationen der humanen EP4-Rezeptor-cDNA}

\subsubsection{Verlängerung des translatierten Bereichs der hEP4-Rezeptor-cDNA um eine für das FLAG-Epitop codierende Sequenz}

Zu Beginn dieser Arbeit gab es noch keinen Antikörper gegen den humanen EP4-Rezeptor, mit dem ein immunologischer Nachweis der exprimierten Rezeptorproteine möglich war. Die immunologische Detektion der in den HEK293-Zellen exprimierten rekombinanten Rezeptorproteine sollte daher über ein künstlich angefügtes Epitop für den käuflichen monoklonalen FLAG-M2-Antikörper erfolgen. Die Verlängerung der hEP4-Rezeptor-cDNA um die FLAG-Epitop codierende Sequenz wurde, wie unter 3.1.4 beschrieben, durchgeführt. 
Die PCR-Reaktion wurde mit dem pcDNA/AMP-hEP4-Plasmid als Matrize und dem Hind FLAG EP4 $f$ als Vorwärts- und dem EP4 Xba $r$ als Rückwärts-Primer durchgeführt. Die PCR wurde unter den gleichen Bedingungen, wie unter 3.1.3 beschrieben, durchgeführt.

\subsubsection{Sequenzgerichtete Mutagenese der FLAG-hEP4-Rezeptor-cDNA zum Einführen der SnaB I-Restriktions-Erkennungssequenz}

Da die für die sequenzgerichtete Mutagenese verwendete Taq-Polymerase keine „proofreading"-Aktivität hat können unerwünschte Mutationen bei der Replikation eingeführt werden. Die Wahrscheinlichkeit, unerwünschte Mutationen einzufügen, steigt mit der Länge des zu amplifizierenden DNA-Fragments. Um mit einem möglichst kurzen cDNA-Fragment arbeiten zu können, wurde die SnaB I-Restriktions-Erkennungssequenz unmittelbar vor der für die C-terminale Domäne codierenden Sequenz eingefügt.

Zur Herstellung des 5'- und des 3'-cDNA-Fragmentes der modifizierten FLAG-hEP4Rezeptor-cDNA wurden der pcDNA/AMP FLAG-hEP4 wt-Rezeptor als Matrize und folgende Primerkombinationen gewählt:

Tab. 2: Durchführung der sequenzgerichteten Mutagenese zum Einfügen der SnaB ISchnittstelle in die FLAG-hEP4-R-cDNA

\begin{tabular}{ccccc}
\hline PCR & Primer & Matrizen cDNA & Mutation & Produkt \\
\hline \multirow{2}{*}{1} & Hind FLAG EP4 f & pcDNA AMP & Einfügen der SnaB I- & 5'-Fragment mit 3' \\
& SnaBI EP4 r & FLAG-hEP4 & Restriktionsschnittstelle & SnaB I-Sequenz \\
& SnaBI EP4 f & pcDNA AMP & Einfügen der SnaB I- & 3'-Fragment mit 5' \\
2 & EP4 Xba r & FLAG-hEP4 & Restriktionsschnittstelle & SnaB I-Sequenz \\
& Hind FLAG EP4 f & 5'-Fragment aus 1 & komplette FLAG- \\
3 & EP4 Xba r & 3'-Fragment aus 2 & hEP4-cDNA \\
\hline
\end{tabular}

Alle anderen Komponenten der PCR-Ansätze waren mit denen unter 3.1.3 beschriebenen identisch. Das 5'- und das 3'-Fragment sowie die komplette modifizierte FLAG-hEP4-RcDNA wurden mit dem unter 3.1.3 beschriebenen PCR-Programm durchgeführt. Die durch die PCR 1 und PCR 2 erhaltenen Produkte wurden über Agarose-Gele aufgetrennt (siehe 3.2), gereinigt (siehe 3.3) und in die PCR 3 eingesetzt. Das PCR-Produkt wurde ebenfalls über ein Agarose-Gel aufgetrennt und daraus isoliert. Die komplette mutierte FLAG-hEP4R-cDNA wurde mit Hind III ind Xba I in Puffer B geschnitten (siehe 3.4.2) und in den mit den gleichen Enzymen geschnittenen pcDNA3-Vektor kloniert (siehe 3.4.3). Mit dem Ligationsprodukt wurden E. coli XL1 (blue) Zellen transformiert (siehe 3.6), die PlasmidDNA aus einer Übernachtkultur isoliert (siehe 3.7) und die Klonierung durch Restriktionsenzymspaltung (siehe 3.9) und Sequenzierung überprüft (siehe 3.10). 


\subsection{Einfügen der Mutationen zur Substitution der Serine und Threonine in der für die C-terminalen Domäne codierenden 3'-Sequenz der FLAG-hEP4 wt-R-cDNA}

Zum Austausch einzelner Basen in der für die C-terminale Domäne codierenden Sequenz wurden sequenzgerichtete Mutagenesen durchgeführt, in denen jedoch keine komplementären Primer verwendet wurden. In den verschiedenen PCR-Reaktionen wurde mit Primern gearbeitet, die sowohl die zu mutierenden Basen als auch RestriktionsErkennungssequenzen enthielten, über die das synthetisierte, gereinigte und mit den jeweiligen Enzymen geschnittene PCR-Produkt in die jeweilige Ausgangs-cDNA kloniert werden konnte. Als Ausgangs-Matrize diente das pcDNA3 FLAG-hEP4 wt-RezeptorPlasmid. Für die Synthese der mutierten, für die C-terminale Domäne codierenden Sequenzen konnte der pcDNA3-Vektor nicht verwendet werden, da die für die Klonierung benötigen Restriktionsschnittstellen mehrmals in diesem Vektor lokalisiert waren. Daher wurde der pBluescript-Vektor gewählt, da er die nötigen Restriktionsschnittstellen nach der Klonierung des für die C-terminale Domäne codierenden DNA-Fragmentes nur noch einmal enthielt.

\subsubsection{Amplifizierung des 5' um die Kpn l-Restriktions-Erkennungssequenz verlängerten 3'-cDNA-Fragments der FLAG-hEP4-Rezeptor-cDNA und Einfügen der ST335-338A-Mutationen}

Da der pBluescript über keine SnaB I-Schnittstelle verfügte, wurde die die multiple Klonierungsstelle des pBluescript flankierende Kpn I-Schnittstelle, wie unter 3.1 .4 beschrieben, 5' an das für die C-terminale Domäne codierende 3'-Fragment des FLAG-hEP4 wt-Rezeptors angefügt, was die Klonierung des Fragments in diesen Vektor erlaubte. Zusätzlich wurde in dieser PCR-Reaktion die Substitution von T335 und S338 durchgeführt. Für die PCR-Reaktion wurde der pcDNA3/FLAG-hEP4 wt-Rezeptor als Matrize und der SM $1 \mathrm{f}$ als Vorwärts- und der EP4 Xba $r$ als Rückwärts-Primer eingesetzt. Alle anderen Komponenten des PCR-Ansatzes entsprachen den unter 3.1.3 beschriebenen. Das Produkt wurde mit dem unter 3.1.3 beschriebenen PCR-Programm amplifiziert. Das Produkt wurden zur Analyse und Reinigung in einem 2\% (w/v) Agarose-Gel aufgetrennt und mit Kpn I und Xba I in Puffer MULTI CORE ${ }^{\mathrm{TM}}$ geschnitten (siehe 3.4.2), anschließend in den mit den gleichen Enzymen geschnittenen pBluescript-Vektor kloniert (siehe 3.4 ) und E. coli XL1 (blue) Zellen transformiert (siehe 3.6.2). Die aus einer Übernachtkultur isolierte (siehe 3.7) und charakterisierte (siehe 3.9 und 3.10) Plasmid-DNA wurde als pBluescript hEP4 CT ST335-338A bezeichnet. 
3.12.2 Synthese der C-terminalen Sequenz der FLAG-hEP4-R-cDNA mit der Substitution aller Serine und Threonine

Für die Synthese der für die C-teminalen Domäne codierenden Sequenz der FLAG-hEP4-RcDNA, in der alle Serine und Threonine substitutiert waren, wurden mehrere aufeinanderfolgende PCR-Reaktionen durchgeführt. Dazu wurde das durch PCR amplifizierte cDNA-Fragment mit den jeweiligen, flankierenden Restriktionsenzymen verdaut und in das Plasmid kloniert, das als Matrizen-cDNA für die Amplifizierung dieses Fragmentes diente. Das erhaltene Klonierungsprodukt wurde für die weitere Synthese verwendet, die nach dem gleichen Prinzip erfolgte. Als Ausgangsplasmid diente der pBluescript hEP4 CT ST335-338A. Alle PCR-Reaktionen wurden mit denen unter 3.1 .3 beschriebenen Komponenten und Bedingungen durchgeführt. Die amplifizierten Produkte wurden zur Analyse und Reinigung in einem 2\% (w/v) Agarose-Gel aufgetrennt (siehe 3.2). Die einzelnen PCR-Reaktionen sowie die dazu verwendeten Primer, Matrizen-cDNAs und die eingefügten Mutationen sind in Tabelle 3 dargestellt.

Tab. 3: PCR-Reaktionen zur Synthese der für die C-terminale Domäne codierenden Sequenz der FLAG-hEP4-R-cDNA mit der Substitution aller Serine und Threonine. Dargestellt sind die synthetisierten Ziel-cDNA-Fragmente mit den zum Einfügen der Mutationen verwendeten Primer, sowie die verwendeten Matrizen-cDNAs, die neu eingefügten Mutationen und die Größe der amplifizierten Produkte.

\begin{tabular}{|c|c|c|c|c|}
\hline $\begin{array}{l}\text { Ziel-cDNA } \\
\text { Fragment }\end{array}$ & Primer & Matrizen-cDNA & Mutation & $\begin{array}{c}\text { Errechnete } \\
\text { Produktgröße }\end{array}$ \\
\hline $\begin{array}{c}\text { hEP4 CT } \\
\text { ST335-338A } \\
\text { ST369-382A }\end{array}$ & $\begin{array}{l}\text { SM } 1 f \\
\text { SM } 3 r\end{array}$ & $\begin{array}{c}\text { pBs EP4 } \\
\text { ST335-338A }\end{array}$ & ST369-382A & 177 bp \\
\hline $\begin{array}{l}\text { 5'-Fragment } \\
\text { ST428-443A }\end{array}$ & $\begin{array}{l}\text { Hind FLAG } \\
\qquad \begin{array}{l}\text { EP4 } \mathrm{f} \\
\text { SM } 6 r\end{array}\end{array}$ & $\begin{array}{l}\text { pcDNA AMP FLAG- } \\
\text { hEP4 }\end{array}$ & ST428-443A & 1372 bp \\
\hline $\begin{array}{l}\text { 3'-Fragment } \\
\text { ST428-443A }\end{array}$ & $\begin{array}{c}\text { SM } 6 f \\
\text { EP4 Xba r }\end{array}$ & $\begin{array}{c}\text { pcDNA AMP FLAG- } \\
\text { hEP4 }\end{array}$ & ST428-443A & 207 bp \\
\hline $\begin{array}{l}\text { FLAG-hEP4 } \\
\text { ST428-443A }\end{array}$ & $\begin{array}{l}\text { Hind FLAG } \\
\text { EP4 } \mathrm{f} \\
\text { EP4 Xba r }\end{array}$ & $\begin{array}{l}\text { 5'-Fragment ST428- } \\
\text { 443A } \\
\text { 3'-Fragment ST428- } \\
\text { 443A }\end{array}$ & ST428-443A & $1519 \mathrm{bp}$ \\
\hline
\end{tabular}




$\begin{array}{ccccc}\text { hEP4 CT } & \text { SM 2f } & \text { pBluescript hEP4 CT } & \text { ST354-366A } & \\ \text { ST 354-369; } & \text { SM 5r } & \text { ST335-338; 369-382A } & \text { ST400-405A } & 182 \text { bp } \\ \text { 400-405A } & & & & \\ \text { hEP4 CT } & \text { SM 4f } & \text { pBluescript hEP4 CT } & \text { ST389-392A } & \\ \text { ST389-394; } & \text { SM 7r } & \begin{array}{c}\text { ST335-338; 369-382; } \\ \text { 428-443A }\end{array} & \text { ST448-460A } & 245 \text { bp } \\ \text { 428-460A } & & \text { pBluescript hEP4 CT } & & \\ \text { hEP4 CT } & \text { SM 7f } & \text { ST335-338; 369-382; } & \text { ST448-484A } & 139 \text { bp } \\ \text { ST448-484A } & \text { SM 8r } & \text { 428-443A } & & \\ \text { hEP4 CT } & & \text { hEP4 CT ST389-394; } & \text { ST389-394 } & 337 \text { bp } \\ \text { ST389-394; } & \text { SM 4f } & \text { 428-460A hEP4 CT } & 428-484 A & \\ \text { 428-484A } & \text { SM 8r } & \text { ST448-484A } & & \\ \text { hEP4 CT } & \text { SM 4f } & \text { pBluescript hEP4 CT } & \text { ST389-392A } & 337 \text { bp } \\ \text { ST389-484A } & \text { SM 8r } & \text { ST335-382; 400-484A } & & \end{array}$

Tab. 4: Restriktionsansätze zur Generierung der verschiedenen hEP4 CT-cDNAFragmente. 5' und 3' geben die Enzyme an, mit denen das Fragment geschnitten wurde. $5^{\prime}$ = Schnittstelle 5' des cDNA-Fragmentes 3' = Schnittstelle 3' des cDNA-Fragmentes.

\begin{tabular}{llccc}
\hline & \multicolumn{1}{c}{ PCR-Fragment } & $\mathbf{5}^{\prime}$ & $\mathbf{3}^{\prime}$ & Puffer \\
\hline $\mathbf{1}$ & hEP4 CT ST335-338A & Kpn I & Xba I & MULTI CORE $^{\text {TM }}$ \\
$\mathbf{2}$ & hEP4 CT ST335-338; 369-382A & Kpn I & Sma I & MULTI CORE $^{\mathrm{TM}}$ \\
$\mathbf{3}$ & hEP4 CT ST428-443A & Sty I & Xba I & D \\
$\mathbf{4}$ & hEP4 CT ST354-369; 400-405A & Dra II & Sty I & F \\
$\mathbf{5}$ & hEP4 CT ST389-394; 428-484A & Sma I & Xba I & MULTI CORE \\
$\mathbf{6}$ & hEP4 CT ST389-484A & Sma I & Xba I & MULTI CORE \\
\hline & cDNA-Fragment & & & \\
\hline $\mathbf{7}$ & hEP4 CT & Dra II & Sma I & J \\
$\mathbf{8}$ & hEP4 CT ST335-382A & Kpn I & Sma I & J \\
\hline
\end{tabular}


Tab. 5: Restriktionsansätze zur Generierung der verschiedenen pBluescript hEP4 CT Vektor-Fragmente. 5' und 3' geben die Enzyme an, mit denen das Fragment geschnitten wurde. 5' = Schnittstelle 5' des cDNA-Fragmentes 3' = Schnittstelle 3' des cDNAFragmentes.

\begin{tabular}{|c|c|c|c|c|}
\hline & $\begin{array}{l}\text { cDNA-Fragment tragende pBluescript- } \\
\text { Vektoren }\end{array}$ & $5^{\prime}$ & $3^{\prime}$ & Puffer \\
\hline 1 & pBluescript & Kpn I & Xba I & MULTI CORE $^{\text {TM }}$ \\
\hline 2 & pBluescript hEP4 CT ST335-338A & Kpn I & Sma I & MULTI CORE ${ }^{T M}$ \\
\hline 3 & pBluescript hEP4 CT ST335-338; 369-382A & Sty 1 & Xba I & $\mathrm{D}$ \\
\hline 4 & $\begin{array}{l}\text { pBluescript hEP4 CT ST335-338; 369-382; } \\
\text { 428-443A }\end{array}$ & Dra II & Sty I & $\mathrm{F}$ \\
\hline 5 & pBluescript hEP4 CT ST335-382; 400-443A & Sma I & Xba I & MULTI CORE ${ }^{\text {TM }}$ \\
\hline 6 & pBluescript hEP4 CT ST335-394; 428-484A & Sma I & Xba I & MULTI CORE ${ }^{T M}$ \\
\hline 7 & pBluescript hEP4 CT & SnaB I & Sty I & B \\
\hline 8 & pBluescript hEP4 CT ST335-484A & SnaB I & Sty 1 & $\mathrm{~B}$ \\
\hline 9 & pBluescript hEP4 CT & Dra II & Sma I & J \\
\hline 10 & pBluescript hEP4 CT ST335-484A & Kpn I & Sma I & $\mathrm{J}$ \\
\hline
\end{tabular}

\subsubsection{Klonierung der gereinigten Fragmente in pBluescript}

Die durch PCR synthetisierten cDNA-Fragmente sowie die verwendeten Matrizen-Vektoren (Tab. 3) wurden mit den in Tabelle 4 und Tabelle 5 angegebenen Restriktionsenzymen geschnitten (siehe 3.4.2).

Die Restriktionsansätze wurden, wie unter 3.2 beschrieben, elektrophoretisch getrennt und die entsprechenden Fragmente aus den Agarose-Gelen isoliert (siehe 3.3). Anschließend wurden die DNA-Konzentration photometrisch quantifiziert (siehe 3.2.3) und die entsprechenden Mengen in eine Ligation (siehe 3.4.3) eingesetzt (Tab. 6). 
Tab. 6: Ligationsansätze zur Synthese der verschiedenen C-terminalen cDNAFragmente. Gezeigt sind die jeweiligen cDNA-Fragmente und die mit den gleichen Enzymen geschnittenen pBluescript-Vektoren (eckige Klammer), sowie das daraus resultierende Ligationsprodukt.

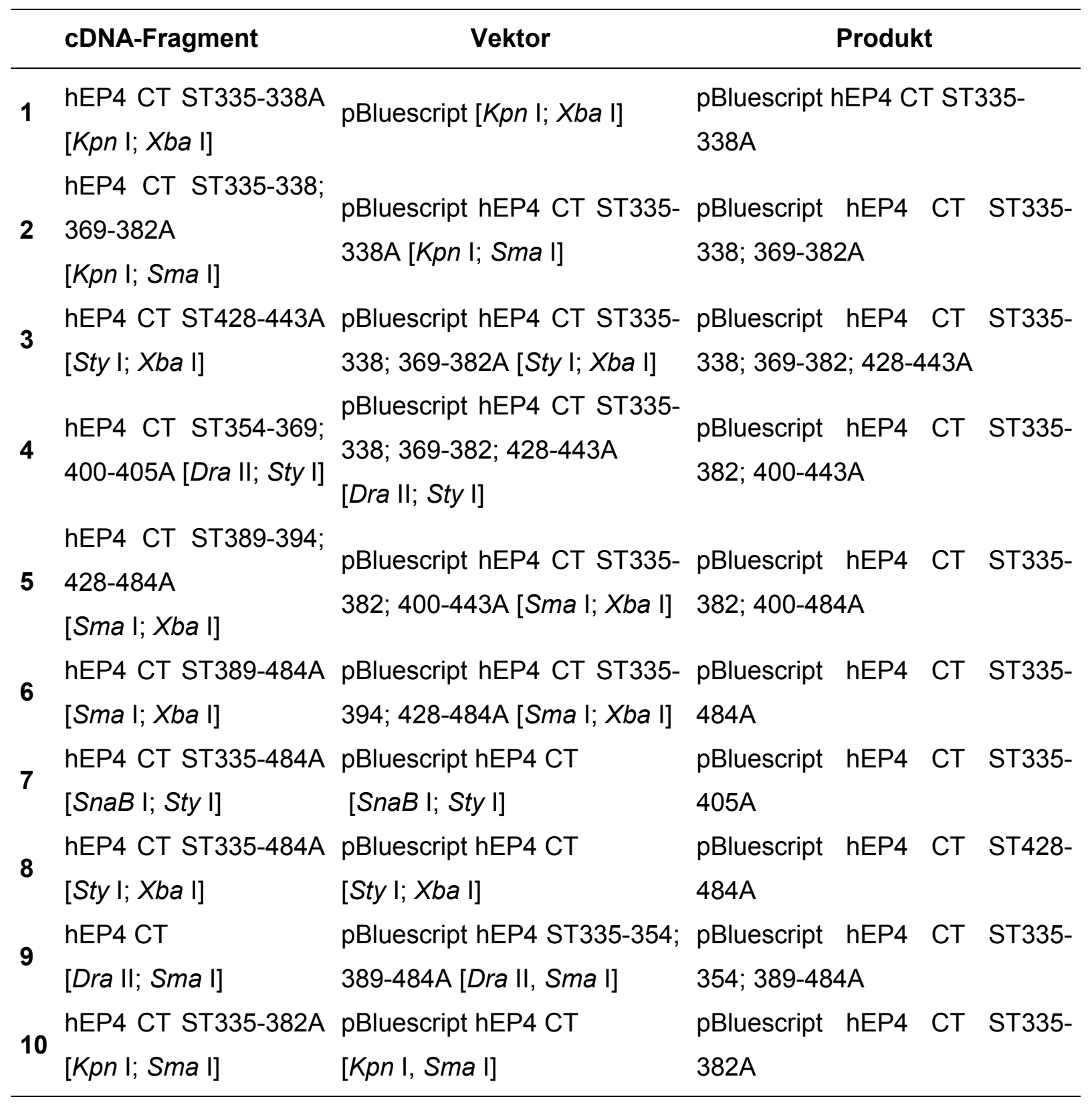

Mit den Ligationsprodukten wurden E. coli XL1 (blue) Zellen transformiert (siehe 3.6), die Plasmid-DNA aus Übernachtkulturen isoliert (siehe 3.7) und die Klonierung durch Restriktionsenzymspaltung mit SnaB I und Xba I in Puffer B überprüft (siehe 3.9). 


\subsection{Klonierung der gesamten FLAG-hEP4 wt-Rezeptor-cDNA sowie der mutierten Rezeptor-cDNAs in den pcDNA3-Vektor}

\subsubsection{Puffer und Enzyme}

Enzyme: Hind III, SnaB I und Xba I sowie Puffer B (siehe 2.9.1)

\subsubsection{Vorbereitung der cDNA-Fragmente und Ligation}

Da der pcDNA3-Vektor über eine $S n a B$ I-Restriktionsschnittstelle verfügte und das Restriktionsenzym SnaB I Fragmente mit nicht überlappenden Enden generiert, wären nach Spaltung des pcDNA3 FLAG-hEP4 wt-R drei Fragmente entstanden von denen eines 5' und 3' nicht überlappende Enden gehabt hätte. Da die Orientierung dieses Fragmentes während der Klonierung nicht bestimmt werden konnte, wurde die FLAG-hEP4 wt-R-cDNA zuerst aus dem pcDNA3-Vektor über Hind III und Xba I herausgeschnitten und anschließend mit SnaB I gespalten. Dadurch entstanden Fragmente mit verschiedenen flankierenden Schnittstellen am 5' und am 3' Ende, durch die die richtige Orientierung in der Ligation gewährleistet wurde. Dazu wurden je $3 \mu \mathrm{g}$ der verschiedenen pBluescript-Konstrukte (siehe Tab. 6) mit den Restriktionsenzymen SnaB I und Xba I und $2 \mu \mathrm{g}$ der zuvor aus pcDNA3 FLAG-hEP4 wtR Plasmid-DNA über Hind III und Xba I isolierten FLAG-hEP4 wt-R-cDNA mit SnaB I geschnitten (siehe 3.4.2), in Agarose-Gelen aufgetrennt (siehe 3.2) und die mutierten 3'hEP4 CT- und das 5'-FLAG-hEP4 wt-R-Fragmente daraus isoliert (siehe 3.3). In einer anschließenden 3'-Fragment-Ligation wurde das 5'-Fragment (Hind III, SnaB I) und die aus pBluescript herausgeschnittenen 3'-Fragmente (SnaB I, Xba I) der FLAG-hEP4-R-cDNAs in den zuvor mit Hind III und Xba I linearisierten pcDNA3-Vektor (Hind III, Xba I), ligiert (siehe 3.4.3), E coli XL1 (blue)-Zellen transformiert (siehe 3.6) und die Plasmid-DNA aus einer Übernachtkultur isoliert (siehe 3.7). Die Ligation wurde durch Restriktionsenzymspaltung (siehe 3.9) und Sequenzierung (siehe 3.10) überprüft. Aus den positiv getesteten Klonen wurden erneut Übernachtkulturen angesetzt und anschließend die Plasmid-DNA im MaxiMaßstab isoliert (siehe 3.8). 


\section{ZELLBIOLOGISCHE UND BIOCHEMISCHE METHODE}

3.14 Eukaryote Expression der gentechnisch modifizierten Rezeptorproteine in HEK293-Zellen

Soweit nicht anders angegeben, wurden alle Puffer und Lösungen mit entmineralisiertem $\mathrm{H}_{2} \mathrm{O}$ angesetzt, sterilfiltriert und bei $4^{\circ} \mathrm{C}$ gelagert.

\subsubsection{Puffer und Lösungen}

$10 \times$ PBS-Stammlösung

$5000 \mathrm{ml}$

$\mathrm{NaCl}$

$1370 \mathrm{mM}$

$400,31 \mathrm{~g}$

$\mathrm{KCl}$

$27 \mathrm{mM}$

$10,07 \mathrm{~g}$

$\mathrm{KH}_{2} \mathrm{PO}_{4}$

$15 \mathrm{mM}$

$10,27 \mathrm{~g}$

$\mathrm{Na}_{2} \mathrm{HPO}_{4}$

$80 \mathrm{mM}$

$56,78 \mathrm{~g}$

$\mathrm{pH} 7,3$

Die Lösung wurde autoklaviert und bei Raumtemperatur gelagert.

DMEM-Medium

$5000 \mathrm{ml}$

DMEM-Trockenpulver

$66,8 \mathrm{~g}$

$\mathrm{NaHCO}_{3}$

$44 \mathrm{mM}$

$18,5 \mathrm{~g}$

Die Lösung wurde mit $\mathrm{HCl}$ auf $\mathrm{pH} 7,25$ eingestellt, sterilfiltriert und bei $4^{\circ} \mathrm{C}$ gelagert.

DMEM-komplett

$500 \mathrm{ml}$

DMEM

$445 \mathrm{ml}$

FCS

$10 \%(\mathrm{v} / \mathrm{v})$

$50 \mathrm{ml}$

Penicillin/Streptomycin-Lösung

$1 \%(v / v)$

$5 \mathrm{ml}$

Das Medium wurde bei $4^{\circ} \mathrm{C}$ gelagert.

$10 \times$ Trypsin-EDTA-Stammlösung

$100 \mathrm{ml}$

Trypsin

$0,5 \%(\mathrm{w} / \mathrm{v})$

$500 \mathrm{mg}$

EDTA

$5,4 \mathrm{mM}$

$158 \mathrm{mg}$

$\mathrm{NaCl}$

$145 \mathrm{mM}$

$850 \mathrm{mg}$

Die Lösung wurde sterilfiltriert und bei $-20^{\circ} \mathrm{C}$ gelagert.

Trypsin-Lösung

Trypsin-EDTA-Lösung

Die Lösung wurde steril angesetzt und bei $-20^{\circ} \mathrm{C}$ gelagert. 
$\mathrm{H}_{2} \mathrm{O}$

Die Lösung wurde sterilfiltriert und in Aliquots von $10 \mathrm{ml}$ bei $-20^{\circ} \mathrm{C}$ gelagert.

$\underline{2 \times \text { BBS-Lösung }}$

BES

$\mathrm{NaCl}$

$\mathrm{Na}_{2} \mathrm{HPO}_{4} \times 2 \mathrm{H}_{2} \mathrm{O}$

$$
50 \mathrm{mM}
$$$$
280 \mathrm{mM}
$$$$
1,5 \mathrm{mM}
$$

$100 \mathrm{ml}$ $1,07 \mathrm{~g}$

Die Lösung wurde auf $\mathrm{pH} 6,96$ eingestellt, sterilfiltriert und bei $-20^{\circ} \mathrm{C}$ gelagert.

$1000 \times 25$-Hydroxycholesterol-Lösung

$10 \mathrm{ml}$

25-Hydroxycholesterol

$0,25 \%(w / v)$

$25 \mathrm{mg}$

Ethanol

ad $10 \mathrm{ml}$

Die Lösung wurde sterilfiltriert und bei $-20^{\circ} \mathrm{C}$ gelagert.

\subsubsection{Kultivierung von HEK293-Zellen}

HEK293-Zellen wurden in DMEM-komplett bei $5 \% \mathrm{CO}_{2}$ und $37^{\circ} \mathrm{C}$ bis zur Konfluenz auf $75 \mathrm{~cm}^{2}$-Flaschen kultiviert. $24 \mathrm{~h}$ vor der Transfektion wurden sie neu ausplattiert. Hierzu wurde das Medium entfernt und die Zellen einmal mit $10 \mathrm{ml}$ PBS gewaschen. Danach wurden 1,5 ml Trypsin-Lösung/75 $\mathrm{cm}^{2}$-Flasche zugegeben und die Zellen im Brutschrank bei $37^{\circ} \mathrm{C} 5$ min inkubiert. Nach der Inkubation wurden die Zellen durch leichtes Klopfen von der Kulturflasche abgelöst und das Trypsin mit $10 \mathrm{ml}$ DMEM-komplett inaktiviert. Die Suspension wurde in ein $15 \mathrm{ml}$-Polypropylenröhrchen überführt, bei $1000 \mathrm{rpm}(140 \times \mathrm{g}) 5 \mathrm{~min}$ in der Hettich-Zentrifuge Universal16 zentrifugiert und der Überstand entfernt. Die Zellen wurden in DMEM-komplett resuspendiert und die Zellzahl mit Hilfe der Neubauer-Zählkammer bestimmt.

\subsubsection{Transiente Transfektion von HEK293-Zellen nach der modifizierten Calcium- Phosphat-Methode}

Die Transfektion der HEK293-Zellen mit der modifizierten Calcium-Phosphat-Methode wurde nach dem Protokoll von Chen und Okoyama (1987) mit Modifikationen durchgeführt.

HEK293-Zellen wurden auf $58 \mathrm{~cm}^{2}$-Platten mit einer Dichte von $4 \times 10^{6}$ Zellen ausplattiert und nach $24 \mathrm{~h}$ mit der modifizierten Calcium-Phosphat-Methode transfiziert. Hierzu wurden die Zellen einmal mit $10 \mathrm{ml}$ DMEM ohne Zusätze gewaschen und anschließend mit $10 \mathrm{ml}$ DMEM + 5\% (v/v) Rinderserum + 0,1\% (v/v) 1000 x 25-Hydroxycholesterol-Lösung versetzt, was die Zellen zur DNA-Aufnahme vorbereitete. $17 \mu \mathrm{g}$ zirkulärer Plasmid-DNA/58 $\mathrm{cm}^{2}$ - 
Platten wurden mit Wasser auf $585 \mu \mathrm{l}$ aufgefüllt und mit $65 \mu \mathrm{l} 2,5 \mathrm{M} \mathrm{CaCl}_{2}$-Lösung und $650 \mu \mathrm{l}$ 2 x BBS-Lösung versetzt. In der anschließenden Inkubationszeit von $20 \mathrm{~min}$ bei Raumtemperatur bildeten sich Calcium-Phosphat-DNA-Präzipitate, was durch leichte Trübung der Lösung angezeigt wurde. Die Lösung wurde anschließend tropfenweise auf die Zellen gegeben und die Kulturschale danach noch einmal geschwenkt. Die Aufnahme der DNA-Präzipitate erfolgte während der Inkubation für $3 \mathrm{~h}$ bei $37^{\circ} \mathrm{C}$ und $3 \% \mathrm{CO}_{2}$. Danach wurden die Zellen zum Entfernen der überschüssigen Präzipitate mit $10 \mathrm{ml}$ DMEM ohne Zusätze gewaschen und wieder mit 15 ml DMEM-komplett zur Proteinexpression kultiviert.

\subsubsection{Selektion stabil transfizierter HEK293-Zellen}

Stabil transfizierte Zellen haben die Plasmid-DNA dauerhaft in ihr Genom integriert und exprimieren das rekombinante Protein permanent.

HEK293-Zellen wurden auf $58 \mathrm{~cm}^{2}$-Platten mit einer Dichte von $4 \times 10^{6}$ Zellen ausplattiert und nach der modifizierten Calcium-Phosphat-Methode mit den verschiedenen RezeptorcDNAs transfiziert. $24 \mathrm{~h}$ nach der Transfektion wurde das Kulturmedium gegen ein Selektionsmedium ausgewechselt, welches zusätzlich $500 \mu \mathrm{g} \mathrm{G}-418 / \mathrm{ml}$ enthielt. Bei G-418 handelt es sich um ein dem Neomycin-verwandtes 2'-Desoxystreptamin-Antibiotikum, gegen das eukaryote Zellen empfindlich sind. Es kann durch Aminoglykosid-3'-PhosphoTransferase-Aktivitäten, welche von den Kanamycin- und Neomycinresistenzgenen codiert werden, inaktiviert werden. Das Neomycinresistenz-Gen war in dem Vektor pcDNA3 lokalisiert (Abb. 6) und sorgte bei stabiler Expression in den transfizierten HEK293-Zellen für eine Resistenz gegenüber G-418. Nach etwa sieben Tagen waren die nichttransfizierten Zellen abgestorben, während die resistenten Zellen zu Kolonien herangewachsen waren. Makroskopisch sichtbare Kolonien von mehr als 15 Zellen wurden mit einem sterilen Wattestäbchen vorsichtig abgenommen und in je eine Vertiefung einer 24-Well-Platte überführt. Der Zelltransfer wurde anschließend mikroskopisch überprüft. Wenn eine Vertiefung bis zur Konfluenz zugewachsen war, wurden die Zellen mit $100 \mu$ Trypsin-Lösung abgelöst und auf zwei $8,7 \mathrm{~cm}^{2}$-Platten bis zur Konfluenz weiterkultiviert. Von jedem Klon wurde die Expressionseffizienz durch einen Bindungsassay mit $\left[{ }^{3} \mathrm{H}\right]-\mathrm{PGE}_{2}$ (siehe 3.18) mit den Zellen einer 8,7 $\mathrm{cm}^{2}$-Platte ermittelt. Diejenigen monoklonalen Zellinien, die im Bindungsassay eine vergleichbare Oberflächenbindung aufwiesen, wurden ausgewählt, und in größerem Maßstab kultiviert, alle anderen positiven Klone wurden in flüssigem Stickstoff gelagert. Die Zellinien werden im folgenden nach den in ihnen stabil exprimierten Rezeptoren benannt. 


\subsubsection{Kryolagerung der stabilen Zellklone in flüssigem Stickstoff}

Da es durch sehr häufiges Passagieren zu einer Reduktion der Rezeptorexpression kommen kann und durch mögliche Kontaminationen Zellklone verloren gehen können, wurden sehr frühe Passagen der stabil exprimierenden Zellen in flüssigem Stickstoff eingefroren.

Zur Lagerung der Zellen in flüssigem Stickstoff wurden zunächst $1 \times 10^{6}$ Zellen auf einer $25 \mathrm{~cm}^{2}$-Kulturflasche ausgesät und bis zur Konfluenz kultiviert. Anschließend wurden die Zellen, wie unter 3.14 .2 beschrieben, von den Kulturflaschen gelöst, zentrifugiert und in 1,5 ml DMEM-komplett mit 10\% (v/v) DMSO resuspendiert. DMSO verhindert beim Einfrieren der Zellen, daß die entstehenden Wasserkristalle die Zellmembranen permeabilisieren. Die konzentrierte Zellsuspension wurde in Kryoröhrchen überführt und im Kühlschrank für 15 min langsam abgekühlt. Danach wurden die Zellen in einem Styroporbehälter bei $-70^{\circ} \mathrm{C}$ eingefroren und anschließend in flüssigen Stickstoff überführt, in dem die Zellen über mehrere Jahre gelagert werden können.

\subsection{Präparation von Gesamt-RNA aus stabil transfizierten HEK293-Zellen}

\subsubsection{Puffer und Lösungen}

Zur Isolierung der Gesamt-RNA aus stabil transfizierten HEK293-Zellen wurde das „SV Total RNA Isolation System" von Promega (Madison/ USA) benutzt.

\section{SV-RNA-Lysis-Buffer}

Guanidin-Isothiocyanat

$$
4 \mathrm{M}
$$

Tris/ $\mathrm{HCl}(\mathrm{pH} 7,5)$

$$
10 \mathrm{mM}
$$

$\beta$-Mercaptoethanol

$$
0,97 \%(v / v)
$$

Der Puffer war im „SV Total RNA Isolation System" enthalten und wurde nach Zugabe des $\beta$-Mercaptoethanols bei $4^{\circ} \mathrm{C}$ gelagert.

\section{SV-DNase-Stop-Solution}

Guanidin-Isothiocyanat

Tris/ $\mathrm{HCl}(\mathrm{pH} 7,5)$

$$
4 \mathrm{mM}
$$

Ethanol (95\%)

Die Lösung war im „SV Total RNA Isolation System" enthalten und wurde bei Raumtemperatur gelagert.

\section{SV-RNA-Wash-Solution}

Kaliumacetat

$60 \mathrm{mM}$

Tris/ $\mathrm{HCl}(\mathrm{pH} 7,5)$

$10 \mathrm{mM}$ 
Ethanol (95\%)

$60 \%(\mathrm{v} / \mathrm{v})$

$100 \mathrm{ml}$

Die Lösung war im „SV Total RNA Isolation System" enthalten und wurde bei Raumtemperatur gelagert.

Yellow-Core-Buffer

$\mathrm{NaCl}$

Tris/HCl $(\mathrm{pH} 7,5)$

$22,5 \mathrm{mM}$

Yellow dye

$0,0025 \%(w / v)$

Die Lösung war im „SV Total RNA Isolation System" enthalten und wurde bei Raumtemperatur gelagert.

DNase I (lyophilisiert)

Die DNase I war im „SV Total RNA Isolation System" enthalten, wurde mit Nuklease-freiem Wasser in einer Konzentration von $14000 \mathrm{U} / \mathrm{ml}$ gelöst und bei $-20^{\circ} \mathrm{C}$ gelagert.

$\underline{\mathrm{MnCl}_{2}}(0,09 \mathrm{M})$

$\mathrm{MnCl}_{2}$ war im „SV Total RNA Isolation System" enthalten und wurde bei Raumtemperatur gelagert.

\section{SV-RNA-Dilution-Buffer}

SV RNA Dilution Buffer war im „SV Total RNA Isolation System" enthalten und wurde bei Raumtemperatur gelagert. Der Hersteller machte keine Angaben zur Zusammensetzung dieses Puffers.

\section{$\underline{D E P C-\mathrm{H}_{2}} \underline{\mathrm{O}}$}

$\begin{array}{lll}\text { DEPC } & 0,1 \%(\mathrm{v} / \mathrm{v}) & 1 \mathrm{ml} / \mathrm{l}\end{array}$

Quarz-bidest $\mathrm{H}_{2} \mathrm{O}$ wurde mit $0,1 \%(\mathrm{v} / \mathrm{v})$ DEPC versetzt und für $12 \mathrm{~h}$ bei Raumtemperatur inkubiert, um evtl. vorhandene RNasen vollständig zu inaktivieren. Das verbliebene DEPC wurde durch Autoklavieren zersetzt.

\subsubsection{Isolierung von Gesamt-RNA aus stabil transfizierten HEK293-Zellen}

$1 \times 10^{6}$ HEK293-Zellen wurden bei $1000 \mathrm{rpm}(140 \times \mathrm{g})$ sedimentiert und das Medium entfernt. Die Zellen wurden in $175 \mu$ SV-RNA-Lysis-Buffer aufgenommen und lysiert. Anschließend wurden $350 \mu \mathrm{l}$ SV-RNA-Dilution-Buffer hinzugegeben, der Ansatz 3-4 mal durch Invertieren gemischt und im Wasserbad für $3 \mathrm{~min}$ bei $70^{\circ} \mathrm{C}$ inkubiert. Die Probe wurde bei $16000 \times g$ für 10 min zentrifugiert, der klare Überstand in ein neues Gefäß überführt, mit $200 \mu \mathrm{l} 95 \%$ (v/v) Ethanol versetzt und gemischt.

Das Gemisch wurde auf eine Mikrosäule aufgetragen und bei $16000 \times g$ für 1 min zentrifugiert. Dabei banden die Nukleinsäuren an die Säulenmatrix. Nach dem Waschen der 
Säule mit $600 \mu \mathrm{l}$ SV-RNA-Wash-Solution wurde diese mit einer Mischung aus $40 \mu \mathrm{l}$ YellowCore-Buffer, $5 \mu \mathrm{l}$ 0,09 $\mathrm{M} \mathrm{MnCl}_{2}$ und $5 \mu \mathrm{l}$ DNase I für 15 min bei Raumtemperatur inkubiert, um gebundene DNA zu entfernen. Danach wurden $200 \mu \mathrm{l}$ der SV-DNase-Stop-Solution auf die Säule pipettiert und bei $16000 \times g$ für 1 min zentrifugiert. Die Säule wurde zuerst mit $600 \mu \mathrm{l}$ und anschließend mit $250 \mu \mathrm{l}$ SV-RNA-Wash-Solution gewaschen. Danach wurde die RNA mit $100 \mu \mathrm{L}$ DEPC- $\mathrm{H}_{2} \mathrm{O}$ eluiert.

Die Konzentration bzw. Reinheit der RNA wurde durch die Messung der Extinktion bei 260 und $280 \mathrm{~nm}$ bestimmt. Dazu wurde eine 1:50 Verdünnung mit DEPC- $\mathrm{H}_{2} \mathrm{O}$ hergestellt und diese bei $260 \mathrm{~nm}$ und $280 \mathrm{~nm}$ gegen den Leerwert (nur DEPC- $\mathrm{H}_{2} \mathrm{O}$ ) in einer Quarzglasküvette gemessen.

Die in der Lösung verbliebenen Proteine besitzen bei $280 \mathrm{~nm}$ ein Absorptionsmaximum, somit kann die Reinheit der RNA durch den Quotienten $\Delta \mathrm{E}_{260 \mathrm{~nm}} / \Delta \mathrm{E}_{280 \mathrm{~nm}}$ charakterisiert werden. Es wurde nur RNA mit einem Quotienten > 1,7 verwendet und die Konzentration der RNA im Eluat nach folgender Formel berechnet:

$$
\text { RNA-Konzentration }[\mathrm{ng} / \mathrm{\mu l}]=\Delta \mathrm{E}_{260 \mathrm{~nm}} \times \text { Verdünnung } \times 40
$$

\subsection{6 cDNA-Synthese durch reverse Transkription}

Für die Synthese von cDNA wurde „Superscript ${ }^{\mathrm{TM}}$ II RT"-Reverse Transkriptase der Firma Invitrogen (Karlsruhe) verwendet, eine retrovirale Polymerase, die in Gegenwart eines DNAOligonukleotides (Oligo-d $\mathrm{dT}_{12-18}$ ) als Startermolekül und mRNA als Matrize, cDNA synthetisiert. Der Oligo-dT ${ }_{12-18}$-Primer lagert sich an den poly-A-Schwanz der mRNA und macht so die cDNA-Synthese möglich.

\subsubsection{Puffer und Lösungen}

$\underline{5 \times \text { Reaktionspuffer („First Strand"-Puffer) }}$

Tris/ $\mathrm{HCl}$

$250 \mathrm{mM}$

$30,275 \mathrm{~g} / \mathrm{l}$

$\mathrm{MgCl}_{2}$

$15 \mathrm{mM}$

$3,050 \mathrm{~g} / \mathrm{l}$

$\mathrm{KCl}$

$375 \mathrm{mM}$

$27,960 \mathrm{~g} / \mathrm{l}$

$\mathrm{pH} 8,3$

Die Lösung war der Reversen Transkriptase beigefügt.

Dithiothreitol (DTT)

DTT

$0,1 \mathrm{M}$

$0,157 \mathrm{~g} / \mathrm{l}$

Die Lösung war der Reversen Transkriptase beigefügt. 


\subsection{2 cDNA-Synthese}

In einem sterilen Eppendorfgefäß wurden $5 \mu \mathrm{g}$ Gesamt-RNA mit $1 \mu \mathrm{l}$ Oligo-dT ${ }_{12-18}(0,5 \mu \mathrm{g} / \mu \mathrm{l})$ gemischt und mit DEPC- $\mathrm{H}_{2} \mathrm{O}$ auf $12 \mu$ laufgefüllt. Zur Denaturierung von Sekundärstrukturen innerhalb der RNA wurde der Ansatz für 10 min auf $70^{\circ} \mathrm{C}$ erhitzt und danach sofort auf Eis schockgekühlt. Anschließend wurde der Ansatz mit je $4 \mu$ l Reaktionspuffer, $2 \mu$ DTT und $1 \mu \mathrm{l}$ $10 \mathrm{mM}$ dATP, dCTP, dGTP, dTTP versetzt und bei $42^{\circ} \mathrm{C}$ für 2 min vorinkubiert. Die cDNASynthese wurde durch Zugabe von $1 \mu \mathrm{l}(200 \mathrm{U})$ „Superscript ${ }^{\mathrm{TM}}$ II RT"-Reverse Transkriptase gestartet und für 50 min bei $42^{\circ} \mathrm{C}$ fortgeführt. Die Reaktion wurde durch Erhitzen des Ansatzes auf $70^{\circ} \mathrm{C}$ für 15 min gestoppt und der Ansatz bis zur weiteren Verwendung bei $-20^{\circ} \mathrm{C}$ gelagert.

\subsection{PCR-gestützt Analyse zur Identifikation der stabil transfizierten HEK293-Zellen}

\subsubsection{Puffer und Lösungen}

\section{$10 \times$ Taq DNA-Polymerase-Puffer}

$\begin{array}{lll}\mathrm{Tris} / \mathrm{HCl} & 100 \mathrm{mM} & \mathrm{pH} \mathrm{9,0} \\ \mathrm{MgCl}_{2} & 15 \mathrm{mM} & \\ \mathrm{KCl} & 500 \mathrm{mM} & \end{array}$

Der Puffer wurde von der Firma mitgeliefert und bei $-20^{\circ} \mathrm{C}$ gelagert.

$\underline{\mathrm{MgCl}_{2}}$ Stammlösung

$\mathrm{MgCl}_{2} 25 \mathrm{mM}$

Die $\mathrm{MgCl}_{2}$-Stammlösung wurde von der Firma mitgeliefert und bei $-20^{\circ} \mathrm{C}$ gelagert.

\subsubsection{Amplifizierung spezifischer cDNA-Fragmente}

Die aus HEK293-Zellen synthetisierte cDNA wurde in einer Verdünnung von 1:10 bis 1:100 in eine PCR-Reaktion (siehe 3.1.2) mit spezifischen Primern eingesetzt. Die PCR-Ansätze enthielten folgende Komponenten:

Matrize:

Vorwärts-Primer:

Rückwärts-Primer:

Desoxyribonukleosidtriphosphate:

DMSO:

Taq DNA-Polymerase:

$10 \times$ Taq DNA-Polymerase-Puffer:

$\mathrm{MgCl}_{2}$ :

Wasser:
cDNA-Verdünnung

EP4-SnaB I f bzw. SM $1 f^{*}$

EP4 Xba r bzw. EP4 Xba r mut **

dATP, dCTP, dGTP, dTTP

$3 \%(\mathrm{v} / \mathrm{v})$

$2 \mathrm{U}$

$1 \mathrm{x}$

$1,5 \mathrm{mM}$
$1: 10$ bis $1: 100$

$15 \mathrm{pmol}$

$15 \mathrm{pmol}$

$1 \mathrm{mM}$

$1,5 \mu \mathrm{l}$

$0,5 \mu \mathrm{l}$

$5 \mu \mathrm{l}$

$3 \mu \mathrm{l}$

ad $50 \mu \mathrm{l}$ 
* In PCR-Reaktionen, in denen mit cDNA von Zellen gearbeitet wurde, die den FLAG-hEP4 ST335-484A-, den FLAG-hEP4 ST335-405A-, den FLAG-hEP4 ST335-354; 389-484A-, den FLAG-hEP4 ST335-382A- oder den FLAG-hEP4 ST335-377; 379-484A-Rezeptor exprimierten, wurde der SM $1 \mathrm{f}$ als Vorwärts-Primer eingesetzt.

** In PCR-Reaktionen, in denen mit cDNA von Zellen gearbeitet wurde, die den FLAG-hEP4 ST335-484A-, den FLAG-hEP4 ST428-484A-, den FLAG-hEP4 ST335-354; 389-484A- oder den FLAG-hEP4 ST335-377; 382-484A-Rezeptor exprimierten, wurde der EP4 Xba r mut als Rückwärts-Primer eingesetzt.

Die PCR-Reaktionen wurden mit folgendem PCR-Programm durchgeführt: 3 min $95^{\circ} \mathrm{C}$, $35 \times\left(1 \min 95^{\circ} \mathrm{C}, 1 \min 55^{\circ} \mathrm{C}, 2 \min 72^{\circ} \mathrm{C}\right), 10 \min 72^{\circ} \mathrm{C}$. Die Amplifizierung der Produkte wurde in der Gelelektrophorese überprüft (siehe 3.2) und das erhaltene Produkt sequenziert (siehe 3.10).

\subsection{Nachweis der Rezeptorproteine durch $\left[{ }^{3} \mathrm{H}\right]-\mathrm{PGE}_{2}$-Bindung}

\subsubsection{Puffer und Lösungen}

Pefabloc-Stammlösung

Pefabloc

$200 \mathrm{mM}$

$2,3 \mathrm{~g} / 50 \mathrm{ml}$

Pefabloc wurde in Wasser gelöst und in Aliquots bei $-20^{\circ} \mathrm{C}$ gelagert.

Leupeptin-Stammlösung

Leupeptin wurde in einer Konzentration von $10 \mathrm{mg} / \mathrm{ml}$ gelöst und in Aliquots bei $-20^{\circ} \mathrm{C}$ gelagert.

Trypsin-Inhibitor-Stammlösung

Trypsin-Inhibitor wurde in einer Konzentration von $10 \mathrm{mg} / \mathrm{ml}$ gelöst und in Aliquots bei $-20^{\circ} \mathrm{C}$ gelagert.

Homogenisierungspuffer

$1000 \mathrm{ml}$

Saccharose

$250 \mathrm{mM}$

$85,58 \mathrm{~g}$

Tris/ $\mathrm{HCl}$

$10 \mathrm{mM}$

EDTA

$1 \mathrm{mM}$

$\mathrm{MgCl}_{2}$

$10 \mathrm{mM}$

$10 \mathrm{ml} 1 \mathrm{M}$ Stlsg, $\mathrm{pH} 7,5$

$2 \mathrm{ml} \mathrm{0,5} \mathrm{M} \mathrm{Stlsg}$

$5 \mathrm{ml} 1 \mathrm{M}$ Stlsg

Der Puffer wurde auf $\mathrm{pH} 7,5$ eingestellt bei $4^{\circ} \mathrm{C}$ gelagert.

Pro $100 \mathrm{ml}$ wurden als Protease-Inhibitoren frisch hinzugefügt:

Pefabloc

$0,2 \mathrm{mM}$

$100 \mu \mathrm{l} 200 \mathrm{mM}$ Stlsg

Leupeptin

$10 \mu \mathrm{g} / \mathrm{ml}$

$100 \mu \mathrm{l} 10 \mathrm{mg} / \mathrm{ml}$ Stlsg

Trypsin-Inhibitor

$10 \mu \mathrm{g} / \mathrm{ml}$

$100 \mu \mathrm{l} 10 \mathrm{mg} / \mathrm{ml}$ Stlsg 
Bindungspuffer

MES

$10 \mathrm{mM}$

$\mathrm{MgCl}_{2}$

$10 \mathrm{mM}$

$10 \mathrm{ml} 2 \mathrm{M}$ Stlsg

EDTA

$1 \mathrm{mM}$

$4 \mathrm{ml} \mathrm{0,5}$ MStlsg

Der Puffer wurde mit $\mathrm{NaOH}$ auf $\mathrm{pH} 6,2$ eingestellt und bei $4^{\circ} \mathrm{C}$ gelagert.

Für die Membranpräparation wurden pro $\mathrm{ml}$ als Protease-Inhibitoren frisch hinzugefügt:

Pefabloc

Leupeptin

Trypsin-Inhibitor

Bradford-Reagenz

Serva Blue (Nr. 35050)

Phosphorsäure (85\%)

Ethanol (95\%)
$0,2 \mathrm{mM}$

$10 \mu \mathrm{g} / \mathrm{ml}$

$10 \mu \mathrm{g} / \mathrm{ml}$

$$
\begin{array}{r}
0,01 \%(w / v) \\
8,5 \%(w / v) \\
4,75 \%(v / v)
\end{array}
$$

BSA-Standard

Der BSA-Standard wurde in Aliquots bei $-20^{\circ} \mathrm{C}$ gelagert.

$\underline{P G E_{2}}$-Stammlösung

$\mathrm{PGE}_{2}$ wurde in einer Konzentration von $10 \mathrm{mM}$ in $70 \%$ (v/v) Ethanol gelöst und in Aliquots bei $-20^{\circ} \mathrm{C}$ gelagert.

\section{$\left[{ }^{3} \mathrm{H}\right]-\mathrm{PGE}_{2}$ Stammlösung}

$\left[{ }^{3} \mathrm{H}\right]-\mathrm{PGE}_{2}$ wurde in einer Konzentration von $621 \mathrm{nM}$ in $70 \%$ (v/v) Ethanol vom Hersteller geliefert und bei $-20^{\circ} \mathrm{C}$ gelagert.

\subsubsection{Membranpräparation}

Es wurden $3 \times 10^{6}$ Zellen auf $58 \mathrm{~cm}^{2}$-Platten bis zur Konfluenz kultiviert. Anschließend wurde das Medium abgesaugt, die Zellen einmal mit $10 \mathrm{ml}$ PBS gewaschen und die Zellkulturplatte $1 \mathrm{~min}$ auf Eis mit $1 \mathrm{ml}$ Homogenisierungspuffer inkubiert. Danach wurden die Zellen abgeschabt und in ein Schraubdeckelgefäß überführt, für weitere 20 min auf Eis inkubiert und durch mehrmaliges Aufziehen durch eine 0,4 mm-Kanüle aufgeschlossen und homogenisiert. Die Membransuspension wurde $30 \mathrm{~min}$ bei $4^{\circ} \mathrm{C}$ und $20000 \mathrm{rpm}$ (36 $700 \times \mathrm{g}$, SIGMA 3K30-Zentrifuge) zentrifugiert. Der Überstand wurde verworfen und das Sediment in $800 \mu \mathrm{l}$ Bindungspuffer mit Protease-Inhibitoren mit Hilfe einer Pipette und anschließend erneut durch mehrmaliges Aufziehen durch eine $0,4 \mathrm{~mm}$-Kanüle resuspendiert. Der 
Proteingehalt der Membransuspension wurde nach Bradford (siehe 3.18.3) bestimmt und die Suspension anschließend bei $-70^{\circ} \mathrm{C}$ gelagert.

\subsubsection{Proteinbestimmung nach Bradford (1976)}

Mit der Proteinbestimmung nach Bradford (1976) können Proteinkonzentrationen zwischen 1 und $10 \mu \mathrm{g}$ photometrisch bestimmt werden. Um im idealen Meßbereich messen zu können, wurden die Proben zwischen 1:2,5 und 1:5 verdünnt. $10 \mu \mathrm{l}$ der Verdünnung wurden mit $\mathrm{H}_{2} \mathrm{O}$ auf $100 \mu \mathrm{l}$ aufgefüllt und mit $1 \mathrm{ml}$ Bradford-Reagenz versetzt. Für den Leerwert wurden $100 \mu \mathrm{H} \mathrm{H}_{2} \mathrm{O}$ mit $1 \mathrm{ml}$ Bradford-Reagenz versetzt. Als Eichreihe dienten $1 \mu \mathrm{g}, 2 \mu \mathrm{g}, 4 \mu \mathrm{g}, 6 \mu \mathrm{g}$, $8 \mu \mathrm{g}$ und $10 \mu \mathrm{g}$ BSA. Es entwickelte sich innerhalb von $10 \mathrm{~min}$ eine Blau-Färbung, die mindestens $1 \mathrm{~h}$ stabil war und bei $578 \mathrm{~nm}$ photometrisch quantifiziert werden konnte.

\subsubsection{Nachweis der $\left[{ }^{3} \mathrm{H}\right]-\mathrm{PGE}_{2}$-Bindung in Membranen}

Die Bindungsreaktion wurde in Polypropylenröhrchen durchgeführt. Um die spezifische Bindung für einen Meßpunkt zu erhalten, wurde die Differenz zwischen unspezifischer und gesamter Bindung ermittelt. Für einen Meßpunkt wurden $25 \mu \mathrm{l} 20 \mathrm{nM}\left[{ }^{3} \mathrm{H}\right]-\mathrm{PGE}_{2}$ in Bindungspuffer für die gesamte Bindung und parallel der gleiche Ansatz mit zusätzlich $25 \mu \mathrm{l}$ $40 \mu \mathrm{M}$ nicht- $\left[{ }^{3} \mathrm{H}\right]$-markiertem $\mathrm{PGE}_{2}$ zur Bestimmung der unspezifischen Bindung vorgelegt und mit Bindungspuffer auf $50 \mu \mathrm{l}$ aufgefüllt. Die Bindungsreaktion wurde bei Raumtemperatur durch Zugabe von $50 \mu \mathrm{l}$ Membransuspension der stabil transfizierten Zellen mit einem Proteingehalt von ca. 0,5 $\mathrm{\mu g}$ Protein/ $\mu \mathrm{l}$ in Bindungspuffer gestartet. Der Ansatz wurde $1 \mathrm{~h}$ bei Raumtemperatur geschüttelt. Nach Ablauf der Inkubationszeit wurden die Membranen durch Vakuumfiltration über zuvor in Bindungspuffer angefeuchtete GF 52-Filter in einer Absaugvorrichtung vom Inkubationsansatz getrennt und dreimal mit $4 \mathrm{ml}$ kaltem Bindungspuffer gewaschen. Die Filter wurden abgenommen, in Scintillationsgefäße überführt und mit $5 \mathrm{ml}$ Hydroluma-Scintillator versetzt. Nach ca. 2 h, in denen die Chemilumineszenz abgeklungen war, wurde die Aktivität von gebundenem $\left[{ }^{3} \mathrm{H}\right]-\mathrm{PGE}_{2}$ im Flüssigkeitsscintillationszähler gemessen.

\subsection{Immunologischer Nachweis der Rezeptorproteine durch Westernblot-Analyse}

\subsubsection{Puffer und Lösungen}

Pefabloc-Stammlösung

siehe 3.18.1 
Leupeptin-Stammlösung

siehe 3.18 .1

Trypsin-Inhibitor-Stammlösung

siehe 3.18 .1

FLAG-Solubilisierungspuffer

$1000 \mathrm{ml}$

HEPES

$50 \mathrm{mM}$

$11,9 \mathrm{~g}$

EDTA

$5 \mathrm{mM}$

$1,5 \mathrm{~g}$

$\mathrm{NaCl}$

$150 \mathrm{mM}$

$8,8 \mathrm{~g}$

Triton X-100

$15 \%(\mathrm{v} / \mathrm{v})$

$10 \mathrm{ml}$

SDS

$0,05 \%(\mathrm{v} / \mathrm{v})$

$0,5 \mathrm{~g}$

Der Puffer wurde auf $\mathrm{pH}$ 7,5 eingestellt und danach wurden 0,42 g Natriumfluorid (10 mM) und $4,5 \mathrm{~g}$ Natriumpyrophosphat $(10 \mathrm{mM})$ zugegeben. Der Puffer wurde bei $4^{\circ} \mathrm{C}$ gelagert.

Pro ml wurden als Protease-Inhibitoren frisch hinzugefügt:

Pefabloc

Leupeptin

Trypsin-Inhibitor

$\underline{5 \times \text { SDS-Probenpuffer }}$

Tris

SDS

Glycerol

Bromphenolblau

$4 \times$ SDS-Probenpuffer

$5 \times$ SDS-Probenpuffer

$\beta$-Mercaptoethanol

Sammelgelpuffer

Tris

SDS
$0,2 \mathrm{mM}$ $10 \mu \mathrm{g} / \mathrm{ml}$

$10 \mu \mathrm{g} / \mathrm{ml}$ $1 \mu \mathrm{l} 200 \mathrm{mM}$ Stlsg $1 \mu \mathrm{l} 10 \mathrm{mg} / \mathrm{ml}$ Stlsg $1 \mu \mathrm{l} 10 \mathrm{mg} / \mathrm{ml}$ Stlsg

$50 \mathrm{ml}$ 1,25 ml 1 M Stlsg pH 6 $25 \mathrm{ml} 20 \%$ (w/v) Stlsg $14,35 \mathrm{ml} 87 \%$ (w/v) Stlsg $52 \mathrm{mg}$ $1 \mathrm{ml}$ $800 \mu \mathrm{l}$ $200 \mu \mathrm{l}$

$20 \%(v / v)$ $100 \mathrm{ml}$ $50 \mathrm{ml} 1 \mathrm{M}$ Stlsg $0,5 \mathrm{M}$ $0,4 \%(w / v)$ $4 \mathrm{ml} \mathrm{10 \% (w/v)} \mathrm{Stlsg}$

Der Puffer wurde mit $\mathrm{HCl}$ auf $\mathrm{pH}$ 6,8 eingestellt und bei $4^{\circ} \mathrm{C}$ gelagert.

$\underline{\text { Trenngelpuffer }}$

Tris

SDS
$1,5 \mathrm{M}$ $0,4 \%(w / v)$
$100 \mathrm{ml}$

$18,17 \mathrm{~g}$ $4 \mathrm{ml} 10 \%$ Stlsg

Der Puffer wurde mit $12 \mathrm{~N} \mathrm{HCl}$ auf $\mathrm{pH} 8,8$ eingestellt und bei $4^{\circ} \mathrm{C}$ gelagert. 


\section{Acrylamid-Lösung}

Bei der Acrylamid-Lösung handelt es sich um eine gebrauchsfertige, gasstabilisierte wäßrige $30 \%(\mathrm{v} / \mathrm{v})$ Acrylamidstammlösung mit $0,8 \%(\mathrm{w} / \mathrm{v})$ Bisacrylamid im Verhältnis 37,5:1 (rotiphorese Gel 30 der Firma Roth).

Ammoniumpersulfat-Lösung

$100 \mathrm{ml}$

Ammoniumpersulfat

$10 \%(w / v)$

$10 \mathrm{~g}$

Dle Lösung wurde bei $4^{\circ} \mathrm{C}$ gelagert.

Elektrophorese-Laufpuffer

$5000 \mathrm{ml}$

Tris

$25 \mathrm{mM}$

$15,45 \mathrm{~g}$

Glycin

$191 \mathrm{mM}$

$72,05 \mathrm{~g}$

SDS

$0,1 \%(w / v)$

$5 \mathrm{ml} \mathrm{10 \%} \mathrm{Stlsg}$

Der Puffer wurde bei Raumtemperatur gelagert.

Coomassie-Blue Fixierlösung

$500 \mathrm{ml}$

Coomassie-Brilliant Blue R 250

$0,1 \%(w / v)$

$0,5 \mathrm{~g}$

Essigsäure

$12,5 \%(\mathrm{v} / \mathrm{v})$

$62,5 \mathrm{ml}$

Methanol

$20 \%(\mathrm{v} / \mathrm{v})$

$100 \mathrm{ml}$

Die Lösung wurde durch einen Faltenfilter filtriert und bei Raumtemperatur gelagert.

Coomassie-Entfärbelösung

$500 \mathrm{ml}$

Essigsäure

$10 \%(\mathrm{v} / \mathrm{v})$

$50 \mathrm{ml}$

Methanol

$40 \%(\mathrm{v} / \mathrm{v})$

$200 \mathrm{ml}$

Die Lösung wurde bei Raumtemperatur gelagert.

Blottransferpuffer A

$1000 \mathrm{ml}$

Tris

$300 \mathrm{mM}$

$300 \mathrm{ml} 1 \mathrm{M}$ Stlsg

SDS

$0,1 \%(w / v)$

$10 \mathrm{ml} \mathrm{10 \%} \mathrm{Stlsg}$

Methanol

$20 \%(\mathrm{v} / \mathrm{v})$

$200 \mathrm{ml}$

Der Puffer mit dem pH Wert von 11,5 wurde bei Raumtemperatur gelagert.

Blottransferpuffer B

$1000 \mathrm{ml}$

Tris

$25 \mathrm{mM}$

$25 \mathrm{ml} 1 \mathrm{M}$ Stlsg

SDS

$0,1 \%(w / v)$

$10 \mathrm{ml} \mathrm{10 \%} \mathrm{(w/v)} \mathrm{Stlsg}$

Methanol

$20 \%(\mathrm{v} / \mathrm{v})$

$200 \mathrm{ml}$

Der Puffer mit dem pH Wert von 10,5 wurde bei Raumtemperatur gelagert. 
Blottransferpuffer C

$1000 \mathrm{ml}$

Tris/Borat

$25 \mathrm{mM}$

$25 \mathrm{ml} 1 \mathrm{M}$ Stlsg

SDS

$0,1 \%(w / v)$

$10 \mathrm{ml} \mathrm{10 \% (w/v)} \mathrm{Stlsg}$

Methanol

$20 \%(\mathrm{v} / \mathrm{v})$

$200 \mathrm{ml}$

Der Puffer wurde mit $1 \mathrm{M}$ Borsäure auf $\mathrm{pH}$ 9,0 eingestellt und bei Raumtemperatur gelagert.

Ponceau S-Färbelösung

$1000 \mathrm{ml}$

Ponceau S

$0,25 \%(w / v)$

$2,5 \mathrm{~g}$

Methanol

$40 \%(\mathrm{v} / \mathrm{v})$

$400 \mathrm{ml}$

Essigsäure

$15 \%(\mathrm{v} / \mathrm{v})$

$150 \mathrm{ml}$

Die Lösung wurde durch einen Faltenfilter filtriert und war mindestens 12 Monate verwendbar.

PBS-Tween-Waschpuffer

$1000 \mathrm{ml}$

PBS

$1 x$

Tween 20

$0,05 \%(v / v)$

$0,5 \mathrm{ml}$

Blockierungslösung

Magermilchpulver

$5 \%(w / v) \quad 5 \mathrm{~g} / 100 \mathrm{ml}$ PBS-Tween-Waschpuffer

Die Lösung wurde immer frisch angesetzt.

SuperSignal West Pico Chemiluminescent Substrate

Die beiden Nachweislösungen „Luminol/Enhancer Solution“ und "Stable Peroxide Solution“ wurden ohne Angaben des Herstellers (PIERCE) geliefert und bei $4^{\circ} \mathrm{C}$ gelagert.

\subsubsection{Immunpräzipitation der Rezeptorproteine}

Die die verschiedenen Rezeptor-exprimierenden HEK293-Zellen wurden 72 h auf $58 \mathrm{~cm}^{2}$ Kulturschalen inkubiert. Danach wurde das Medium entfernt, die Zellen einmal mit PBS gewaschen und $800 \mu \mathrm{l}$ FLAG-Solubilisierungspuffer mit Proteaseinhibitoren hinzupipettiert. Die Zellen wurden anschließend abgeschabt, die Zellsuspension in ein $1,5 \mathrm{ml}$ Reaktionsgefäß überführt und für $30 \mathrm{~min}$ bei $20000 \mathrm{rpm}(36700 \times \mathrm{g}$, SIGMA-Zentrifuge $3 \mathrm{~K} 30$, Rotor $12154-\mathrm{H} 3 \mathrm{~K} 30$ ) und $4^{\circ} \mathrm{C}$ zentrifugiert. Danach wurde der Überstand in ein neues 1,5 ml-Reaktionsgefäß überführt und mit $100 \mu \mathrm{l} 10 \%$ Sepharose 4-B in FLAGSolubilisierungspuffer und $1 \%(\mathrm{w} / \mathrm{v}) \mathrm{BSA}$ für $1 \mathrm{~h}$ in einem Überkopfschüttler bei $4^{\circ} \mathrm{C}$ inkubiert. Auf diese Weise wurden Proteine entfernt, die Antikörper-unabhängig (unspezifisch) an die Sepharose banden. Zusätzlich wurden parallel für jeden Ansatz $100 \mu$ l 10\% Protein GSepharose in FLAG-Solubilisierungspuffer und 1\% (w/v) BSA mit $15 \mu \mathrm{g}$ FLAG-M2-Antikörper zur Bindung des Antikörpers an die Protein G-Sepharose pipettiert und mitinkubiert. Nach der Inkubation wurden die Ansätze für 5 min bei 15000 rpm (20 600 x g, SIGMA-Zentrifuge 
$3 \mathrm{~K} 30$, Rotor $12154-\mathrm{H} 3 \mathrm{~K} 30$ ) und $4^{\circ} \mathrm{C}$ zentrifugiert und der Überstand in ein neues $1,5 \mathrm{ml}-$ Reaktionsgefäß überführt. Zu jedem Ansatz wurden $100 \mu \mathrm{l}$ der Protein G-Sepharose in FLAG-Solubilisierungspuffer und 1\% (w/v) BSA mit $15 \mu \mathrm{g}$ FLAG-M2 Antikörper pipettiert und die Ansätze wiederum für $2 \mathrm{~h}$ in einem Überkopfschüttler bei $4^{\circ} \mathrm{C}$ inkubiert. Danach wurden die Ansätze für 5 min bei 15000 rpm (20 600 x g, SIGMA-Zentrifuge 3K30, Rotor 12154-H $3 \mathrm{~K} 30$ ) und $4^{\circ} \mathrm{C}$ zentrifugiert, der Überstand verworfen und das Sediment fünfmal mit $1 \mathrm{ml}$ FLAG-Solubilisierungspuffer gewaschen. Während der Waschschritte wurde der Ansatz durch wiederholtes Zentrifugieren für $4 \mathrm{~min}$ bei $15000 \mathrm{rpm} \mathrm{(20} 600 \mathrm{x} \mathrm{g}$, SIGMA-Zentrifuge $3 \mathrm{~K} 30$, Rotor $12154-\mathrm{H} 3 \mathrm{~K} 30$ ) und $4^{\circ} \mathrm{C}$ sedimentiert. Zu dem Sediment wurde anschließend ein auf die spezifische Bindung (siehe 3.18.4) normalisiertes 1 x SDS-Probenpuffer-Volumen (siehe 3.19.1) mit 5\% (v/v) $\beta$-Mercaptoethanol pipettiert. Die Ansätze wurden bei $-20^{\circ} \mathrm{C}$ gelagert.

\subsubsection{Vorbereitung der Proben für die SDS-Polyacrylamid-Gelelektrophorese}

Die Ansätze wurden für $1 \mathrm{~h}$ unter Schütteln bei $37^{\circ} \mathrm{C}$ inkubiert, danach für weitere $10 \mathrm{~min}$ unter Schütteln auf $60^{\circ} \mathrm{C}$ erhitzt und dann für 5 min bei $13000 \mathrm{rpm}(16000 \mathrm{x} \mathrm{g})$ in der Tischzentrifuge zentrifugiert. Anschließend wurden die Proben auf ein $10 \%(\mathrm{w} / \mathrm{v})$ Polyacrylamid-Gel aufgetragen.

\subsubsection{Vorbereitung der Polyacrylamid-Gele für die SDS-PAGE}

Zur analytischen Trennung von Proteinen aufgrund ihres Molekulargewichtes wurden diskontinuierliche Polyacrylamidgele nach Laemmli (1970) eingesetzt. Die verwendeten Gele für den immunologischen Nachweis hatten eine Stärke von 1,0 mm und eine Abmessung von $8,5 \times 5,5 \mathrm{~cm}$ und wurden mit dem Elektrophorese-System Mini Protean II (BioRad) gegossen und betrieben. Die verwendeten Gele für die Auftrennung der [ $\left.{ }^{32} \mathrm{P}\right]$-ortho-Phosphat markierten Proteine hatten eine Stärke von 1,0 mm und eine Abmessung von $9 \times 14 \mathrm{~cm}$ und wurden mit einem am Institut hergestellen System betrieben. Die Glasplatten wurden mit Aceton gereinigt und mit zwei Abstandhaltern zwischen den Platten zusammengesetzt, abgedichtet und die $8,5 \times 5,5 \mathrm{~cm}$ großen Gele wie folgt gegossen (für die $9 \times 14 \mathrm{~cm}$ großen Gele wurden die Volumen der einzelnen Puffer und Lösungen entsprechend angepaßt):

Trenngel (10\% (w/v) PAA)

Acrylamid-Lösung

$3,3 \mathrm{ml}$

$\mathrm{H}_{2} \mathrm{O}$

$4,2 \mathrm{ml}$

Trenngelpuffer

$2,5 \mathrm{ml}$

Ammoniumpersulfat-Lösung

$75 \mu \mathrm{l}$

TEMED 
Die einzelnen Komponenten wurden gemischt und bis zu einer Höhe von 5,5 cm (bzw. $9 \mathrm{~cm})$ zwischen die Glasplatten gefüllt. Zur Glättung des Oberfläche wurde das Gel daraufhin mit $\mathrm{H}_{2} \mathrm{O}$-gesättigtem n-Butanol überschichtet. Nachdem das Trenngel vollständig polymerisiert war, wurde das n-Butanol entfernt, die Geloberfläche vorsichtig mit $\mathrm{H}_{2} \mathrm{O}$ gespült und mit einem Filterpapier getrocknet.

Anschließend wurde das Sammelgel wie folgt gegossen:

Sammelgel $(4,5 \%(w / v)$ PAA)

Acrylamid-Lösung

$\mathrm{H}_{2} \mathrm{O}$

Sammelgelpuffer

Ammoniumpersulfat-Lösung

TEMED

$$
\begin{array}{r}
0,75 \mathrm{ml} \\
3 \mathrm{ml} \\
1,25 \mathrm{ml} \\
50 \mu \mathrm{l} \\
15 \mu \mathrm{l}
\end{array}
$$

Die Lösungen wurde gemischt, bis zum oberen Rand zwischen die Glasplatten gefüllt und der Probenkamm luftblasenfrei eingesetzt. Nach $20 \mathrm{~min}$ wurde das $\mathrm{Gel}$ in die Elektrophoresekammer eingesetzt, diese mit Elektrophorese-Laufpuffer gefüllt, der Probenkamm unter Flüssigkeit entfernt und Luftblasen entfernt.

\subsubsection{Trennung der Membranproteine durch SDS-PAGE}

Die aufbereiteten Proben wurden mit einer Hamilton-Spitze in die Geltaschen gegeben. Als Molekulargewichts-Standard dienten $10 \mu \mathrm{l}$ des LMW-Standard. Die Elektrophorese erfolgte bei $15 \mathrm{~mA} / \mathrm{Gel}$ im Sammelgel bis die Proben konzentriert waren und anschließend bei $20 \mathrm{~mA} / \mathrm{Gel}$ im Trenngel. Sie wurde beendet, wenn die Bromphenolblaubande den unteren Rand des Trenngels erreicht hatte. Anschließend wurden die Gele entweder für die Detektion der metabolisch $\left[{ }^{32} \mathrm{P}\right]$-ortho-Phosphat-markierten Proteine in Coomassie-BlueFixierlösung angefärbt, fixiert und getrocknet oder die getrennten Proteine für die immunologische Detektion auf eine PVDF-Membran transferiert.

\subsubsection{Fixierung mit Coomassie-Blue-Fixierlösung und Trocknung der Gele für den Nachweis der metabolisch [ $\left.{ }^{32} \mathrm{P}\right]$-ortho-Phosphat markierten Rezeptorproteine}

Nach der Gelelektrophorese wurde das Sammelgel abgetrennt, die linke obere Ecke des Trenngels zur Markierung entfernt und die aufgetrennten Proteine zur Kontrolle für $30 \mathrm{~min}$ in Coomassie Blue-Fixierlösung angefärbt und das Gel fixiert. Anschließend wurde die

Fixierlösung durch Waschen mit Coomassie-Entfärbelösung wieder entfernt, das Gel in Einmachfolie eingelegt und für $2 \mathrm{~h}$ bei $65^{\circ} \mathrm{C}$ unter Vakuum getrocknet. 


\subsubsection{Transfer der getrennten Proteine auf PVDF-Membranen durch Elektroblotting für den immunologischen Nachweis der Rezeptorproteine}

Nach der Gelelektrophorese wurde das Sammelgel abgetrennt, die linke obere Ecke des Trenngels zur Markierung entfernt und das Gel für 20 min in Blottransferpuffer $C$ äquilibriert. Währenddessen wurden eine PVDF-Membran und vier Whatman-Filter ( $3 \mathrm{~mm})$ auf das entsprechende Gelmaß $(8,5$ x 5,5 cm) zugeschnitten und die linke obere Ecke der Membran ebenfalls markiert. Nachfolgend wurde die PVDF-Membran kurz in reinem Methanol geschwenkt, wodurch sie gleichmäßig angefeuchtet wurde. Danach wurde die Membran 2 min in $\mathrm{H}_{2} \mathrm{O}$ bidest. gespült und anschließend in Blottransferpuffer $\mathrm{B}$ für 15 min äquilibriert.

Der Blotaufbau wurde auf der Anodenplatte der Blotvorrichtung durchgeführt. Es mußte darauf geachtet werden, die einzelnen Schichten möglichst luftblasenfrei aufzulegen. Zuerst wurde ein Filterpapier in Blottransferpuffer $A$ angefeuchtet und aufgelegt. Darauf wurde ein zuvor mit Blottransferpuffer B benetztes Filterpapier gelegt. Auf die beiden Filter wurde die PVDF-Membran vorsichtig aufgelegt und auf diese dann das Polyacrylamidgel, so daß die beiden markierten Ecken übereinander lagen. Abschließend wurden zwei zuvor in Blottransferpuffer $C$ angefeuchtete Filter auf das Gel geschichtet und der Aufbau mit einem Glasröhrchen vorsichtig komprimiert, um eventuell noch vorhandene Luftblasen und überschüssige Flüssigkeit zu entfernen. Nun wurde die Kathodenplatte vorsichtig aufgelegt. Der Transfer erfolgte bei konstanter Stromstärke von $1,2 \mathrm{~mA} / \mathrm{cm}^{2}$ Gelfläche über einen Zeitraum von $45 \mathrm{~min}$.

\subsubsection{Nachweis der geblotteten Proteine durch Ponceau S-Färbung}

Nach Ablauf der Transferzeit wurde der Blotaufbau abgebaut, die PVDF-Membran mit einer Pinzette entnommen und in eine Schale mit Ponceau S-Färbelösung für die reversible Proteinfärbung gelegt. Die Membran wurde einige Minuten angefärbt und anschließend mit $\mathrm{H}_{2} \mathrm{O}$ bidest. gespült, bis die Hintergrundfärbung verschwunden war. Anschließend wurden die Banden des Molekulargewichtstandards und die Proteinspuren mit Nadelstichen markiert und die Membran in PBS-Tween-Waschpuffer entfärbt, wobei je nach Intensität der Färbung ein oder mehrere Pufferwechsel nötig waren.

\subsubsection{Immunologischer Nachweis der Rezeptorproteine durch Immunperoxidase- Färbung der geblotteten Proteine}

Zur Absättigung der unspezifischen Bindungsstellen wurde die Membran für $1 \mathrm{~h}$ bei Raumtemperatur in Blockierungslösung geschwenkt. Danach wurde die Membran zweimal 10 min mit PBS-Tween-Waschpuffer gewaschen und über Nacht bei $4^{\circ} \mathrm{C}$ unter Schwenken mit einem Antiserum gegen Epitope in der C-terminalen Domäne des hEP4-R in einer 
Verdünnung von $0,4 \mu \mathrm{g} / \mathrm{ml}$ in PBS-Tween-Waschpuffer mit $1 \%(\mathrm{w} / \mathrm{v})$ Magermilchpulver inkubiert. Nachfolgend wurde die Antikörperlösung entfernt, die Membran dreimal 15 min mit PBS-Tween-Waschpuffer gewaschen, $1 \mathrm{~h}$ mit Peroxidase-gekoppeltem Ziege-AntiKaninchen-Antikörper in einer Verdünnung von 1:10 000 in PBS-Tween-Waschpuffer mit 1\% (w/v) Milchpulver inkubiert und anschließend die Membran wie zuvor gewaschen. Der Nachweis wurde durch eine Chemilumineszenz-Reaktion mit dem ChemilumineszenzSubstrat „SuperSignal ${ }^{R}$ West Pico Chemiluminescence Substrate“ der Firma Pierce (Rochford, USA) durchgeführt. Dazu wurden Lösung 1 und 2 zu gleichen Teilen zu einem Endvolumen von 2 ml/PVDF Membran gemischt und auf die Membran aufgetropft. Nach 5 min wurde die Membran luftblasenfrei in Frischhaltefolie eingepackt und überschüssige Lösung entfernt. Die entstandene Lumineszenz wurde direkt mit Hilfe des ChemiDoc ${ }^{\mathrm{TM}}$ Systems der Firma BioRad detektiert. Die spezifischen Banden wurden mit dem SoftwareProgramm Quantity One der Firma BioRad quantifiziert.

\subsection{Charakterisierung der Bindungseigenschaften der modifizierten Rezeptor- proteine im Vergleich mit dem nativen Rezeptorprotein}

\subsubsection{Puffer und Lösungen}

Bindungspuffer

Die Zusammensetzung des Puffers wurde unter 3.18.1 beschrieben.

\subsubsection{Bestimmung der Affinität und der maximalen Bindungskapazität der verschiedenen Rezeptorproteine durch Sättigungsbindungsstudien}

Zur Ermittlung der Rezeptordichte und Rezeptoraffinität der exprimierten Rezeptorproteine für $\mathrm{PGE}_{2}$ wurden Membranen von stabil transfizierten HEK293-Zellen mit $5 \mathrm{nM}\left[{ }^{3} \mathrm{H}\right]-\mathrm{PGE}_{2}$ und 0 bis $20 \mu \mathrm{M}$ nicht-[ $\left.{ }^{3} \mathrm{H}\right]$-markiertem $\mathrm{PGE}_{2}$ in einem $100 \mu \mathrm{l}$-Ansatz für $1 \mathrm{~h}$ bei Raumtemperatur, wie unter 3.18 .4 beschrieben, inkubiert. Die Reaktion wurde durch Vakuumfiltration beendet und die membrangebundene Radioaktivität im Flüssigkeitsscintillationszähler gemessen. Dabei wurde in jeder Sättigungsbindungsserie die unspezifische Bindung in Gegenwart von $20 \mu \mathrm{M} \mathrm{PGE}_{2}$ gemessen. Die Bindungskonstanten wurden durch nichtlineare Regression mit dem Programm LIGAND ermittelt. 
3.21 Nachweis der funktionellen Eigenschaften der Rezeptorproteine durch Bestimmung der $\mathrm{PGE}_{2}$-induzierten cAMP-Bildung

\subsubsection{Puffer und Lösungen}

$\underline{\text { PBS }}$

$137 \mathrm{mM}$

$1000 \mathrm{ml}$

$\mathrm{NaCl}$

$2,7 \mathrm{mM}$

$8,006 \mathrm{~g}$

$\mathrm{KCl}$

$1,5 \mathrm{mM}$

$201 \mathrm{mg}$

$\mathrm{KH}_{2} \mathrm{PO}_{4}$

$8 \mathrm{mM}$

$205 \mathrm{mg}$

$\mathrm{Na}_{2} \mathrm{HPO}_{4}$

$1,136 \mathrm{~g}$

Die Lösung wurde auf pH 7,3 eingestellt und bei Raumtemperatur gelagert.

Pefabloc-Stammlösung

siehe 3.18 .1

Leupeptin-Stammlösung

siehe 3.18 .1

Trypsin-Inhibitor-Stammlösung

siehe 3.18 .1

Hypotoner Homogenisierungspuffer

$1000 \mathrm{ml}$

Tris/ $\mathrm{HCl}$

$50 \mathrm{mM}$

$20 \mathrm{ml} 1 \mathrm{M} \mathrm{Stlsg}, \mathrm{pH} 7,5$

EDTA

$5 \mathrm{mM}$

$10 \mathrm{ml} \mathrm{0,5} \mathrm{M} \mathrm{Stlsg}$

Der Puffer wurde auf $\mathrm{pH} 7,5$ eigestellt und bei $4^{\circ} \mathrm{C}$ gelagert.

Pro $\mathrm{ml}$ wurden als Protease-Inhibitoren frisch hinzugefügt:

Pefabloc

$0,2 \mathrm{mM}$

$1 \mu \mathrm{l} 200 \mathrm{mM}$ Stlsg

Leupeptin

Trypsin-Inhibitor

$10 \mu \mathrm{g} / \mathrm{ml}$

$1 \mu \mathrm{l} 10 \mathrm{mg} / \mathrm{ml}$ Stlsg

$10 \mu \mathrm{g} / \mathrm{ml}$

$1 \mu \mathrm{l} 10 \mathrm{mg} / \mathrm{ml}$ Stlsg

Resuspendierungspuffer

$100 \mathrm{ml}$

Tris $/ \mathrm{HCl}$

$60 \mathrm{mM} \quad 1,667 \mathrm{ml} 1 \mathrm{M}$ Stlsg, $\mathrm{pH} 7,5$

Der Puffer wurde mit $\mathrm{HCl}$ auf $\mathrm{pH} 7,5$ eingestellt und bei $4^{\circ} \mathrm{C}$ gelagert.

Pro $\mathrm{ml}$ wurden als Protease-Inhibitoren frisch hinzugefügt:

Pefabloc

$0,2 \mathrm{mM}$

$1 \mu \mathrm{l} 200$ mM Stlsg

Leupeptin

$10 \mu \mathrm{g} / \mathrm{ml}$

$1 \mu \mathrm{l} 10 \mathrm{mg} / \mathrm{ml}$ Stlsg

Trypsin-Inhibitor

$10 \mu \mathrm{g} / \mathrm{ml}$

$1 \mu \mathrm{l} 10 \mathrm{mg} / \mathrm{ml}$ Stlsg

$\underline{P G E}_{2}$-Stammlösung

siehe 3.18.1 
GTP-Stammlösung

GTP

$10 \mathrm{mM}$

$53,5 \mathrm{mg}$

Die Lösung wurde in $60 \mathrm{mM}$ Tris $/ \mathrm{HCl} \mathrm{pH} 7,5$ angesetzt und bei $-20^{\circ} \mathrm{C}$ gelagert.

$\underline{\text { IBMX-Stammlösung }}$

$10 \mathrm{ml}$

IBMX

$100 \mathrm{mM}$

$222,2 \mathrm{mg}$

Die Lösung wurde in DMSO angesetzt und bei $-20^{\circ} \mathrm{C}$ gelagert.

$\underline{2 \times \text { Reaktionspuffer }}$

$100 \mathrm{ml}$

ATP

$4 \mathrm{mM}$

$220 \mathrm{mg}$

$\mathrm{MgCl}_{2}$

$20 \mathrm{mM}$

$407 \mathrm{mg}$

DTT

$2 \mathrm{mM}$

$25 \mathrm{mg}$

GTP

$20 \mu \mathrm{M}$

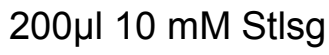

IBMX

$2 \mathrm{mM}$

$2 \mathrm{ml} 100 \mathrm{mM}$ Stlsg

EDTA

$4 \mathrm{mM}$

$117 \mathrm{mg}$

Creatin-Phosphat

$10 \mathrm{mM}$

$372 \mathrm{mg}$

Creatin-Kinase

$20 \mathrm{U} / \mathrm{ml}$

$0,6 \mathrm{mg}$

$60 \mathrm{mM}$ Tris/HCl pH 7,5 ad $10 \mathrm{ml}$

Der Puffer wurde mit $\mathrm{HCl}$ auf $\mathrm{pH} 7,5$ eingestellt und bei $-20^{\circ} \mathrm{C}$ gelagert.

Poly-L-Lysin-Lösung

$100 \mathrm{ml}$

Poly-L-Lysin

$0,1 \mathrm{mg} / \mathrm{ml}$

$10 \mathrm{mg}$

Die Lösung wurde in PBS angesetzt und bei $4^{\circ} \mathrm{C}$ gelagert.

cAMP-Inkubationsmedium

$1000 \mathrm{ml}$

HEPES

$15 \mathrm{mM}$

$3,57 \mathrm{~g}$

$\mathrm{NaCl}$

$140 \mathrm{mM}$

$8,18 \mathrm{~g}$

$\mathrm{KCl}$

$4,7 \mathrm{mM}$

$0,35 \mathrm{~g}$

$\mathrm{KH}_{2} \mathrm{PO}_{4}$

$1,2 \mathrm{mM}$

$0,35 \mathrm{~g}$

Glucose $\times 1 \mathrm{H}_{2} \mathrm{O}$

$11 \mathrm{mM}$

$2,09 \mathrm{~g}$

$\mathrm{CaCl}_{2}$

2,2 mM

$1,1 \mathrm{ml} / 2 \mathrm{M} \mathrm{Stlsg}$

Der Puffer wurde auf $\mathrm{pH} 7,5$ eingestellt und bei $4^{\circ} \mathrm{C}$ gelagert.

Aufschlußpuffer

$100 \mathrm{ml}$

$\mathrm{HCl}$

$10 \mathrm{mM}$

$0,5 \mathrm{ml} 2 \mathrm{~N} \mathrm{Stlsg}$

IBMX

$1 \mathrm{mM}$

$1 \mathrm{ml} 100 \mathrm{mM}$ Stlsg

Der Puffer wurde immer frisch angesetzt. 


\section{Forskolin-Stammlösung}

Forskolin wurde in einer Konzentration von $10 \mathrm{mM}$ in DMSO gelöst und in Aliquots bei $-20^{\circ} \mathrm{C}$ gelagert.

cAMP-RIA-Puffer

Acetat $50 \mathrm{mM}$

Azid $\quad 0,01 \%(w / v)$

Thimerosal ohne Angabe

$\mathrm{pH} 5,8$

$10 \mathrm{ml}$ der vom Hersteller mitgelieferten konzentrierten Pufferlösung wurden auf $500 \mathrm{ml}$ mit entmineralisiertem $\mathrm{H}_{2} \mathrm{O}$ aufgefüllt. Der Puffer wurde bei $4^{\circ} \mathrm{C}$ gelagert.

${ }^{125}$ I]CAMP (Tracer)

Adenosin-3',5'-Phosphorsäure-2'-O-Succinyl-3-[ $\left.{ }^{125} \mid\right]$ iodothyrosin-Methylester, lyophilisiert, $\sim 59 \mathrm{kBq}$

Der Tracer wurde vom Hersteller mitgeliefert, mit $11 \mathrm{ml}$ cAMP-RIA-Puffer rekonstituiert und bei $4^{\circ} \mathrm{C}$ gelagert.

\section{Antiserum (Anti-cAMP Antikörper)}

Kaninchen-Anti-Succinyl-cAMP-Serum, lyophilisiert mit 0,05\% (w/v) BSA

Das Antiserum wurde vom Hersteller mitgeliefert, mit $11 \mathrm{ml}$ cAMP-RIA-Puffer rekonstituiert und bei $4^{\circ} \mathrm{C}$ gelagert.

cAMP-Standard (,non-acetylation-protocol")

cAMP-Standard, lyophilisiert in $50 \mathrm{mM}$ Acetat mit 0,01\% (v/v) Thimerisol

Der cAMP-Standard wurde vom Hersteller mitgeliefert, mit $2 \mathrm{ml}$ cAMP-RIA-Puffer rekonstituiert und gemischt. Aus dieser Stammlösung (32 pmol/ml) wurde durch Verdünnung mit cAMP-RIA-Puffer eine Standardreihe (0,5-16 nM) hergestellt. Der cAMP-Standard wurde bei $4^{\circ} \mathrm{C}$ gelagert.

Amerlex-M Reagenz (immobilisierter 2. Antikörper)

Das Reagenz wurde vom Hersteller mitgeliefert und bei $4^{\circ} \mathrm{C}$ gelagert.

\subsubsection{Präparation von Membranen der Rezeptor exprimierenden HEK293-Zellen}

Die Membranpräparation wurde, wie unter 3.18 .2 beschrieben, durchgeführt, jedoch wurden die stabil transfizierten HEK293-Zellen in $1,5 \mathrm{ml}$ eiskaltem hypotonen Homogenisierungspuffer mit Protease-Inhibitoren (Leupeptin, Trypsin-Inhibitor, Pefablock) abgeschabt und vor der Zentrifugation mit einer 0,4 mm-Kanüle homogenisiert. Nach der Zentrifugation wurde der Überstand verworfen und die Membranen in $500 \mu \mathrm{l}$ 
Resuspendierungspuffer, wie unter 3.18 .2 beschrieben, resuspendiert und eine Proteinbestimmung durchgeführt (siehe 3.18.3). Die Konzentration wurde auf $1 \mu \mathrm{g}$ Membranprotein/ $\mu$ l eingestellt.

\subsubsection{Nachweis der Dosis-abhängigen cAMP-Bildung an Membranen Rezeptor- exprimierender HEK293-Zellen}

Zur Stimulation der cAMP-Bildung an Membranen wurden $50 \mu \mathrm{l} 2 \times$ Reaktionspuffer mit $20 \mu \mathrm{l}$ einer 5-fach konzentrierten $\mathrm{PGE}_{2}$-Lösung in Resuspendierungspuffer mit Konzentrationen von 0 oder $5 \times 10^{-5}-10^{-11} \mathrm{M} \mathrm{PGE}_{2}$ auf Eis pipettiert. Anschließend wurden $30 \mu \mathrm{l}$ Membransuspension zugegeben und der Reaktionsansatz für 5 min bei $37^{\circ} \mathrm{C}$ zur cAMPBildung inkubiert. Die Reaktion wurde durch Erhitzen des Ansatzes auf $95^{\circ} \mathrm{C}$ für 2 min abgestoppt. Anschließend wurden die Proben für $10 \mathrm{~min}$ bei $15000 \mathrm{rpm}(20600 \times \mathrm{g}$, SIGMA-Zentrifuge $3 \mathrm{~K} 30$, Rotor $12154-\mathrm{H} 3 \mathrm{~K} 30$ ) und $4^{\circ} \mathrm{C}$ zentrifugiert. Der Überstand, in dem sich das zu bestimmende cAMP befand, wurde 1:100 verdünnt und in den $\left[{ }^{125} \mathrm{I}\right]$-cAMP. Radioimmunoassay (siehe 3.21.5) eingesetzt oder bei $-70^{\circ} \mathrm{C}$ gelagert.

\subsubsection{Kinetik der Forskolin-abhängigen cAMP-Bildung in intakten Zellen}

8,7 $\mathrm{cm}^{2}$-Kulturplatten wurden $30 \mathrm{~min}$ mit $1 \mathrm{ml}$ Poly-L-Lysin-Lösung inkubiert und anschließend einmal mit PBS gewaschen. Poly-L-Lysin verbessert die Haftung der Zellen auf den Kulturplatten und vermeidet ein Wegwaschen der Zellen im Versuch. Danach wurden $2 \times 10^{5}$ der stabil transfizierten HEK293-Zellen auf die beschichteten Kulturplatten ausplattiert und für $48 \mathrm{~h}$ kultiviert. Anschließend wurde das Kulturmedium abgesaugt und die Zellen zweimal mit $1 \mathrm{ml} 37^{\circ} \mathrm{C}$-warmen cAMP-Inkubationsmedium gewaschen. Danach wurden $990 \mu \mathrm{l}$ cAMP-Inkubationsmedium zugeben und die Zellen für $10 \mathrm{~min}$ bei $37^{\circ} \mathrm{C}$ in Anwesenheit von $1 \mathrm{mM}$ IBMX vorinkubiert. IBMX ist ein Phosphodiesterase-Inhibitor und verhindert, daß das gebildete cAMP wieder abgebaut werden kann. Anschließend wurden die Zellen für $0,2,5,10,15,30$ min mit $1 \mu \mathrm{M}$ Forskolin in Anwesenheit von $1 \mathrm{mM}$ IBMX zur cAMP-Bildung stimuliert. Nach der Stimulation wurde das Medium abgesaugt und die Kulturplatten in flüssigen Stickstoff überführt, um die Reaktion zu stoppen. Anschließend wurden die Zellen aus dem flüssigen Stickstoff herausgenommen und während sie auftauten, wurden sie mit $500 \mu \mathrm{l}$ Aufschlußpuffer versetzt und $1 \mathrm{~h}$ auf Eis aufgeschlossen. Danach wurden die Zellen abgeschabt und die Zellsuspension in ein Schnappdeckelgefäß überführt und bei $-70^{\circ} \mathrm{C}$ gelagert oder direkt in den $\left.{ }^{125} \mathrm{I}\right]$-cAMP-Radioimmunoassay (siehe 3.21.5) eingesetzt. 


\subsubsection{Bestimmung der cAMP-Konzentration durch Radioimmunoassay (RIA)}

Die Quantifizierung der cAMP-Konzentrationen wurde mit dem cAMP-[ ${ }^{125}$ I] Biotrak Assay System der Firma Amersham-Phamacia nach Anweisung des Herstellers durchgeführt.

Die bei $-70^{\circ} \mathrm{C}$ gelagerten Proben wurden aufgetaut und für $10 \mathrm{~min}$ bei $15000 \mathrm{rpm}$ (20 $600 \times \mathrm{g}$, SIGMA-Zentrifuge 3K30, Rotor 12154-H 3K30) und $4^{\circ} \mathrm{C}$ zentrifugiert. $10 \mu \mathrm{l}$ des Überstandes wurden mit $990 \mu \mathrm{l}$ des cAMP-RIA-Puffers verdünnt und $50 \mu \mathrm{l}$ dieser Verdünnung wurden in den RIA eigesetzt. Für die Eichreihe wurden $50 \mu \mathrm{l}$ des nichtacetylierten cAMP-Standard (32 nM) mit $50 \mu \mathrm{l}$ des cAMP-RIA-Puffers verdünnt und mit jeweils $50 \mu \mathrm{l}$ cAMP-RIA-Puffer siebenmal 1:2 weiterverdünnt. Für die Standardreihe wurden zwei Leerwerte (nur cAMP-RIA-Puffer) und sieben Standard-Punkte eingesetzt (16, 8, 4, 2, 1, 0,5 und 0,25 nM nicht-acetylierter cAMP-Standard).

Zu den $50 \mu$ Probe oder Standard wurden $50 \mu \mathrm{l}\left[{ }^{125}\right.$ ] -cAMP (Tracer) und $50 \mu \mathrm{l}$ Antiserum (cAMP-Antikörper) pipettiert und für $3 \mathrm{~h}$ bei $4^{\circ} \mathrm{C}$ inkubiert. Danach wurden $250 \mu \mathrm{l}$ Amerlex-M Reagenz (immobilisierter 2. Antikörper) zugegeben und $15 \mathrm{~min}$ bei Raumtemperatur inkubiert. Anschließend wurden die Proben für 10 min bei $13000 \mathrm{rpm}(16000 \times \mathrm{g}$ ) in der Tischzentrifuge bei Raumtemperatur zentrifugiert, der Überstand vollständig abgenommen und das Sediment im $\gamma$-Zähler für 1 min gemessen.

\subsection{Untersuchung der Desensitisierung der in HEK293-Zellen stabil exprimierten Rezeptorproteine}

\subsubsection{Puffer und Lösungen}

\section{Poly-L-Lysin-Lösung}

Die Zusammensetzung der Poly-L-Lysin-Lösung wurde unter 3.21.1 beschrieben.

cAMP-Inkubationsmedium

Die Zusammensetzung des Inkubationsmediums wurde unter 3.21.1 beschrieben.

\section{IBMX-Stammlösung}

Die Zusammensetzung des Puffers wurde unter 3.21.1 beschrieben.

Hypotoner Homogenisierungspuffer

Die Zusammensetzung des Puffers wurde unter 3.21.1 beschrieben.

Resuspendierungspuffer

Die Zusammensetzung des Puffers wurde unter 3.21.1 beschrieben.

\section{$2 \times$ Reaktionspuffer}

Die Zusammensetzung des Puffers wurde unter 3.21.1 beschrieben. 


\section{ONO604-Stammlösung}

Der EP4-R-Agonist (ONO604) wurde in einer Konzentration von $10 \mathrm{mM}$ in $70 \%$ (v/v) in Ethanol gelöst und in Aliqots bei $-20^{\circ} \mathrm{C}$ gelagert.

Saurer Puffer

Glycin

$\mathrm{NaCl}$
$50 \mathrm{mM}$

$150 \mathrm{mM}$
$100 \mathrm{ml}$

$375 \mathrm{mg}$

$877 \mathrm{mg}$

Der Puffer wurde mit $\mathrm{HCl}$ auf $\mathrm{pH} 3$ eingestellt und bei $4^{\circ} \mathrm{C}$ gelagert.

\subsubsection{Bestimmung der Desensitisierung der $\mathrm{PGE}_{2}$-abhängigen $\mathrm{cAMP}-$ Bildung nach Vorstimulation der Rezeptor-exprimierenden HEK293-Zellen mit PGE 2}

Stabil transfizierte HEK293-Zellen wurden auf acht zuvor mit Poly-L-Lysin beschichtete $8,7 \mathrm{~cm}^{2}$-Platten mit einer Dichte von $2 \times 10^{5}$ Zellen ausplattiert und bis zur Konfluenz kultiviert. Anschließend wurden die Zellen zweimal mit cAMP-Inkubationsmedium gewaschen und je vier Platten mit $100 \mathrm{nM} \mathrm{PGE}_{2}$ für 10 min vorstimuliert, während vier weitere Platten ohne $\mathrm{PGE}_{2}$ inkubiert wurden. Nach der Vorstimulation wurden die Zellen zweimal mit cAMP-Inkubationsmedium gewaschen und für 1 min in Saurem Puffer inkubiert, um den Liganden von der Zelloberfläche zu eluieren. Anschließend wurden die Zellen wiederum zweimal mit cAMP-Inkubationsmedium gewaschen und zwei Platten der nichtvorstimulierten und zwei Platten der vorstimulierten Zellen für 10 min mit $10 \mathrm{nM} \mathrm{PGE} 2$ in Anwesenheit von $1 \mathrm{mM}$ IBMX restimuliert. Die jeweils anderen beiden Platten wurden als Kontrolle für 10 min ohne $\mathrm{PGE}_{2}$ in Anwesenheit von $1 \mathrm{mM}$ IBMX inkubiert. Nach der Restimulation wurden das Medium abgesaugt und die Reaktion in flüssigem Stickstoff abgestoppt. Die Ansätze wurden wie unter 3.21.4 beschrieben aufgearbeitet.

\subsubsection{Kinetik der $\mathrm{PGE}_{2}$-induzierten cAMP-Bildung nach Vorstimulation der Rezeptor- exprimierenden HEK293-Zellen mit PGE 2}

$2 \times 10^{5}$ der stabil transfizierten HEK293-Zellen wurden auf zuvor mit Poly-L-Lysin beschichteten Kulturplatten ausplattiert und für $48 \mathrm{~h}$ kultiviert. Anschließend wurde das Kulturmedium abgesaugt und die Zellen zweimal mit $1 \mathrm{ml} 37^{\circ} \mathrm{C}$-warmen cAMPInkubationsmedium gewaschen. Danach wurden $980 \mu \mathrm{l}$ cAMP-Inkubationsmedium zugeben und die Zellen für 10 min bei $37^{\circ} \mathrm{C}$ mit $1 \mu \mathrm{M} \mathrm{PGE}$ in Abwesenheit von IBMX vorstimuliert. Danach wurde die Kinetik durch Zugabe von $1 \mathrm{mM}$ IBMX gestartet und die Zellen für 0-30 min zur cAMP-Bildung inkubiert. Die Reaktion wurde in flüssigem Stickstoff abgestoppt (siehe 3.21.4.), die Ansätze, wie unter 3.21.4 beschrieben, aufgearbeitet und das gebildete cAMP, wie unter 3.21 .5 beschrieben, bestimmt. 


\subsubsection{Kinetik der ONO604-induzierten cAMP-Bildung nach Vorstimulation der Rezeptor-exprimierenden HEK293-Zellen mit ONO604 und verzögerter Gabe von IBMX}

$2 \times 10^{5}$ der stabil transfizierten HEK293-Zellen wurden auf zuvor mit Poly-L-Lysin beschichteten Kulturplatten ausplattiert und für $48 \mathrm{~h}$ kultiviert. Anschließend wurde das Kulturmedium abgesaugt und die Zellen dreimal mit $1 \mathrm{ml} 37^{\circ} \mathrm{C}$ warmen cAMPInkubationsmedium gewaschen. Danach wurde $1 \mathrm{ml}$ cAMP-Inkubationsmedium zugegeben und die Zellen für 10 min bei $37^{\circ} \mathrm{C}$ mit $10 \mathrm{nM}$ ONO604 in Abwesenheit von IBMX stimuliert. Danach wurde das Medium entfernt und die Zellen dreimal mit cAMP-Inkubationsmedium gewaschen. Anschließend wurden die Zellen in $990 \mu \mathrm{l}$ cAMP-Inkubationsmedium für 10 min ohne Agonist und ohne IBMX inkubiert. Danach wurde die Kinetik durch Zugabe von $10 \mu \mathrm{I}$ IBMX-Stammlösung gestartet und die Zellen für 0-30 min zur cAMP-Bildung inkubiert. Die Reaktion wurde in flüssigem Stickstoff abgestoppt (siehe 3.21.4.), die Ansätze, wie unter 3.21.4 beschrieben, aufgearbeitet und das gebildete cAMP bestimmt (siehe 3.21.5).

\subsubsection{Bestimmung der Konzentrations-abhängigen cAMP-Bildung nach Vorstimulation mit $\mathrm{PGE}_{2}$}

Stabil transfizierte HEK293-Zellen wurden auf zuvor mit Poly-L-Lysin beschichteten $58 \mathrm{~cm}^{2}$ Platten mit einer Dichte von $3 \times 10^{6}$ Zellen ausplattiert und für $72 \mathrm{~h}$ inkubiert. Anschließend wurde das Kulturmedium abgesaugt und die Zellen zweimal mit $10 \mathrm{ml} 37^{\circ} \mathrm{C}$ warmen cAMPInkubationsmedium gewaschen. Danach wurden $10 \mathrm{ml}$ CAMP-Inkubationsmedium $/ 58 \mathrm{~cm}^{2}$ Platte pipettiert und die Zellen mit $1 \mu \mathrm{M} \mathrm{PGE}_{2}$ für 5 min stimuliert, parallel wurden Zellen ohne $\mathrm{PGE}_{2}$ inkubiert. Nach der Stimulation wurde das cAMP-Inkubationsmedium absaugt, die Zellen zweimal mit $10 \mathrm{ml}$ kaltem PBS gewaschen und für $1 \mathrm{~min}$ in $5 \mathrm{ml}$ Saurem Puffer zur Elution des auf der Zelloberfläche gebundenen Liganden inkubiert. Anschließend wurden die Zellen zweimal mit $10 \mathrm{ml}$ kaltem PBS gewaschen und 1,5 ml hypotoner Homogenisierungspuffer mit Protease-Inhibitoren zupipettiert. Danach wurden Membranen aus den Zellen präpariert (siehe 3.21.2) und eine Proteinbestimmung durchgeführt (siehe 3.18.3) Die Konzentration wurde auf $1 \mu \mathrm{g}$ Membranprotein/ $\mu$ l eingestellt. Die Dosisabhängige cAMP-Bildung wurde, wie unter 3.21 .3 beschrieben, durchgeführt und anschließend das gebildete cAMP bestimmt (siehe 3.21.5). 
3.23 Nachweis der Internalisierung der Rezeptorproteine durch einen OberflächenELISA (EEnzyme-linked İmmunoșorbent Ássay)

\subsubsection{Puffer und Lösungen}

Poly-L-Lysin

siehe 3.21 .1

$\underline{5 \times \text { Saccharose-Lösung }}$ $50 \mathrm{ml}$

Saccharose $2,25 \mathrm{M}$ $38,509 \mathrm{~g}$

Die Lösung wurde bei Raumtemperatur gelagert.

Tween 20-Stammlösung

$100 \mathrm{ml}$

Tween 20

$20 \%(v / v)$

$20 \mathrm{ml}$

Die Lösung wurde bei Raumtemperatur gelagert.

PBS-Tween-Waschpuffer

Tween 20

PBS

Blockierungspuffer I

BSA

BS

PBS

Der Puffer wurde bei $-20^{\circ} \mathrm{C}$ gelagert.

Ablösungspuffer

$100 \mathrm{mM}$

$50 \mathrm{mM}$

$\mathrm{Na}$-Citrat $\times 2 \mathrm{H}_{2} \mathrm{O}$

$\mathrm{NaCl}$
$0,05 \%$

$1 \mathrm{x}$

$2,5 \mathrm{ml} \mathrm{20 \%} \mathrm{Stlsg}$ ad $1000 \mathrm{ml}$

$100 \mathrm{ml}$

$$
3 \%(w / v)
$$
$20 \mathrm{ml}$

$1 \mathrm{x}$ $20 \%(v / v)$ $77 \mathrm{ml}$
Der Puffer wurde mit $\mathrm{HCl}$ auf $\mathrm{pH} 3$ eingestellt und bei $4^{\circ} \mathrm{C}$ gelagert.

Beschichtungspuffer $100 \mathrm{ml}$ $\mathrm{Na}_{2} \mathrm{CO}_{3}$ $34 \mathrm{mM}$ $360 \mathrm{mg}$

$\mathrm{NaHCO}_{3}$ $16 \mathrm{mM}$ $134 \mathrm{mg}$

Der Puffer wurde bei $4^{\circ} \mathrm{C}$ gelagert.

Blockierungspuffer II $100 \mathrm{ml}$ $\mathrm{Na}_{2} \mathrm{CO}_{3}$ $34 \mathrm{mM}$ $360 \mathrm{mg}$ $\mathrm{NaHCO}_{3}$ $16 \mathrm{mM}$ $134 \mathrm{mg}$

Gelatine $1 \%(\mathrm{w} / \mathrm{v})$ $100 \mathrm{ml}$ $2,941 \mathrm{~g}$ $0,292 \mathrm{~g}$

Der Puffer wurde für jeden Versuch frisch angesetzt. 
ABTS-Lösung

$500 \mathrm{ml}$

Natriumacetat

$100 \mathrm{mM}$

$\mathrm{NaH}_{2} \mathrm{PO}_{4} \times \mathrm{H}_{2} \mathrm{O}$

$50 \mathrm{mM}$

$3,45 \mathrm{~g}$

ABTS

$0,55 \%(w / v)$

$0,55 \mathrm{~g}$

Die Lösung wurde in $10 \mathrm{ml}$ Aliquots bei $-20^{\circ} \mathrm{C}$ gelagert und vor Gebrauch mit $7 \mu \mathrm{l} \mathrm{H}_{2} \mathrm{O}_{2}$ pro $10 \mathrm{ml}$ ABTS-Lösung versetzt.

\subsubsection{Stimulation der Rezeptor exprimierenden HEK293-Zellen und Antikörper- bindung}

Stabil transfizierte HEK293-Zellen wurden auf zuvor mit Poly-L-Lysin beschichteten 6-Wellplatten mit einer Dichte von $3 \times 10^{5}$ Zellen/Vertiefung ausplattiert und für $48 \mathrm{~h}$ kultiviert. Anschließend wurden optional $500 \mu \mathrm{l}$ der $5 \times$ Saccharose-Lösung zupipettiert und die Zellen für $30 \mathrm{~min}$ bei $37^{\circ} \mathrm{C}$ und $5 \% \quad \mathrm{CO}_{2}$ im Begasungsbrutschrank vorinkubiert. Durch die hyperosmolare Saccharosekonzentration kann die Clathrin-vermittelte Internalisierung der Rezeptorproteine inhibiert werden. Danach wurden die Zellen mit $1 \mu \mathrm{M} \mathrm{PGE}$ für 45 min bei $37^{\circ} \mathrm{C}$ und $5 \% \mathrm{CO}_{2}$ im Begasungsbrutschrank stimuliert.

Nach Beendigung der Stimulation wurden die Zellen auf Eis gestellt, das Medium abgesaugt und die Zellen zweimal mit $2 \mathrm{ml}$ eiskaltem PBS/Vertiefung gewaschen. Zum Abblocken der unspezifischen Bindungsstellen wurden die Zellen mit $500 \mu$ l Blockierungspuffer I/Vertiefung für $1 \mathrm{~h}$ bei $4^{\circ} \mathrm{C}$ unter Schwenken inkubiert. Danach wurde der Puffer abgesaugt und die Zellen einmal mit $2 \mathrm{ml}$ eiskaltem PBS gewaschen.

Zur Antikörperbindung wurden in einer 1:3-Verdünnung in Blockierunspuffers I 2,5 $\mu \mathrm{g}$ FLAGM2-mAk/ml angesetzt und die Zellen mit $250 \mu \mathrm{l}$ dieser Verdünnung für $2 \mathrm{~h}$ bei $4^{\circ} \mathrm{C}$ unter Schwenken inkubiert. Anschließend wurden die Zellen sechsmal mit eiskaltem PBS gewaschen, mit $500 \mu \mathrm{l}$ Ablösungspuffer versetzt und für $30 \mathrm{~min}$ bei $4^{\circ} \mathrm{C}$ unter Schwenken inkubiert, um den FLAG-M2-mAk von den Rezeptoren wieder in Lösung zu bringen. Danach wurden die Zellen in Ablösungspuffer abgeschabt, in ein 1,5 ml-Reagiergefäß überführt und die Zellsuspension mit einer Spatelspitze $\mathrm{NaHCO}_{3}$ neutralisiert. Die Suspension wurde bei $-20^{\circ} \mathrm{C}$ gelagert.

\subsubsection{Vorbereitung der ELISA-Platte}

Es wurde ein polyklonaler Antikörper aus Ziege gegen Immunglobuline (lgG) der Maus (Dianova) 1:250 in Beschichtungspuffer verdünnt und $100 \mu \mathrm{l} /$ Vertiefung einer ELISA-Platte Microlon $96 \mathrm{~K}$ (Greiner) über Nacht bei $4^{\circ} \mathrm{C}$ inkubiert. Danach wurde einmal mit PBS-TweenWaschpuffer gewaschen und mit $100 \mu \mathrm{l}$ Blockierungspuffer II/Vertiefung für $1 \mathrm{~h}$ bei Raumtemperatur die unspezifischen Bindungsstellen geblockt. 


\subsubsection{Antigenbindung}

Die zellulären Bestandteile der Zellsuspension wurden durch Zentrifugation für 5 min bei $13000 \mathrm{rpm}(16000 \times \mathrm{g})$ in der Tischzentrifuge sedimentiert und der sich im Überstand befindende FLAG-M2-mAk im Verhältnis 1:12,5 mit PBS-Tween-Waschpuffer verdünnt. Es wurden $100 \mu \mathrm{l}$ der Verdünnung/Vertiefung pipettiert und für $2 \mathrm{~h}$ bei Raumtemperatur inkubiert. Zusätzlich wurde eine Standardreihe mit 0-1 ng FLAG-M2-mAk in PBS-TweenWaschpuffer in einem Ansatz von $100 \mu \mathrm{l} /$ Vertiefung pipettiert.

\subsubsection{Nachweis der Rezeptorproteine durch einen Sekundärantikörper, Streptavidin- Peroxidase und eine Farbreaktion mit ABTS}

Nach der Antigenbindung wurde die ELISA-Platte fünfmal mit PBS-Tween gewaschen und $100 \mu$ l einer 1:500-Verdünnung eines polyklonalen, Biotin-gekoppelten Antikörpers aus Schaf gegen Immunglobuline (IgG) der Maus (Amersham-Buchler) in PBS-Tween-Waschpuffer für $1 \mathrm{~h}$ bei Raumtemperatur inkubiert. Danach wurde wiederum fünfmal mit PBS-TweenWaschpuffer gewaschen und $100 \mu$ leiner 1:500-Verdünnung des Peroxidase-gekoppelten Streptavidins in PBS-Tween-Waschpuffer für $1 \mathrm{~h}$ bei Raumtemperatur inkubiert. Nach fünf Waschschritten mit PBS-Tween-Waschpuffer wurde die Farbreaktion durch Zugabe von $100 \mu \mathrm{l}$ ABTS-Lösung mit $\mathrm{H}_{2} \mathrm{O}_{2}$ gestartet. Nach ca. 10 min wurde die Intensität der Farbreaktion mit dem Microplate-Reader MRX II (Dynex Technologies) mit einem Testfilter von $405 \mathrm{~nm}$ und einem Referenzfilter von $490 \mathrm{~nm}$ gemessen.

\subsection{Bestimmung der Internalisierung aufgrund der Reduktion der Oberflächen- $\left[{ }^{3} \mathrm{H}\right]-$ $\mathrm{PGE}_{2}$-Bindung}

\subsubsection{Puffer und Lösungen}

\section{$5 \times$ Saccharose-Lösung}

Die Zusammensetzung der Lösung wurde unter 3.23.1 beschrieben.

cAMP-Inkubationsmedium

Die Zusammensetzung des Inkubationsmediums wurde unter 3.21.1 beschrieben.

\section{Saurer Puffer}

Die Zusammensetzung des Puffers wurde unter 3.22.1 beschrieben. 
Lysis-Puffer

$250 \mathrm{ml}$

$\mathrm{NaOH}$

$0,3 \mathrm{M}$

$7,5 \mathrm{ml} 10 \mathrm{M} \mathrm{Stlsg}$

SDS

$1 \%(w / v)$

$2,5 \mathrm{~g}$

Der Puffer wurde bei Raumtemperatur gelagert.

\subsubsection{Nachweis der Internalisierung durch Bestimmung des nach Stimulation internalisierten $\left[{ }^{3} \mathrm{H}\right]-\mathrm{PGE}_{2}$}

Es wurden $1 \times 10^{5}$ Zellen der die verschiedenen Rezeptoren stabil exprimierenden HEK293-Zellen pro Vertiefung einer 24 Well-Kulturschale ausplattiert und für $24 \mathrm{~h}$ kultiviert. Anschließend wurde optional das Kulturmedium abgesaugt und die Zellen für $30 \mathrm{~min}$ bei $37^{\circ} \mathrm{C}$ und $5 \% \mathrm{CO}_{2}$ in DMEM-komplett und 0,45 $\mathrm{M}$ Saccharose vorinkubiert. Durch die hyperosmolare Saccharosekonzentration kann die Clathrin-vermittelte Internalisierung der Rezeptorproteine inhibiert werden.

Die Zellen wurden zweimal mit cAMP-Inkubationsmedium gewaschen und anschließend wurden in An- oder Abwesenheit von 0,45 M Saccharose $5 \mathrm{nM}\left[{ }^{3} \mathrm{H}\right]-\mathrm{PGE}_{2}$ in An- und Abwesenheit von $10 \mu \mathrm{M}$ nicht $\left[{ }^{3} \mathrm{H}\right]$-markiertem $\mathrm{PGE}_{2}$ in $200 \mu \mathrm{l}$ cAMP-Inkubationsmedium pro Vertiefung pipettiert und $2 \mathrm{~h}$ bei $4^{\circ} \mathrm{C}$ zur Bestimmung der Oberflächenbindung unter Bedingungen, bei denen keine Internalisierung möglich sein sollte, inkubiert. Parallel wurde der gleiche Reaktionsansatz für 30 min bei $37^{\circ} \mathrm{C}$ zur Bestimmung der Oberflächenbindung unter Bedingungen, bei denen eine Internalisierung stattfinden kann, inkubiert.

Nach der Inkubation wurden die Zellen auf Eis gestellt und dreimal mit cAMPInkubationsmedium gewaschen. Anschließend wurden die Zellen für 5 min mit $200 \mu \mathrm{l}$ Saurem Puffer zur Elution des an der Zelloberfläche verbliebenen $\left[{ }^{3} \mathrm{H}\right]-\mathrm{PGE}_{2}$ inkubiert und die Überstande in Scintillationsgefäße überführt. Die Inkubation mit Saurem Puffer wurde wiederholt und die Überstände in die gleichen Scintillationsgefäße pipettiert. Danach wurden die Zellen vom Eis genommen, $400 \mu$ Lysis-Puffer zugegeben und die Zellsuspension zur Bestimmung der intrazellulären Radioaktivität ebenfalls in Scintillationsgefäße pipettiert. Die Proben wurden mit $5 \mathrm{ml}$ Hydroluma-Scintillator versetzt und nach ca. $2 \mathrm{~h}$, in denen die Chemilumineszenz abgeklungen war, wurde die Aktivität des eluierten und des intrazellulären [ $\left.{ }^{3} \mathrm{H}\right]-\mathrm{PGE}_{2}$ im Flüssigkeitsscintillationszähler gemessen. 
3.25 Nachweis der Plasmamembranlokalisation und der Internalisierung der in den HEK293-Zellen stabil exprimierten Rezeptorproteine durch ImmunfluoreszenzMikroskopie

\subsubsection{Puffer und Lösungen}

\section{Poly-L-Lysin-Lösung}

Die Zusammensetzung der Lösung wurde unter 3.21.1 beschrieben.

Fibronectin-Lösung

$1 \mathrm{ml}$

Fibronectin

$0,005 \%(w / v)$

$50 \mu l 0,1 \%(w / v)$ Stlsg

Die Lösung wurde immer frisch angesetzt.

Kulturmedien

Die Zusammensetzung der Medien wurde unter 3.14.1 beschrieben.

\section{$\underline{5 \times \text { Saccharose-Lösung }}$}

Die Zusammensetzung der Lösung wurde unter 3.23.1 beschrieben.

\section{$\underline{\text { PBS }}$}

Die Zusammensetzung des Puffers wurde unter 3.14.1 beschrieben.

Natriumacetat-Puffer

$1000 \mathrm{ml}$

Natriumacetat

$100 \mathrm{mM}$

Der $\mathrm{pH}$-Wert wurde mit $1 \mathrm{~N} \mathrm{HCl}$ auf $\mathrm{pH}$ 5,5 eingestellt.

Natriumperiodat-Lösung

Natriumperiodat

$10 \mathrm{mM}$

$214 \mathrm{mg}$

PBS

ad $100 \mathrm{ml}$

Die Lösung wurde immer frisch angesetzt.

N-Biotin-Hydrazid-Lösung

$100 \mathrm{ml}$

N-Biotin-Hydrazid

$1 \mathrm{mM}$

$25 \mathrm{mg}$

Natriumacetat-Puffer

ad $100 \mathrm{ml}$

Die Lösung wurde immer frisch angesetzt. 
Fixierlösung

$100 \mathrm{ml}$

Paraformaldehyd

$4 \%(w / v)$

$4 \mathrm{~g}$

PBS

ad $100 \mathrm{ml}$

Die Lösung wurde für ca. 5-10 min auf $60^{\circ} \mathrm{C}$ erhitzt, bis sich das Paraformaldehyd gelöst hatte und anschließend in ein vorgekühltes Gefäß filtriert. Die Lösung wurde immer frisch angesetzt.

Ammoniumchlorid-Puffer

$100 \mathrm{ml}$

Ammoniumchlorid

$50 \mathrm{mM}$

$267 \mathrm{mg}$

PBS

ad $100 \mathrm{ml}$

Der Puffer wurde bei $4^{\circ} \mathrm{C}$ gelagert.

Permeabilisierungslösung

$100 \mathrm{ml}$

Saponin

$0,1 \%(w / v)$

$100 \mathrm{mg}$

PBS ad $100 \mathrm{ml}$

Die Lösung wurde immer frisch angesetzt.

PBS mit $1 \%(w / v) B S A$

$100 \mathrm{ml}$

BSA

$1 \%(w / v)$

PBS

Die Lösung wurde bei $-20^{\circ} \mathrm{C}$ gelagert.

Mowiol-Lösung

$24 \mathrm{ml}$

Mowiol 4-88

$10 \%(w / v)$

$2,4 \mathrm{~g}$

Glycerol

$25 \%(w / v)$

$6 \mathrm{ml}$

Tris/ $\mathrm{HCl}$

$0,1 \mathrm{M}$

$12 \mathrm{ml} \mathrm{0,2} \mathrm{M} \mathrm{Stlsg} \mathrm{pH} \mathrm{8,5}$

Es wurden 2,4 g Mowiol 4-88 in $6 \mathrm{ml}$ Glycerol und $6 \mathrm{ml} \mathrm{H} \mathrm{H}_{2} \mathrm{O}$ über Nacht gerührt und anschließend kurz erwärmt. Danach wurden $12 \mathrm{ml} \mathrm{0,2} \mathrm{M} \mathrm{Tris/HCl} \mathrm{pH} \mathrm{8,5} \mathrm{zugegeben} \mathrm{und} \mathrm{für}$ $10 \mathrm{~min}$ auf $60^{\circ} \mathrm{C}$ erhitzt. Anschließend wurde die Lösung bei $5000 \times \mathrm{g}$ für $30 \mathrm{~min}$ bei Raumtemperatur zentrifugiert, der Überstand aliquotiert und bei $-20^{\circ} \mathrm{C}$ gelagert.

Diazobicyclooctan (DABCO) $5 \mathrm{ml}$

Diazobicyclooctan $20 \%(w / v)$

Die Lösung wurde bei $-20^{\circ} \mathrm{C}$ gelagert.

Mowiol-DABCO-Einbettungsmedium

$10 \mathrm{ml}$

Diazobicyclooctan

$5 \%(w / v)$

$2,5 \mathrm{ml} 20 \%$ Stlsg

Mowiol-Lösung

$7,5 \mathrm{ml}$

Das Einbettungsmedium wurde in 1 ml-Aliqots bei $-20^{\circ} \mathrm{C}$ gelagert und vor Gebrauch zur Verflüssigung kurz auf $95^{\circ} \mathrm{C}$ erhitzt . 


\subsubsection{Kultivierung und Stimulation der Rezeptor-exprimierenden HEK293-Zellen}

Die Untersuchung der subzellulären Rezeptorverteilung durch Immunfluoreszenz erfolgte mit kleineren Modifikationen nach Hille et al. (1992).

Runde Glasdeckgläschen wurden zur Sterilisation in 100\% Ethanol getaucht und kurz abgeflammt. Anschließend wurden sie in Platten mit 6 Vertiefungen von je 9,6 $\mathrm{cm}^{2}$ gelegt und $30 \mu \mathrm{l}$ Fibronectin-Lösung auf die Deckgläschen pipettiert. Fibronectin ermöglicht den HEK293-Zellen ein besseres Wachstum auf den Glasdeckgläschen. Nachdem die Fibronectin-Lösung getrocknet war, wurden die Deckgläschen für 30 min mit $1 \mathrm{ml}$ Poly-LLysin/Vertiefung überschichtet und danach einmal mit PBS gewaschen. Die Poly-L-LysinBeschichtung verbessert die Haftung der Zellen an die Deckgläschen. Anschließend wurden $2 \times 10^{5}$ der mit den verschiedenen Rezeptoren stabil transfizierten HEK293-Zellen/Vertiefung ausplattiert und bei $37^{\circ} \mathrm{C}$ unter $5 \% \mathrm{CO}_{2}$ für $24 \mathrm{~h}$ kultiviert.

Für die transiente Transfektion mit $\beta$-Arrestin/GFP nach der modifizierten Calcium-PhosphatMethode (siehe 3.14.3) wurden $1,5 \times 10^{5}$ Zellen/Vertiefung ausplattiert, nach $24 \mathrm{~h}$ transient transfiziert und für weitere $24 \mathrm{~h}$ kultiviert. Anschließend wurden die Zellen optional für $30 \mathrm{~min}$ mit 0,45 M Saccharose vorinkubiert und danach für 45 min mit $1 \mu \mathrm{M} \mathrm{PGE}_{2}$ im Kulturmedium stimuliert.

\subsubsection{Plasmamembranmarkierung der HEK293-Zellen}

Nach der Stimulation wurden die Zellen mit $1,5 \mathrm{ml} \mathrm{PBS}$ gewaschen und für 30 min bei $4^{\circ} \mathrm{C}$ im Dunkeln mit $500 \mu \mathrm{l}$ Natriumperiodatlösung inkubiert, wodurch die an den plasmamembranständigen Kohlenhydraten vorkommenden Hydroxylgruppen zu Aldehydgruppen oxidiert wurden. Danach wurden die Zellen einmal mit PBS und einmal mit Natriumacetat-Puffer gewaschen und für 30 min bei $4^{\circ} \mathrm{C}$ im Dunkeln mit $500 \mu \mathrm{l}$-BiotinHydrazid-Lösung inkubiert, wodurch eine Biotinylierung der Kohlenhydratreste durch Reduktion der Aldehyde mit dem Hydrazid erfolgte (Schiff'sche Basen-Bildung). Die Zellen wurden erneut einmal mit Natriumacetat-Puffer und einmal mit PBS gewaschen und anschließend fixiert.

\subsubsection{Fixierung, Permeabilisierung und Blockierung der HEK293-Zellen}

Die Zellen wurden für $30 \mathrm{~min}$ mit $500 \mu \mathrm{l}$ Fixierlösung/Vertiefung bei $4^{\circ} \mathrm{C}$ fixiert, einmal mit PBS gewaschen und verbleibendes Paraformaldehyd mit $500 \mu \mathrm{l}$ Ammoniumchlorid-Puffer für 10 min durch Reaktion der Aldehydgruppen mit den Ammoniumionen entfernt. Die Zellen wurden nochmals mit PBS gewaschen, mit $500 \mu$ Permeabilisierungslösung für 15 min permeabilisiert und die Zellen für $60 \mathrm{~min}$ bei Raumtemperatur mit $500 \mu$ l unverdünntem 
Ziegenserum (Gibco BRL, Eggenstein) blockiert, um die unspezifische Bindung der Antikörper zu verringern. Das Serum wurde vollständig entfernt und die Zellen abermals mit PBS gewaschen.

\subsubsection{Nachweis der FLAG-markierten Rezeptorproteine und Gegenfärbung der biotinylierten Plasmamembran}

Zum Nachweis der Rezeptorproteine wurden die so vorbereiteten Zellen mit $450 \mu \mathrm{l}$ pro Vertiefung einer $5 \mu \mathrm{g} / \mathrm{ml}$ FLAG-M2-mAK-Verdünnung in PBS mit $1 \%(\mathrm{w} / \mathrm{v}) \mathrm{BSA}$ für $1 \mathrm{~h}$ bei $37^{\circ} \mathrm{C}$ im Begasungsbrutschrank inkubiert. Anschließend wurde der ungebundene Antikörper durch achtmaliges Waschen mit PBS entfernt. Gebundener Antikörper wurde mit einem Cy3gekoppelten polyklonalen Antikörper aus Ziege gegen Immunglobuline (IgG) der Maus nachgewiesen. Die Präparate wurden mit $450 \mu \mathrm{l}$ einer 1:250-Verdünnung dieses Antikörpers für $1 \mathrm{~h}$ unter Lichtausschluß bei $37^{\circ} \mathrm{C}$ im Begasungsbrutschrank inkubiert. Die biotinylierten Proteine in der Plasmamembran wurden mit FITC-markiertem Streptavidin gegengefärbt. Dazu wurden die Präparate mit $450 \mu$ l einer 1:75-Verdünnung des FITC-markierten Streptavidins für $1 \mathrm{~h}$ unter Lichtausschluß bei $37^{\circ} \mathrm{C}$ im Brutschrank inkubiert und und anschließend die Markierung durch achtmaliges Waschen mit PBS beendet.

\subsubsection{Einbettung der HEK293-Zellen für die Visualisierung der markierten Rezeptorproteine am konfokalen Laser-Scan-Mikroskop}

Das Einbettungsmedium wurde zur Verflüssigung kurz auf $95^{\circ} \mathrm{C}$ erhitzt und $4 \mu \mathrm{l}$ davon auf einen Objektträger pipettiert. Die Deckgläschen wurden mit den Zellen nach unten auf das Einbettungsmedium gelegt und überschüssiges Medium vorsichtig mit Zellstoff entfernt. Die Präparate wurden mit farblosem Nagellack abgedichtet und konnten so unter Lichtausschluß bei $4^{\circ} \mathrm{C}$ für mehrere Wochen gelagert werden.

Die markierten Zellen wurden mit einem konfokalen Laser-Scan-Mikroskop der Firma Zeiss aufgenommen. Bei der Bildentstehung durch Scannen mit einem auf die Objektebene fokussierten monochromatischen Laserstrahl sind Abbildungs-, Streuungs- und Beugungsfehler minimal, wodurch sich die optische Auflösung erhöht. Der Scanbetrieb erlaubt die Erstellung optischer Schnitte in xy- und xz-Ebenen. Ihre Dicke wurde auf $350 \mathrm{~nm}$ eingestellt (White et al. (1987)). 


\subsection{Metabolische [ $\left.{ }^{32} \mathrm{P}\right]$-ortho-Phosphat-Markierung zur Bestimmung der Agonisten- induzierten Phosphorylierung der in HEK293-Zellen stabil exprimierten Rezeptorproteine}

Alle Experimente zur Untersuchung der Agonisten-induzierten Phosphorylierung der Rezeptorproteine wurden von Herrn Dr. Frank Neuschäfer Rube durchgeführt.

\subsubsection{Puffer und Lösungen}

Zellkulturmedien

Die Zusammensetzung der Medien wurde unter 3.14.1 beschrieben.

Dialysepuffer $1000 \mathrm{ml}$

HEPES

$$
10 \mathrm{mM}
$$

$\mathrm{NaCl}$

$150 \mathrm{mM}$

$8,766 \mathrm{~g}$

Der Puffer wurde auf $\mathrm{pH} 7,5$ eingestellt und bei $4^{\circ} \mathrm{C}$ gelagert.

\section{Dialysiertes FCS}

10 ml FCS wurden in einem Dialyseschlauch mit einer Ausschlußgröße von 4000 Da für $24 \mathrm{~h}$ gegen 1 I Dialysepuffer bei $4^{\circ} \mathrm{C}$ dialysiert. Der Puffer wurde nach 8 und $16 \mathrm{~h}$ gewechselt. Das dialysierte FCS wurde in $1 \mathrm{ml}-$ Aliquots bei $-20^{\circ} \mathrm{C}$ gelagert.

\section{DMEM-Minusmedium}

Das Minusmedium wurde als Glutamat- und Phosphat-freies Medium von der Firma ICN bezogen und durch 100 x Glutamat-Stammlösung (siehe 2.1) komplettiert. Phosphat wurde nicht zugesetzt, weiterhin wurden 10\% (v/v) dialysiertes FCS und 1\% Penicillin/Streptomycin zugegeben.

${ }^{32} \mathrm{P}$ ]-ortho-Phosphat-DMEM komplett $\quad 50 \mathrm{ml}$

DMEM $44,5 \mathrm{ml}$

dialysiertes FCS

$10 \%(\mathrm{v} / \mathrm{v})$ $5 \mathrm{ml}$

Pen/Strep-Stammlösung $1 \%(\mathrm{v} / \mathrm{v})$ $0,5 \mathrm{ml}$

$\left[{ }^{32} \mathrm{P}\right]$-ortho-Phosphat $150 \mu \mathrm{Ci} / \mathrm{ml}$

\section{PGE 2 -Stammlösung}

siehe 3.18 .1

Foskolin-Stammlösung

siehe 3.21.1 


\section{PMA-Stammlösung}

PMA wurde in einer Konzentration von $10 \mathrm{mM}$ in DMSO gelöst und in Aliquots bei $-20^{\circ} \mathrm{C}$ gelagert.

Staurosporin-Stammlösung

Staurosporin wurde in einer Konzentration von $10 \mathrm{mM}$ in DMSO gelöst und in Aliquots bei $-20^{\circ} \mathrm{C}$ gelagert.

\section{FLAG-Solubilisierungspuffer}

siehe 3.19 .1

\subsubsection{Metabolische $\left[{ }^{32} \mathrm{P}\right]$-ortho-Phosphat-Markierung und Stimulation der Rezeptor- exprimierenden HEK293-Zellen}

$5 \times 10^{5}$ Zellen der stabil transfizierten HEK293-Zellen wurden auf zuvor mit Poly-L-Lysin beschichteten $8,7 \mathrm{~cm}^{2}$-Kulturschalen ausplattiert und für $48 \mathrm{~h}$ in DMEM-komplett kultiviert. Danach wurde das Kulturmedium entfernt, die Zellen zweimal mit Phosphat-freiem Medium gewaschen und für $90 \mathrm{~min}$ bei $37^{\circ} \mathrm{C}$ mit $150 \mu \mathrm{Ci} / \mathrm{ml}\left[{ }^{32} \mathrm{P}\right.$ ]-ortho-Phosphat in $500 \mu \mathrm{l}\left[{ }^{32} \mathrm{P}\right]$-orthoPhosphat-DMEM-komplett/Kulturschale vormarkiert. Nach der Vormarkierung wurden die Zellen in An- oder Abwesenheit von 400 nM Staurosporin zur Inhibition der „secondmessenger"-abhängigen Kinasen für 20 min bei $37^{\circ} \mathrm{C}$ vorinkubiert und anschließend für $10 \mathrm{~min}$ bei $37^{\circ} \mathrm{C}$ mit $1 \mu \mathrm{M} \mathrm{PGE}, 2 \mu \mathrm{M}$ PMA oder $50 \mu \mathrm{M}$ Forskolin in Phosphat-freiem Medium stimuliert. Nach der Stimulation wurden die Zellen zweimal mit $2 \mathrm{ml}$ eiskaltem PBS gewaschen, durch Zugabe von $800 \mu \mathrm{l}$ FLAG-Solubilisierungspuffer aufgeschlossen und die solubilisierten Rezeptorproteine durch Immunpräzipitation (siehe 3.19.2) und anschließende SDS-PAGE aufgetrennt (siehe 3.19).

\subsubsection{Auftrennung und Visualisierung der markierten Rezeptorproteine}

Nach der Immunpräzipitation wurden die Rezeptorproteine durch eine SDS-PAGE aufgetrennt (siehe 3.19.4) und das Gel nach der Fixierung und der Coomassie-Färbung für die Analyse im Molecular-Imager der Firma BioRad getrocknet (siehe 3.19.5). Zur Quantifizierung der Rezeptorphosphorylierung wurden die Intensitäten der detektierten Banden bestimmt und die Phosphorylierung des FLAG-hEP4 wt-R als 100\% gesetzt. 


\section{Ergebnisse}

\subsection{Einfügen der SnaB I-Restriktionsschnittstelle in die FLAG-hEP4-Rezeptor-cDNA durch sequenzgerichtete Mutagenese}

Der offene Leserahmen des humanen EP4-Rezeptors umfaßt 1464 Basen, was einem Protein von 488 Aminosäuren entspricht. 468 Basen des 3'-Bereichs dieser Sequenz codieren für die ungewöhnlich lange, 156 Aminosäuren umfassende C-terminale Domäne des Rezeptorproteins, in der sich 38 Serine und Threonine befinden, die als mögliche Phosphorylierungsstellen dienen können und daher gegen Alanine ausgetauscht werden sollten. Die für die sequenzgerichtete Mutagenese verwendete Taq-Polymerase hat keine „proof-reading“-Aktivität und daher eine relativ hohe Fehlerrate bei der Replikation, durch die unerwünschte Mutationen eingeführt werden können. Die Wahrscheinlichkeit, unerwünschte Mutationen einzufügen, steigt mit der Länge des amplifizierten DNA-Fragments. Daher sollte das zu amplifizierende DNA-Fragment möglichst klein gehalten werden. Zu diesem Zweck wurde eine zusätzliche Restriktionsschnittstelle unmittelbar vor der für die C-terminale Domäne codierenden Sequenz eingefügt, die jedoch keine Änderung in der Proteinsequenz zur Folge hatte.

Die sequenzgerichtete Mutagenese zum Einfügen dieser SnaB I-Schnittstelle wurde nach dem unter 3.1.3 beschriebenen Prinzip durch PCR mit pcDNA/AMP FLAG-hEP4-R als Matrize und den Primern Hind FLAG hEP4 $f$ und EP4 SnaB $f$ sowie EP4 SnaBI $r$ und EP4 Xba r durchgeführt (Abb. 8).

Das Produkt der dritten PCR-Reaktion wurde mit Hind III, und Xba I geschnitten und in den pcDNA3-Vektor einkloniert. Die Klonierung der in E. coli amplifizierten und daraus isolierten Plasmide wurde durch eine Spaltungsreaktion mit anschließender Gelelektrophorese überprüft (Abb. 9) und das Einfügen der SnaB I-Schnittstelle durch Sequenzierung der gesamten Rezeptor-cDNA mit dem T7-, SP6- und dem EP4 2f-Sequenzierprimer bestätigt. Das erhaltene Plasmid pcDNA3 FLAG-hEP4 wt-R wurde für die weitere Synthese der Rezeptormutanten verwendet. 
Matrize: pcDNA/AMP FLAG-hEP4-R

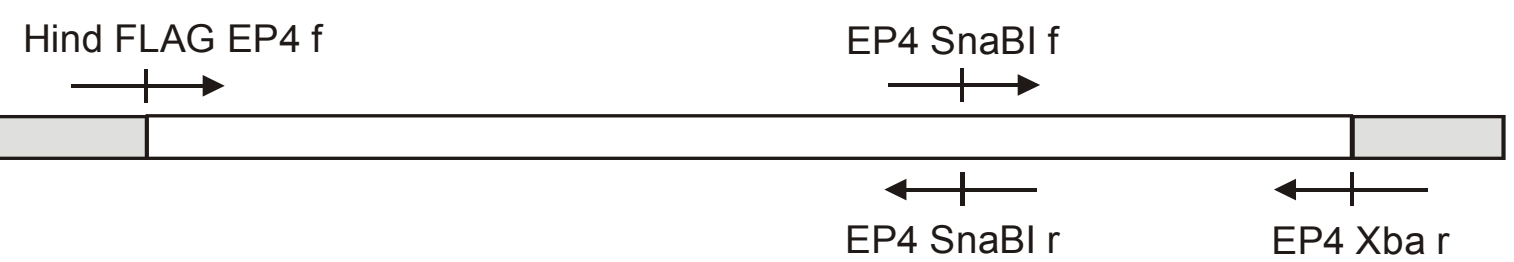

Kloniert in: pcDNA3

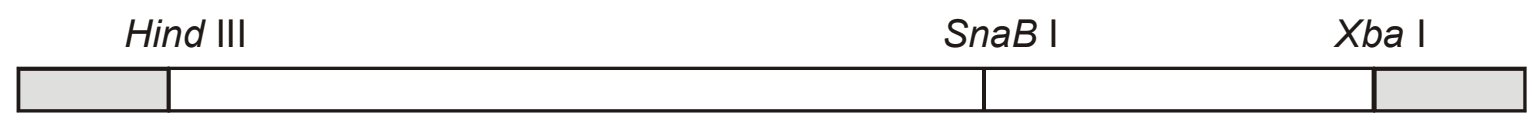

Name des neuen Produktes: pcDNA3 FLAG-hEP4 wt-R

Abb. 8: Synthese des pcDNA3 FLAG-hEP4 wt-Rezeptors mit der eingefügten SnaB IRestriktionserkennungssequenz. Dargestellt ist das für die PCR-Reaktion verwendete Plasmid und die notwendigen Primer (Hind FLAG EP4 $f$ und EP4 SnaBI $r$ sowie EP4 SnaBI $f$ und EP4 Xba r). Die für den FLAG-hEP4-R codierende Sequenz ist weiß, die flankierenden Elemente der Vektoren sind grau dargestellt. Weiterhin sind die verwendeten Restriktionsschnittstellen und das erhaltene Klonierungsprodukt mit der eingefügten SnaB ISchnittstelle gezeigt.

\subsection{1 Überprüfung der sequenzgerichteten Mutagenese durch Restriktionsfragment- längen-Analyse}

Die Mutationen zur Einführung der $S n a B$ I-Restriktionsschnittstelle wurde durch Restriktionsfragmentlängen-Analyse überprüft. Da der pcDNA3-Vektor und der pcDNA/AMPVektor ebenfalls eine SnaB I-Schnittstelle besitzen, wurden nach der Spaltung mit Hind III, SnaB I und Xba I für den pcDNA3 FLAG-hEP4 wt-R vier Fragmente erwartet. Nach der Auftrennung der Spaltprodukte auf einem 1\% (w/v) Agarose-Gel waren für den pcDNA3 FLAG-hEP4 wt-R vier Fragmente zu erkennen, ein 300 bp und 5051 bp großes Fragment, die den Spaltprodukten des Vektors, und ein 460 bp und 1045 bp großes Fragment, die den Spaltprodukten der FLAG-hEP4 wt-R-cDNA entsprachen. In der Spur der pcDNA/Amp FLAG-hEP4-R-cDNA waren nur drei Fragmente mit einer Größe von 300 bp und 4407 bp für den pcDNA/AMP-Vektor und 1505 bp für die nicht gespaltene FLAG-hEP4-R-cDNA zu erkennen (Abb. 9). 


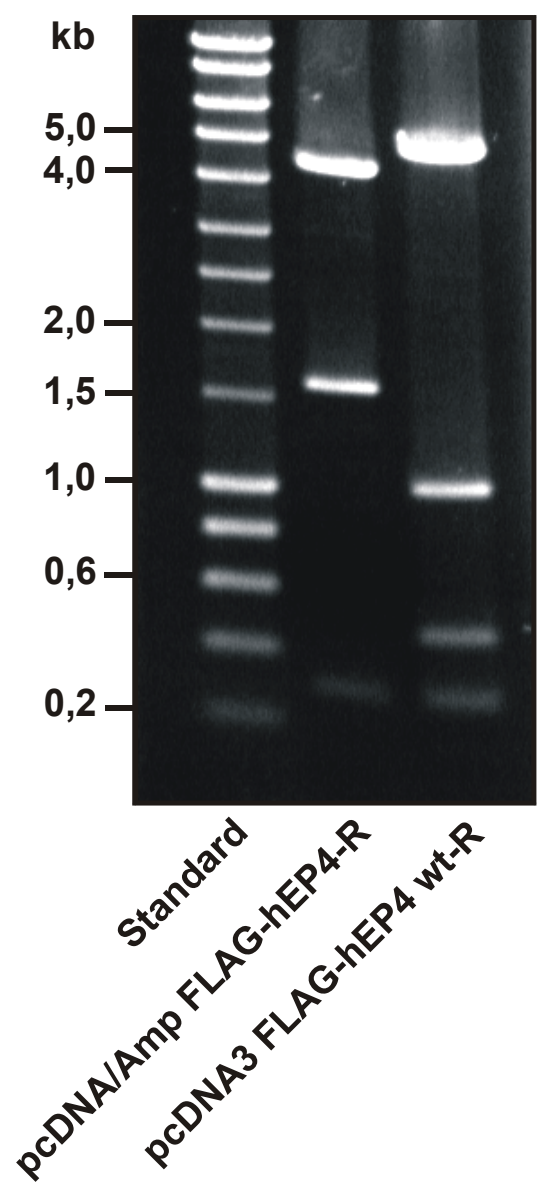

Abb. 9: Charakterisierung der isolierten PlasmidDNA des pcDNAIAmp FLAG-hEP4- und des pcDNA3 FLAG-hEP4 wt-Rezeptors durch Spaltung mit den Restriktionsenzymen Hind III, SnaB I und $X$ ba I. Die mit den Restriktionsenzymen Hind III und $X b a \mid$ vorbehandelte FLAG-hEP4 wt-R-cDNA wurde mit dem ebenfalls durch diese Enzyme linearisierten Vektor pcDNA3 für $2 \mathrm{~h}$ bei $24^{\circ} \mathrm{C}$ ligiert. Anschließend wurden E. coli XL1 (blue) Zellen durch Elektroporation mit diesen Konstrukten transformiert. Je ca. 1,5 $\mu \mathrm{g}$ der Plasmide wurden mit den Restriktionsenzymen Hind III, SnaB I und Xba I geschnitten und die Fragmente in einem $1 \%(\mathrm{w} / \mathrm{v})$ Agarose-Gel aufgetrennt.

Die Analyse zeigte wie erwartet die ca. 300 bp und 4500 bp großen Fragmente des pcDNA/Amp und das ca. 1500 bp große Fragment der FLAG-hEP4-RcDNA und die ca. 300 bp und 5000 bp großen Fragmente des pcDNA3 und die ca. 500 bp und 1000 bp großen Fragmente der FLAG-hEP4 wt-R-cDNA. Standard $=5 \mu$ l Smart-Ladder.

\subsection{Synthese der mutierten FLAG-hEP4-Rezeptor-cDNAs zur Substitution aller} Serine und Threonine durch Alanine mittels sequenzgerichteter Mutagenese

Um alle Serine und Threonine in der C-terminalen Domäne des FLAG-hEP4 wt-R, die als potentielle Phosphorylierungsstellen dienen können, gegen Alanine auszutauschen, wurden mehrere sequenzgerichtete Mutagenesen durchgeführt. Da die Serine und Threonine z. T. unmittelbar aufeinander folgten, wurden Primer verwendet, mit denen mehrere Serine und Threonine gleichzeitig substituiert werden konnten. Zusätzlich waren die Primer so gewählt, daß sie möglichst die Erkennungssequenzen der Restriktionsendonukleasen Dra II, Sty I oder Sma I enthielten, die in der für die C-terminale Domäne codierenden Sequenz nur einmal vorkommen. Dazu wurde das für die C-terminale Domäne codierende cDNAFragment (hEP4 CT) über Kpn I und Xba I in den Vektor pBluescript kloniert. Das Konstrukt enthielt die Schnittstellen SnaB I, Dra II, Sma I, Sty I und Xba I nur einmal. Die Klonierung der einzelnen, nacheinander synthetisierten cDNA-Fragmente erfolgte über die zuvor in die FLAG-hEP4-R-cDNA eingefügte SnaB I-Schnittstelle sowie über eine Kpn I-, Dra II-, Sma I-, Sty I- und die 3' flankierende Xba I-Schnittstelle. 


\subsubsection{Einfügen der ST335-338A-Mutationen und Anfügen einer 5' der SnaB I- Restriktionsschnittstelle gelegenen Kpn I-Restriktionserkennungssequenz in hEP4 CT}

Da der pBluescript-Vektor über keine SnaB I-Restriktionsschnittstelle verfügte, wurde die die multiple Klonierungsstelle flankierende $\mathrm{Kpn}$ I-Schnittstelle an die für die C-terminale Domäne codierende Sequenz der FLAG-hEP4 wt-R-cDNA angefügt. Diese Schnittstelle war nicht in der für die C-terminale Domäne codierenden Sequenz vorhanden und durch Klonierung des Fragmentes in pBluescript über Kpn I und Xba I wurden die in der multiplen Klonierungsstelle des Vektors vorhandene Sma I- und Dra II-Schnittstelle eliminiert. Die 5' der SnaB IErkennungssequenz gelegene Kpn I-Erkennungssequenz und die notwendigen Basenaustausche für die T335A- und S338A-Mutationen waren in dem Primer SM $1 f$ lokalisiert. Es wurde eine PCR-Reaktion durchgeführt, in der pcDNA3 FLAG-hEP4 wt-R als Matrize und die Primer SM $1 \mathrm{f}$ und EP4 Xba $r$ eingesetzt wurden. Das 5' um eine Kpn IErkennungssequenz verlängerte 502 bp große Produkt (Abb. $10 \mathrm{~B}$ ) wurde mit Kpn I und $X b a$ I geschnitten und in den pBluescript-Vektor kloniert (Abb. 10 A). Die Klonierung der in E. coli amplifizierten und daraus isolierten Plasmide wurde durch eine Spaltungsreaktion mit anschließender Gelelektrophorese überprüft und das Einfügen der ST335-338A-Mutationen durch Sequenzierung bestätigt. Der erhaltene pBluescript hEP4 CT ST335-338A wurde für die Synthese weiterer Rezeptormutanten verwendet.

\subsubsection{Einfügen der ST369-382A-Mutationen in pBluescript hEP4 CT ST335-338A und Eliminierung der durch S372A-Substitution neu entstehenden Sty I-Schnittstelle}

Zum Einfügen der ST369-382A-Mutationen wurde eine PCR-Reaktion durchgeführt, in der pBluescript hEP4 CT ST335-338A als Matrize und die Primer SM 1f und SM 3r eingesetzt wurden. Der Primer SM 1f war mit dem in 4.2.1 beschriebenen Primer identisch, die notwendigen Basenaustausche für T369A und $S(370,371,374,377,379,382) A$ waren in dem SM 3r-Primer lokalisiert, der 5' eine Sma I-Erkennungssequenz trug. Zusätzlich enthielt der SM $3 r$ an Position 1116 eine weitere stille Punktmutation (C-T), die eine durch die S372ASubstitution neu entstehende Sty I-Schnittstelle eliminierte und die Klonierung der einzelnen Fragmente mit den nur einmal im Fragment vorkommenden Enzymen ermöglichte. Die Klonierung wurde über die Kpn I- und die Sma I-Schnittstelle durchgeführt, da durch Spaltung mit den Enzymen SnaB I und Sma I ein cDNA-Fragment mit nicht überlappenden Enden entstanden wäre, wodurch die Orientierung des Fragmentes während der Klonierungen nicht hätte bestimmt werden können. Das 177 bp große Produkt (Abb. 11 B) wurde mit Kpn I und Sma I geschnitten und in den pBluescript hEP4 CT ST335-338A kloniert (Abb. $11 \mathrm{~A}$ ). Die Klonierung der in E. coli amplifizierten und daraus isolierten Plasmide wurde 
durch eine Spaltungsreaktion mit anschließender Gelelektrophorese überprüft und das Einfügen der Mutationen durch Sequenzierung bestätigt. Der erhaltene pBluescript hEP4 CT ST335-338; 369-382A wurde für die weitere Synthese der Rezeptormutanten verwendet.

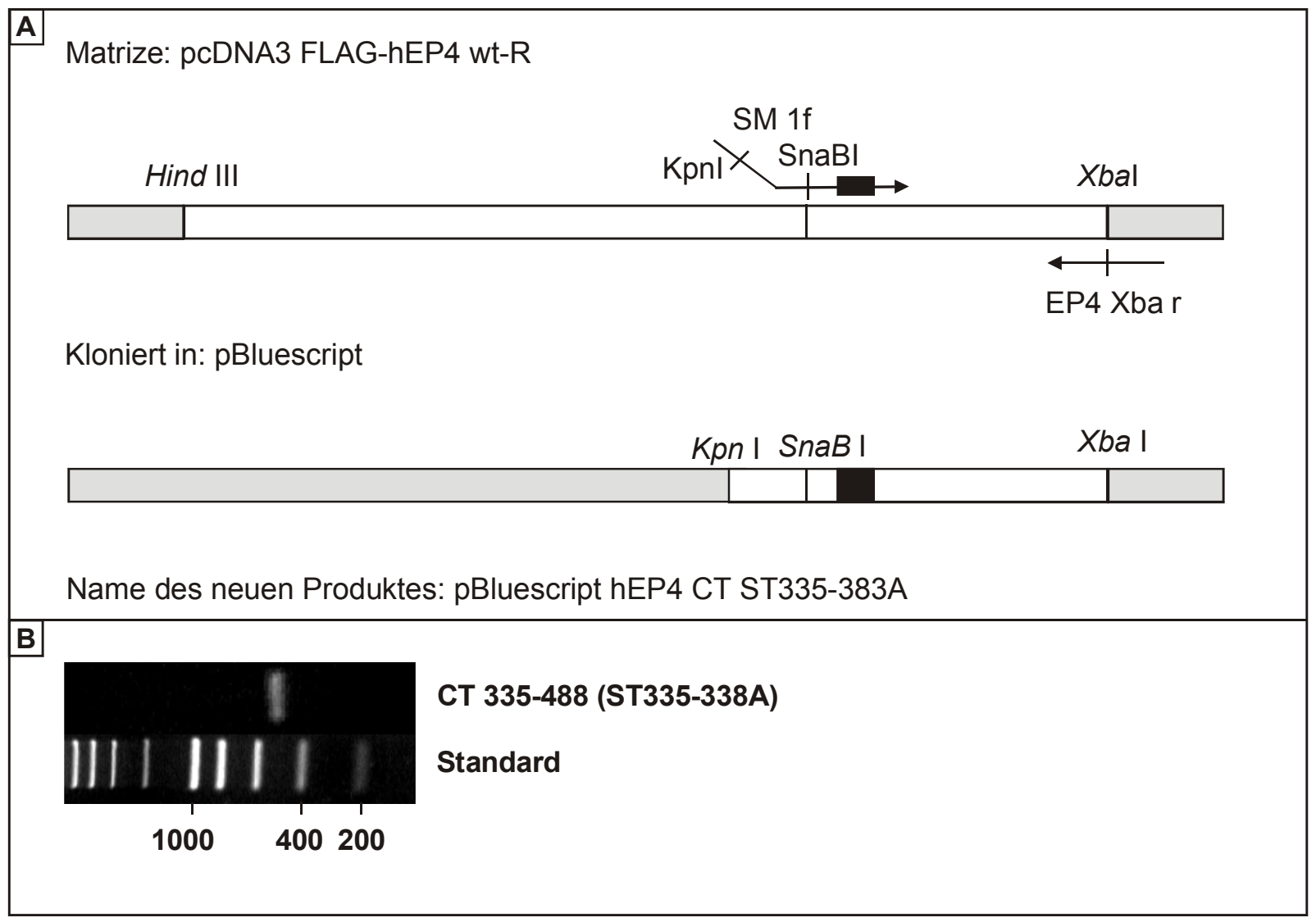

Abb. 10: Synthese des pBluescript hEP4 CT ST335-338A. A) Dargestellt ist das für die PCR-Reaktion verwendete Plasmid und die notwendigen Primer (SM 1f und EP4 Xba r). Mit dem Primer SM $1 \mathrm{f}$ wurden die Mutationen ST335-338A in die cDNA eingefügt und die Kpn IErkennungssequenz an das für die C-terminale Domäne codierende Fragment angefügt. Über die in den Primern enthaltenen Schnittstellen wurde das neue cDNA-Fragment in den pBluescript-Vektor einkloniert. Die für den FLAG-hEP4 wt-Rezeptor und die für den hEP4 CT codierenden Sequenzen sind weiß, die flankierenden Elemente der Vektoren sind grau dargestellt. Weiterhin sind die verwendeten Restriktionsschnittstellen ( Kpn I und Xba I) und das erhaltene Klonierungsprodukt mit den eingefügten Mutationen ST335-338A (schwarz) gezeigt. B) Dargestellt ist das durch PCR amplifizierte Produkt. Für einen $50 \mu \mathrm{l} \mathrm{PCR-Ansatz}$ wurden 5 ng Plasmid mit je 30 pmol Vorwärts- und Rückwärtsprimer und 2 U PowerscriptDNA-Polymerase eingesetzt (siehe 3.1.3). Das mutierte DNA-Fragment wurde mit folgendem Programm amplifiziert: $3 \min 95^{\circ} \mathrm{C} ; 35 \times\left(1 \min 95^{\circ} \mathrm{C} ; 1 \min 55^{\circ} \mathrm{C} ; 2 \min 72^{\circ} \mathrm{C}\right) ; 10 \min 72^{\circ} \mathrm{C}$ und in einem 1\% (w/v) Agarose-Gel aufgetrennt. Die Analyse zeigte das bei ca. 500 bp erwartete DNA-Fragment CT 335-488(ST335-338A). 


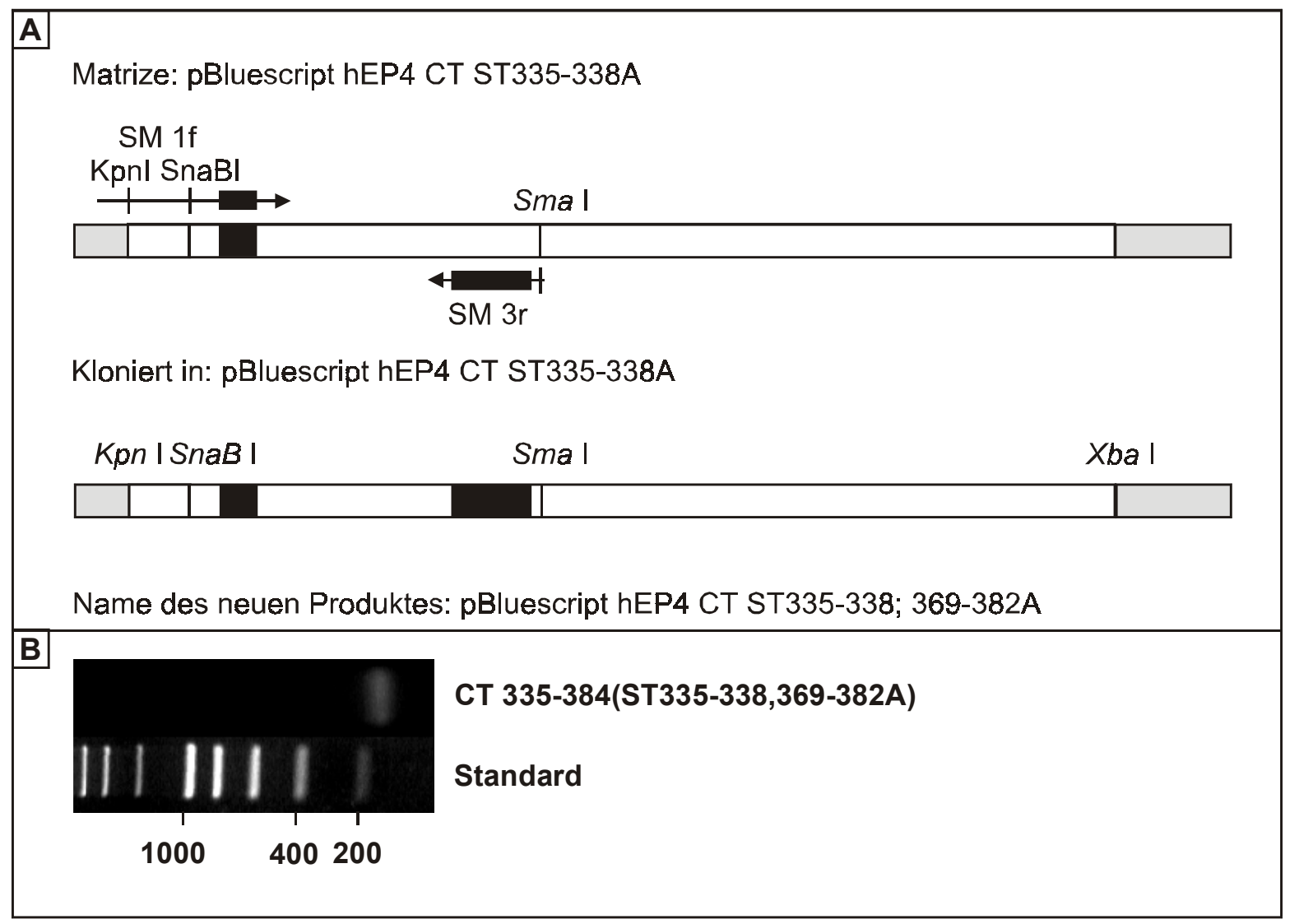

Abb. 11: Synthese des pBluescript hEP4 CT ST335-338; 369-382A. A) Dargestellt ist das für die PCR-Reaktion verwendete Plasmid und die notwendigen Primer (SM 1f und SM 3r). Mit dem Primer SM 3r wurden die Mutationen ST369-382A in die cDNA eingefügt. Über die in den Primern enthaltenen Schnittstellen wurde das neue cDNA-Fragment in den pBluescript hEP4 CT ST335-338A einkloniert. Die für die C-terminale Domäne codierende Sequenz der hEP4-R-cDNA ist weiß, die flankierenden Elemente des Vektors sind grau dargestellt. Weiterhin sind die verwendeten Restriktionsschnittstellen (Kpn I und Sma I) und das erhaltene Klonierungsprodukt mit den eingefügten ST369-382A-Mutationen (schwarz) gezeigt. B) Dargestellt ist das, wie in Abb. 10 beschrieben, durch PCR amplifizierte Produkt. Die Analyse in einem 2\% (w/v) Agarose-Gel zeigte das bei ca. 180 bp erwartete DNAFragment CT 335-384(ST335-338; 369-382A).

\subsubsection{Einfügen der ST428-443A-Mutationen in den pBluescript hEP4 CT ST335-338; 369-382A}

Zum Einfügen der ST428-443A-Mutationen wurden drei PCR-Reaktionen durchgeführt, in denen der pcDNA3 FLAG-hEP4 wt-R in der ersten und zweiten Reaktion als Matrizen-cDNA und die Primer Hind EP4 $f$ und SM 6r bzw. SM 6f und EP4 Xba $r$ eingesetzt wurden. Der pcDNA3 FLAG-hEP4 wt-R wurde als Matrizen-cDNA gewählt, da die PCR-Reaktionen parallel zur Synthese des pBluescript hEP4 ST ST335-338; 369-382A durchgeführt wurden. Die notwendigen Basenaustausche für $\mathrm{T}(428,429,433,439) \mathrm{A}$ und $\mathrm{S}(430,437,440,442,443) \mathrm{A}$ waren in den komplementären SM 6f- und SM 6r-Primern lokalisiert. Die amplifizierten 1372 bp großen (NT 1-444(ST428-443A)) und 207 bp großen (CT 427-488(ST428-443A)) Megaprimer (Abb. 12 B) wurden mit den flankierenden Primern Hind FLAG EP4 $f$ und EP4 
Xba $r$ in eine dritte PCR-Reaktion eingesetzt. Das 1519 bp große Produkt (Abb. 12 B) der dritten PCR wurde mit Sty I und Xba I geschnitten und in den pBluescript hEP4 CT ST335338; 369-382A kloniert (Abb. 12 A). Die Klonierung der in E. coli amplifizierten und daraus isolierten Plasmide wurde durch eine Spaltungsreaktion mit anschließender Gelelektrophorese überprüft und das Einfügen der Mutationen durch Sequenzierung bestätigt. Der erhaltene pBluescript hEP4 CT ST335-338; 369-382; 428-443A wurde für die weitere Synthese der Rezeptormutanten verwendet.

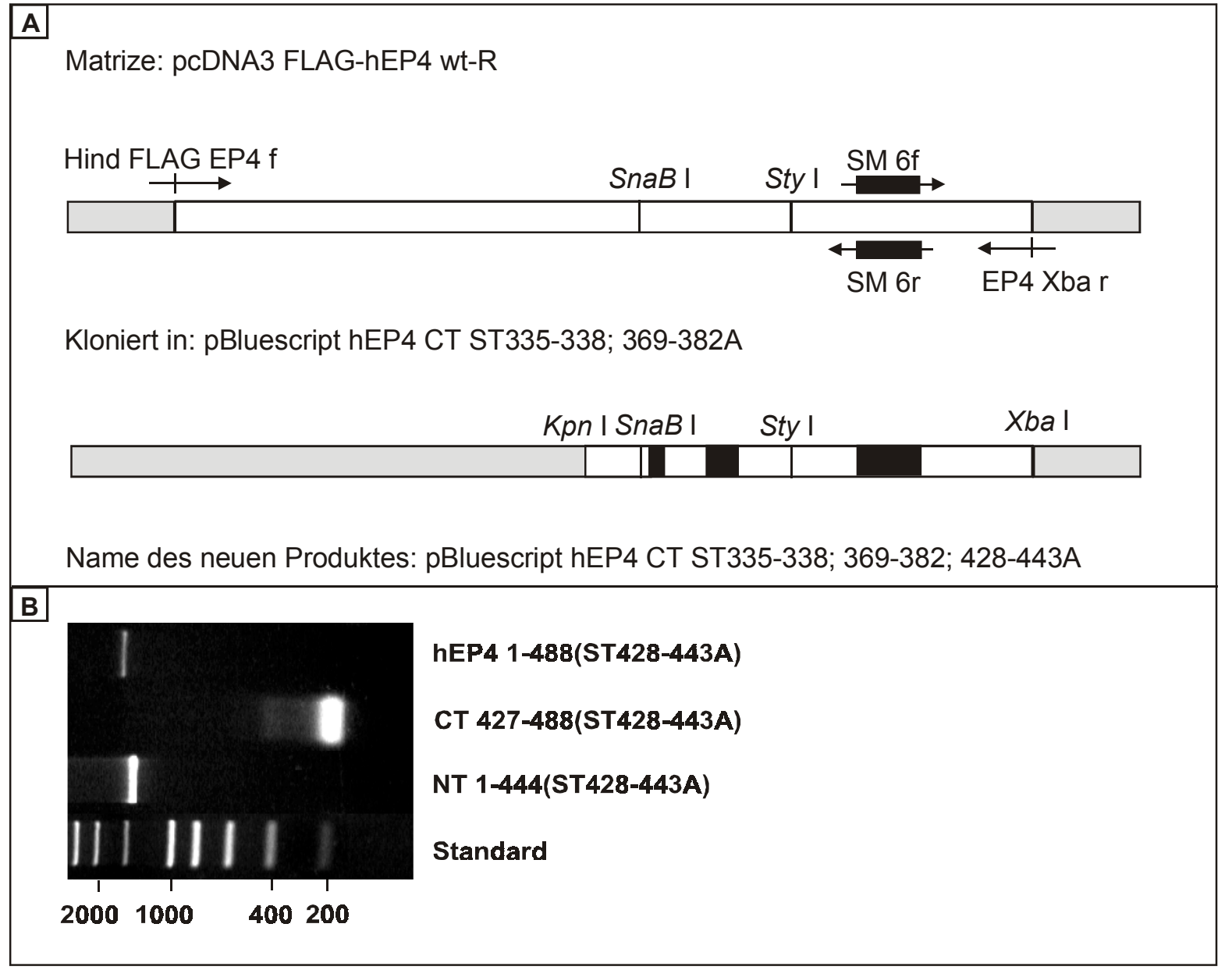

Abb. 12: Synthese des pBluescript hEP4 CT ST335-338; 369-382; 428-443A. Dargestellt ist das für die PCR-Reaktionen verwendete Plasmid und die notwendigen Primer (Hind FLAG EP4 $f$ und SM $6 r$ sowie SM $6 f$ und EP4 Xba $r$ ). Mit den Primern SM 6f und SM $6 r$ wurden die neuen Mutationen ST428-443A in die cDNA eingefügt. Über die in der cDNA enthaltenen Schnittstellen wurde das neu synthetisierte cDNA-Fragment in den pBluescript hEP4 CT ST335-338; 369-382A einkloniert. Die für den FLAG-hEP4 wt-Rezeptor und die für den hEP4 CT codierenden Sequenzen sind weiß, die flankierenden Elemente des Vektors sind grau dargestellt. Weiterhin sind die verwendeten Restriktionsschnittstellen (Sty I und $X b a$ I) und das erhaltene Klonierungsprodukt mit den eingefügten ST428-443A-Mutationen (schwarz) gezeigt. B) Dargestellt sind die, wie in Abb. 10 beschrieben, durch PCR amplifizierten Produkte. Die Analyse in einem 1\% (w/v) Agarose-Gel zeigte wie erwartet das ca. 1300 bp große, durch Hind FLAG EP4 f und SM 6r (NT 1-444(ST428-443)), das ca. 200 bp große, durch SM $6 f$ und EP4 Xba r (CT 427-488(ST428-443)) und das ca. 1500 bp große, durch Hind FLAG EP4 f und EP4 Xba r (hEP4 1-488(ST428-443)) amplifizierte cDNAFragment. 


\subsubsection{Einfügen der ST354-366; 400-405A-Mutationen in pBluescript hEP4 CT ST335- 338; 369-382; 428-443A}

Zum Einfügen der ST354-366; 400-405A-Mutationen wurde eine PCR-Reaktion durchgeführt, in der der pBluescript hEP4 CT ST335-338; 369-382; 428-443A als Matrize und die Primer SM $2 f$ und SM $5 r$ eingesetzt wurden. Die notwendigen Basenaustausche für S(354,359,364,366)A waren in dem Primer SM 2f lokalisiert, der 5' die Dra IIErkennungssequenz trug, die notwendigen Basenaustausche für S(400,405)A waren in dem Primer SM 5r lokalisiert, der 5' die Sty I-Erkennungssequenz trug. Das 182 bp große Produkt (Abb. 13 B) wurde mit Dra II und Sty I geschnitten und in den pBluescript hEP4 CT ST335338; 369-382; 428-443A, der mit den gleichen Enzymen geschnitten worden war, einkloniert (Abb. $13 \mathrm{~A}$ ). Die Klonierung der in E. coli amplifizierten und daraus isolierten Plasmide wurde durch eine Spaltungsreaktion mit anschließender Gelelektrophorese überprüft und das Einfügen der Mutationen durch Sequenzierung bestätigt. Der erhaltene pBluescript hEP4 CT ST335-382; 400-443A wurde für die weitere Synthese der Rezeptormutanten verwendet.

\subsubsection{Einfügen der ST448-484A-Mutationen in pBluescript hEP4 CT ST335-382; 400- 443A}

Zum Einfügen der ST448-484A-Mutationen wurden drei PCR-Reaktionen durchgeführt, in denen der pBluescript hEP4 CT ST335-338; 369-382; 428-443A als Matrize und die Primer $S M \quad 4 f$ und SM $7 r$ bzw. SM $7 f$ und SM $8 r$ eingesetzt wurden. Die notwendigen Basenaustausche für $S(448,450,460)$ A waren auf den komplementären Primern SM $7 f$ und SM $7 r$ lokalisiert, die notwendigen Basenaustausche für die $S(470,471,478,484) A-$ und T(475,480)A-Mutationen waren auf dem SM 8r-Primer lokalisiert, der 5' die Xba IErkennungssequenz trug. Die in den PCR-Reaktionen amplifizierten, 245 bp großen (CT 383-462(ST389-394, 428-460A)) und 139 bp großen (CT 448-488(ST448-488)) Megaprimer (Abb. $14 \mathrm{~B}$ ) wurden in eine dritte PCR-Reaktion mit den Primern SM 4f und SM 8r eingesetzt. Das 337 bp große Produkt (CT 383-488(ST389-394,428-488)) (Abb. 14 B) wurde mit Sty I und Xba I geschnitten und in den pBluescript hEP4 CT ST335-382; 400-443A kloniert (Abb. 14 A). Da die PCR-Reaktionen parallel zur Synthese des pBluescript hEP4 ST335-382; 400-443A durchgeführt wurden, konnte dieses Konstrukt nicht als MatrizencDNA verwendet werden. Daher diente der SM $4 \mathrm{f}$ nur als Synthese-Primer und die über diesen Primer eingefügten Mutationen gingen durch die Klonierung des Produktes über Sty I und $X b a$ I verloren, wurden aber über eine weitere PCR-Reaktion eingefügt. Die Klonierung der in E. coli amplifizierten und daraus isolierten Plasmide wurde durch eine Spaltungsreaktion mit anschließender Gelelektrophorese überprüft und das Einfügen der 
Mutationen durch Sequenzierung bestätigt. Der erhaltene pBluescript hEP4 CT ST335-382; 400-484A wurde für die weitere Synthese der Rezeptormutanten verwendet.

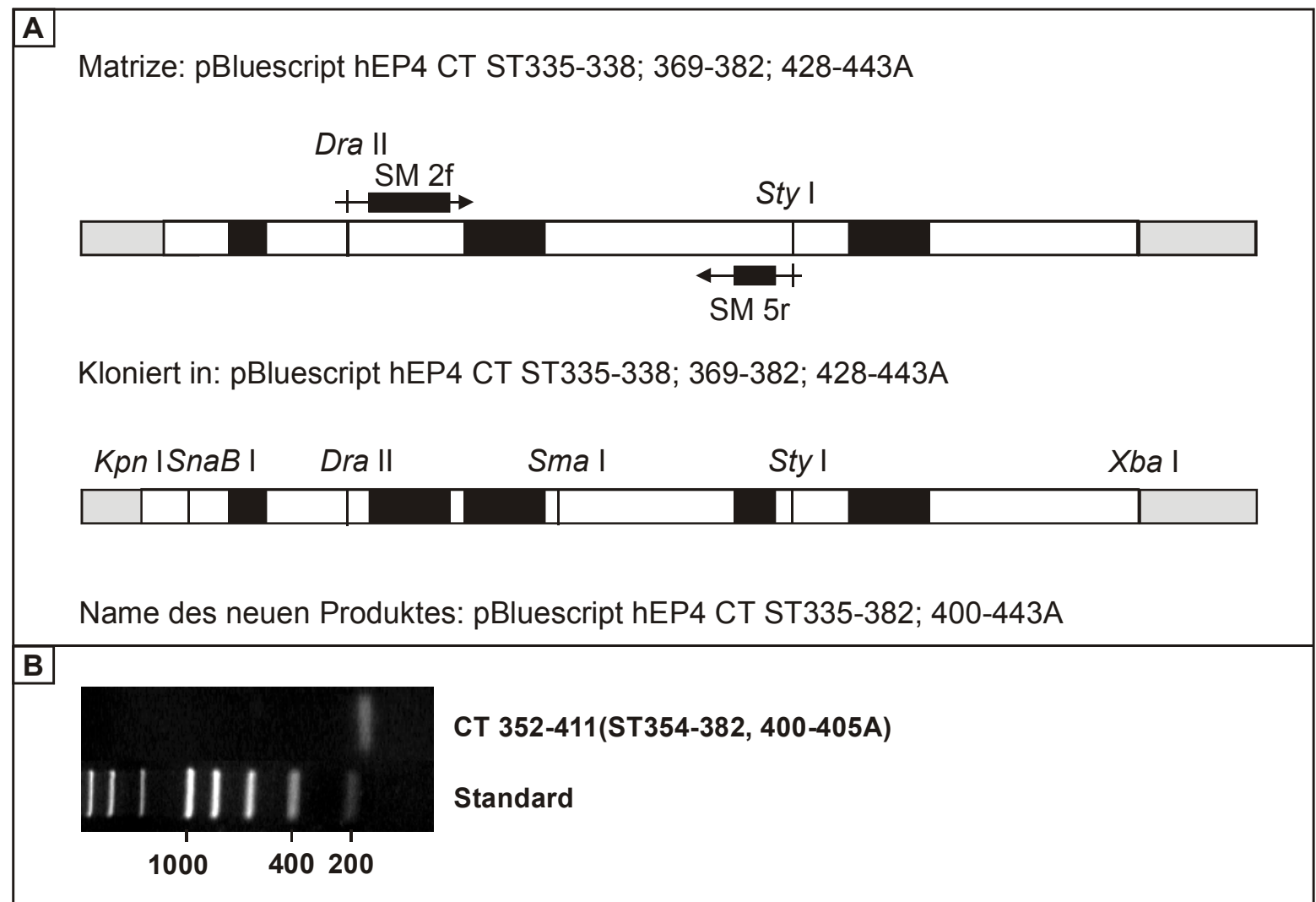

Abb. 13: Synthese des pBluescript hEP4 CT ST335-382; 400-443A. A) Dargestellt ist das für die PCR-Reaktion verwendete Plasmid und die notwendigen Primer (SM $2 f$ und SM $5 r$ ). Mit den Primern SM $2 f$ und SM $5 r$ wurden die neuen Mutationen ST534-366A und ST400$405 \mathrm{~A}$ in die cDNA eingefügt. Über die in den Primern enthaltenen Schnittstellen wurde das neu synthetisierte cDNA-Fragment in den pBluescript hEP4 CT ST335-338; 369-382; 428443A einkloniert. Die für den hEP4 CT codierende Sequenz ist weiß, die flankierenden Elemente des Vektors sind grau dargestellt. Weiterhin sind die verwendeten Restriktionsschnittstellen (Dra II und Sty I) und das erhaltene Klonierungsprodukt mit den eingefügten Mutationen (schwarz) gezeigt. B) Dargestellt ist das, wie in Abb. 10 beschrieben, durch PCR amplifizierte Produkt. Die Analyse in einem 2\% (w/v) Agarose-Gel zeigte das erwartete ca. 180 bp große cDNA-Fragment CT 352-411(ST354-382, 400-405A). 


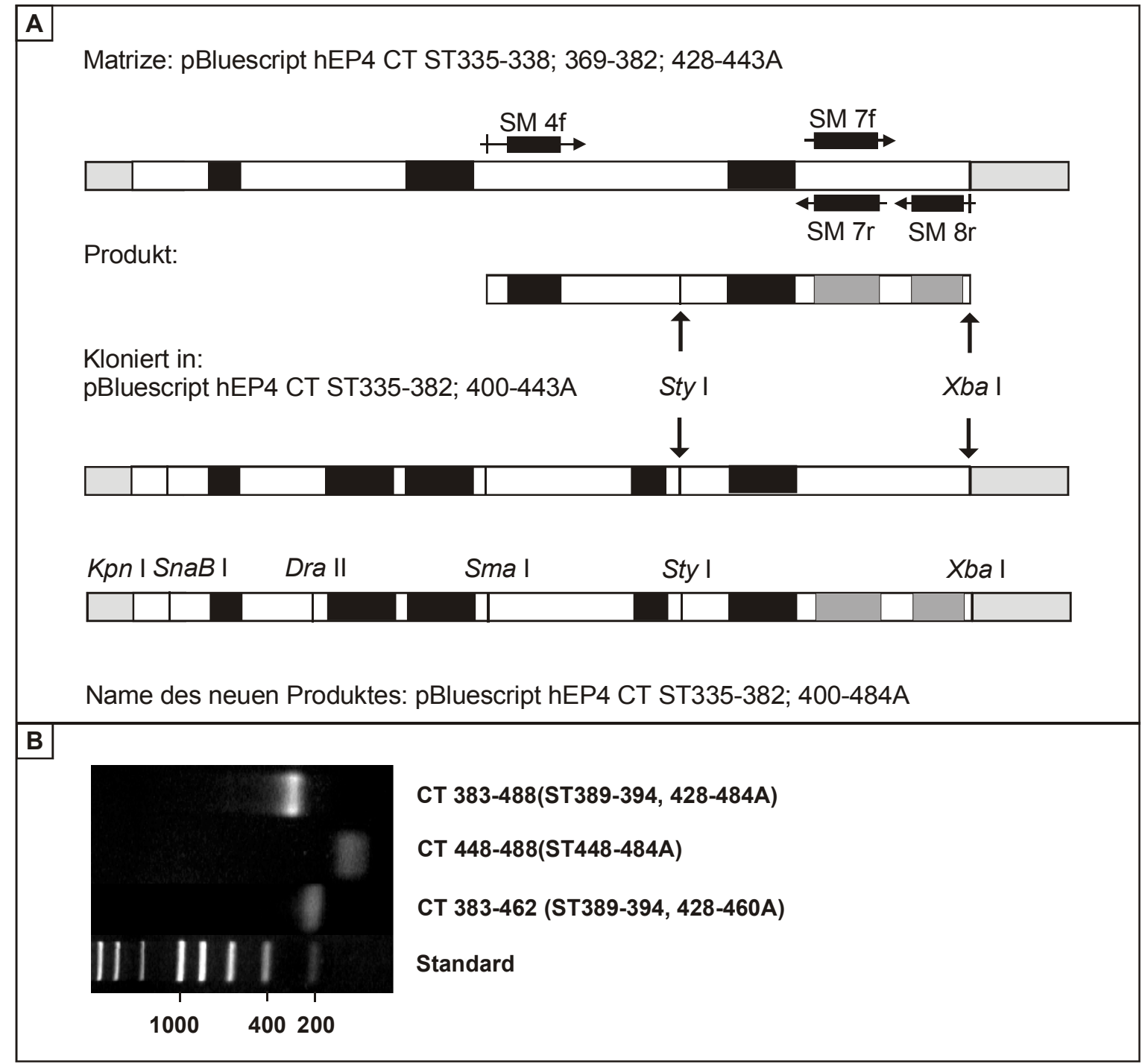

Abb. 14: Synthese des pBluescript hEP4 CT ST335-382; 400-484A. A) Dargestellt ist das für die PCR-Reaktion verwendete Plasmid und die notwendigen Primer (SM 4f und SM 7r sowie SM $7 f$ und SM 8r). Mit den Primern SM 4f und SM 7r sowie SM $7 f$ und SM $8 r$ wurden zwei Megaprimer synthetisiert, mit deren Hilfe zusammen mit den Primern SM 4f und SM 8r ein cDNA-Fragment amplifiziert wurde, das über Sty I und $X b a I$ in das zuvor synthetisierte Konstrukt pBluescript hEP4 CT ST335-382; 400-443A kloniert wurde. Mit den Primern SM $7 f$ und SM 7r wurden die Mutationen ST448-460A und mit dem Primer SM 8r die Mutationen ST470-484A eingefügt. Die für hEP4 CT codierende Sequenz ist weiß, die flankierenden Elemente des Vektors sind hellgrau dargestellt. Weiterhin sind die verwendeten Restriktionsschnittstellen (Sty I und Xba I (Pfeile)) und das erhaltene Klonierungsprodukt mit den eingefügten Mutationen (dunkelgrau) gezeigt. B) Dargestellt sind die, wie in Abb. 10 beschrieben, durch PCR amplifizierten Produkte. Die Analyse in einem 2\% (w/v) AgaroseGel zeigte wie erwartet das ca. 240 bp große, durch SM 4f und SM 7r (CT 383-462(ST389394, 428-460A)), das ca. 140 bp große, durch SM 7f und SM 8r (CT 448-488(ST448-488)) und das ca. 340 bp große, durch SM 4f und SM 8r (CT 383-488(ST389-394,428-488)) amplifizierte DNA-Fragment. 


\subsubsection{Einfügen der ST389-394A-Mutationen in pBluescript hEP4 CT ST335-382; 400- 484A und Eliminierung der durch T394A-Substitution neu entstehenden Dra II- Schnittstelle}

Zum Einfügen der ST389-394A-Mutationen wurde eine PCR-Reaktion durchgeführt, in der der pBluescript hEP4 CT ST335-382; 400-484A als Matrize und die Primer SM 4f und SM 8r eingesetzt wurden. Die notwendigen Basenaustausche für $\mathrm{S}(389,390,392) A$ und $\mathrm{T}(391,394) \mathrm{A}$ waren in dem SM 4f-Primer lokalisiert, der 5' die Sma I-Erkennungssequenz trug. Zusätzlich enthielt der SM 4f an Position 1179 eine weitere stille Mutation (G-A), die die durch die T394A-Substitution neu entstehende Dra II-Schnittstelle eliminierte und die Klonierung der einzelnen Fragmente mit den nur einmal im Fragment vorkommenden Schnittstellen ermöglichte. Der SM 8r entsprach dem unter 4.2.5 beschriebenen Primer. Das amplifizierte 337 bp große Produkt (CT 383-488(ST389-488A)) (Abb. 15 B) wurde mit Sma I und $X$ ba I geschnitten und in den pBluescript hEP4 CT ST335-382; 400-484A kloniert (Abb. 15 A). Die Klonierung der in E. coli amplifizierten und daraus isolierten Plasmide wurde durch eine Spaltungsreaktion mit anschließender Gelelektrophorese überprüft und das Einfügen der Mutationen durch Sequenzierung bestätigt. In dem erhaltenen pBluescript hEP4 CT ST335-484A waren alle Serine und Threonine durch Alanine substituiert. Durch verschiedene Spaltungsreaktionen und Klonierungen wurden die weiteren Rezeptormutanten hergestellt.

\subsubsection{Synthese des pBluescript hEP4 CT ST335-405A und des pBluescript hEP4 CT ST428-484A}

Es wurden zwei Rezeptormutanten synthetisiert, in denen entweder alle im proximalen Teil oder alle im distalen Teil der C-terminalen Domäne des hEP4-Rezeptors gelegenen Serine und Threonine durch Alanine substituiert waren, um weiter eingrenzen zu können, welche dieser potentiellen Phosphorylierungsstellen Agonisten-abhängig phosphoryliert werden und an der Agonisten-induzierten Internalisierung beteiligt sind. Dazu wurde der pBluescript hEP4 CT und der pBluscript hEP4 CT ST335-484A mit Kpn I und Sty I geschnitten und die Kpn I/Sty I-Fragmente zwischen den beiden Konstrukten ausgetauscht. In den Produkten, dem pBluescript hEP4 CT ST335-405A und dem pBluescript hEP4 CT ST428-484A, waren alle im proximalen bzw. distalen Teil der C-terminalen Domäne lokalisierten Serine und Threonine durch Alanine substituiert (Abb. 16). Die Klonierung der in E. coli amplifizierten und daraus isolierten Plasmide wurde durch eine Spaltungsreaktion und anschließende Gelelektrophorese überprüft. 


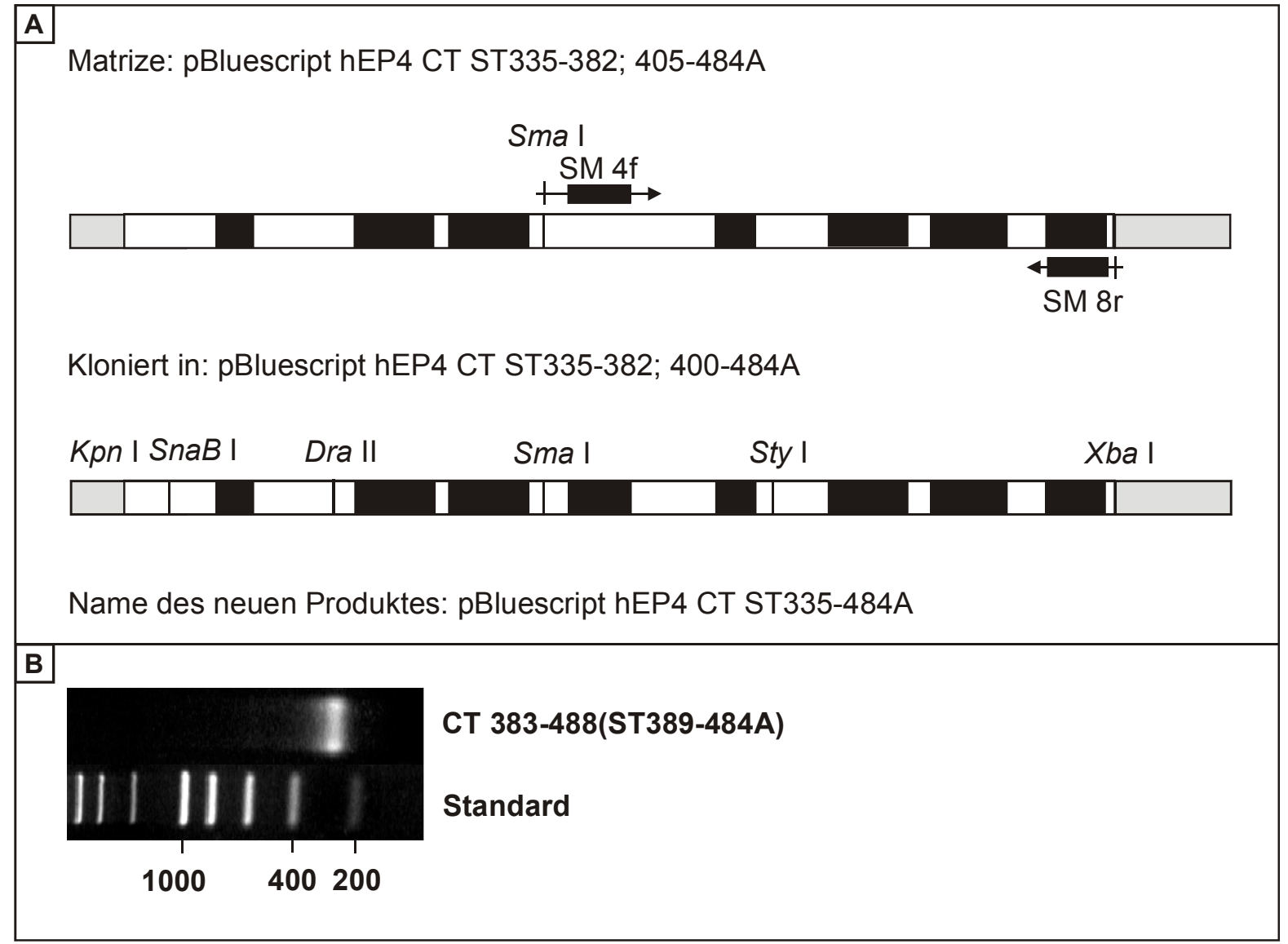

Abb. 15: Synthese des pBluescript hEP4 CT ST335-484A. A) Dargestellt ist das für die PCR-Reaktion verwendete Plasmid und die notwendigen Primer (SM 4f und SM 8r). Mit dem Primern SM $4 \mathrm{f}$ wurden die Mutationen ST389-394A eingefügt. Über die in den Primern enthaltenen Schnittstellen wurde das neu synthetisierte cDNA-Fragment in den pBluescript hEP4 CT ST335-382; 400-443A einkloniert. Die für hEP4 CT codierende Sequenz ist weiß, die flankierenden Elemente des Vektors sind grau dargestellt. Weiterhin sind die verwendeten Restriktionsschnittstellen (Sma I und Xba I) und das erhaltene Klonierungsprodukt mit den eingefügten Mutationen (schwarz) gezeigt. B) Dargestellt ist das, wie in Abb. 10 beschrieben, durch PCR amplifizierte Produkt. Die Analyse in einem 1\% (w/v) Agarose-Gel zeigte das erwartete ca. 340 bp große cDNA-Fragment CT 383-488(ST389488A). 
Ausgangsplasmide: pBluescript hEP4 CT und -hEP4 CT ST335-484A

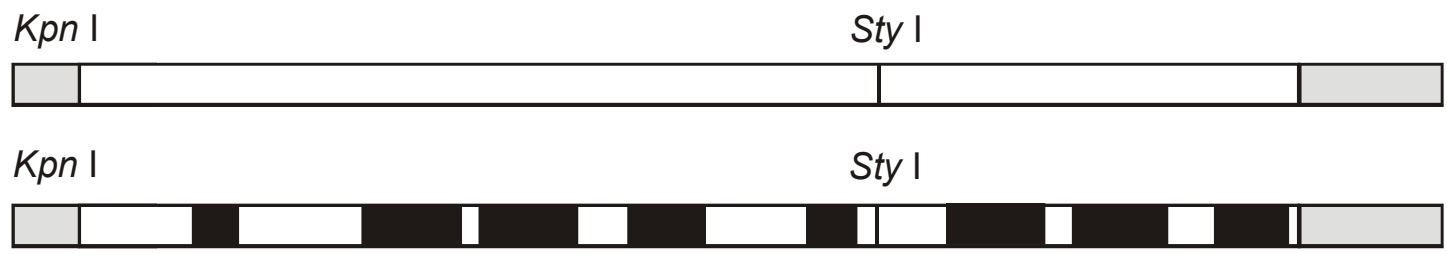

Kloniert in: pBluescript hEP4 CT und -hEP CT ST335-484A

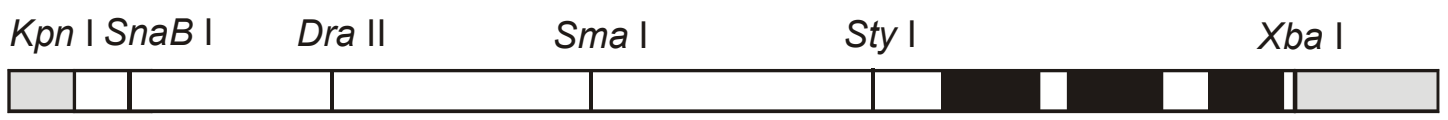

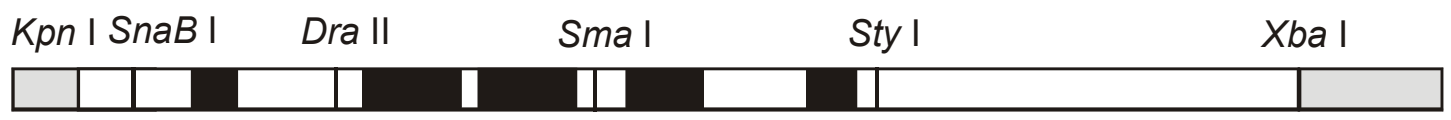

Name der neuen Produkte: pBluescript hEP4 CT ST335-405A pBluescript hEP4 CT ST428-484A

Abb. 16: Synthese des pBluescript hEP4 CT ST335-405A und des pBluescript hEP4 CT ST428-484A. Dargestellt sind die verwendeten Ausgangsplasmide und die erhaltenen Klonierungsprodukte. Die Ausgangsplasmide wurden mit SnaB I und Sty I geschnitten und die einzelnen Fragmente isoliert. Das cDNA-Fragment mit den Mutationen ST335-405A wurde in das Plasmid pBluescript hEP4 CT, das cDNA-Fragment, in dem ST335-405 erhalten waren, in das Plasmid pBluescript hEP4 CT ST335-484A kloniert. Die für die Cterminalen Domänen codierenden Sequenzen sind weiß, die flankierenden Elemente des Vektors sind grau dargestellt. Weiterhin sind die verwendeten Restriktionsschnittstellen (SnaB I und Sty I) und die Mutationen (schwarz) gezeigt.

\subsubsection{Synthese des pBluescript hEP4 CT ST335-354; 389-484A und des pBluescript hEP4 CT ST335-382A}

Die Analyse der Agonisten-induzierten Phosphorylierung der Mutanten, in denen die Phosphorylierungsstellen entweder im proximalen oder im distalen Teil der C-terminalen Domäne eliminiert worden waren, deutete darauf hin, daß vorwiegend Serine und Threonine im proximalen Teil der C-terminalen Domäne Agonisten-abhängig phosphoryliert werden (siehe 4.6.2). Daher wurden weitere Mutanten mit dem Ziel hergestellt, den Bereich, in dem die für die Agonisten-induzierte Phosphorylierung relevanten Serine und Threonine liegen, weiter einzugrenzen. Dazu wurden entweder die Serine und Threonine im Bereich zwischen 359-382 (ST335-354; 389-484A) bzw. Serin 379 (ST335-377; 382-484A) als einzige in der C-terminalen Domäne belassen oder nur die Serine und Threonine bis einschließlich Serin 382 (ST335-382A) bzw. selektiv Serin 379 (S379A) eliminiert. Zur Synthese des pBluescript 
hEP4 CT ST335-354; 389-484A wurden der pBluescript hEP4 CT ST335-484A und der pBluescript hEP4 CT mit den Restriktionsenzymen Dra II und Sma I geschnitten und anschließend das aus dem pBluescript hEP4 CT herausgeschnittene cDNA-Fragment, in dem die ST359-382 erhalten waren, in den pBluescript hEP4 CT ST335-484A ligiert (Abb. 17).

Ausgangsplasmid: pBluescript hEP4 CT

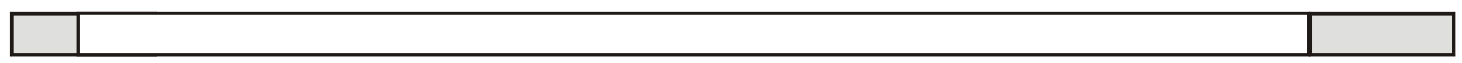

Kloniert in: pBluescript hEP CT ST335-484A

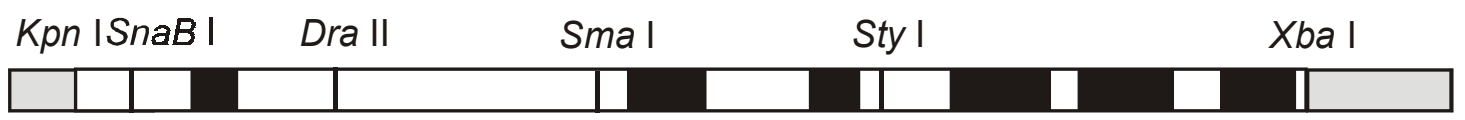

Name des neuen Produktes: pBluescript hEP4 CT ST335-354; 389-405A

Abb. 17: Synthese des pBluescript hEP4 CT ST335-354; 389-484A. Dargestellt ist das verwendete Ausgangsplasmid und das erhaltene Klonierungsprodukt. Das Ausgangsplasmid und das Zielplasmid wurden mit Dra II und Sma I geschnitten und die einzelnen Fragmente isoliert. Das cDNA-Fragment, in dem ST359-382 erhalten waren, wurde anschließend in das Plasmid pBluescript hEP4 CT ST335-484A kloniert. Die für die C-terminalen Domänen codierenden Sequenzen sind weiß, die flankierenden Elemente des Vektors sind grau und die Mutationen sind schwarz dargestellt.

Zur Synthese des pBluescript hEP4 CT ST335-382A wurden der pBluescript hEP4 CT ST335-484A und der pBluescript hEP4 CT mit den Restriktionsenzymen Kpn I und Sma I geschnitten und anschließend das aus dem pBluescript hEP4 CT ST335-484A herausgeschnittene cDNA-Fragment, in dem die ST335-382 durch Alanine substituiert waren, in den pBluescript hEP4 CT ligiert (Abb. 18). Anschließend wurde die Klonierung der in E. coli amplifizierten und daraus isolierten Plasmide durch eine Spaltungsreaktion und Gelelektrophorese überprüft. 
Ausgangsplasmid: pBluescript hEP4 CT ST335-484A

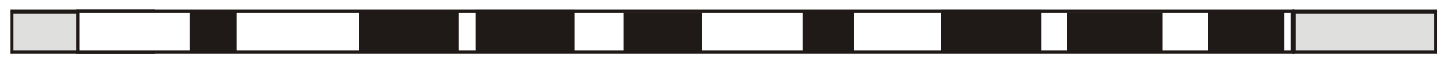

Kloniert in: pBluescript hEP4 CT

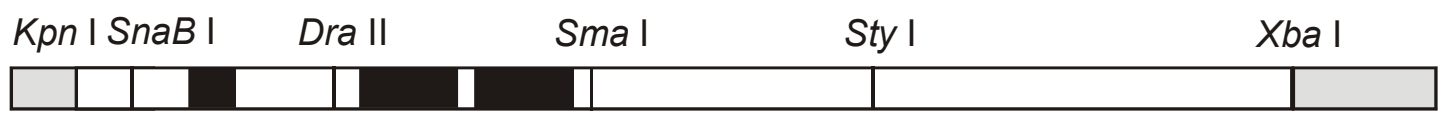

Name des neuen Produktes: pBluescript hEP4 CT ST335-382A

Abb. 18: Synthese des pBluescript hEP4 CT ST335-382A. Dargestellt ist das verwendete Ausgangsplasmid und das erhaltene Klonierungsprodukt. Das Ausgangsplasmid und das Zielplasmid wurden mit Kpn I und Sma I geschnitten und die einzelnen Fragmente isoliert. Das cDNA-Fragment mit den Mutationen ST335-382A wurde anschließend in das Plasmid pBluescript hEP4 CT kloniert. Die für die C-terminalen Domänen codierenden Sequenzen sind weiß, die flankierenden Elemente des Vektors sind grau und die Mutationen sind schwarz dargestellt.

Die mutierten, für die C-terminale Domäne codierenden Fragmente wurden über SnaB I und $X b a I$ aus pBluescript herausgeschnitten (siehe 3.4). Anschließend wurden die in AgaroseGelen aufgetrennten und daraus isolierten 3'-Fragmente des hEP4-R zusammen mit dem 5'Fragment des hEP4-R in den eukaryoten Expressionsvektor pcDNA3 kloniert (siehe 4.3).

\subsubsection{Synthese der FLAG-hEP4 S379A- und der FLAG-hEP4 ST335-377; 382-484A- Rezeptor-cDNA}

Durch sequenzgerichtete Mutagenese mit dem pcDNA3 FLAG-hEP4 wt-R und den Primern Hind FLAG EP4 $\mathrm{f}$ und EP4 S379A r sowie EP4 S379A f und EP4 Xba $r$ wurden ein 1187 bp großer Megaprimer (NT 1-382(S379A)) und ein 356 bp großer Megaprimer (CT 376488(S379A)) amplifiziert (Abb. 19 B), mit deren Hilfe unter Verwendung der flankierenden Primer Hind FLAG EP4 $f$ und EP4 Xba $r$ die komplette mutierte FLAG-hEP4-cDNA amplifiziert wurde (Abb.19 A). Das erhaltene 1519 bp große Produkt wurde mit SnaB I und $X b a$ I verdaut und das für die C-terminale Domäne codierende mutierte cDNA-Fragment mit dem zuvor sequenzierten FLAG-hEP4 NT in den pcDNA3-Vektor ligiert (Abb 19 A). Die erfolgreiche Klonierung wurde durch Restriktionsfragmentlängen-Analyse überprüft und die eingeführte Mutation durch Sequenzierung mit dem SP6-Sequenzierprimer in einer Richtung bestätigt. 


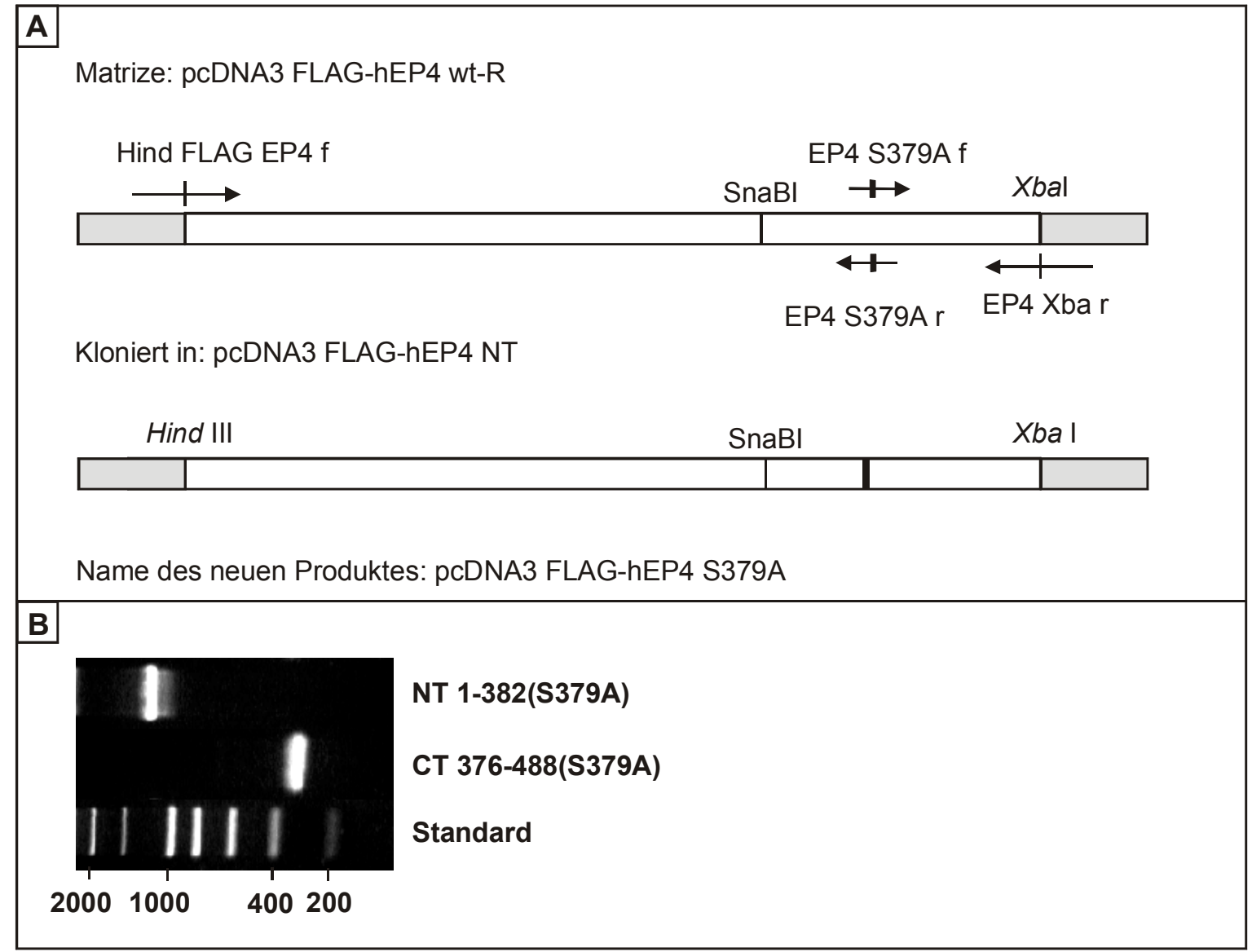

Abb. 19: Synthese des pcDNA3 FLAG-hEP4 S379A. A) Dargestellt ist das für die PCRReaktionen verwendete Plasmid und die notwendigen Primer (Hind FLAG EP4 $f$ und EP4 S379A r sowie EP4 S379A $f$ und EP4 Xba $r$ ). Mit den Primern Hind FLAG EP4 $f$ und EP4 S379A r sowie EP4 S379A f und EP4 Xba $r$ wurden zwei Megaprimer synthetisiert, mit deren Hilfe zusammen mit den Primern Hind FLAG EP4 $f$ und EP4 Xba $r$ die komplette FLAG-hEP4 S379A cDNA amplifiziert wurde. Mit den komplementären Primern EP4 S379A $f$ und EP4 S379A $r$ wurde die S379A-Mutation eingefügt. Die die Mutation tragende FLAG-hEP4-cDNA wurde mit $S n a B I$ und $X b a$ I verdaut und die für die C-terminale Domäne codierende Sequenz in den pcDNA3 FLAG-hEP4 NT kloniert. Die für den FLAG-hEP4 codierende Sequenz ist weiß, die flankierenden Elemente des Vektors sind grau dargestellt. Weiterhin sind die verwendeten Restriktionsschnittstellen (SnaB I und Xba I) und das erhaltene Klonierungsprodukt mit der eingefügten Mutation (schwarz) gezeigt. B) Dargestellt sind die, wie in Abb. 10 beschrieben, durch PCR amplifizierten Produkte. Die Analyse in einem 1\% (w/v) Agarose-Gel zeigte wie erwartet das ca. 1200 bp große, durch Hind FLAG EP4 $\mathrm{f}$ und EP4 S379A r (NT 1-382(S379A)) und das ca. 350 bp große, durch EP4 S379A $f$ und EP4 Xba r (CT 376-488(S379A)) amplifizierte DNA-Fragment.

Zur Synthese der Rezeptor-cDNA, in der alle Serine und Threonine außer S379 mutiert waren, wurde eine sequenzgerichtete Mutagenese mit drei PCR-Reaktionen mit pcDNA3 FLAG-hEP4 ST335-484A als Matrizen-cDNA und den Primern Hind FLAG EP4 $\mathrm{f}$ und EP4 A379S $r$ sowie EP4 A379S f und EP4 Xba $r$ durchgeführt. Der in der ersten PCR-Reaktion amplifizierte 1187 bp große Megaprimer (NT 1-382 (ST335-377,382A)) und der in der zweiten PCR-Reaktion amplifizierte 356 bp große Megaprimer (CT 376-488(S377,382484A)) (Abb. 20 B) wurden unter Verwendung der flankierenden Primer Hind FLAG EP4 $f$ 
und EP4 Xba $r$ in eine dritte PCR-Reaktion eingesetzt, in der die FLAG-hEP4 ST335-377; 382-484A-cDNA amplifiziert wurde (Abb. 20 A).

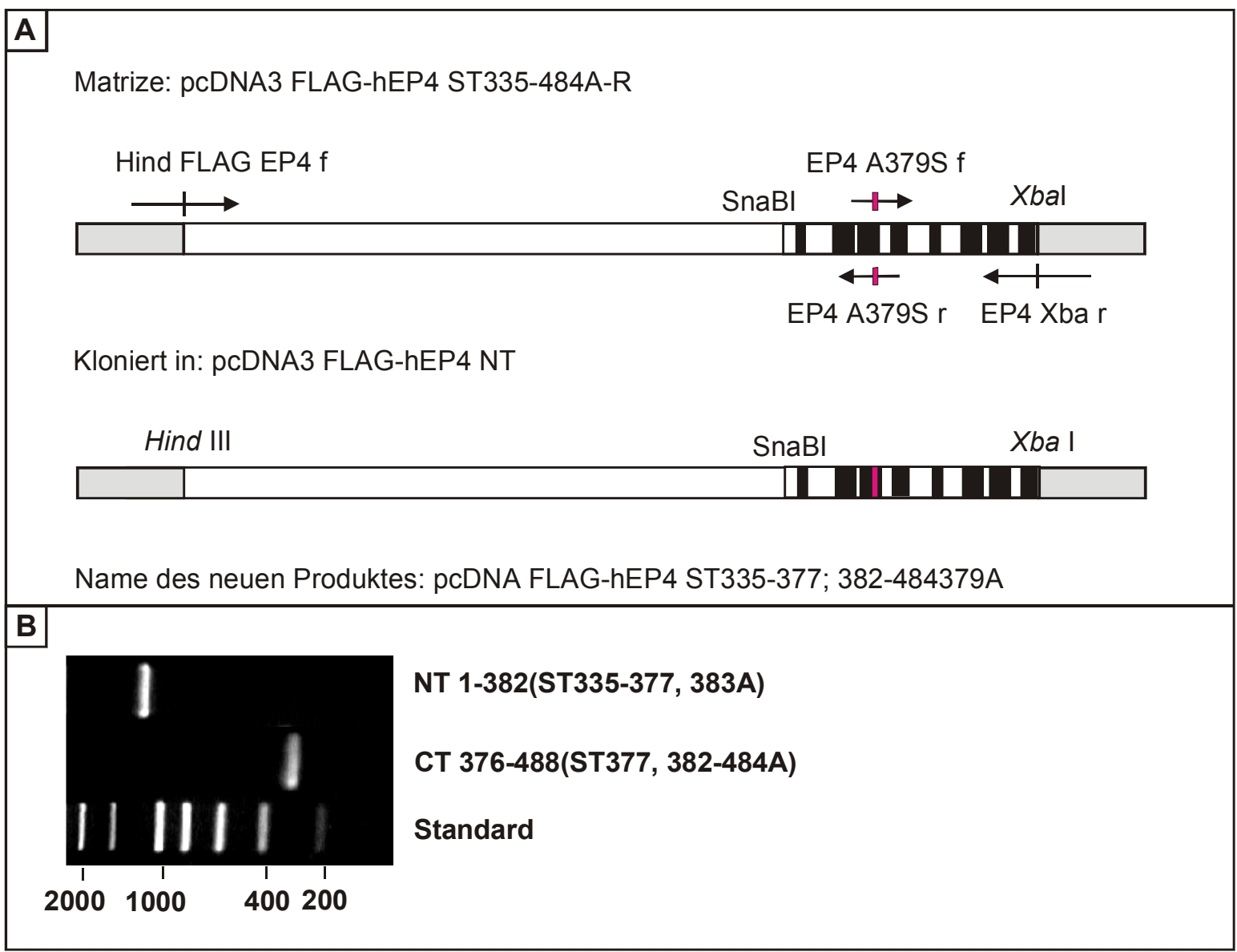

Abb. 20: Synthese des pcDNA3 FLAG-hEP4 S335-377; 382-484A. A) Dargestellt ist das für die PCR-Reaktionen verwendete Plasmid und die notwendigen Primer (Hind FLAG EP4 $f$ und EP4 A379S $r$ sowie EP4 A379S $f$ und EP4 Xba r). Mit den Primern Hind FLAG EP4 $f$ und EP4 A379S $r$ sowie EP4 A379S f und EP4 Xba $r$ wurden zwei Megaprimer synthetisiert, mit deren Hilfe zusammen mit den Primern Hind FLAG EP4 $f$ und EP4 Xba $r$ die komplette FLAG-hEP4 ST33-337; 382-484A-cDNA amplifiziert wurde. Mit den komplementären Primern EP4 A379S $f$ und EP4 A379S $r$ wurde das ursprünglich an dieser Position vorhandene Serin wieder eingefügt. Die FLAG-hEP4 ST335-377; 382-484A-cDNA wurde mit $S n a B I$ und $X$ ba I gespalten und die für die C-terminale Domäne codierende Sequenz in den pcDNA3 FLAG-hEP4 NT kloniert. Die für FLAG-hEP4 codierende Sequenz ist weiß, die flankierenden Elemente des Vektors sind grau dargestellt. Weiterhin sind die verwendeten Restriktionsschnittstellen (SnaB I und $X b a$ I) und das erhaltene Klonierungs-produkt mit dem eingefügten S379 (magenta) gezeigt. B) Dargestellt sind die, wie in Abb. 10 beschrieben, durch PCR amplifizierten Produkte. Die Analyse in einem 1\% (w/v) Agarose-Gel zeigte wie erwartet das ca. 1200 bp große, durch Hind FLAG EP4 $f$ und EP4 A379S $r$ (NT 1382(ST335-377,383A)) und das ca. 350 bp große, durch EP4 A379S $f$ und EP4 Xba r (CT 376-488(ST377,382-484A)) amplifizierte DNA-Fragment.

Die erhaltene 1519 bp große komplette Rezeptor-cDNA wurde mit SnaB I und Xba I gespalten und das für die C-terminale Domäne codierende Fragment mit dem zuvor sequenzierten FLAG-hEP4 NT in den pcDNA3-Vektor ligiert (Abb. 20 A). Die erfolgreiche 
Klonierung wurde durch Restriktionsfragmentlängen-Analyse überprüft und die Einführung des Ser379 durch Sequenzierung mit dem SP6-Sequenzierprimer in einer Richtung bestätigt.

\subsection{Klonierung der verschiedenen mutierten 3'-Fragmente und des 5'-Fragmentes der FLAG-hEP4-Rezeptor-cDNA in den Expressionvektor pcDNA3}

Zur Expression der verschiedenen kompletten FLAG-hEP4 Rezeptor-cDNAs wurde der pcDNA3-Vektor gewählt, da er über den starken CMV-Promotor und die nötigen Prozessierungssignale verfügt. Zusätzlich trägt dieser Vektor auch ein NeomycinResistenzgen, durch das er sich zur stabilen Expression der Rezeptorpoteine in eukaryoten Zellen durch G-418-Selektion eignet.

Die verschiedenen pcDNA3/FLAG-hEP4-R-Plasmide wurden aus transformierten E. coli XL1 (blue)-Zellen isoliert und 500 ng der Plasmid-DNA mit den Restriktionsenzymen Hind III und Xba I gespalten. Die Spaltprodukte wurden in einem 1\% (w/v) Agarose-Gel aufgetrennt und visualisiert. Es waren zwei Framente mit einer Größe von 1505 bp für die jeweilige FLAGhEP4-R-cDNA und von 5351 bp für den pcDNA3-Vektor zu sehen (Abb. 21).

Von den Bakterienkolonien, welche die Plasmide der verschiedenen pcDNA3 FLAG-hEP4-RcDNAs mit der richtigen Sequenz trugen, wurde anschließend eine Übernachtkultur in LBAmp-Medium angelegt und die Plasmid-DNA aus den Bakterienkulturen im Maxi-Maßstab isoliert. Die gewonnene Plasmid-DNA wurde zur Transfektion der eukaryoten Zellen eingesetzt. 


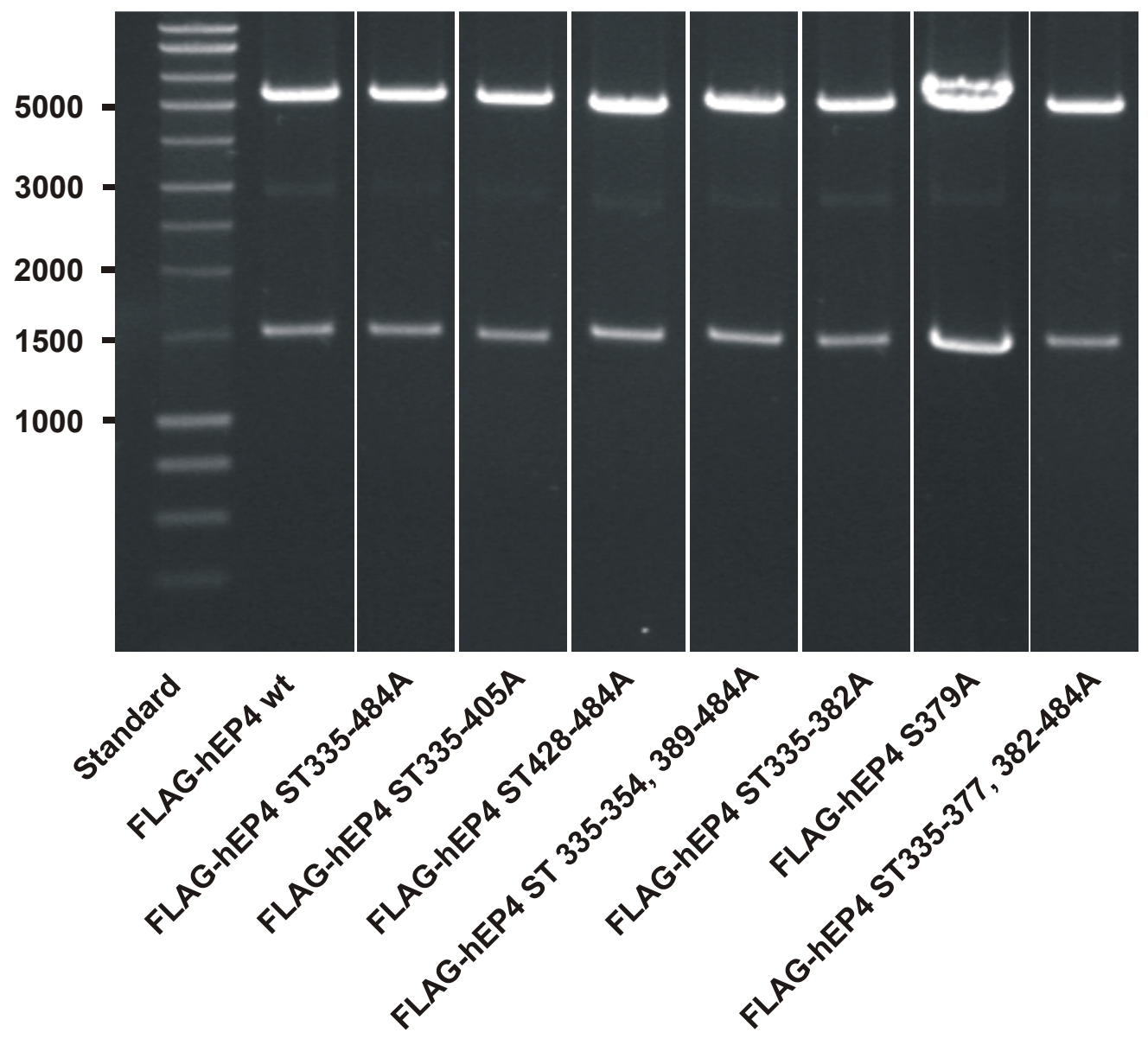

Abb. 21: Überprüfung der Klonierung der verschiedenen Rezeptor-cDNAs in den Expressionsvektor pcDNA3. Die Plasmid-DNA wurde aus den Übernachtkulturen durch Affinitätschromatographie isoliert und $1 \mu \mathrm{g}$ der isolierten DNA für $90 \mathrm{~min}$ mit den Restriktionsenzymen Hind III und Xba I geschnitten, anschließend auf einem 1\% AgaroseGel aufgetennt und mittels Ethidiumbromid-Interkalation visualisiert. Dargestellt ist jeweils eines der positiv getesteten Plasmide. Es waren die erwarteten Framente mit einer Größe von ca. 1500 bp für die FLAG-hEP4-Rezeptor-cDNA und ca. 5400 bp für den pcDNA3Vektor für alle klonierten Rezeptoren zu sehen.

\subsection{Stabile Expression des FLAG-hEP4 wt-Rezeptors und der verschiedenen mutierten FLAG-hEP4-Rezeptoren}

Zur stabilen Expression der pcDNA3/FLAG-hEP4 wt-R und der entsprechenden mutierten Rezeptor-cDNAs wurden HEK293-Zellen mit der modifizierten Calcium-Phosphat-Methode transfiziert (siehe 3.14.3) und die die verschiedenen Rezeptorproteine stabil exprimierenden Zellen mittels des Neomycinderivates G-418 selektiert (siehe 3.14.4). Für alle Rezeptoren konnten mehrere G-418-resistente Kolonien isoliert und die daraus resultierenden Zellklone kultiviert werden. Die Rezeptorexpression dieser Klone wurde durch Bestimmung der spezifischen $\left[{ }^{3} \mathrm{H}\right]-\mathrm{PGE}_{2}$-Bindung getestet. Von den Zellinien, welche die mutierten RezeptorcDNAs exprimierten, wurden die Klone ausgewählt, die die höchste spezifische $\left[{ }^{3} \mathrm{H}\right]-\mathrm{PGE}_{2^{-}}$ 
Bindung zeigten. Aus den stabilen Zellinien wurde, um zu überprüfen, ob der richtige Rezeptor exprimiert wurde, Gesamt-RNA isoliert (siehe 3.15), diese in cDNA umgeschrieben (siehe 3.16) und anschließend mit Primerkombinationen, mit denen der zu überprüfende Sequenzabschnitt amplifiziert werden konnte, PCR-Reaktionen durchgeführt (siehe 3.17). Die erhaltenen PCR-Produkte wurden in eine Sequenzierreaktion eingesetzt (siehe 3.10), wodurch die in den Zellen exprimierten hEP4-R identifiziert wurden.

\subsection{Charakterisierung der in HEK293-Zellen stabil exprimierten FLAG-hEP4- Rezeptorproteine}

\subsubsection{Immunologischer Nachweis der stabil exprimierten FLAG-hEP4 wt- und der mutierten FLAG-hEP4-Rezeptorproteine durch SDS-PAGE und Western-Blot- Analyse}

Für den immunologischen Nachweis der stabil exprimierten Rezeptorproteine wurden die verschiedenen Rezeptorproteine solubilisiert, mit dem FLAG-M2-Antikörper immunpräzipitiert (siehe 3.19.2) und parallel die spezifische $\left[{ }^{3} \mathrm{H}\right]-\mathrm{PGE}_{2}$-Bindung von Rezeptor-exprimierenden HEK293-Zellen bestimmt (siehe 3.18.4). Die auf die spezifische $\left[{ }^{3} \mathrm{H}\right]-\mathrm{PGE}_{2}$-Bindung normalisierte hEP4-Rezeptormenge wurde in einer SDS-PAGE getrennt, auf eine PVDFMembran transferiert und mit Hilfe eines gegen die C-terminale Domäne des hEP4-R gerichteten, polyklonalen Antiserums aus Kaninchen, einem Peroxidase-gekoppelten Sekundärantikörper und einem Chemilumineszenzsubstrat der Peroxidase detektiert (siehe 3.19). Als Kontrolle dienten Immunpräzipitate nicht-transfizierter HEK293-Zellen.

Das von der cDNA-Sequenz des hEP4-R abgeleitete Molekulargewicht des hEP4-R beträgt ca. 54 kDa. Der FLAG-hEP4-R, sowie die modifizierten Rezeptorproteine konnten jedoch alle als breite Bande mit einem Molekulargewicht von ca. 70-100 kDa nachgewiesen werden, welche in nicht-transfizierten HEK293-Zellen nicht zu beobachten war (Abb. 22). Die Differenz von errechnetem und tatsächlichem Molekulargewicht der Rezeptorproteine ist möglicherweise auf eine komplexe Glykosylierung der Rezeptoren an den potentiellen NGlykosylierungsstellen Asn 7 und/oder Asn 177 zurückzuführen, was auf eine korrekte Prozessierung der Rezeptoren beim Transport vom endoplasmatischen Retikulum zur Plasmamembran rückschließen lassen würde.

Die Intensität der Rezeptorbande für die Rezeptoren FLAG-hEP4 ST335-484A-R und FLAG-hEP4 ST335-377; 382-484A-R lag unter der Intensität der restlichen Rezeptorbanden. Dies ist möglicherweise darauf zurückzuführen, daß durch die Mutation aller/nahezu aller Serine und Threonine in der C-terminalen Domäne dieser Rezeptoren potentielle Epitope für Antikörper des polyklonalen anti-hEP4-R-Ct-Antiserums zerstört wurden. 
Neben der Hauptrezeptorbande bei ca. 70-100 kDa konnte bei dem FLAG-hEP4-R S379A noch eine Bande bei ca. 54 kDa und bei dem FLAG-hEP4-R ST335-377; 382-484A noch zwei Banden von ca. 62 und $65 \mathrm{kDa}$ nachgewiesen werde, welche in nicht-transfizierten HEK293-Zellen nicht zu beobachten waren. Hierbei könnte es sich möglicherweise um nicht glykosylierte bzw. nur „core“-glykosylierte Formen der Rezeptoren handeln. Es ist jedoch nicht auszuschließen, daß es sich bei diesen Banden um proteolytische, C-terminale Abbauprodukte der Rezeptoren handelt, die nach der Immunpräzipitation mit dem FLAG-M2 Antikörper entstanden sein müßten.

Zusätzlich zu den Banden des hEP4-R konnte in allen Spuren, einschließlich der nichttransfizierten Kontrollzellen, eine prominente Bande bei ca. $50 \mathrm{kDa}$ beobachtet werden, bei der es sich wahrscheinlich um eine unspezifische Reaktion des Primär- oder Sekundärantikörpers mit der schweren Kette des FLAG-M2-Antikörpers handelt.

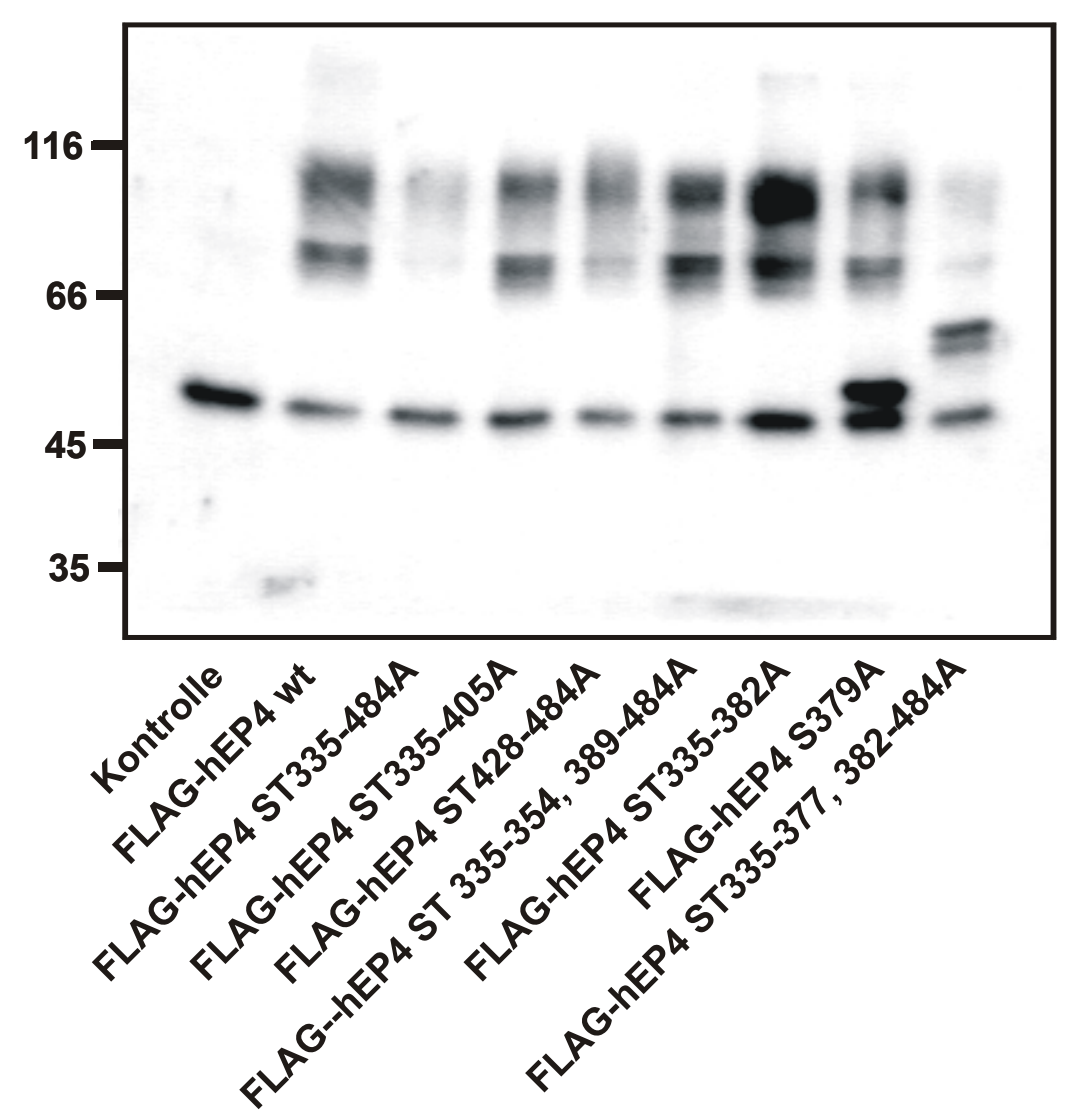

Abb. 22: Westernblotanalyse der in HEK293-Zellen stabil exprimierten Rezeptorproteine. Die das FLAG-Epitop tragenden hEP4-Rezeptoren wurden solubilisiert, mit dem FLAG-M2-Antikörper immunpräzipitiert (siehe 3.19.2) und die Rezeptor-Expression in einem parallelen Ansatz durch Bestimmung der spezifischen $\left[{ }^{3} \mathrm{H}\right]-\mathrm{PGE}_{2}$-Bindung quantifiziert. Die auf die spezifische Bindung normalisierte Menge an Rezeptorprotein wurde in einer SDS-PAGE aufgetrennt (siehe 3.19.4), durch Elektrotransfer auf eine PVDFMembran überführt (siehe 3.19.6) und die Rezeptorproteine mit einem gegen die C-terminale Domäne des FLAG-hEP4-Rezeptors gerichteten polyklonalen Antiserum, einem Peroxidasegekoppelten Sekundärantikörper und einem Chemilumineszenzsubstrat der Peroxidase detektiert (siehe 3.19.8). 


\subsubsection{Untersuchung der Plasmamembranlokalisation der verschiedenen stabil exprimierten FLAG-hEP4-Rezeptorproteine durch Immunfluoreszenz- Mikroskopie}

Zur Untersuchung der Plasmamembranlokalisation der verschiedenen FLAG-hEP4Rezeptorproteine wurden Rezeptor-exprimierende HEK293-Zellen auf Glasdeckgläschen kultiviert (siehe 3.25.2). Nach Fixierung und Permeabilisierung wurden die Rezeptorproteine mit dem FLAG-M2-mAk und einem Cy3-gekoppelten Sekundärantikörper (siehe 3.25.5) nachgewiesen. Nach Biotinylierung der intakten Zellen vor der Fixierung wurde die Plasmamembran mit einem FITC-gekoppelten Streptavidin-Konjugat (siehe 3.25.3) markiert. Die Aufnahmen wurden mit einem konfokalen Laser-Scan-Mikroskop gemacht (siehe 3.25.6).

In den nicht-transfizierten HEK293-Kontrollzellen war mit dem FLAG-M2-mAk und dem Cy3gekoppelten Sekundärantikörper (rot) keine spezifische Bindung zu erkennen; es war in den Überlagerungen der bei den unterschiedlichen Anregungs- und Emissions-Wellenlängen aufgenommenen Bilder nur die durch das FITC-Konjugat (grün) markierte Plasmamembran sichtbar (Abb. 23 a). In den die verschiedenen Rezeptoren stabil exprimierenden HEK293Zellen (Abb. 23 b-i) konnte die Expression und die Plasmamembranlokalisation der exprimierten Rezeptorproteine nachgewiesen werden, was durch die Kolokalisation der grün dargestellten Plasmamembran mit den rot dargestellten Rezeptorproteinen und der daraus resultierenden Gelbfärbung zu sehen war. Für die den FLAG-hEP4 S379A-R exprimierenden HEK293-Zellen (Abb. 23 h) konnte eine geringe perinukleäre Ansammlung der Rezeptorproteine nachgewiesen werden, die auf ein mögliches Verbleiben eines Teils der Rezeptorproteine im endoplasmatischen Retikulum hindeutete. Dies steht im Einklang mit den Ergebnissen des Rezeptornachweises im Western-Blot, bei der der FLAG-hEP4 S379A$\mathrm{R}$ als potentiell nicht-glykosylierter, nicht prozessierter Rezeptor nachgewiesen werden konnte (Abb. 22). Allerdings wies diese Zellinie in Bindungsstudien (siehe 4.5.3) auch die höchste Rezeptordichte von allen Zellinien auf. 

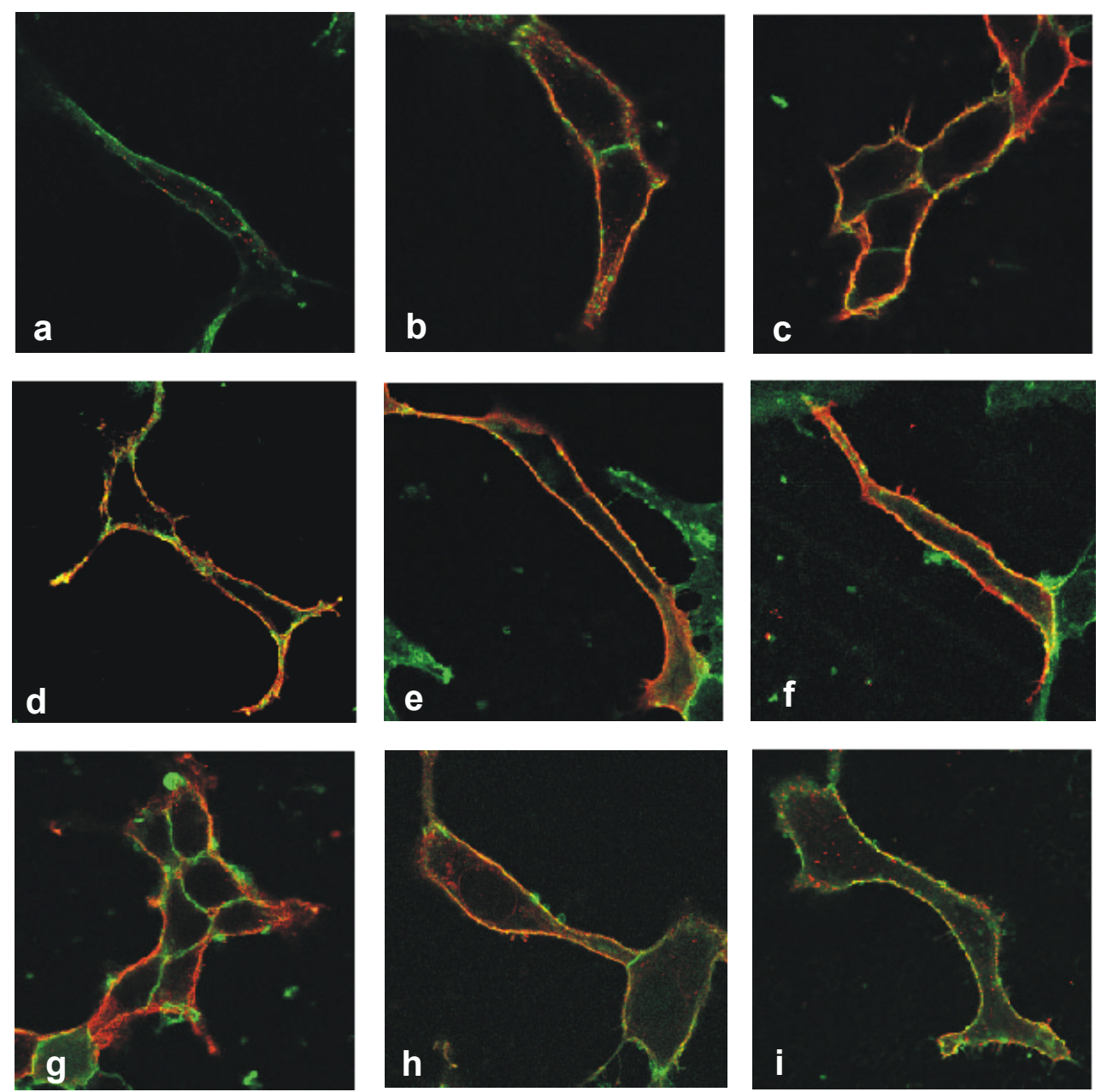

Abb. 23: Plasmamembranlokalisation der verschiedenen, in HEK293-Zellen stabil exprimierten FLAG-hEP4-Rezeptoren. Stabil transfizierte HEK293-Zellen wurden auf Fibronectin- und Poly-L-Lysin-beschichteten Glasdeckgläschen für $24 \mathrm{~h}$ kultiviert. Anschließend wurden die Hydroxylgruppen der plasmamembranständigen Kohlenhydrate zu Aldehydgruppen oxidiert und die entstandenen Aldehydgruppen biotinyliert. Die Zellen wurden fixiert, permeabilisiert und die Rezeptoren mit dem FLAG-M2-mAk und einem Cy3gekoppelten Sekundärantikörper (rot), die Plasmamembran mit einem FITC-gekoppelten Streptavidin-Konjugat (grün) markiert. Die Präparate wurden in Mowiol eingebettet und die Aufnahmen mit einem konfokalen Laser-Scan-Mikroskop gemacht. Dargestellt ist die Überlagerung der bei den unterschiedlichen Anregungs- und Emissions-Wellenlängen aufgenommenen Bilder. $a=$ nicht transfizierte HEK293-Zellen, $b=$ FLAG-hEP4 wt-R, $c=$ FLAG-hEP4 ST335-484A-R, d = FLAG-hEP4 ST335-405A-R, e = FLAG-hEP4 ST428-484A$\mathrm{R}, \mathrm{f}=\mathrm{FLAG}-\mathrm{hEP} 4$ ST335-354; 389-484A-R, $\mathrm{g}=$ FLAG-hEP4 ST335-382A-R, $\mathrm{h}$ = FLAGhEP4 S379A-R, i = FLAG-hEP4 ST335-377; 382-484A. Die Plasmamembran erscheint grün (a). Durch die Überlagerung der grün dargestellten Plasmamembran mit dem rot dargestellten Sekundärantikörper für den Rezeptornachweis erscheint die Plasmamembran in den Rezeptor-exprimierenden HEK293-Zellen gelb (b-i). 


\subsubsection{Bestimmung der Affinität und der maximalen Bindungskapazität der verschiedenen stabil exprimierten FLAG-hEP4-Rezeptoren für PGE $_{2}$ durch Sättigungsbindungsstudien}

Zur Bestimmung der Affinität und der maximalen Bindungskapazität für $\mathrm{PGE}_{2}$ wurden Membranen der mit den verschiedenen Rezeptoren stabil transfizierten HEK293-Zellen präpariert (siehe 3.18.2) und in Sättigungsbindungsstudien eingesetzt. $25 \mu \mathrm{g}$ Membranprotein wurden mit steigenden Konzentrationen $\mathrm{PGE}_{2}$ von 0-20 $\mu \mathrm{M}$ und $5 \mathrm{nM}\left[{ }^{3} \mathrm{H}\right]-$ $\mathrm{PGE}_{2}$ für $1 \mathrm{~h}$ bei Raumtemperatur unter Schütteln inkubiert und die Reaktion durch anschließende Vakuumfiltration beendet (siehe 3.20.2). Aus den Bindungsdaten wurden mit dem Computerprogramm LIGAND (Munson und Rodbard (1980)) die $K_{d}$-Werte und die maximale Bindungkapazität durch nicht-lineare Regression berrechnet (Tab. 7).

Die ermittelte Dissotiationskonstante $\left(\mathrm{K}_{\mathrm{d}}\right)$ für $\mathrm{PGE}_{2}$ betrug für den FLAG-hEP4 wt-R 1,31 \pm $0,51 \mathrm{nM}$ (Tab. 7). Durch Einführen der Mutationen in die C-terminale Domäne kam es nicht zu einer signifikanten Verschiebung der $\mathrm{K}_{d}$-Werte (Tab. 7). Lediglich der FLAG-hEP4 ST335377; 382-484A-R wies eine tendenziell höhere Affinität zum Liganden als der FLAG-hEP4 wt-R auf.

Tab. 7: $K_{d}$-Werte und maximale Bindungskapazität der verschiedenen in HEK293Zellen stabil exprimierten FLAG-hEP4-Rezeptoren. Aus HEK293-Zellen, die den Wildtyp hEP4-R oder Mutanten exprimierten, in denen die Serine und Threonine der C-terminalen Domäne teilweise oder vollständig durch Alanine ersetzt worden waren, wurden Membranen isoliert. Die Membranen wurden in Sättigungsbindungsstudien mit $\left[{ }^{3} \mathrm{H}\right]-\mathrm{PGE}_{2}$ eingesetzt. $\mathrm{K}_{d}$ und $B_{\max }$ wurden durch nicht-lineare Regressionsanalyse (LIGAND) berechnet. Die Werte sind Mittelwerte \pm S.D. aus drei unabhängigen Versuchen.

\begin{tabular}{lcc}
\hline \multicolumn{1}{c}{ Rezeptor } & $\mathbf{K}_{\mathbf{d}}(\mathbf{n M})$ & $\mathbf{B}_{\max }(\mathbf{p m o l} / \mathbf{m g})$ \\
\hline FLAG-hEP4 wt & $1,31 \pm 0,51$ & $1,83 \pm 0,16$ \\
FLAG-hEP4 ST335-484A & $3,30 \pm 2,60$ & $1,63 \pm 0,44$ \\
FLAG-hEP4 ST335-405A & $1,74 \pm 1,20$ & $2,07 \pm 0,27$ \\
FLAG-hEP4 ST428-484A & $1,08 \pm 0,97$ & $1,68 \pm 0,22$ \\
FLAG-hEP4 ST335-354; 389-484A & $2,09 \pm 0,49$ & $1,24 \pm 0,27$ \\
FLAG-hEP4 ST335-382A & $1,07 \pm 0,33$ & $4,41 \pm 0,53$ \\
FLAG-hEP4 S379A & $2,37 \pm 0,62$ & $6,19 \pm 1,80$ \\
FLAG-hEP4 ST335-377; 382-484A & $0,49 \pm 0,1$ & $1,19 \pm 0,65$ \\
\hline
\end{tabular}

Für die den Wildtyprezeptor exprimierende Zellinie ergab sich eine $B_{\max }$ von $1,83 \pm 0,16 \mathrm{pmol} / \mathrm{mg}$ Membranprotein (Tab. 7). Die $B_{\max }-$ Werte der Zellinien, die die mutierten Rezeptorproteine exprimierten, unterschieden sich nicht signifikant von der den 
hEP4-R-Wildtyp exprimierenden Zellinie. Lediglich die Zellinien mit den Mutanten FLAGhEP4 ST335-382A-R und FLAG-hEP4 S379A-R hatten einen 2- bzw. 3-fach höhere $B_{\max }$ (Tab. 7).

\subsubsection{Nachweis der Funktionalität der verschiedenen in HEK293-Zellen stabil exprimierten FLAG-hEP4-Rezeptoren an Membranen}

Es ist gezeigt worden, daß die C-terminale Domäne der Prostanoidrezeptoren für die GProtein-Kopplungskontrolle (Hasegawa et al. (1996)) und/oder -Spezifität (Namba et al. (1993)) relevant ist. Daher war nicht auszuschließen, daß die Substitution einzelner oder mehrerer Serine und Threonine in der C-terminalen Domäne zu einer Veränderung der Kopplungseigenschaften der Rezeptoren führte. Daher wurde die $\mathrm{PGE}_{2}$ - und die Forskolininduzierte cAMP-Bildung der die verschiedenen Rezeptoren stabil exprimierenden HEK293Zellen untersucht. Da die $\mathrm{G}_{\mathrm{s}}$-Proteine und die Adenylatcyclase membranassoziiert sind, konnten die Versuche zur Funktionalität der Rezeptorproteine an Membranen dieser Zellinien durchgeführt werden. Dazu wurden Membranen aus den die Rezeptoren exprimierenden HEK293-Zellen präpariert (siehe 3.21.2) und in einem ATP-regenerierenden System mit $1 \mu \mathrm{M} \mathrm{PGE}_{2}$ oder $1 \mu \mathrm{M}$ Forskolin, in Anwesenheit von $1 \mathrm{mM}$ IBMX zur Hemmung der Phosphodiesterase, stimuliert (siehe 3.21.3). Anschließend wurde die Menge des gebildeten cAMP mit einem RIA ermittelt (siehe 3.21.4) und parallel die $\left[{ }^{3} \mathrm{H}\right]-\mathrm{PGE}_{2}$-Bindung der verwendeten Membranen in Bindungsstudien bestimmt (siehe 3.18.4). Die Menge an gebildetem cAMP wurde unter Einbeziehung der Rezeptoraffinitäten auf die Rezeptordichte bezogen.

In Membranen nicht-transfizierter HEK293-Zellen war eine schwache basale cAMP-Bildung nachweisbar, die durch $\mathrm{PGE}_{2}$ nur geringfügig gesteigert werden konnte. Diese leichte $\mathrm{PGE}_{2}-$ abhängige Steigerung der cAMP-Bildung in nicht-transfizierten HEK293-Zellen könnte auf den endogen schwach exprimierten EP2-R zurückzuführen sein (Daten nicht gezeigt).

Die basale unstimulierte cAMP-Bildung war in Membranen von HEK293-Zellen, die mit dem Wildtyp hEP4-R oder den Rezeptormutanten transfiziert waren, nicht signifikant höher als in nicht-transfizierten Zellen. Daher konnte ausgeschlossen werden, daß der Wildtyprezeptor die $\mathrm{G}_{\mathrm{s}}$-abhängige Signalkette Ligand-unabhängig aktivierte oder die Einführungen der Mutationen in die C-terminale Domäne zu solch einer konstitutiven Aktivität führten.

$\mathrm{PGE}_{2}$ stimulierte in Membranen von HEK293-Zellen, die mit dem FLAG-hEP4 wt-R oder einer der Rezeptormutanten transfiziert waren, die cAMP-Bildung. Dabei unterschied sich bei Rezeptor-sättigenden (ca. 1000x $\mathrm{K}_{\mathrm{d}}$ ) $\mathrm{PGE}_{2}$-Konzentrationen die auf die Rezeptordichte normalisierte cAMP-Bildung in Membranen aller untersuchten, die Rezeptormutanten exprimierenden Zellinien, nicht signifikant von der des FLAG-hEP4 wt-R (Abb. 24). 


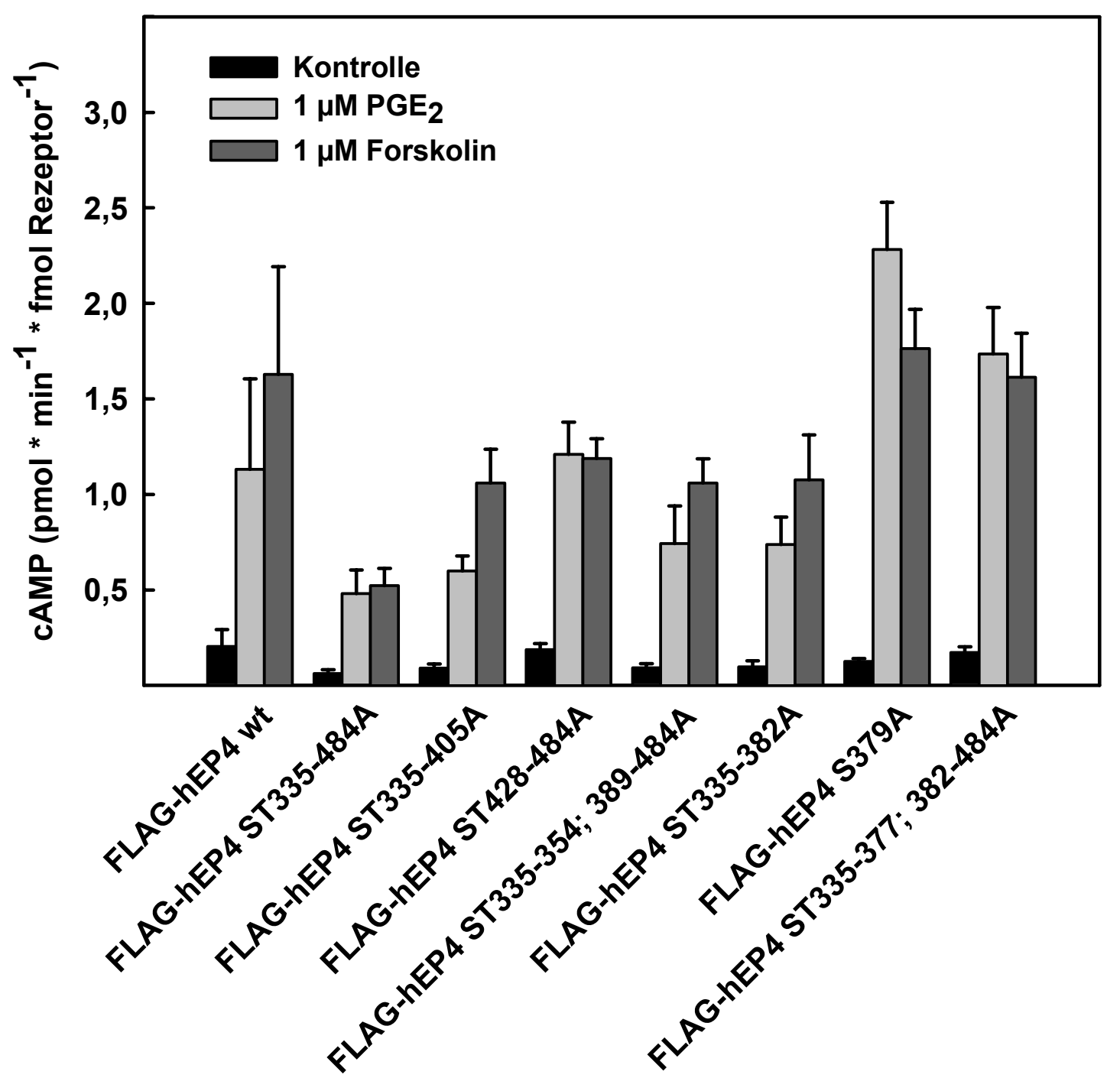

Abb. 24: Nachweis der PGE $_{2^{-}}$und Forskolin-induzierten cAMP-Bildung der die verschiedenen Rezeptoren exprimierenden HEK293-Zellen. Aus HEK293-Zellen, die mit den verschiedenen Rezeptoren stabil transfiziert waren, wurden Membranen präpariert (siehe 3.21.2). Die durch $1 \mu \mathrm{M} \mathrm{PGE}_{2}$ oder $1 \mu \mathrm{M}$ Forskolin in Anwesenheit von $1 \mathrm{mM}$ IBMX in dieser Membranpräparation stimulierte (siehe 3.21.3) cAMP-Bildung wurde mit einem RIA ermittelt (siehe 3.21.4) und parallel die spezifische $\left[{ }^{3} \mathrm{H}\right]-\mathrm{PGE}_{2}$-Bindung der verwendeten Membranen ermittelt (siehe 3.18.4). Die cAMP-Bildungsrate wurde auf die Rezeptormenge normalisiert. Die Werte stellen die Mittelwerte \pm S.E.M. aus drei Versuchen in Doppelbestimmung dar.

Dies deutet darauf hin, daß die Einführung der Mutationen in die C-terminale Domäne des hEP4-R nicht zu einer Veränderung der G-Protein-Kopplungseffizienz der entsprechenden Rezeptorproteine führte.

Diese Annahme wird auch dadurch unterstützt, daß das Verhältnis der Rezeptorunabhängigen, durch Foskolin stimulierten cAMP-Bildung (Abb. 24) zur maximalen $\mathrm{PGE}_{2^{-}}$ stimulierten cAMP-Bildung in Membranen aller Zellinien annährend gleich war. 


\subsubsection{Bestimmung der EC50-Werte der verschiedenen FLAG-hEP4-Rezeptoren für die $\mathrm{PGE}_{2}$-stimulierte cAMP-Bildung an Membranen}

Zur Bestimmung der EC50-Werte der $\mathrm{PGE}_{2}$-stimulierten cAMP-Bildung wurden DosisWirkungskurven für die verschiedenen Rezeptoren bestimmt. Dazu wurden Membranen aus den verschiedenen FLAG-hEP4-R stabil exprimierenden HEK293-Zellen präpariert (siehe 3.21.2), die cAMP-Bildung mit steigenden $\mathrm{PGE}_{2}-$ Konzentrationen stimuliert (siehe 3.21.3) und das gebildete cAMP mit einem RIA bestimmt (siehe 3.21.5). Anschließend wurde durch nicht-lineare Regression die $\mathrm{PGE}_{2}$-Konzentrationen ermittelt, bei denen die Agonistenabhängige cAMP-Bildung halbmaximal war (EC 50).

Die so ermittelten EC50-Werte für den Wildtyprezeptor und die meisten Rezeptormutanten (Tab. 8) unterschieden sich nicht signifikant von den ermittelten $\mathrm{K}_{\mathrm{d}}$-Werten. Lediglich die für den FLAG-hEP4 S379A-R ermittelte EC50 war signifikant niedriger als der korrespondierende $\mathrm{K}_{\mathrm{d}}$-Wert, was wahrscheinlich auf die hohe Rezeptordichte in diesen Membranen zurückgeführt werden kann. In diesem Fall würden auch bei niedrigeren Ligandkonzentrationen genügend Rezeptoren aktiviert, um die nachgeschaltete Signalkette zu aktivieren („spare-receptor“-Hypothese (Zhu (1993)).

Tab. 8: EC50-Werte der $\mathrm{PGE}_{2}$-stimulierten cAMP-Bildung der verschiedenen in HEK293-Zellen stabil exprimierten FLAG-hEP4-Rezeptoren. Aus HEK293-Zellen, die mit den verschiedenen FLAG-hEP4-Rezeptoren stabil transfiziert waren, wurden Membranen präpariert (siehe 3.21.2). Die durch steigende Konzentrationen $\mathrm{PGE}_{2}\left(10^{-11}-10^{-5} \mathrm{M}\right.$ ) in Anwesenheit von $1 \mathrm{mM}$ IBMX in diesen Membranpräparationen stimulierte cAMP-Bildung wurde mit einem RIA bestimmt (siehe 3.21.4). Die EC50-Werte wurden durch nicht-lineare Regression ermittelt. Die Werte sind Mittelwerte \pm S.D. aus drei Versuchen in Doppelbestimmung.

\begin{tabular}{lc}
\hline \multicolumn{1}{c}{ Rezeptor } & EC50-Wert [nM] \\
\hline FLAG-hEP4 wt & $2,19 \pm 0,63$ \\
FLAG-hEP4 ST335-484A & $1,67 \pm 0,87$ \\
FLAG-hEP4 ST335-405A & $1,13 \pm 0,14$ \\
FLAG-hEP4 ST428-484A & $0,62 \pm 0,53$ \\
FLAG-hEP4 ST335-354; 389-484A & $2,67 \pm 3,04$ \\
FLAG-hEP4 ST335-382A & $2,77 \pm 1,63$ \\
FLAG-hEP4 ST379A & $0,49 \pm 0,11$ \\
FLAG-hEP4 ST335-377; 382-484A & $1,33 \pm 0,41$ \\
\hline
\end{tabular}




\subsection{Untersuchung der Phosphorylierung des FLAG-hEP4-Rezeptors und der verschiedenen mutierten Rezeptorproteine}

Die Agonisten-induzierte Phosphorylierung des hEP4-Rezeptors wurde durch NeuschäferRube et al. (1999) und Slipetz et al. (2001) nachgewiesen. Aus diesen Studien ging hervor, daß die für die Agonisten-induzierte Phosphorylierung relevanten Phosphorylierungsstellen innerhalb der C-terminale Domäne lokalisiert sind.

Alle Experimente zur Untersuchung der Phosphorylierung wurden von Herrn Dr. F. Neuschäfer-Rube durchgeführt.

\subsubsection{Untersuchung der durch $\mathrm{PGE}_{2}$-Stimulation induzierten Phosphorylierung des FLAG-hEP4 wt-Rezeptors}

Die den FLAG-hEP4 wt-Rezeptor stabil exprimierenden HEK293-Zellen wurden für 90 min in $150 \mu \mathrm{Ci} / \mathrm{ml}\left[{ }^{32} \mathrm{P}\right.$ ]-ortho-Phosphat-haltigen Medium kultiviert, in An- oder Abwesenheit von 400 nM Staurosporin für 20 min vorinkubiert und danach für 10 min mit $\mathrm{PGE}_{2}$, Forskolin oder PMA stimuliert (siehe 3.26.2). Die Rezeptorproteine wurden immunpräzipitiert (siehe 3.19.2), über eine SDS-PAGE aufgetrennt und die phosphorylierten Rezeptorproteine mit einem Imager-System visualisiert.

Der FLAG-hEP4 wt-R zeigte in den nicht stimulierten stabil exprimierenden HEK293-Zellen eine geringe basale Phosphorylierung, die durch $\mathrm{PGE}_{2}$-Stimulation auf das 3-fache gesteigert werden konnte (Abb. 25). Das phosphorylierte Protein erschien als einzelne breite Bande mit einer Größe von ca. 70-100 kDa, was dem durch Western-Blot bestimmten Molekulargewicht des FLAG-hEP4 wt-Rezeptors (Abb. 22) entsprach. Durch Stimulation der Zellen mit Forskolin konnte die Phosphorylierung des Rezeptors nicht gesteigert werden. Dies deutet darauf hin, daß die Agonisten-induzierte Phosphorylierung unabhängig von der hEP4-R-vermittelten Aktivierung der Proteinkinase A stattfand. Die Phosphorylierung des FLAG-hEP4 wt-R konnte nach Stimulation der Zellen mit PMA, einem Aktivator der PKC, minimal gegenüber der basalen Phosphorylierung gesteigert werden (Abb. 25). Durch Behandlung der Zellen mit Staurosporin, einem Inhibitor der „second-messenger“abhängigen Proteinkinasen PKA und PKC wurde die $\mathrm{PGE}_{2}$-induzierte Phosphorylierung nicht, dagegen aber die PMA-induzierte Phosphorylierung reduziert (Abb. 25). Daher wurde die Agonisten-induzierte Phosphorylierung wahrscheinlich nicht durch „second messenger“abhängige Kinasen sondern durch GRKs vermittelt. 


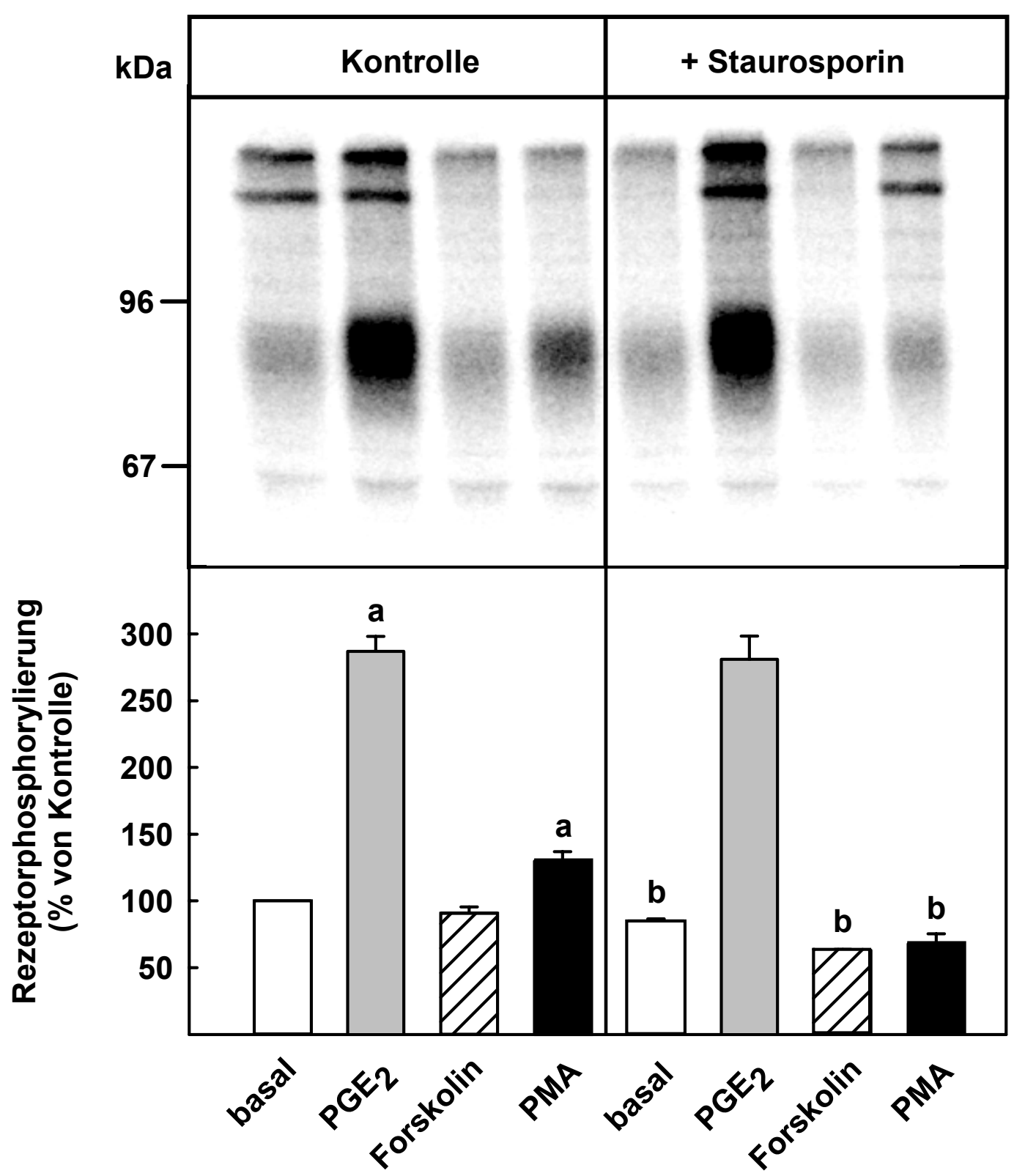

Abb. 25: Phosphorylierung des FLAG-hEP4 wt-Rezeptors durch PGE 2 , Forskolin und PMA. Mit dem FLAG-hEP4 wt-R stabil transfizierte HEK293-Zellen wurden für 90 min in Kulturmedium mit $150 \mu \mathrm{Ci}\left[{ }^{32} \mathrm{P}\right]$-ortho-Phosphat/ml inkubiert, wo angezeigt die letzten $20 \mathrm{~min}$ mit Staurosporin bei $37^{\circ} \mathrm{C}$ behandelt und danach mit $1 \mu \mathrm{M} \mathrm{PGE}_{2}, 50 \mu \mathrm{M}$ Forskolin $+1 \mathrm{mM}$ IBMX oder $2 \mu \mathrm{M}$ PMA für $10 \mathrm{~min}$ stimuliert (siehe 3.26.2). Die phosphorylierten Rezeptorproteine wurden immunpräzipitiert (siehe 3.19.2), über eine SDS-PAGE aufgetrennt (siehe 3.19.4 und 3.19.5) und anschließend mit einem Imager-System visualisiert. Dargestellt sind die aus drei unabhängigen Versuchen \pm S.E.M. ermittelten Phosphorylierungen in Relation zur basalen Phosphorylierung der nicht mit Staurosporin behandelten Zellen. Statistik: Student's $t$-Test für ungepaarte Proben; a: signifikant unterschiedlich von basal, b: signifikant unterschiedlich von den unter gleichen Bedingungen nicht mit Staurosporin vorbehandelten Zellen. 


\subsubsection{Untersuchung der durch $\mathrm{PGE}_{2}$ induzierten Phosphorylierung des FLAG-hEP4 wt-Rezeptors und der mutierten Rezeptorproteine}

Die Untersuchung der Agonisten-induzierten Phosphorylierung der verschiedenen FLAGhEP4-R-Mutanten wurde, wie für den Wildtyprezeptor beschrieben, (siehe 4.6.1) durchgeführt, wobei die Menge an auf die SDS-PAGE aufgetragenem Immunpräzipitat auf die $\left[{ }^{3} \mathrm{H}\right]-\mathrm{PGE}_{2}$-Oberflächenbindung der unterschiedlichen hEP4-Rezeptoren exprimierenden Zelllinien normalisiert wurde.

Der Wildtyprezeptor wurde, wie vorher gezeigt, Agonisten-abhängig phosphoryliert. Die Agonisten-induzierte Phosphorylierung des Wildtyprezeptors wurde densitometrisch quantifiziert und arbiträr als $100 \%$ gesetzt (Abb. 26). Die Agonisten-abhängige Phosphorylierung der Rezeptormutanten wurde dazu ins Verhältnis gesetzt.

Der FLAG-hEP4 ST335-484A-Rezeptor, in dem alle potentiellen Phosphorylierungsstellen in der C-terminalen Domäne eliminiert waren, wurde im Gegensatz zum Wildtyprezeptor nicht mehr Agonisten-abhängig phosphoryliert. Dieses Ergebnis bestätigt frühere Studien mit einem Rezeptorhybrid aus dem Ratten EP3-R dessen C-terminale Domäne gegen die des hEP4-R ausgetauscht worden war (Neuschäfer-Rube et al. (1999)). Hier konnte gezeigt werden, daß nur die C-terminale Domäne des hEP4-R Agonisten-abhängig phosphoryliert wird.

Die Agonisten-abhängige Phosphorylierung des FLAG-hEP4 ST335-405A-R, in dem alle potentiellen Phosphorylierungsstellen im proximalen Bereich der C-terminalen Domäne eliminiert waren, betrug noch $25 \%$ von der des Wildtyprezeptors, während die Agonistenabhängige Phosphorylierung der Mutante FLAG-hEP4 ST428-484A, der alle potentiellen Phosphorylierungsstellen im distalen Teil der C-terminalen Domäne fehlten, noch $75 \%$ von der des Wildtyps betrug. Aus diesen Ergebnissen konnte geschlossen werden, daß die Agonisten-induzierte Phosphorylierung im wesentlichen im proximalen Teil der C-terminalen Domäne des hEP4-R stattfand. Die Bereich, in dem der Hauptanteil der Agonisteninduzierten Phosphorylierung stattfand, konnte weiter eingegrenzt werden. Die Agonistenabhängige Phosphorylierung des FLAG-hEP4 ST335-354; 389-484A-R war mit der Phosphorylierung des Wildtyp vergleichbar (Abb. 26), was auf eine Hauptphosphorylierung im proximalen Teil der C-terminalen Domäne zwischen Serin 359 und Serin 382 hindeutete. 


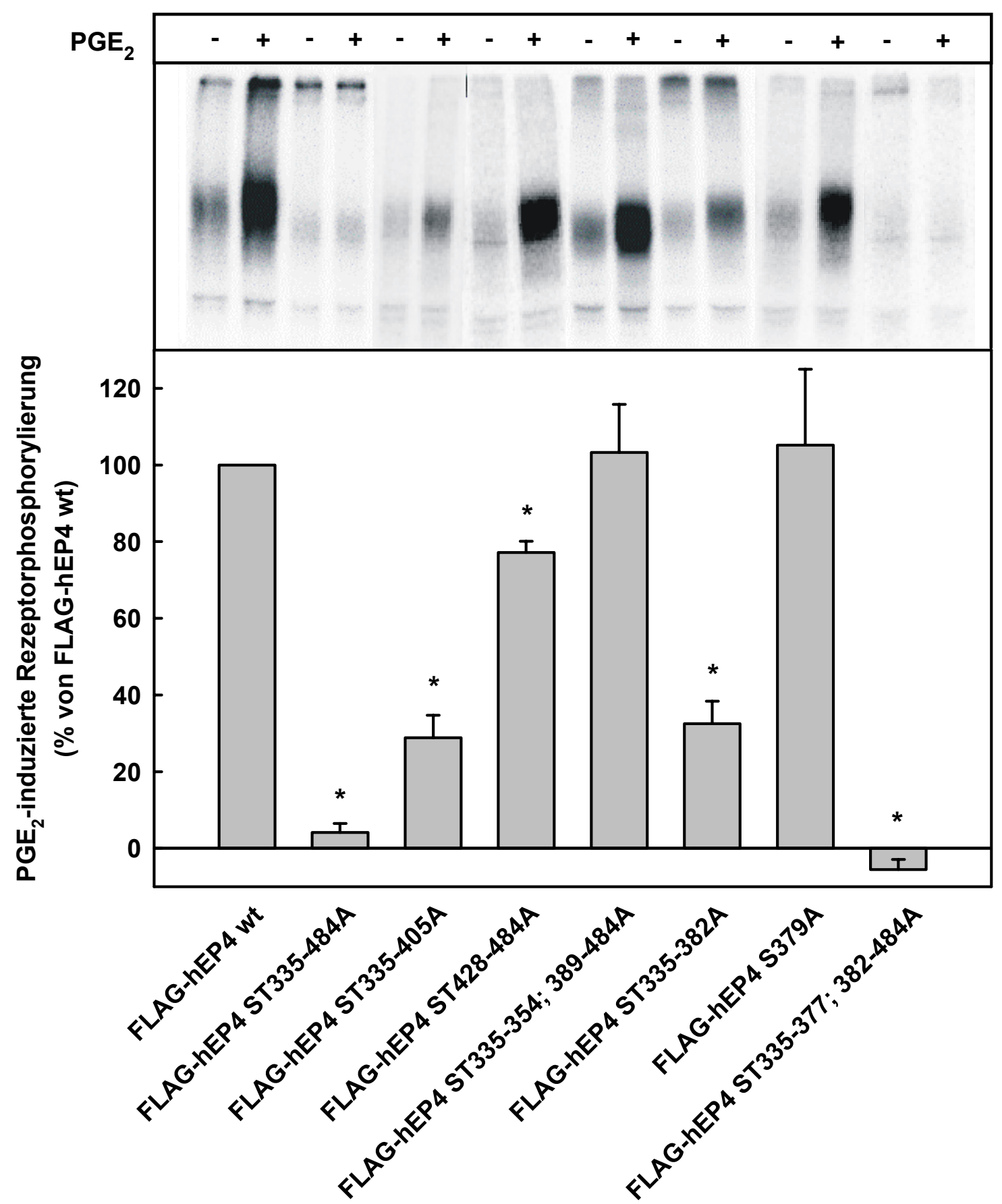

Abb. 26: Nachweis der Lokalisation der für die Agonisten-induzierte Phosphorylierung des FLAG-hEP4 wt-Rezeptors relevanten Ser und Thr in der C-terminalen Domäne. Die mit den verschiedenen Rezeptoren stabil transfizierten HEK293-Zellen wurden für 90 min in Kulturmedium mit $150 \mu \mathrm{Ci} / \mathrm{ml}\left[{ }^{32} \mathrm{P}\right]$-ortho-Phosphat $/ \mathrm{ml}$ inkubiert und anschließend mit $1 \mu \mathrm{M}$ $\mathrm{PGE}_{2}$ für 10 min stimuliert (siehe 3.26.2). Die phosphorylierten Rezeptorproteine wurden wie unter Abb 21. beschrieben visualisiert (siehe 3.26.3 und siehe 3.19.) Dargestellt sind die Ergebnisse aus drei unabhängigen Versuchen \pm S.E.M. Zur Berechnung der relativen Phosphorylierungen der verschiedenen Rezeptoren wurde von der $\mathrm{PGE}_{2}$-induzierten Phosphorylierung des FLAG-hEP4 wt-R die basale Phosphorylierung subtrahiert und als $100 \%$ gesetzt. Zur Bestimmung der Phosphorylierung der verschiedenen Rezeptoren wurde von deren $\mathrm{PGE}_{2}$-induzierter Phosphorylierung deren basale Phosphorylierung subtrahiert und die mit der des FLAG-hEP4 wt-R ins Verhältnis gesetzt. Statistik: Student's $t$-Test für ungepaarte Proben; ${ }^{*}=$ signifikant unterschiedlich vom FLAG-hEP4 wt-R. 
Allerdings wäre zu erwarten gewesen, daß die Phosphorylierung dieses Rezeptors der des FLAG-hEP4 ST428-484A-R entsprach, da in beiden Rezeptoren die distalen Serine und Threonine substituiert waren. Die Agonisten-abhängige Phosphorylierung des FLAG-hEP4 ST335-382A-R, die noch ca $25 \%$ von der des FLAG-hEP4 wt-R betrug und mit der des FLAG-hEP4 ST335-405A-R vergleichbar war, unterstützte die Annahme der Lokalisation der Hauptphosphorylierung zwischen Serin 359 und Serin 382.

Erste Phosphopeptidsequenzierungen von Peptiden, die durch enzymatische Spaltung des phosphorylierten FLAG-hEP4 wt-R generiert wurden, gaben eine Hinweis darauf, daß dem Serin an Position 379 eine besondere Rolle bei der Phosphorylierung des hEP4-R zukommen könnte. Der FLAG-hEP4 S379A-R, in dem nur Serin 379 substituiert war, zeigte jedoch nach $\mathrm{PGE}_{2}$-Stimulation eine dem FLAG-hEP4 wt-R entsprechende Phosphorylierung, woraus resultierte, das Serin 379 nicht essentiell für die Agonisten-induzierte Phosphorylierung des hEP4-R war. Dieses Resultat wurde durch den FLAG-hEP4 ST335377; 382-484A-R, der wie der FLAG-hEP4 ST335-484A-R keine Phosphorylierung mehr zeigte, unterstützt (Abb. 26). Da sich die beiden Rezeptoren wie der Wildtyprezeptor bzw. wie der FLAG-hEP4 ST335-484A-R verhielten, wurden sie daraufhin als positive bzw. negative Kontrollen in den weiteren Experimenten verwendet.

\subsection{Untersuchung der Desensitisierung des FLAG-hEP wt- und des FLAG-hEP4 ST335-484A-Rezeptors in stabil transfizierten HEK293-Zellen}

Der in CHO-Zellen exprimierte EP4-R desensitisierte, im Gegensatz zu dem ebenfalls $\mathrm{G}_{\mathrm{s}}$ gekoppelten EP2-R, nach Agonisten-Exposition schnell (Nishigaki et al. (1996)). Diese Agonisten-induzierte Desensitisierung war in einer hEP4-R-Mutante aufgehoben, die am Anfang der C-terminalen Domäne trunkiert war (Bastepe und Ashby (1997)). Andererseits war ein Hybridrezeptor, in dem die C-terminale Domäne des nicht-desensitisierbaren EP3 $\beta$ $\mathrm{R}$ durch die C-terminale Domäne des desensitisierbaren hEP4-R ersetzt worden war, desensitisierbar (Neuschäfer-Rube et al. (1997b)). Daraus folgte, daß die C-terminale Domäne des hEP4-R sowohl notwendig wie hinreichend für die Agonisten-induzierte Desensitisierung war. Eine Voraussetzung für die Agonisten-induzierte Desensitisierung ist die Agonisten-induzierte Phosphorylierung. Daher wurde angenommen, daß der FLAG-hEP4 ST335-484A-R, in dem alle potentiellen Phosphorylierungsstellen eliminiert waren, nicht mehr Agonisten-abhängig desensitisierte. 


\subsubsection{Untersuchung der Desensitisierung der $\mathrm{PGE}_{2}$-induzierten cAMP-Bildung des FLAG-hEP4 wt- und des FLAG-hEP4 ST335-484A-Rezeptors nach Vorstimulation mit $\mathrm{PGE}_{2}$}

Die Desensitisierung der in HEK293-Zellen exprimierten Rezeptoren sollte dadurch gezeigt werden, daß die $\mathrm{PGE}_{2}$-stimulierte cAMP-Bildung in einer zweiten Stimulationsphase nach vorheriger Stimulation der Zellen mit $\mathrm{PGE}_{2}$ geringer ausfällt, als in nicht vorstimulierten Zellen.

Die den FLAG-hEP4 wt- oder den FLAG-hEP4 ST335-484A-Rezeptor exprimierenden HEK293-Zellen wurden mit 100 nM PGE 2 für 10 min vorstimuliert und anschließend mit saurem Puffer $(\mathrm{pH} 3)$ zur Entfernung des Liganden inkubiert. Danach wurden die Zellen in Anwesenheit von $1 \mathrm{mM}$ IBMX mit $10 \mathrm{nM} \mathrm{PGE}$ für 10 min restimuliert (siehe 3.22.2) und die CAMP-Bildung mit einem RIA bestimmt (siehe 3.21.5).

Die basale Agonisten-unabhängige cAMP-Bildung war in den hEP4-R-Wiltdtyp und den FLAG-hEP4 ST335-484A-R exprimierenden HEK293-Zellen gleich. Sie lag in der Größenordnung von $1,5 \mathrm{pmol}^{*}\left(\min { }^{*} 10^{6} \text { Zellen }\right)^{-1}$. In beiden Zellinien steigerte $10 \mathrm{nM} \mathrm{PGE} 2$ die cAMP-Bildung um das 15-20-fache (Abb. 27). Wurden die Zellen mit PGE 2 (100 nM) vorbehandelt, der Agonist entfernt und die Zellen in Gegenwart des PhosphodiesteraseInhibitors IBMX weiterinkubiert, stieg die cAMP-Bildung auf das 10-20-fache gegenüber den unvorbehandelten Zellen (Abb. 27). Diese ohne weiteren Stimulus ausgelöste cAMP-Bildung war in Zellen, die den Wildtyprezeptor exprimierten, signifikant kleiner als die durch $10 \mathrm{nM}$ $\mathrm{PGE}_{2}$ ohne Vorstimulation ausgelöste cAMP-Bildung. In Zellen, die den FLAG-hEP4 ST335484A-R exprimierten, war diese ohne weiteren Stimulus ausgelöste cAMP-Bildung gleich der durch $10 \mathrm{nM} \mathrm{PGE} E_{2}$ ohne Vorstimulation ausgelösten cAMP-Bildung und konnte durch erneute Stimulation mit $10 \mathrm{nM} \mathrm{PGE}_{2}$ nicht mehr weiter gesteigert werden (Abb. 27).

Diese Ergebnisse zeigen, daß zum einen ganz offensichtlich der Ligand $\left(\mathrm{PGE}_{2}\right)$ durch den sauren Waschschritt nach der ersten Stimulationsphase nicht vollständig vom Rezeptor gelöst werden konnte und der weiterhin gebundene Ligand auch ohne Zusatz von weiterem $\mathrm{PGE}_{2}$ die cAMP-Bildung stimulierte. Aufgrund der hohen cAMP-Spiegel nach Vorstimulation ohne Zugabe von weiterem Liganden konnte die cAMP-Bildung nach erneuter Ligandzugabe nicht vernünftig quantifiziert werden. Die Ergebnisse weisen aber auch daraufhin, daß der nach dem Waschschritt an den Rezeptoren verbleibende Ligand in Wildtyprezeptor exprimierenden Zellen zu einer geringeren cAMP-Bildung führte als in den FLAG-hEP4 ST335-484A-R exprimierenden Zellen. Dies könnte ein Hinweis auf eine Desensitisierung des FLAG-hEP4 wt-R sein, die in FLAG-hEP4 ST335-484A-R exprimierenden Zellen nicht mehr nachweisbar war. 


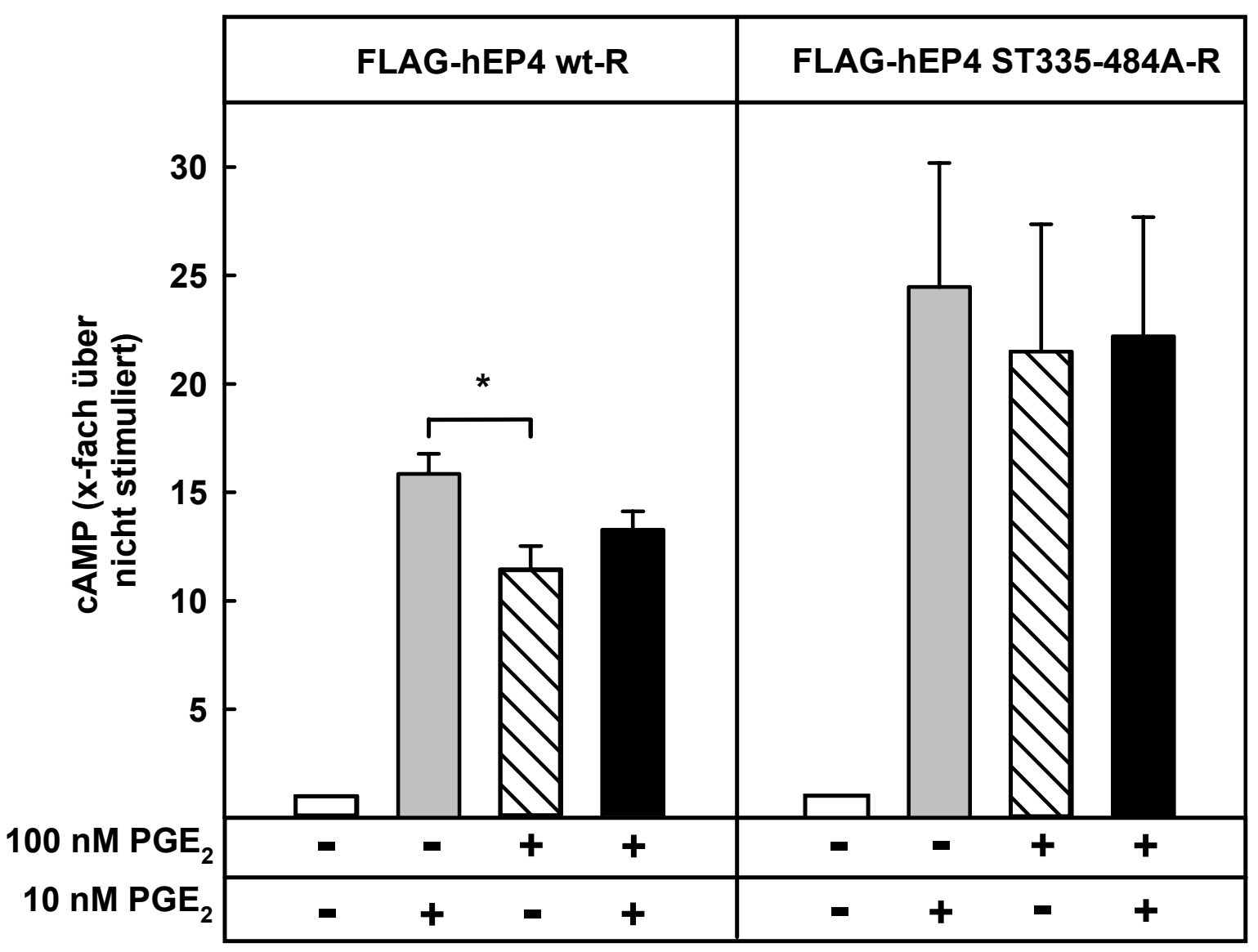

Abb. 27: PGE $_{2}$-induzierte cAMP-Bildung in FLAG-hEP4 wt- und in FLAG-hEP4 ST335484A-Rezeptor exprimierenden HEK293-Zellen mit und ohne Vorstimulation durch PGE $_{2 .} 2 \times 10^{5}$ Zellen, der mit dem FLAG-hEP4 wt-R oder dem FLAG-hEP4 ST335-484A-R stabil transfizierten HEK293-Zellen, wurden auf Poly-L-Lysin beschichten Kulturplatten $48 \mathrm{~h}$ kultiviert. Anschließend wurden die Zellen mit 100 nM PGE ${ }_{2}$ oder Puffer für 10 min vorstimuliert und darauffolgend 2 min mit saurem Puffer zur Entfernung des Liganden inkubiert. Danach wurden die Zellen in Anwesenheit von $1 \mathrm{mM} I B M X$ mit $10 \mathrm{nM} \mathrm{PGE}_{2}$ für 10 min in cAMP-Inkubationsmedium stimuliert (siehe 3.22.2). Das Medium wurde entfernt, die Zellen lysiert und das gebildete cAMP mit einem RIA bestimmt (siehe 3.21.5). Die Werte stellen die Mittelwerte \pm S.E.M. aus drei Versuchen in Doppelbestimmung dar. ${ }^{*} p<0,05$, Student's $t$-Test für ungepaarte Proben

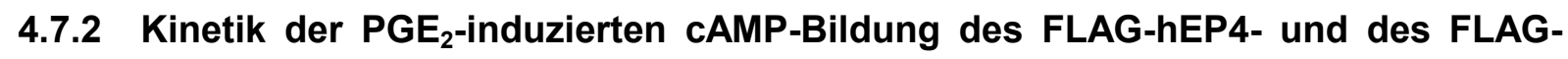
hEP4 ST335-484A-Rezeptors nach Vorstimulation und verzögerter Gabe von IBMX und Kinetik der Forskolin-induzierten cAMP-Bildung an ganzen Zellen

Da durch Vorstimulation der den FLAG-hEP4 wt-R exprimierenden Zellen die Agonisteninduzierte cAMP-Bildung gering reduziert war (Abb. 27), wurde die Kinetik der $\mathrm{PGE}_{2^{-}}$ induzierten cAMP-Bildung nach Vorstimulation der Rezeptor-exprimierenden Zellen mit $\mathrm{PGE}_{2}$ untersucht. Dazu wurden die den FLAG-hEP4 wt- und den FLAG-hEP4 ST335-484ARezeptor exprimierenden HEK293-Zellen für 10 min mit $1 \mu \mathrm{M} \mathrm{PGE}_{2}$ vorstimuliert und die 
intrazelluläre cAMP-Akkumulation durch Zugabe von $1 \mathrm{mM}$ IBMX gestartet. Die Ansätze wurden für 0-30 min zur cAMP-Bildung inkubiert (siehe 3.22.3) und anschließend das gebildete cAMP mit einem RIA bestimmt (siehe 3.21.5).

Für die den FLAG-hEP4 wt-R exprimierenden HEK293-Zellen sollte nach Vorstimulation mit $\mathrm{PGE}_{2}$ noch ein Anstieg des cAMP-Spiegels erfolgen, jedoch wurde das Erreichen eines konstanten cAMP-Spiegels erwartet, da nach der Entkopplung des Rezeptors kein weiteres cAMP mehr gebildet werden kann. Dagegen wurde in den den FLAG-hEP4-ST335-484A-R exprimierenden Zellen ein kontinuierlicher Anstieg des cAMP-Spiegels erwartet.

Nach Vorstimulation zeigten die den FLAG-hEP4 wt-R und den FLAG-hEP4 ST335-484A-R exprimierenden HEK293-Zellen einen geringen basalen cAMP-Spiegel, der nach Zugabe von IBMX für den FLAG-hEP4 wt-R im gleichen Maße wie für den FLAG-hEP4 ST335-484A$R$ anstieg (Abb. 28). Die den FLAG-hEP wt-R exprimierenden Zellen zeigten nach 10 min einen maximalen cAMP-Spiegel, der für weitere 20 min nicht mehr gesteigert werden konnte. Allerdings zeigten auch die den FLAG-hEP4 ST335-484A-R exprimierenden Zellen ein Maximum der $\mathrm{PGE}_{2}$-induzierten $\mathrm{CAMP}$-Bildung nach $10 \mathrm{~min}$, welches ebenfalls konstant blieb. Der erwartete kontinuierliche, Agonisten-abhängige cAMP-Anstieg für den FLAG-hEP4 ST335-484A-R konnte nicht nachgewiesen werden (Abb. 28). Dies Ergebnis könnte bedeuten, daß entweder beide Rezeptoren Agonisten-abhängig desensitisieren, oder aber, daß ein sehr hoher cAMP-Spiegel die weitere cAMP-Bildung hemmt.

Um diesen möglichen zellulären Effekt auf die cAMP-Bildung zu untersuchen, wurde die Kinetik der Forskolin-induzierten cAMP-Bildung mit den den FLAG-hEP4 wt-R oder den FLAG-hEP4 ST335-484A-R exprimierenden HEK293-Zellen bestimmt (siehe 3.21.4). Da Forskolin ein direkter, Rezeptor-unabhängiger Aktivator der Adenylatcyclase ist, sollte in der Kinetik ein konstanter cAMP-Anstieg in den beiden Rezeptor exprimierenden Zellinien messbar sein.

Durch Stimulation der Rezeptor exprimierenden HEK293-Zellen kam es zu einem Forskolinvermittelten Anstieg des intrazellulären cAMP-Spiegels, allerdings erreichte auch die Forskolin-induzierte cAMP-Bildung ein Maximum nach $10 \mathrm{~min}$ und blieb über weitere $20 \mathrm{~min}$ konstant (Abb. 29). Die Kinetikprofile der Forskolin-induzierten cAMP-Bildung in den beiden Rezeptor exprimierenden Zellen waren mit den Rezeptor-vermittelten Kinetikprofilen nach $\mathrm{PGE}_{2}$-Simulation vergleichbar (vgl. Abb. 28, Abb. 29). Dieses Ergebnis deutete darauf hin, daß nicht beide Rezeptoren desensitisieren, sondern daß durch einen Rezeptorunabhängigen Mechanismus die weitere cAMP-Bildung inhibiert wird.

Weiterhin ist nicht auszuschließen, daß die Expression des FLAG-hEP4 wt-Rezeptors so hoch war, daß der Anteil an desensitisierten Rezeptoren zu gering war und die verbleibenden nicht desensitisierten Rezeptoren noch ausreichten, um ein maximales cAMPSignal auszulösen. Zusätzlich könnte auch der in den verwendeten HEK293-Zellen in 
geringem Maße endogen exprimierte EP2-Rezeptor die mögliche Desensitisierung des hEP4-wt-R überlagern.

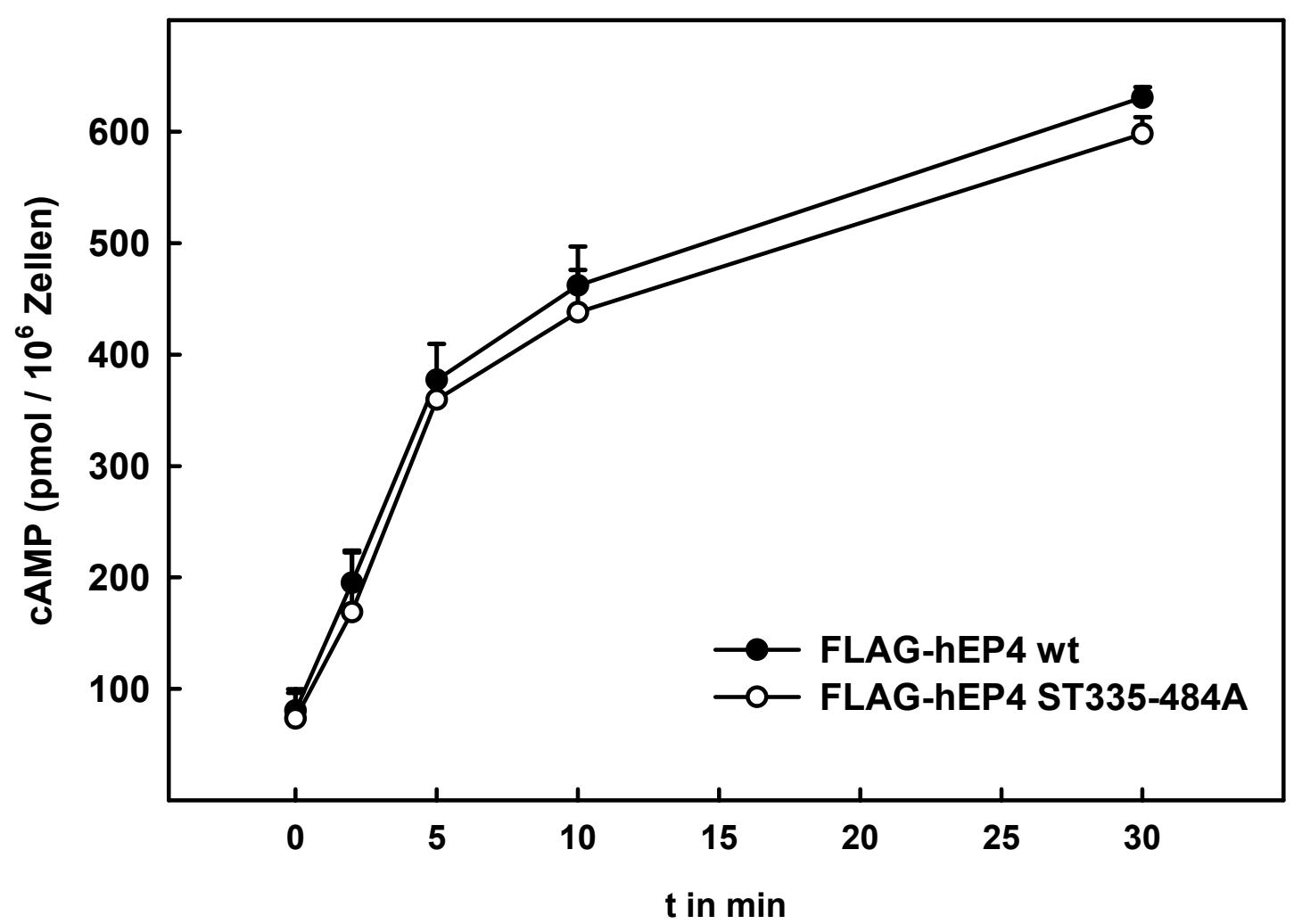

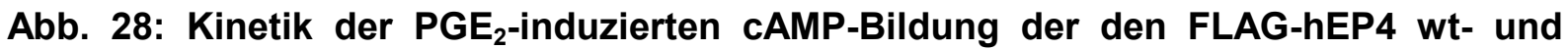
FLAG-hEP4 ST335-484A-Rezeptor stabil exprimierenden HEK293-Zellen nach verzögerter Gabe von IBMX. 2 × $10^{5}$, der mit dem FLAG-hEP4 wt-R und dem FLAG-hEP4 ST335-484A-R stabil transfizierten HEK293-Zellen, wurden auf Poly-L-Lysin beschichteten Kulturplatten für $48 \mathrm{~h}$ kultiviert. Das Kulturmedium wurde entfernt und die Zellen für $10 \mathrm{~min}$ mit $1 \mu \mathrm{M} \mathrm{PGE}_{2}$ in $\mathrm{CAMP}^{-I n k u b a t i o n s m e d i u m ~ v o r i n k u b i e r t . ~ D a n a c h ~ w u r d e ~ I B M X ~ i n ~ e i n e r ~}$ Endkonzentration von $1 \mathrm{mM}$ zugegeben und damit die cAMP-Akkumulation in den Zellen für 0-30 min bei $37^{\circ} \mathrm{C}$ stimuliert (siehe 3.21.4). Die cAMP-Bildung wurde, wie in Abb. 27 beschrieben, bestimmt. Die Werte stellen die Mittelwerte \pm S.E.M. aus zwei Versuchen in Doppelbestimmung dar. 


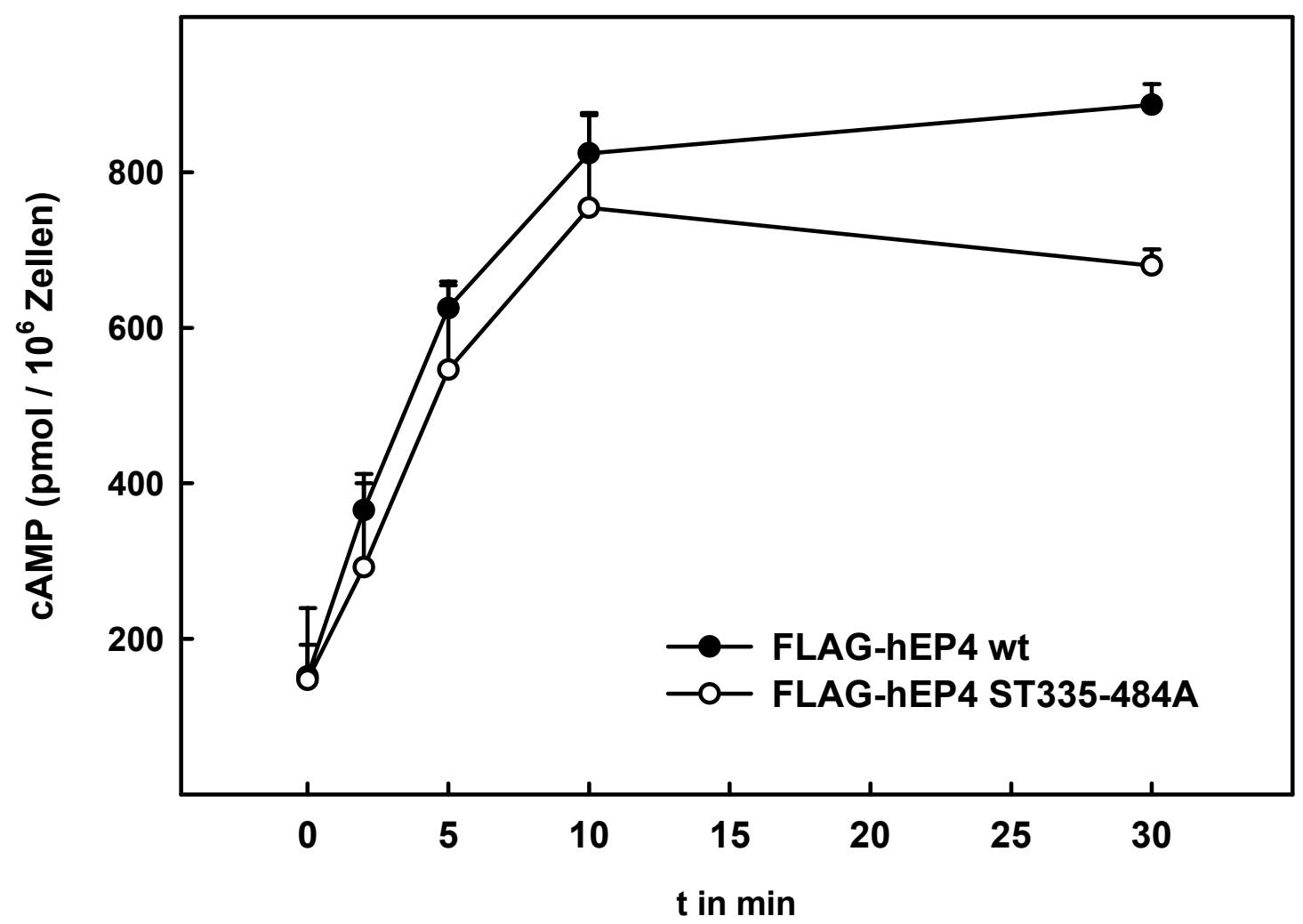

Abb. 29: Kinetik der Forskolin-induzierten cAMP-Bildung der mit dem FLAG-hEP4 wtund dem FLAG-hEP4 ST335-484A-Rezeptor stabil transfizierten HEK293-Zellen. $2 \times 10^{5}$, der mit dem FLAG-hEP4 wt- und dem FLAG-hEP4 ST335-484A-Rezeptor stabil transfizierten HEK293-Zellen, wurden auf Poly-L-Lysin beschichteten Kulturplatten für $48 \mathrm{~h}$ kultiviert. Das Kulturmedium wurde entfernt und die Zellen für 10 min mit $1 \mathrm{mM}$ IBMX in cAMP-Inkubationsmedium vorinkubiert. Danach wurden die Zellen für 0-30 min mit $1 \mu \mathrm{M}$ Forskolin bei $37^{\circ} \mathrm{C}$ zur cAMP-Bildung stimuliert (siehe 3.21.4). Die cAMP-Bildung wurde, wie in Abb. 27 beschrieben, bestimmt. Die Werte stellen die Mittelwerte \pm S.E.M. aus drei Versuchen in Doppelbestimmung dar.

4.7.3 Kinetik der cAMP-Bildung des FLAG-hEP4 wt- und des FLAG-hEP4 ST335484A-Rezeptors nach Vorstimulation mit dem EP4-Rezeptor-spezifischen synthetischen Agonisten ONO604 und verzögerter Gabe von IBMX

Da die verwendeten HEK293-Zellen in geringem Maße endogen den EP2-Rezeptor exprimieren und ein möglicher Überlagerungseffekt durch diesen $\mathrm{G}_{\mathrm{s}}$-gekoppelten Rezeptor nicht ausgeschlossen werden konnte, wurde eine Kinetik der Agonisten-induzierten cAMPBildung mit dem synthetischen EP4-R-spezifischen Agonisten ONO604 in einer Konzentration durchgeführt, bei der der EP2-Rezeptor nicht aktiviert wurde. Durch den spezifischen Agonisten sollte eine mögliche Desensitisierung des FLAG-hEP wt-Rezeptors, die durch eine potentielle Aktivierung des endogenen EP2-Rezeptors überlagert wurde, nachgewiesen werden. Dazu wurden die den FLAG-hEP4 wt-R und die den FLAG-hEP4 ST335-484A-R exprimierenden HEK293-Zellen für 10 min mit 10 nM ONO604 vorstimuliert, 
anschließend der Ligand entfernt und die Zellen 10 min ohne Ligand inkubiert (siehe 3.22.4). Die cAMP-Akkumulation wurde durch Zugabe von IBMX gestartet und nach verschieden langen Zeiträumen das gebildete cAMP mit einem RIA bestimmt (siehe 3.21.5). Nach Vorstimulation mit ONO604 und Inkubation ohne Agonisten zeigten die den FLAG-hEP4 wt$R$ und die den FLAG-hEP4 ST335-484A-R exprimierenden HEK293-Zellen einen geringen basalen cAMP-Spiegel (Abb. 30), jedoch wurde für beide Rezeptoren nach Zugabe von IBMX ein maximaler CAMP-Spiegel nach ca. 10 min bestimmt, der über weitere 20 min konstant blieb (Abb. 30). Die Kinetikprofile der Rezeptoren unterschieden sich nicht. Dies könnte in der sehr hohen Expression der Rezeptoren begründet sein, sodaß nach Vorstimulation und Inkubation ohne Ligand noch genug FLAG-hEP4 wt-Rezeptoren nicht desensitisiert waren, um ein maximales Signal auszulösen. Die Kinetik bestätigte zusätzlich, daß der Ligand nicht vollständig vom Rezeptor entfernt werden konnte.

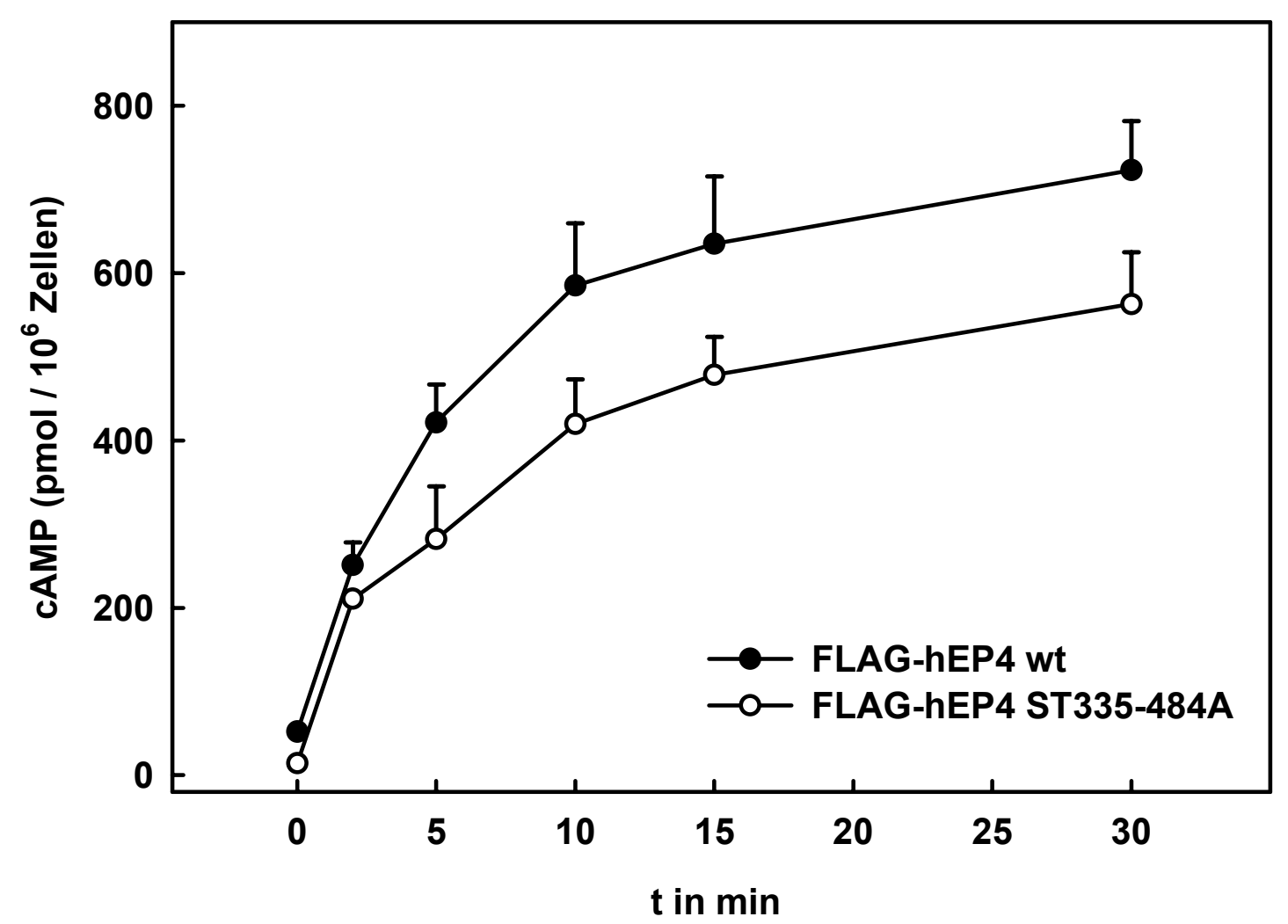

Abb. 30: Kinetik der cAMP-Bildung in FLAG-hEP4 wt- und FLAG-hEP4 ST335-484ARezeptor exprimierenden HEK293-Zellen durch Stimulation mit dem EP4-Rspezifischen Agonisten ONO604 und verzögerter Gabe von IBMX. $2 \times 10^{5}$, der mit dem FLAG-hEP4 wt-R und der mit dem FLAG-hEP4 ST335-484A-R stabil transfizierten HEK293Zellen, wurden für $48 \mathrm{~h}$ kultiviert. Das Kulturmedium wurde entfernt, die Zellen für $10 \mathrm{~min}$ mit $10 \mathrm{nM}$ ONO604 in cAMP-Inkubationsmedium stimuliert und anschließend der Ligand in drei Waschschritten entfernt. Die Zellen wurden ohne Ligand 10 min in cAMP-Inkubationsmedium inkubiert und die cAMP-Akkumulation durch Zugabe von IBMX in einer Endkonzentration von $1 \mathrm{mM}$ gestartet ( siehe 3.22.4). Die Ansätze wurden für $0-30$ min bei $37^{\circ} \mathrm{C}$ zur cAMP-Bildung inkubiert (siehe 3.22.) und das gebildete cAMP, wie in Abb. 27 beschrieben, bestimmt. Die Werte stellen die Mittelwerte \pm S.E.M. aus drei Versuchen in Doppelbestimmung dar. 


\subsubsection{Untersuchung der Verschiebung der Dosis-Wirkungskurven für die $P^{-} E_{2^{-}}$ stimulierte cAMP-Bildung des FLAG-hEP4 wt- und des FLAG-hEP4 ST335-484A- Rezeptors}

Die Desensitisierung eines Rezeptors kann anhand der Rechtsverschiebung seiner DosisWirkungskurve für die Agonisten-induzierten „second-messenger“-Bildung ermittelt werden. Werden die in einer Zelle exprimierten Rezeptoren nach Vorstimulation mit ihrem Liganden von ihrem G-Protein entkoppelt, kann nach Restimulation der Zelle derselbe Ligand ein gleich großes Signal erst mit höheren Konzentrationen auslösen (Nishigaki et al. (1996)). Ferner können sättigende Agonistenkonzentrationen in Zellen, in denen der Rezeptor desensitisiert ist, eine geringere maximale Signalstärke auslösen, als in Zellen mit nichtdesensitisiertem Rezeptor.

Zur Untersuchung der Dosis-Wirkungskurven-Verschiebung der FLAG-hEP4 wt- oder FLAGhEP4 ST335-484A-Rezeptor-vermittelten, $\mathrm{PGE}_{2}$-stimulierten cAMP-Bildung wurden die die Rezeptoren exprimierenden Zellen mit $1 \mu \mathrm{M} \mathrm{PGE}_{2}$ für 10 min vorstimuliert, der Ligand mit saurem Puffer entfernt und Membranen aus den Zellen präpariert (siehe 3.21.2). An den Membranen wurde in einem „in vitro-Assay“ die Dosis-abhängige cAMP-Bildung durch PGE ${ }_{2}$ gemessen (3.21.3). Das gebildete cAMP wurde mit einem RIA bestimmt (siehe 3.21.5).

In Membranen nicht vorstimulierter, FLAG-hEP4 wt-R exprimierender HEK293-Zellen stimulierte $\mathrm{PGE}_{2}$ die cAMP-Bildung mit einer EC50 von 1,98 $\pm 0,7 \mathrm{nM}$. Die EC50 für die $\mathrm{PGE}_{2}$-stimulierte CAMP-Bildung war in Membranen vorstimulierter, Wildtyprezeptorexprimierender HEK293-Zellen zwar tendentiell höher (3,73 $\pm 0,45 \mathrm{nM})$, aber nicht signifikant unterschiedlich von der in Membranen nicht-vorstimulierter Zellen. Auch die maximale PGE ${ }_{2}$ induzierte cAMP-Bildung war in Membranen vorstimulierter Zellen nicht reduziert (Abb. 31). In Membranen aus nicht-vorstimulierten und vorstimulierten HEK293-Zellen, die den FLAGhEP4 ST335-484A-R exprimierten, verliefen die Dosis-Wirkungskurven absolut deckungsgleich (Abb. 31). Trotz dieses kleinen Unterschiedes zwischen dem FLAG-hEP4 wt- und dem FLAG-hEP4 ST335-484A-R konnte eine Desnsitisierung des Wildtyprezeptors auch in diesem experimentellen Ansatz nicht eindeutig nachgewiesen werden. 


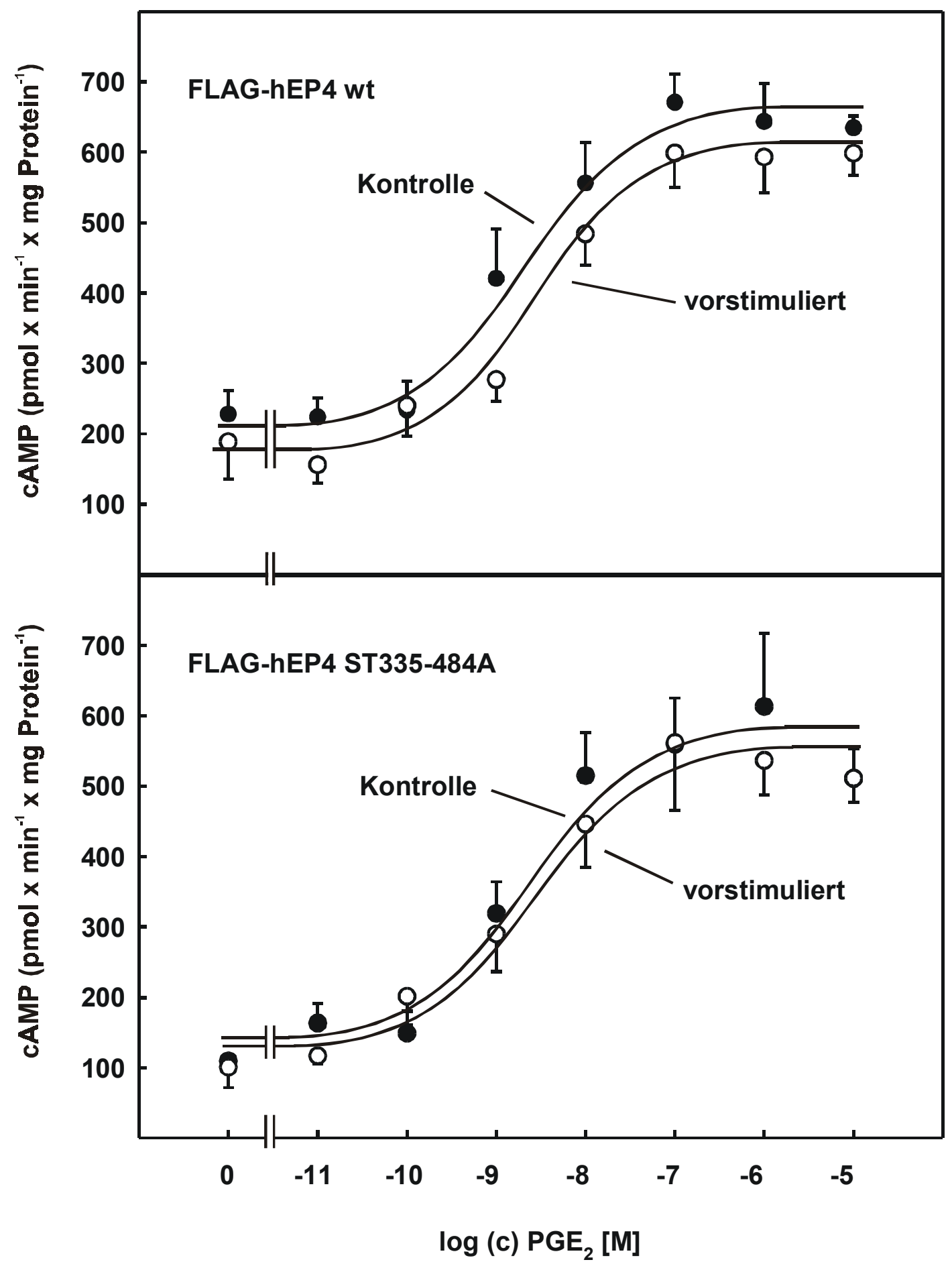

Abb. 31: Konzentrationsabhängigkeit der $\mathrm{PGE}_{2}$-induzierten cAMP-Bildung in FLAGhEP4 wt- und FLAG-hEP4 ST335-484A-Rezeptor exprimierenden HEK293-Zellen nach

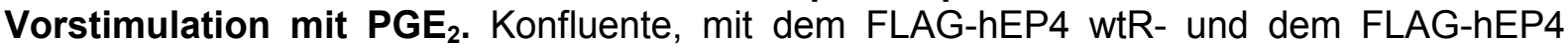
ST335-484A-R stabil transfizierte HEK293-Zellen, wurden für 10 min mit $1 \mu \mathrm{M} \mathrm{PGE}_{2}$ in cAMP-Inkubationmedium stimuliert. Danach wurde der auf der Oberfläche gebundene Ligand 1 min in saurem Puffer eluiert (siehe 3.22.5), der saure Puffer in zwei Waschschritten mit cAMP-Inkubationsmedium entfernt und Membranen aus den Zellen präpariert (siehe 3.21.2). Die Membranen wurden mit steigenden Konzentrationen $P \mathrm{PE}_{2}$ in Gegenwart von IBMX inkubiert (siehe 3.21.3). Das gebildete cAMP wurde mit einem RIA bestimmt (siehe 3.21.5). Die Werte stellen die Mittelwerte aus drei unbahängigen Versuchen \pm S.E.M. in Doppelbestimmung dar. 


\subsection{Untersuchung der Internalisierung des in HEK293-Zellen stabil transfizierten FLAG-hEP4 wt- und der verschiedenen mutierten FLAG-hEP4-Rezeptoren}

Nach Phosphorylierung und Desensitisierung kommt es bei vielen G-Protein-gekoppelten Rezeptoren zu einer Clathrin-vermittelten Internalisierung des Rezeptors, daß heißt einer Verlagerung des Rezeptors mit dem gebundenen Liganden von der Zelloberfläche in intrazelluläre Kompartimente (Kraft et al. (2001)). Diese Clathrin-vermittelte Rezeptorinternalisierung kann durch hohe extrazelluläre Saccharosekonzentrationen gehemmt werden (Heuser und Anderson (1989)). Die Relevanz der C-terminalen Domäne für die Internalisierung des EP4-Rezeptors wurde bereits durch Desai et al. (2000) und Slipetz et al. (2001) anhand von Trunkierungsmutanten beschrieben. Hier sollte nun untersucht werden, wie sich die Elimination der potentiellen Phosphorylierungsstellen in der C-terminalen Domäne des hEP4-R auf die Internalisierung auswirkt.

\subsubsection{Untersuchung der Internalisierung der verschiedenen FLAG-hEP4-Rezeptoren anhand der reduzierten FLAG-M2-mAk-Oberflächenbindung durch ELISA}

Zur Untersuchung der Internalisierung wurden die mit den verschiedenen Rezeptoren stabil transfizierten HEK293-Zellen für 30 min in An- oder Abwesenheit von 0,45 M Saccharose inkubiert und danach 45 min mit $1 \mu \mathrm{M} \mathrm{PGE}_{2}$ stimuliert. Anschließend wurden die Zellen für $2 \mathrm{~h}$ bei $4^{\circ} \mathrm{C}$ mit dem FLAG-M2-mAk inkubiert und der an die Zelloberfläche gebundene Antikörper im ELISA quantitativ bestimmt (siehe 3.23).

In Zellen, die den FLAG-hEP4 wt-R exprimierten, war die Anzahl der an der Zelloberfläche zugänglichen FLAG-Epitope und damit die Zahl der an der Zelloberfläche nachweisbaren hEP4-Rezeptorproteine nach Stimulation der Zellen mit $\mathrm{PGE}_{2}$ um ca. 20\% reduziert (Abb. 32). In Zellen, die den FLAG-hEP4 ST335-484A-R exprimierten war keine $\mathrm{PGE}_{2}$-abhängige Reduktion der Rezeptorproteine an der Zelloberfläche nachweisbar. Die Serine und Threonine in der C-terminalen Domäne des hEP4-R waren also für die Agonisten-induzierte Internalisierung essentiell.

In Zellen, die die Rezeptormutanten exprimierten, in denen lediglich die Serine und Threonine im proximalen Teil der C-terminalen Domäne bzw. Serin 379 selektiv gegen Alanin ausgetauscht waren (FLAG-hEP4 ST335-405A-, FLAG-hEP4 ST335-382A- und FLAG-hEP4 S379A-R), reduzierte die Inkubation mit $\mathrm{PGE}_{2}$ die Anzahl der auf der Zelloberfläche für die Antikörper zugänglichen Rezeptoren in ähnlichem Umfang wie in Wildtyprezeptor-exprimierenden Zellen. Im Gegensatz dazu wurden Rezeptoren, in denen die Serine und Threonine im distalen Teil der C-terminalen Domäne gegen Alanine ausgetauscht waren (FLAG-hEP4 ST428-484A-, FLAG-hEP4 ST335-354; 389-484A- und FLAG-hEP4 ST335-377; 382-484A-R), nicht internalisiert. 
Vorbehandlung der Zellen mit Saccharose zur Hemmung der Clathrin-vermittelten Endocytose hob die Internalisierung des FLAG-hEP4 wt-, des FLAG-hEP ST335-405A-und des FLAG-hEP4 S379A-R auf (Abb. 33), was die Annahme unterstützt, daß die Rezeptorendocytose über einen durch Saccharose inhibierbaren, Clathrin-vermittelten Internalisierungweg erfolgt. Überraschenderweise wurde die Internalisierung des FLAGhEP4 ST335-382A-Rezeptors mit Saccharose nicht gehemmt (Abb. 33). Dies könnte auf einen möglichen sekundären, $\beta$-Arrestin- und Clathrin-unabhängigen Internalisierungweg hindeuten.

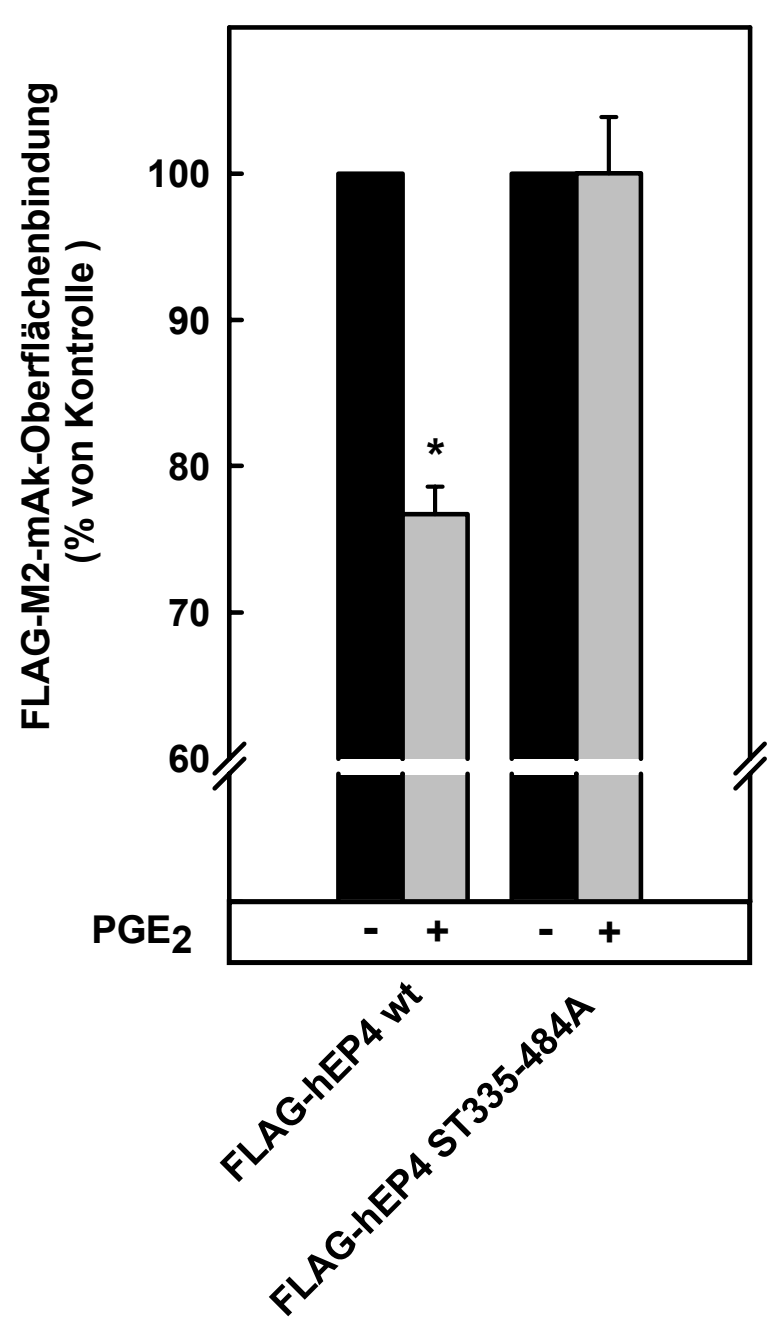

Abb. 32: Bestimmung der Agonisteninduzierten Internalisierung des FLAGhEP4 wt- und des FLAG-hEP4 ST335484A-Rezeptors durch Zell-Oberflächen-ELISA. HEK293-Zellen, die die verschiedenen Rezeptoren stabil exprimierten, wurden für 45 min mit $1 \mu \mathrm{M}$ $\mathrm{PGE}_{2}$ bei $37^{\circ} \mathrm{C}$ stimuliert, anschließend auf $4^{\circ} \mathrm{C}$ abgekühlt und die Menge der an der Oberfläche zugänglichen Rezeptorproteine durch einen Cyto-ELISA (siehe 3.23) mit dem FLAG-M2-mAk bestimmt. Dargestellt ist die ermittelte FLAG-M2mAk-Oberflächenbindung als Prozent der nicht mit $\mathrm{PGE}_{2}$ stimulierten Kontrollzellen. Die Werte stellen die Mittelwerte \pm S.E.M. aus vier (FLAG-hEP4 ST335-484A-R) oder fünf (FLAG-hEP4 wt-R) verschiedenen Versuchen in Dreifachbestimmung dar. ${ }^{*} p<0,05$, Student's $t$ Test für ungepaarte Proben. 


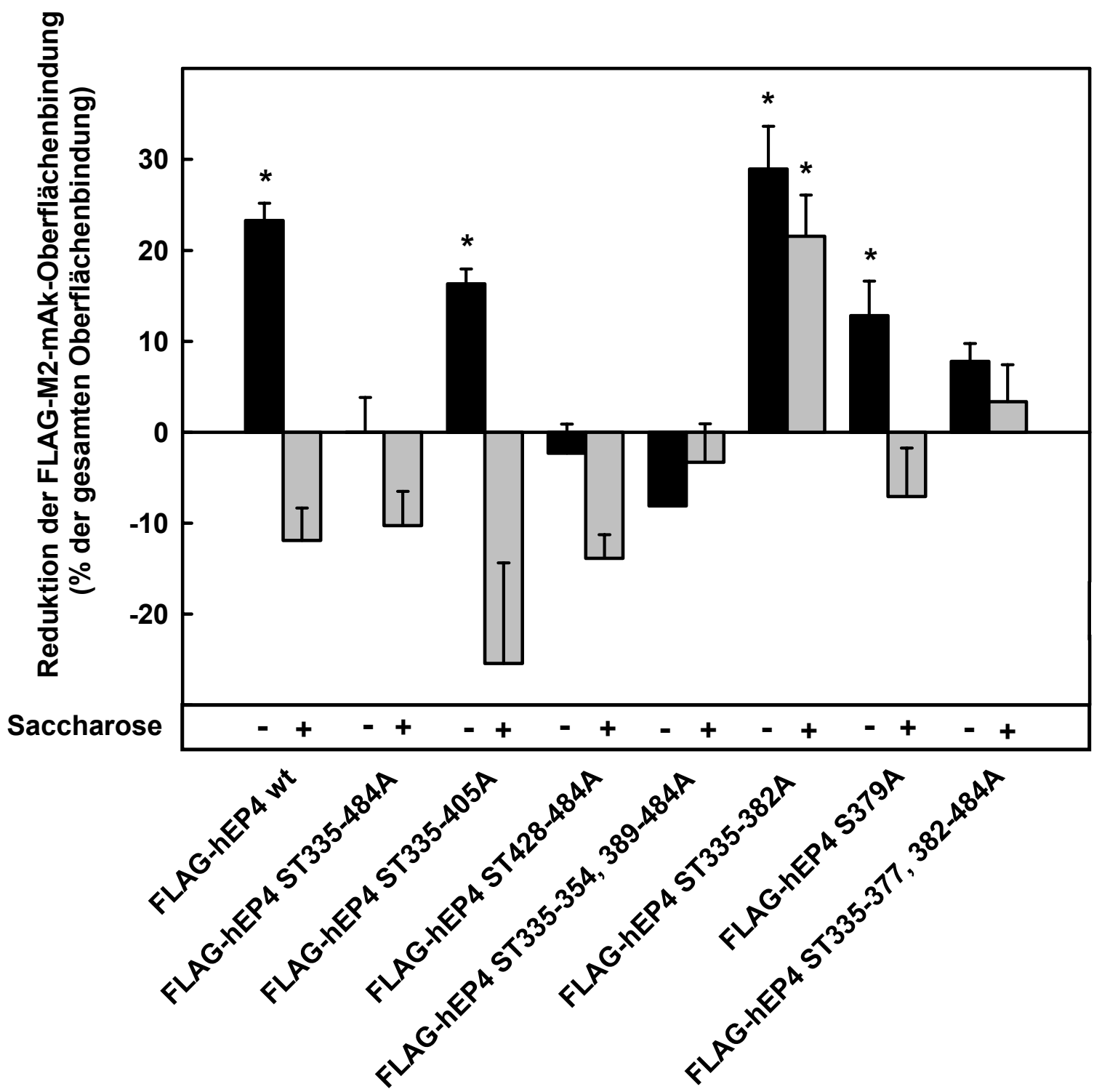

Abb. 33: Bestimmung der Agonisten-induzierten Internalisierung des FLAG-hEP4 wtRezeptors und der mutierten Rezeptorproteine durch Zell-Oberflächen-ELISA ohne und nach Vorbehandlung der Zellen mit Saccharose. HEK293-Zellen, die die verschiedenen Rezeptoren stabil exprimierten, wurden für 30 min in An- oder Abwesenheit von $0,45 \mathrm{M}$ Saccharose bei $37^{\circ} \mathrm{C}$ vorinkubiert. Danach wurden die Zellen für 45 min mit $1 \mu \mathrm{M}$ $\mathrm{PGE}_{2}$ bei $37^{\circ} \mathrm{C}$ stimuliert, anschließend auf $4^{\circ} \mathrm{C}$ abgekühlt und die Menge der an der Oberfläche zugänglichen Rezeptorproteine durch einen Cyto-ELISA (siehe 3.23) mit dem FLAG-M2-mAk bestimmt. Dargestellt ist die reduzierte FLAG-M2-mAk-Oberflächenbindung als Prozent der nicht mit $\mathrm{PGE}_{2}$ stimulierten Kontrollzellen. Die Werte stellen die Mittelwerte \pm S.E.M. aus drei (FLAG-hEP4 ST335-484A-R, FLAG-hEP ST335-405A-R, FLAG-hEP4 ST335-377; 382-484A-R und FLAG-hEP4 S379A-R), vier (FLAG-hEP4 ST428-484A-R, FLAG-hEP4 ST 335-354; 389-484-R und FLAG-hEP4 ST335-382A-R) oder fünf (FLAGhEP4 wt-R) verschiedenen Versuchen in Dreifachbestimmung ohne Vorbehandlung der Zellen mit Saccharose und die Mittelwerte \pm S.E.M. aus drei (FLAG-hEP4 ST335-484A-R, FLAG-hEP ST335-405A-R, FLAG-hEP4 ST428-484A-R, FLAG-hEP4 S379A-R und FLAGhEP4 ST335-377; 382-484A-R) oder vier (FLAG-hEP4 wt-R, FLAG-hEP4 ST 335-354; 389484-R und FLAG-hEP4 ST335-382A-R) verschiedenen Versuchen in Dreifachbestimmung nach Vorbehandlung der Zellen mit Saccharose dar. ${ }^{*} p<0,05$, Student's $t$-Test für ungepaarte Proben. 


\subsubsection{Untersuchung der Internalisierung der verschiedenen FLAG-hEP4-Rezeptoren durch Bindungsstudien mit $\left[{ }^{3} \mathrm{H}\right]-\mathrm{PGE}_{2}$}

Die Quantifizierung der Rezeptorinternalisierung über den Cyto-ELISA erfaßt die Summe aller Epitop-tragender Rezeptorproteine auf der Zelloberfläche. Sie sollte durch ein Verfahren ergänzt werden, bei dem der Weg der Ligand-besetzten Rezeptoren verfolgt werden kann. Da der Rezeptor während der Internalisierung immer noch mit dem Ligand besetzt ist, konnte die Internalisierung anhand der Verteilung von $\left.{ }^{3} \mathrm{H}\right]-\mathrm{PGE}_{2}$ zwischen Plasmamembran und intrazellulären Kompartimenten nach längeren Inkubationszeiten, in denen eine Agonisten-induzierte Internalisierung ausgelöst werden kann, bestimmt werden. Dafür wurden die die verschiedenen Rezeptoren exprimierenden HEK293-Zellen für $2 \mathrm{~h}$ bei $4^{\circ} \mathrm{C}$, einer Temperatur, bei der keine Internalisierung stattfindet und bei der die Internalisierungsunabhängige Bindung von $\left.{ }^{3} \mathrm{H}\right]-\mathrm{PGE}_{2}$ an die Zelloberfläche bestimmt werden kann, und parallel für $30 \mathrm{~min}$ bei $37^{\circ} \mathrm{C}$ mit $5 \mathrm{nM}\left[{ }^{3} \mathrm{H}\right]-\mathrm{PGE}_{2}$ in An- oder Abwesenheit von nichtmarkiertem $\mathrm{PGE}_{2}$ zur Bestimmung der unspezifischen Bindung inkubiert und anschließend das auf der Zelloberfläche gebundene $\left[{ }^{3} \mathrm{H}\right]-\mathrm{PGE}_{2}$ durch Behandlung der Zellen mit saurem Puffer ( $\mathrm{pH} 3)$ eluiert. Danach wurden die Zellen in Lysis-Puffer aufgeschlossen und die Radioaktivität im Zellaufschluß sowie im Eluat bestimmt (siehe 3.24).

In Zellen, die den FLAG-hEP4 wt-R exprimierten, konnten unter Bedingungen, die keine Internalisierung zulassen $\left(4^{\circ} \mathrm{C}\right), 60 \%$ der gesamten spezifisch Zell-assoziierten $\left.{ }^{3} \mathrm{H}\right]-\mathrm{PGE}_{2^{-}}$ Menge an der Plasmamembran von den Zellen eluiert werden. Unter Bedingungen, die eine Internalisierung zulassen $\left(37^{\circ} \mathrm{C}\right)$, war die Menge an Zelloberflächen-assoziiertem [ $\left.{ }^{3} \mathrm{H}\right]-\mathrm{PGE}_{2}$ auf $30 \%$ reduziert (Abb. 34). Daraus wurde geschlossen, daß etwa $50 \%$ der ursprünglich an der Plasmamembran zugänglichen Rezeptoren bei $37^{\circ} \mathrm{C}$ internalisiert werden (Abb. 35$)$. Im Gegensatz dazu war die Zelloberflächen-assoziierte [ $\left.{ }^{3} \mathrm{H}\right]-\mathrm{PGE}_{2}-$ Menge in Zellen, die den FLAG-hEP4 ST335-484A-R exprimierten, unter beiden Bedingungen nahezu identisch (Abb. 34). Es fand also keine Agonisten-induzierte Internalisierung statt (Abb. 35). Dieser Befund ist im Einklang mit den Ergebnissen des Cyto-ELISAs (Abb. 33). Bei allen Mutanten, in denen die Serine und Threonine im distalen Teil der C-terminalen Domäne des hEP4-R gegen Alanine substituiert waren, war der Anteil des von der Zelloberfläche mit dem Rezeptor in die Zelle sequestrierten $\left[{ }^{3} \mathrm{H}\right]-\mathrm{PGE}_{2}$ geringer als beim Wildtyprezeptor; die Rezeptoren wurden also in geringerem Umfang Agonisten-abhängig internalisiert. Auch dies stimmte mit den im Cyto-ELISA erhobenen Daten überein. Von den Mutanten, in denen die Serine und Threonine im proximalen Bereich der C-terminalen Domäne gegen Alanine ausgetauscht worden waren, wurde die Mutante FLAG-hEP4 ST335-382A-R wie der Wildtyprezeptor internalisiert, die Mutante FLAG-hEP4 ST335-405A-R aber deutlich weniger als der Wildtyprezeptor. Dieser Befund weicht von den Ergebnissen des Cyto-ELISAs ab, der 
Anhalt dafür lieferte, daß beide Mutanten gleich stark wie der Wildtyprezeptor internalisiert werden.

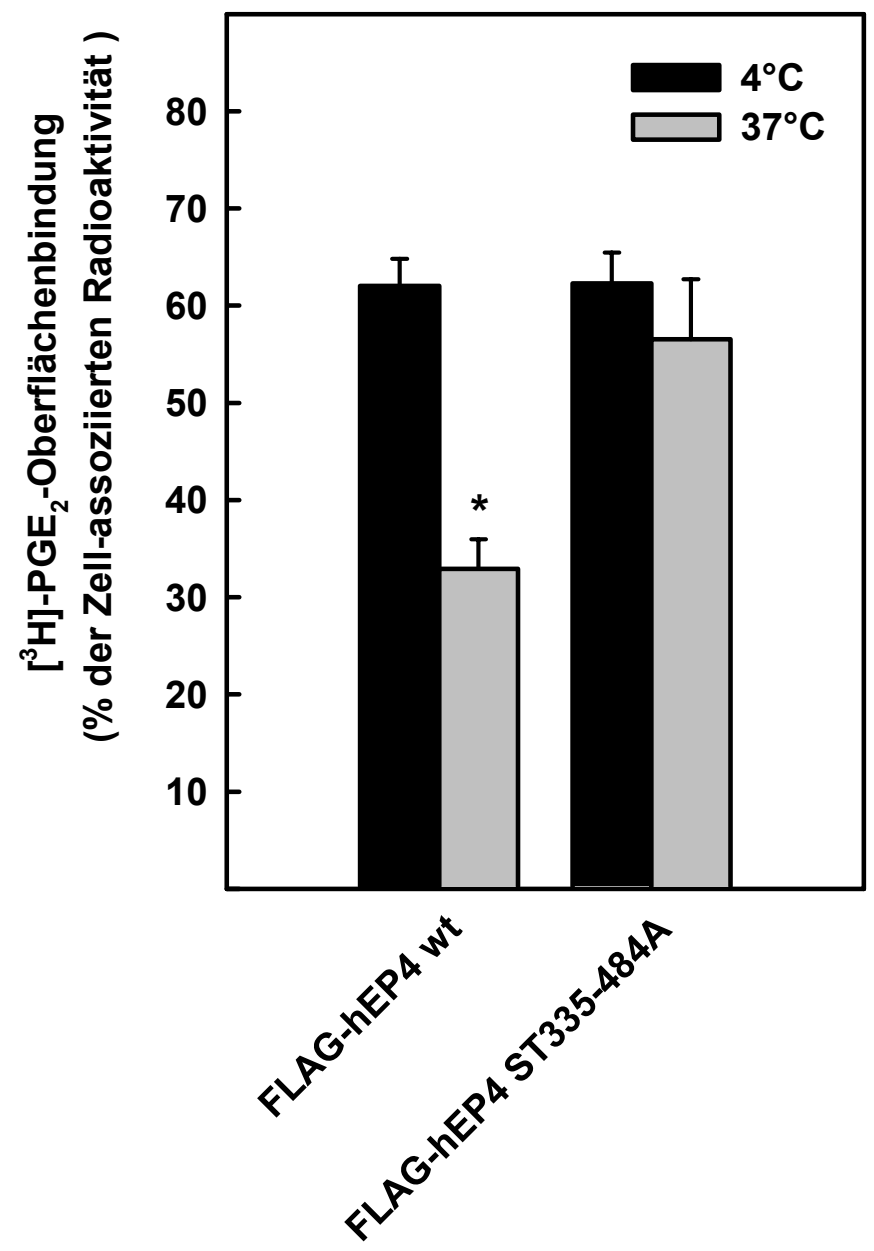

Abb. 34: Bindung von $\left[^{3} \mathrm{H}\right]-\mathrm{PGE}_{2}$ an die Oberflächen von FLAG-hEP4 wt- oder FLAGhEP4 ST335-484A-Rezeptor exprimierenden HEK293-Zellen bei $4^{\circ} \mathrm{C}$ und bei $37^{\circ} \mathrm{C}$. HEK293-Zellen, die die angegebenen Rezeptoren stabil exprimierten wurden mit $5 \mathrm{nM}\left[^{3} \mathrm{H}\right]-$ $\mathrm{PGE}_{2}$ in An- oder Abwesenheit von $10 \mu \mathrm{M}$ nicht-markiertem $\mathrm{PGE}_{2}$ für $2 \mathrm{~h}$ bei $4^{\circ} \mathrm{C}$ und parallel 30 min bei $37^{\circ} \mathrm{C}$ inkubiert. Der Überstand wurde entfernt und das an der Zelloberfläche gebundene $\left[{ }^{3} \mathrm{H}\right]$-markierte $\mathrm{PGE}_{2}$ zweimal 5 min mit saurem Puffer eluiert (siehe 3.24). Danach wurden die Zellen in Lysis-Puffer aufgeschlossen und die Radioaktivität im Eluat sowie im Lysat im $\beta$-Zähler bestimmt. Die $\left[{ }^{3} \mathrm{H}\right]-\mathrm{PGE}_{2}$-Oberflächenbindung wurde berechnet als:

$\left[{ }^{3} \mathrm{H}\right]-P G E_{2}$-Oberflächenbindung $=\left[\frac{\left.{ }^{3} \mathrm{H}\right]-\mathrm{PGE}_{2} \text { Eluat (total-unspez.) }}{\left.\left.\left[{ }^{3} \mathrm{H}\right]-\mathrm{PGE}_{2}(\text { Eluat (total-unspez. })+\text { Lysat (total-unspez. }\right)\right)}\right] * 100$ total $=$ totale $\left[{ }^{3} \mathrm{H}\right]-\mathrm{PGE}_{2}$-Bindung, unspez. = unspezifische $\left[{ }^{3} \mathrm{H}\right]-\mathrm{PGE}_{2}$-Bindung. Die Werte stellen die Mittelwerte \pm S.D. von jeweils drei verschiedenen Versuchen in Dreifachbestimmung dar. Statistik: Student's $t$-Test für ungepaarte Proben. ${ }^{*} p<0,05$, Student's $t$-Test für ungepaarte Proben.

Vorbehandlung der Zellen mit Saccharose hemmte die Internalisierung aller Rezeptormutanten, die Agonisten-abhängig internalisiert wurden (Abb. 35). Die im CytoELISA gefundene Ausnahme der Saccharose-unabhängigen Internalisierung des FLAGhEP4 ST335-382A-R konnte mit diesem Internalisierungsnachweis nicht bestätigt werden. 

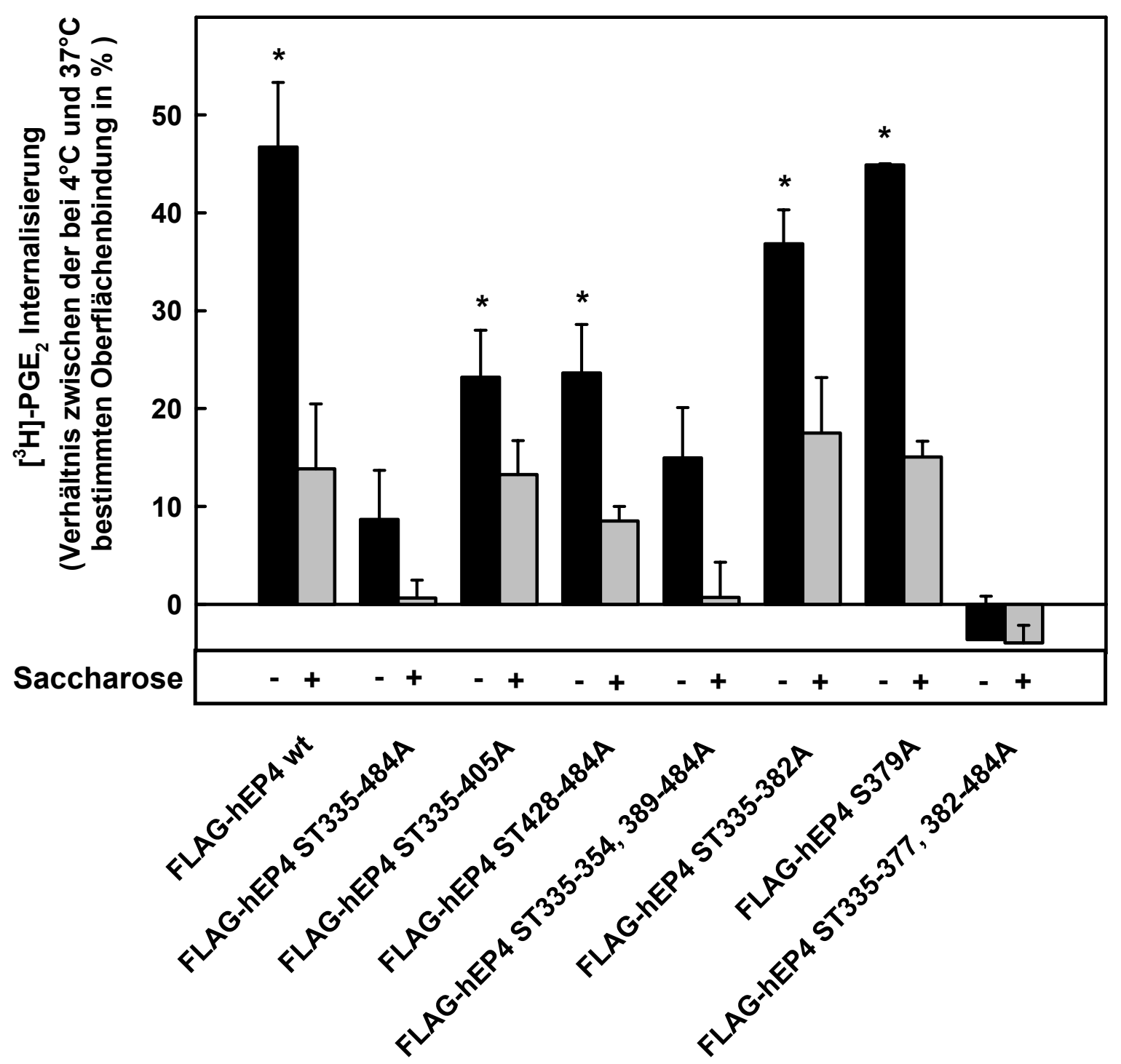

Abb. 35: Internalisierung der verschiedenen Rezeptorproteine durch Bestimmung des intrazellulären $\left.{ }^{3} \mathrm{H}\right]-\mathrm{PGE}_{2}$ ohne und nach Vorbehandlung der Zellen mit Saccharose. HEK293-Zellen, die die angegebenen Rezeptoren stabil exprimierten, wurden für 30 min in An- oder Abwesenheit von 0,45 M Saccharose bei $37^{\circ} \mathrm{C}$ inkubiert und, wie in Abb. 35 beschrieben, mit $\left.{ }^{3} \mathrm{H}\right]-\mathrm{PGE}_{2}$ stimuliert und aufgearbeitet. Die Radioaktivität im Eluat und im Lysat wurde im $\beta$-Zähler bestimmt. Die $\left[{ }^{3} \mathrm{H}\right]-\mathrm{PGE}_{2}$-Internalisierung wurde berechnet als :

$\left[{ }^{3} \mathrm{H}\right]-\mathrm{PGE}_{2}$-Internalisierung $(\%)=100 \%-\left[\frac{\left[{ }^{3} \mathrm{H}\right]-\mathrm{PGE}_{2} \text {-Oberflächenbindung bei } 37^{\circ} \mathrm{C}}{\left.{ }^{3} \mathrm{H}\right]-\mathrm{PGE}_{2} \text {-Oberflächenbindung bei } 4^{\circ} \mathrm{C}} * 100\right]$ wobei die $\left[{ }^{3} \mathrm{H}\right]-\mathrm{PGE}_{2}$-Oberflächenbindung, wie in Abb. 34 beschrieben, berechnet wurde. Die Werte stellen die Mittelwerte \pm S.D. von jeweils drei verschiedenen Versuchen in Dreifachbestimmung dar. Statistik: Student's $t$-Test für ungepaarte Proben. ${ }^{*} p<0,05$, Student's $t$-Test für ungepaarte Proben. 


\subsection{Untersuchung der Internalisierung der verschiedenen FLAG-hEP4-Rezeptoren durch Immunfluoreszenz-Mikroskopie}

Zur Untersuchung der Internalisierung der verschiedenen FLAG-hEP4-Rezeptorproteine an intakten Zellen durch Immunfluoreszenz-Mikroskopie wurden Rezeptor exprimierende HEK293-Zellen auf Glasdeckgläschen kultiviert (siehe 3.25.2) und für 45 min mit $1 \mu \mathrm{M} \mathrm{PGE} 2$ stimuliert. Nach Fixierung und Permeabilisierung wurden die Rezeptorproteine mit dem FLAG-M2-mAk und einem Cy3-gekoppelten Sekundärantikörper (siehe 3.25.5) nachgewiesen. Nach Biotinylierung der intakten Zellen vor der Fixierung wurde die Plasmamembran mit einem FITC-gekoppelten Streptavidin-Konjugat (siehe 3.25.3) markiert. Die Aufnahmen wurden mit einem konfokalen Laser-Scan-Mikroskop gemacht (siehe 3.25.6).

In den nicht-stimulierten, den FLAG-hEP4 wt-Rezeptor exprimierenden HEK293-Zellen war die grün dargestellte Plasmamembran als begrenzt diffuse Linie zu erkennen, was auf eine geringe Deformationen der Plasmamembran während der Fixierung oder auf eine nicht orthogonale Orientierung der Plasmamembran zur Aufnahmeebene zurückzuführen war (Abb. 36 erste Zeile, linke Spalte). Intrazellulär war keine grüne Markierung zu erkennen. Unter den gewählten Bedingungen wurde also tatsächlich nur Protein an der Zelloberfläche biotinyliert. Der rot dargestellte FLAG-hEP4 wt-Rezeptor war in der Plasmamembran lokalisiert, jedoch waren auch geringe Markierungen intrazellulär zu erkennen, die wahrscheinlich auf Rezeptoren hindeuten, die nicht zur Plasmamembran transportiert werden oder ein unspezifisches Signal sind (Abb. 36 erste Zeile, mittlere Spalte). In der Überlagerung war eine deutliche Colokalisation der Rezeptorproteine mit der Plasmamembran durch die Gelbfärbung zu erkennen (Abb. 36 erste Zeile, rechte Spalte). In der „Z-scan“-Darstellung der Überlagerung wurden die Zellen in der dritten Dimension gezeigt. Im unteren Bereich der Darstellung war die Adhäsionsebene der Zelle auf dem Glasdeckgläschen zu sehen, während sich die Plasmamembran mit den darin lokalisierten Rezeptoren als dünne Linie über diese Ebene wölbte. Im Zellinneren, das sich in dieser Darstellung zwischen der Adhäsionsebene und der gewölbten Plasmamembran befindet, war keine Rezeptormarkierung zu erkennen (Abb. 36 zweite Zeile).

Nach Agonisten-Exposition war die grün dargestellte Plasmamembran als begrenzte Linie zu erkennen (Abb. 36 dritte Zeile, linke Spalte) und der rot-dargestellte FLAG-hEP4 wt-Rezeptor war nicht mehr gleichmäßig in der Plasmamembran lokalisiert (Abb. 36 dritte Zeile, mittlere Spalte), sondern geclustert im Inneren der Zelle (Abb. 36 dritte Zeile, rechte Spalte). Die punktuelle Gelbfärbungen in der Plasmamembran läßt noch auf einen Teil nichtinternalisierter Rezeptoren schließen (Abb. 36, dritte Zeile). In der „Z-scan“-Darstellung war die intrazelluläre Lokalisation der rot dargestellten Rezeptoren innerhalb der von der grün dargestellten Plasmamembran umgebenen Zellen zu sehen (Abb. 36, vierte Zeile). 

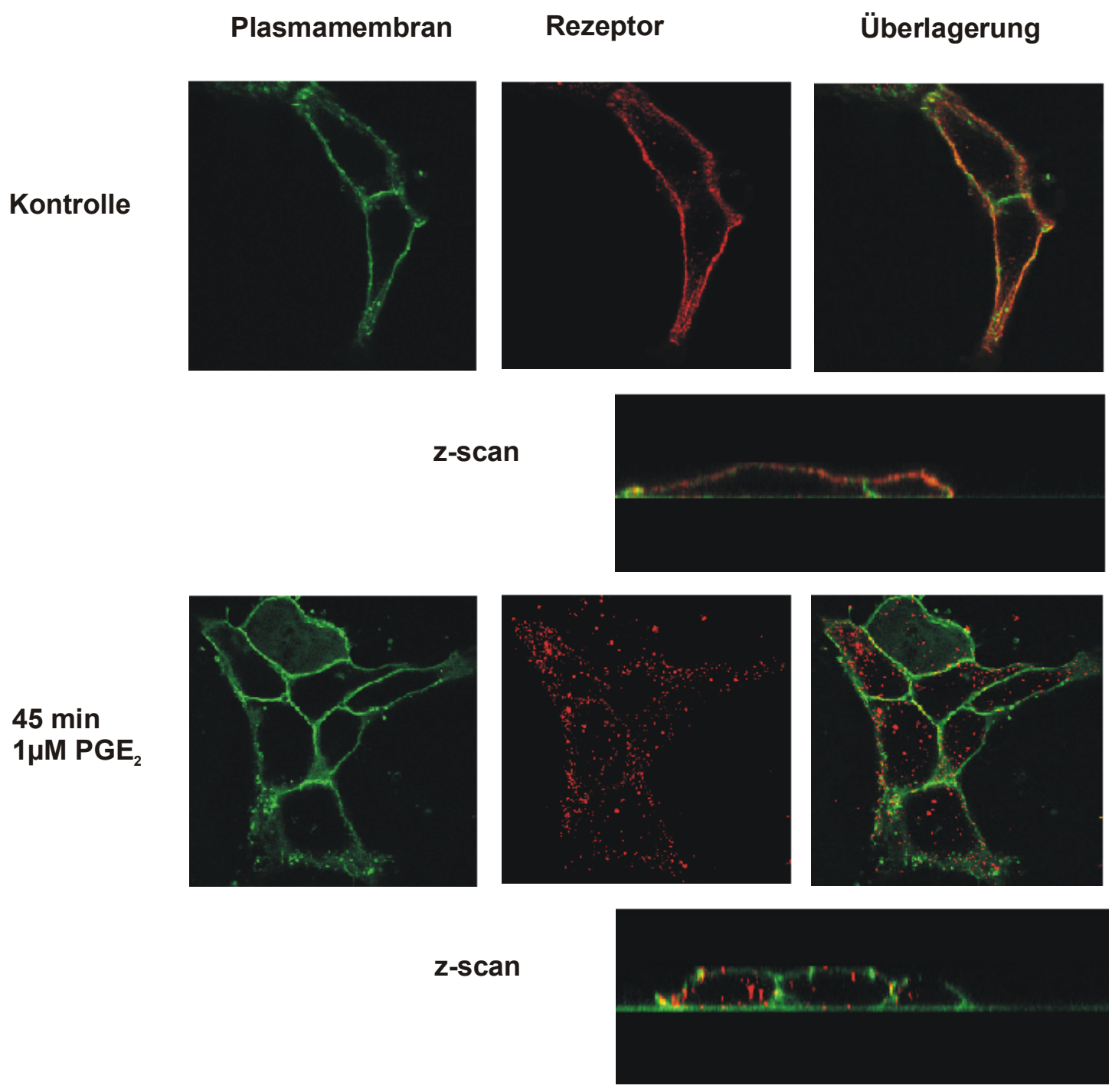

Abb. 36: Internalisierung des FLAG-hPE4 wt-Rezeptors in stabil transfizierten HEK293-

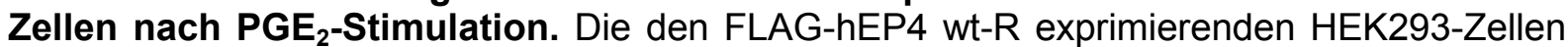
wurden auf Fibronectin und Poly-L-Lysin beschichteten Glasdeckgläschen für $24 \mathrm{~h}$ kultiviert und anschließend für 45 min mit $1 \mu \mathrm{M} \mathrm{PGE}_{2}$ stimuliert. Anschließend wurden die Zellen, wie in Abb. 21 beschrieben, präpariert und Aufnahmen mit einem konfokalen Laser-ScanMikroskop gemacht. Dargestellt sind die bei den unterschiedlichen Anregungs- und Emissions-Wellenlängen aufgenommenen Bilder (Spalte 1 und 2) und die Überlagerung beider Aufnahmen (Spalte 3) (vergleiche Abb. 21). Der FLAG-hEP4 wt-Rezeptor (rot) war in den nicht-stimulierten Kontrollzellen homogen in der Plasmamembran (grün) lokalisiert. (Gelbfärbung in der Überlagerung). Nach Agonisten-Exposition der Zellen war der Rezeptor kaum noch in der Plasmamembran, aber als punktuelle Struktur intrazellulär sichtbar (Verlust der Gelbfärbung in der Überlagerung).

Auch in Zellen, die den FLAG-hEP4 ST335-484A-R, in dem alle Serine und Threonine in der C-terminalen Domäne durch Alanine ersetzt waren, exprimierten, war das Rezeptorprotein vor Stimulation mit $\mathrm{PGE}_{2}$ praktisch vollständig in der Plasmamembran lokalisiert (Abb. 37). Sowohl in der Aufsicht, wie im „z-scan“ war intrazellulär kein Rezeptorprotein nachweisbar. Im Gegensatz zu den Zellen, die den Wildtyprezeptor exprimierten, kam es nach AgonistenExposition jedoch nicht zu einer Umverteilung des FLAG-hEP4 ST335-484A-R. Der Rezeptor verblieb auch nach Agonisten-Exposition vollständig in der Plasmamembran. Die 
für den internalisierten Rezeptor typischen intrazellulären Cluster konnten weder in der Aufsicht noch im „Z-scan“ nachgewiesen werden (Abb. 37).

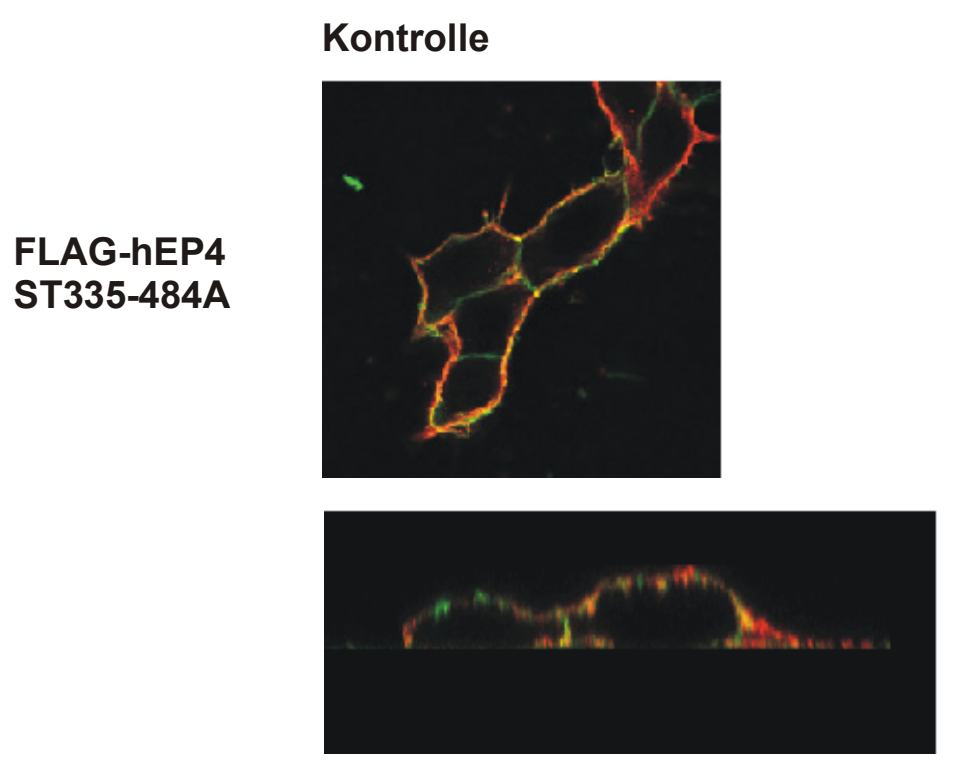

$45 \min 1 \mu \mathrm{M} \mathrm{PGE}_{2}$
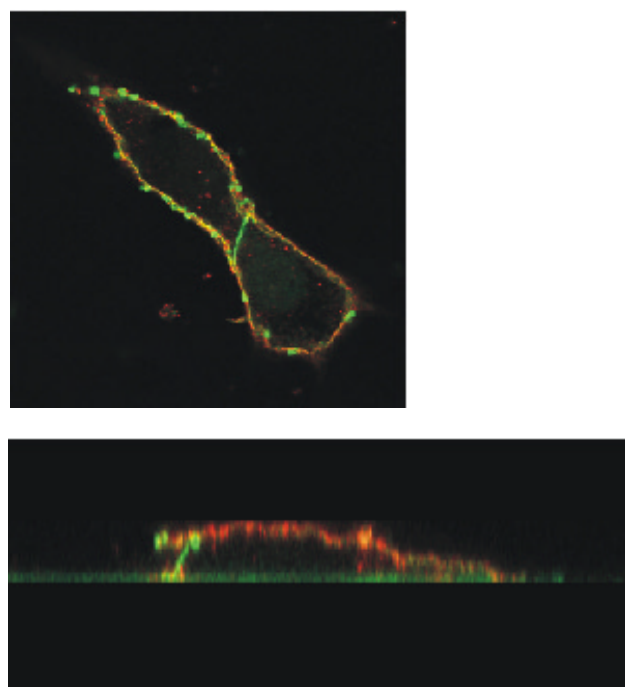

Abb. 37: Plasmamembranlokalisation des FLAG-hPE4 ST335-484A-Rezeptors nach PGE $_{2}$-Stimulation. Die den FLAG-hEP4 ST335-484A-R exprimierenden HEK293-Zellen wurden, wie in Abb. 36 beschrieben, kultiviert und stimuliert und, wie in Abb. 21 beschrieben, präpariert. Die Aufnahmen wurden mit einem konfokalen Laser-Scan-Mikroskop gemacht. Dargestellt sind die Überlagerungen der bei den unterschiedlichen Anregungs- und Emissions-Wellenlängen aufgenommenen Bilder. Der FLAG-hEP4 ST335-484A-R (rot) war in den nicht stimulierten Kontrollzellen in der Plasmamembran (grün) lokalisiert (Gelbfärbung). Nach Stimulation der Zellen mit $\mathrm{PGE}_{2}$ konnte keine Internalisierung der Rezeptorproteine nachgewiesen werden (noch vorhandene Gelbfärbung).

Wurde selektiv nur Serin 379 in der C-terminalen Domäne gegen Alanin getauscht, verhielt sich das Rezeptorprotein wie der Wildtyprezeptor und wurde Agonisten-induziert fast vollständig internalisiert (Abb 38, A). Das Rezeptorprotein, in dem alle Serine und Threonine im proximalen Teil der C-terminalen Domäne bis einschließlich Serin 382 gegen Alanine getauscht waren (FLAG-hEP4 ST335-382A), wurde ebenfalls nach Agonisten-Exposition internalisiert (Abb. 38, B), jedoch verblieb ein großer Teil der Rezeptorproteine auch nach Agonisten-Exposition in der Plasmamembran. Auch unterschied sich die Verteilung des nach Agonisten-Exposition intrazellulär gelegenen Rezeptorproteins von der des Wildtyprezeptors. Während der Wildtyprezeptor und der FLAG-hEP4 S379A-R in großen Clustern an wenigen Stellen intrazellulär konzentriert war, war der FLAG-hEP4 ST335-382A-R über den gesamten intrazellulären Raum verteilt. Das Rezeptorprotein, in dem zusätzlich zu Ser/Thr 335-382 die im direkt dahinter liegenden Block lokalisierten Serine und Threonine gegen Alanine ausgetauscht worden waren (FLAG-hEP4 ST335-405A-R), wurde praktisch nicht mehr Agonisten-abhängig internalisiert. 


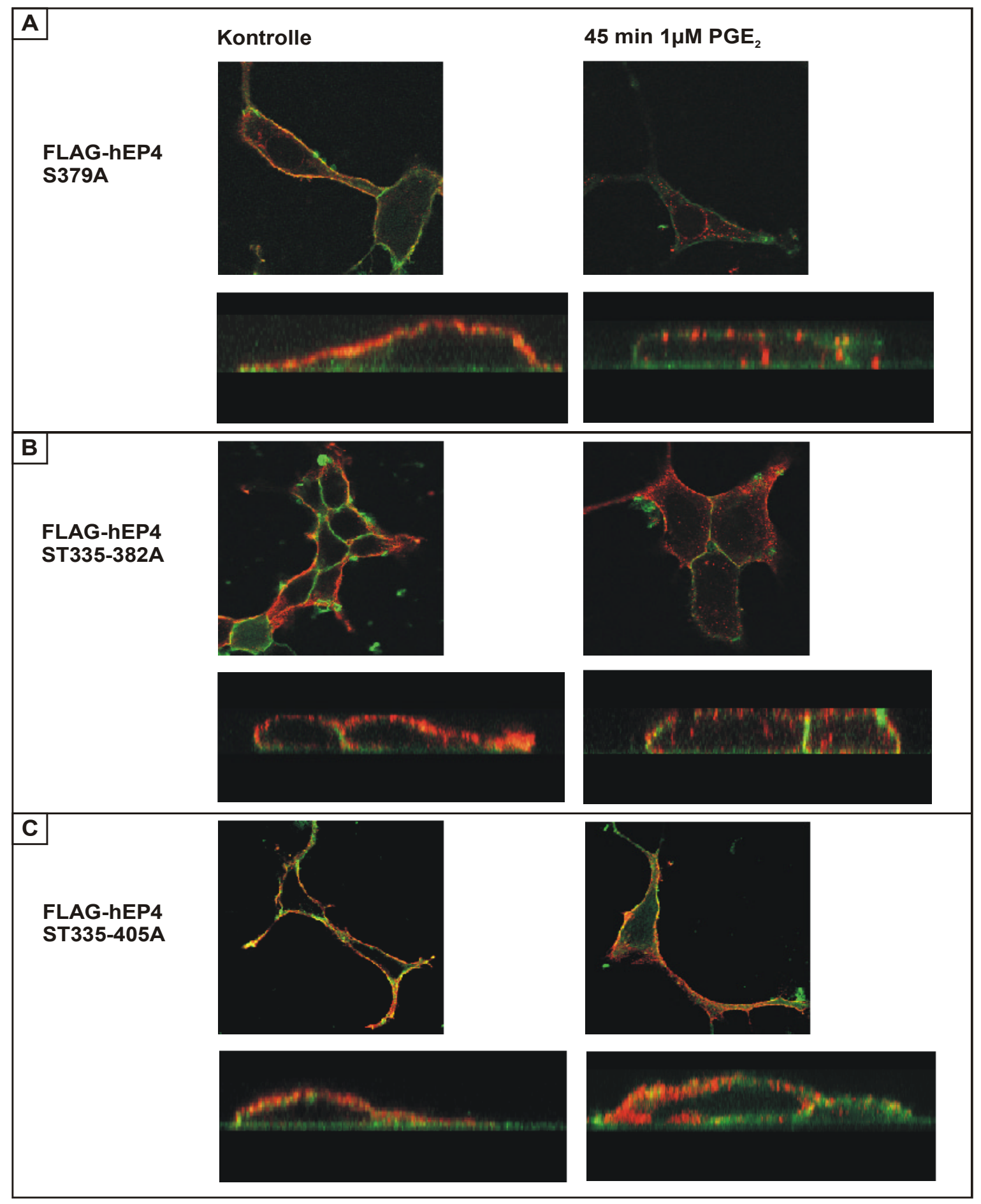

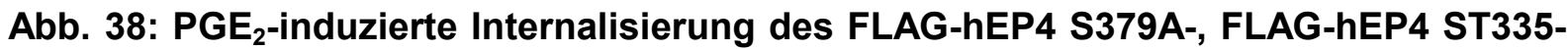
382A- und FLAG-hEP4 ST335-405A-Rezeptors in stabil exprimierenden HEK293-Zellen. Die die Rezeptorproteine exprimierenden HEK293-Zellen wurden, wie in Abb. 36 beschrieben, kultiviert, stimuliert und, wie in Abb. 21 beschrieben, präpariert. Die Aufnahmen wurden mit einem konfokalen Laser-Scan-Mikroskop durchgeführt. Der FLAG-hEP4 S379A-, FLAG-hEP4 ST335-382A- und der FLAG-hEP4 ST335-404A-R (rot) waren in den nicht stimulierten Kontrollzellen in der Plasmamembran (grün) lokalisiert (Gelbfärbung). Nach Stimulation der Zellen mit $\mathrm{PGE}_{2}$ zeigte der FLAG-hEP4 S379A-R eine Internalisierung wie der Wildtyprezeptor, während der FLAG-hEP4 ST335-382A-R eine reduzierte Internalisierung aufwies. Der FLAG-hEP4 ST335-404A-R wurde nicht mehr internalisiert, jedoch waren die Rezeptorproteine nicht mehr homogen in der Plasmamembran verteilt (noch vorhandene Gelbfärbung). 
Allerdings kam es nach Agonisten-Exposition zu einer deutlichen Clusterung der Rezeptorproteine in oder unmittelbar unterhalb der Plasmamembran (Abb. $38 \mathrm{C}$ ).

Die Mutante FLAG-hEP4 ST335-377; 382-484A-R, in der Serin 379 als einziges Serin in der C-terminalen Domäne verblieben war, wurde wie die Mutante, in der alle Serine und Threonine in der C-terminalen Domäne substituiert waren nicht mehr internalisiert (Abb. 39, A). Auch die beiden Mutanten, in denen alle Serine und Threonine im distalen Teil der Cterminalen Domäne des hEP4-R durch Alanine ersetzt waren (FLAG-hEP4-ST335-354; 389484A-R und FLAG-hEP4 ST428-484A-R), wurden nicht mehr Agonisten-abhängig internalisiert (Abb. 39 B, C). Auch eine Agonisten-abhängige Clusterung der Rezeptorproteine in oder direkt unterhalb der Plasmamembran, wie bei den den FLAG-hEP4 ST335-405A-R exprimierenden Zellen, war bei diesen Mutanten nicht nachweisbar. 


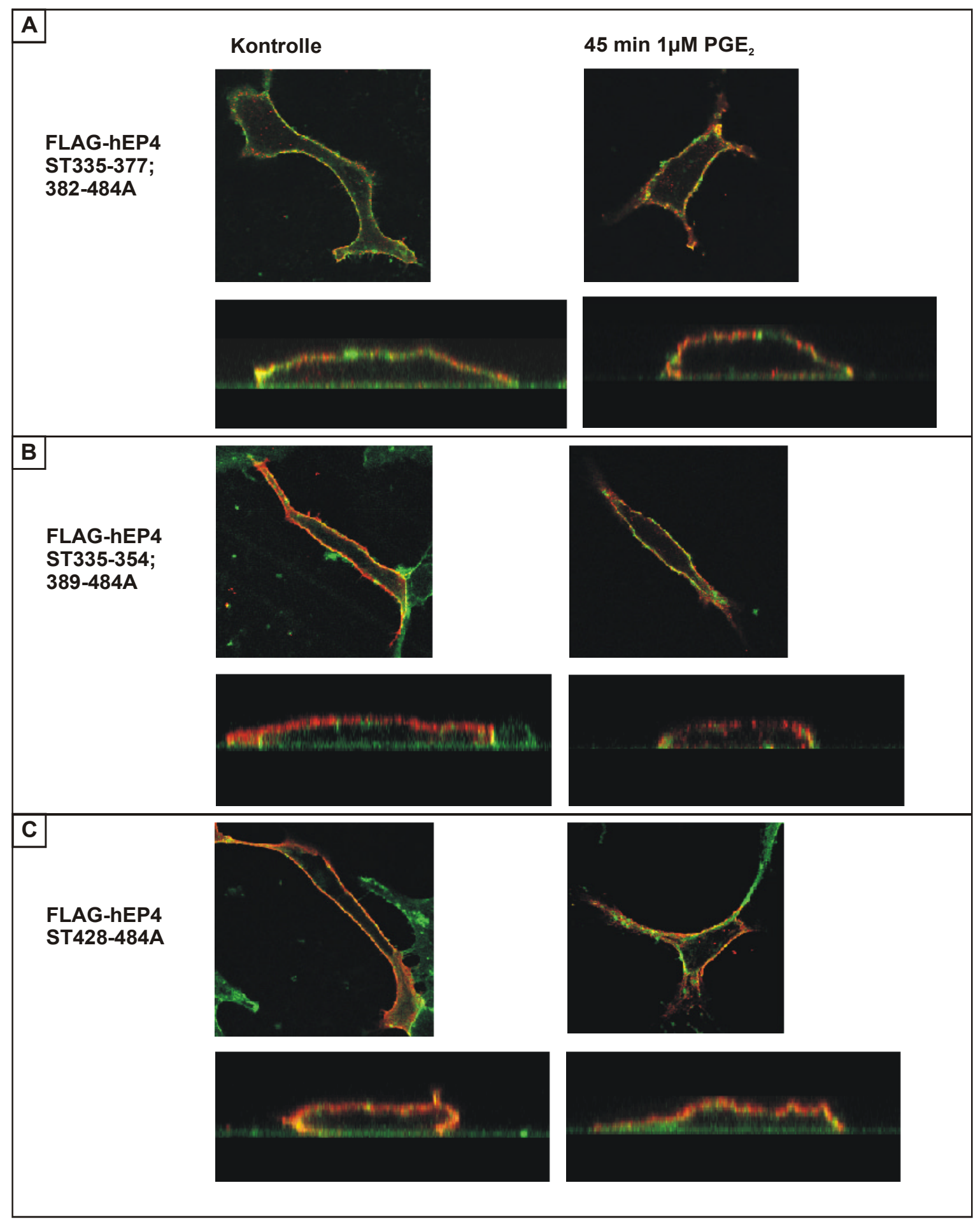

Abb. 39: Plasmamembranlokalisation des FLAG-hEP4 ST335-377; 382-484A-, FLAGhEP4 ST335-354; 382-484A- und FLAG-hEP4 ST428-484A-Rezeptors nach PGE $_{2-}$ Stimulation. Die die Rezeptorproteine exprimierenden HEK293-Zellen wurden, wie in Abb. 36 beschrieben, kultiviert, stimuliert und, wie in Abb. 21 beschrieben, präpariert. Die Aufnahmen wurden mit einem konfokalen Laser-Scan-Mikroskop durchgeführt. Der FLAGhEP4 ST335-377; 382-484A-, der FLAG-hEP4 ST335-354; 382-484A- und der FLAG-hEP4 ST428-484A-Rezeptors (rot) waren in den nicht stimulierten Kontrollzellen in der Plasmamembran (grün) lokalisiert (Gelbfärbung). Nach Agonisten-Exposition der Zellen kam es zu keiner Umverteilung der Rezeptorproteine nach intrazellulär (noch vorhandene Gelbfärbung). 


\subsection{Untersuchung der Rezeptor/ $\beta$-Arrestin-Colokalisation nach Agonisten-Exposition der die FLAG-hEP4-Rezeptoren exprimierenden HEK293-Zellen durch Immunfluoreszenz-Mikroskopie}

Um die direkte Interaktion der verschiedenen Rezeptorproteine mit $\beta$-Arrestin zu untersuchen, wurden die mit den verschiedenen Rezeptoren stabil transfizierten HEK293Zellen transient mit einer cDNA für $\beta$-Arrestin cotransfiziert, die am 3'-Ende um die für das "green fluorescent-protein“ (GFP) codierende Sequenz verlängert worden war. Anschließend wurde die Lokalisation der beiden exprimierten Proteine vor und nach Agonisten-Stimulation untersucht. Dazu wurden die Rezeptor exprimierenden HEK293-Zellen auf Glasdeckgläschen für $24 \mathrm{~h}$ kultiviert, mit pEGFP/ $\beta$-Arrestin transfiziert und für weitere $24 \mathrm{~h}$ kultiviert. Anschließend wurden die Zellen in An- oder Abwesenheit von 0,45 M Saccharose für 45 min mit $1 \mu \mathrm{M} \mathrm{PGE}_{2}$ stimuliert und die Zellen, wie unter 4.9 beschrieben, präpariert.

Das grün dargestellte $\beta$-Arrestin/GFP war in nicht-stimulierten HEK293-Zellen homogen verteilt (Abb. 40). Mit dem FLAG-M2-mAk und dem Cy3-gekoppelten Sekundärantikörper konnte in HEK293-Zellen, die nicht mit der für die Rezeptorproteine codierenden cDNA transfiziert waren, nur eine sehr geringe unspezifische Markierung nachgewiesen werden (Abb. 40).

$\beta-A r r e s t i n$

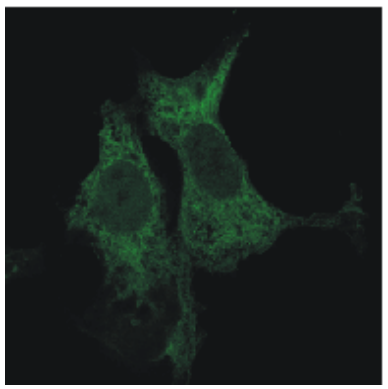

FLAG-M2 mAk

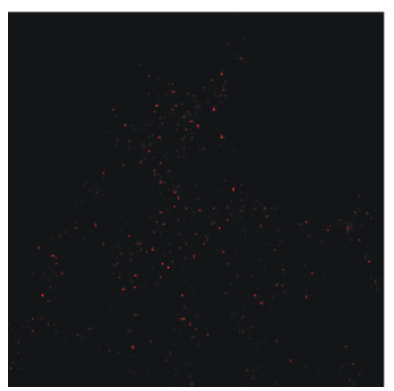

Überlagerung

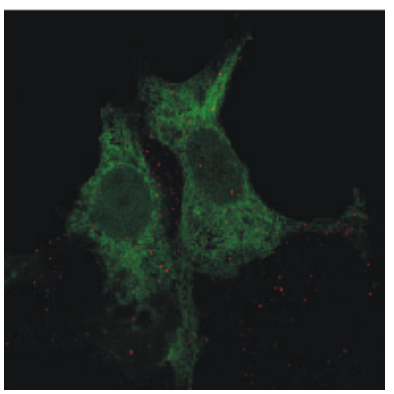

Abb. 40: Nachweis der cytosolischen $\beta$-Arrestin-Lokalisation in HEK293-Zellen. HEK293-Zellen wurden auf mit Fibronectin und Poly-L-Lysin beschichteten Glasdeckgläschen kultiviert und mit der Calcium-Phosphat-Methode mit pEGFP/ $\beta$-Arrestin (grün) transfiziert. Anschließend wurden die Zellen fixiert, permeabilisiert und mit dem FLAGM2-mAk und einem Cy3-gekoppelten Sekundärantikörper (rot) markiert. Die Präparate wurden in Mowiol eingebettet. Die Aufnahmen wurden mit einem konfokalen Laser-ScanMikroskop gemacht. Dargestellt sind die bei den unterschiedlichen Anregungs- und Emissions-Wellenlängen aufgenommenen Bilder und die Überlagerung beider Aufnahmen. Das in den HEK293-Zellen exprimierte $\beta$-Arrestin/GFP war ubiquitär im Cytosol verteilt (linke Aufnahme). Der FLAG-M2-mAk zeigte eine sehr geringe unspezifische Bindung an die HEK293-Zellen (mittlere Aufnahme). In der Überlagerung (rechte Aufnahme) war keine Colokalisation beider Markierungen sichtbar (fehlende Gelbfärbung). 
In den nicht stimulierten FLAG-hEP4 wt-R exprimierenden Kontrollzellen war der Rezeptor ausschließlich in der Plasmamembran lokalisiert und das $\beta$-Arrestin/GFP homogen in der Zelle verteilt. In der Überlagerung war keine Colokalisation beider markierten Proteine zu sehen (Abb. 41 erste Zeile). Nach der Ligand-Exposition zeigte sich eine Translokation des rot dargestellten FLAG-hEP4 wt-Rezeptors von der Plasmamembran in das Zellinnere, zusätzlich kam es zu einer punktuellen Ansammlung des ursprünglich im Cytosol homogen verteilten, grün dargestellten $\beta$-Arrestin/GFP. In der Überlagerung beider Aufnahmen war eine deutliche, gelb dargestellte Colokalisation beider Proteine sichtbar, was auf eine Interaktion des Rezeptors mit dem $\beta$-Arrestin/GFP nach Agonisten-Stimulation hindeutet (Abb. 41 zweite Zeile). In den mit Saccharose vorbehandelten Zellen war nach anschließender Stimulation mit $1 \mu \mathrm{M} \mathrm{PGE}_{2}$ der überwiegende Teil des grün dargestellten $\beta$ Arrestin/GFPs homogen im Cytosol verteilt. Der rot dargestellte Rezeptor wurde nicht internalisiert. Allerdings konnte eine leichte Verstärkung der Grünfärbung an der Plasmamembran beobachtet werden, die in nicht-stimulierten Zelllen nicht nachweisbar war. In der Überlagerung war eine deutliche Gelbfärbung an der Plasmamembran zu sehen, die auf eine Colokalisation der Rezeptorproteine mit $\beta$-Arrestin/GFP an der Plasmamembran nach Agonisten-Exposition deutete. Es kam also noch zur Agonisten-induzierten Translokation des $\beta$-Arrestins zur Plasmamembran, Saccharose aber hemmte die Clathrinabhängige Internalisierung des $\beta$-Arrestin-Rezeptor-Komplexes (Abb. 41 dritte Zeile). Dieses Ergebnis steht im Einklang mit den Ergebnissen des Cyto-ELISA (Abb. 33) und der Internalisierung des $\left[{ }^{3} \mathrm{H}\right]-\mathrm{PGE}_{2}$ (Abb. 35). In beiden experimentellen Ansätzen wurde ebenfalls gefunden, daß die Agonisten-induzierte Internalisierung durch Saccharose gehemmt wurde. Zusammengenommen unterstützen die Ergebnisse die Annahme, daß die Agonisten-induzierte Internalisierung des hEP4-wt-Rezeptors Clathrin-vermittelt und von einer Komplexierung des $\beta$-Arrestin mit dem Ligand-besetzten Rezeptor abhängig ist.

Für den FLAG-hEP4 ST335-484A-, den FLAG-hEP4 ST335-405A-, den FLAG-hEP4 ST428484A-, den FLAG-hEP4 ST335-354, 389-484A- und den FLAG-hEP4 ST335-377; 382-484ARezeptor zeigte sich in den Kontrollzellen keine Überlagerung der rot dargestellten Rezeptoren und des grün dargestellten $\beta$-Arrestin/GFP (Abb. 42, linke Spalte). Nach Agonisten-Stimulation der die verschiedenen Rezeptoren exprimierenden HEK293-Zellen kam es zu keiner Internalisierung der Rezeptorproteine in das Zellinnere und zu keiner punktuellen Ansammlung des $\beta$-Arrestin/GFP. Die Plasmamembran war deutlich von dem durch das $\beta$-Arrestin/GFP markierten Cytosol zu unterscheiden (Abb. 42, rechte Spalte). Für die nicht internalisierenden Rezeptoren wurden keine Studien mit Saccharose durchgeführt. 
$\beta$-Arrestin
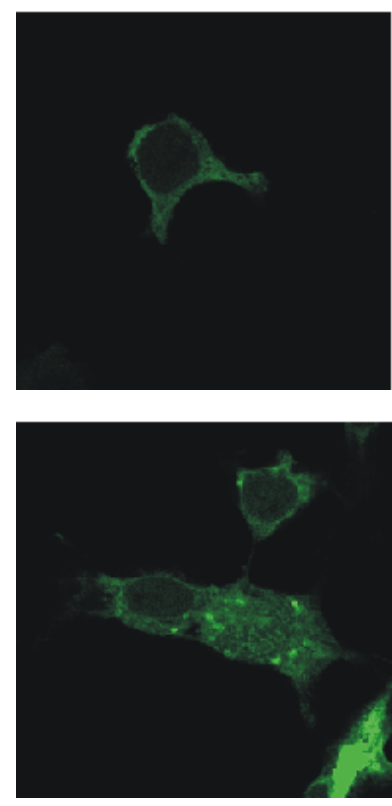

$45 \mathrm{~min}$

$1 \mu \mathrm{M} \mathrm{PGE}_{2}$
Rezeptor
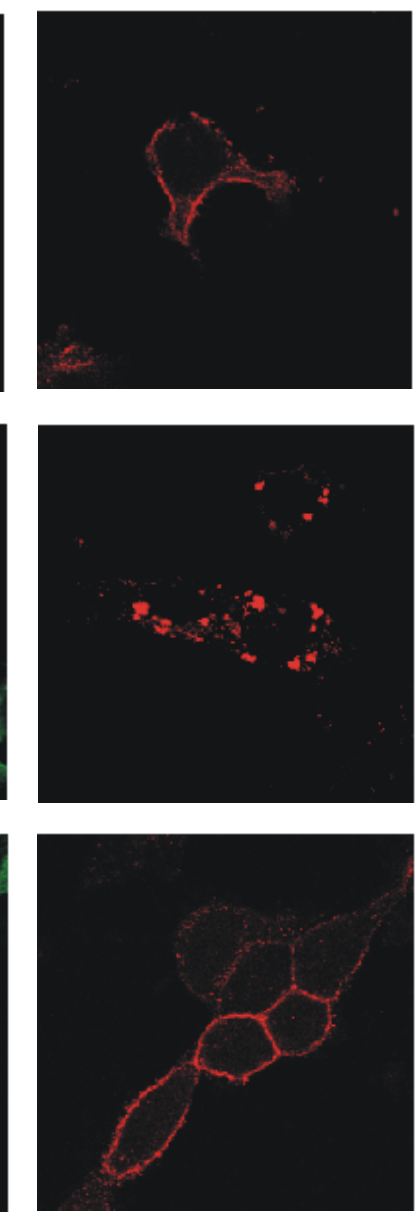

Überlagerung
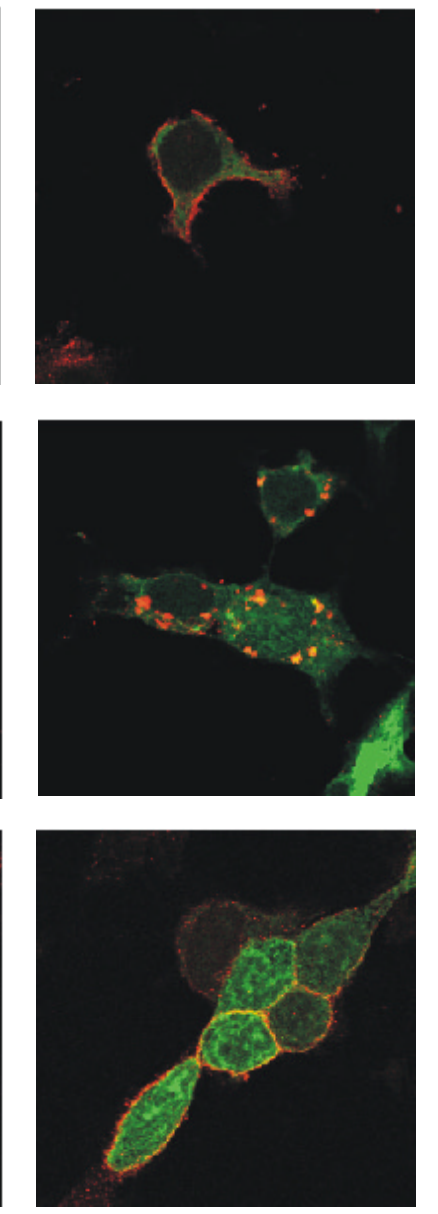

$30 \mathrm{~min}$

0,45 M Sucrose

$45 \mathrm{~min}$

$1 \mu \mathrm{M} \mathrm{PGE}_{2}$

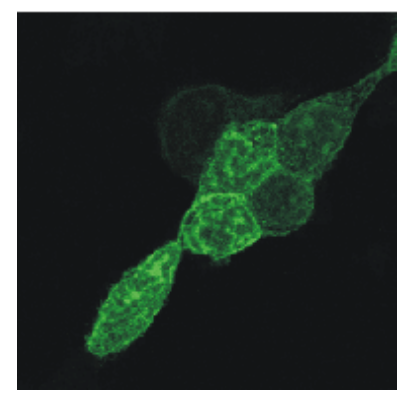

Abb. 41: Translokation und Colokalisation von $\beta$-Arrestin mit dem FLAG-hEP4 wtRezeptors nach $\mathrm{PGE}_{2}$-Stimulation ohne und nach Vorbehandlung der Zellen mit Saccharose dargestellt durch Immunfluoreszenz-Mokroskopie. Mit dem FLAG-hEP4 wt$\mathrm{R}$ stabil transfizierte HEK293-Zellen wurden auf mit Fibronectin und Poly-L-Lysin beschichteten Glasdeckgläschen kultiviert und mit der Calcium-Phosphat-Methode mit pEGFP/ $\beta$-Arrestin (gün) transfiziert (siehe 3.14.3). Nach $24 \mathrm{~h}$ wurden die Zellen für $30 \mathrm{~min}$ in An- oder Abwesenheit von 0,45 M Saccharose vorinkubiert und für 45 min mit $1 \mu \mathrm{M} \mathrm{PGE}{ }_{2}$ stimuliert. Anschließend wurden die Zellen, wie in Abb. 40 beschrieben, präpariert und Aufnahmen mit einem konfokalen Laser-Scan-Mikroskop gemacht. Dargestellt sind die bei den unterschiedlichen Anregungs- und Emissions-Wellenlängen aufgenommenen Bilder (Spalte 1 und 2) und die Überlagerung beider Aufnahmen (Spalte 3). In den den FLAG-hEP4 wt-R exprimierenden HEK293-Zellen war das $\beta$-Arrestin/GFP ubiquitär im Cytosol verteilt. Nach Agonistenexposition kam es zu einer punktuellen cytosolischen Ansammlung von $\beta$ Arrestin/GFP (zweite Reihe, erste Spalte), die eine Colokalisation mit dem internalisierten Rezeptor zeigte (punktuelle Gelbfärbung zweite Reihe, dritte Spalte). Die Internalisierung des Rezeptors konnte durch Saccharose gehemmt werden (dritte Reihe), allerdings kam es noch zu einer Agonisten-abhängigen Translokation von $\beta$-Arrestin/GFP an die Plasmamembran (Gelbfärbung). 


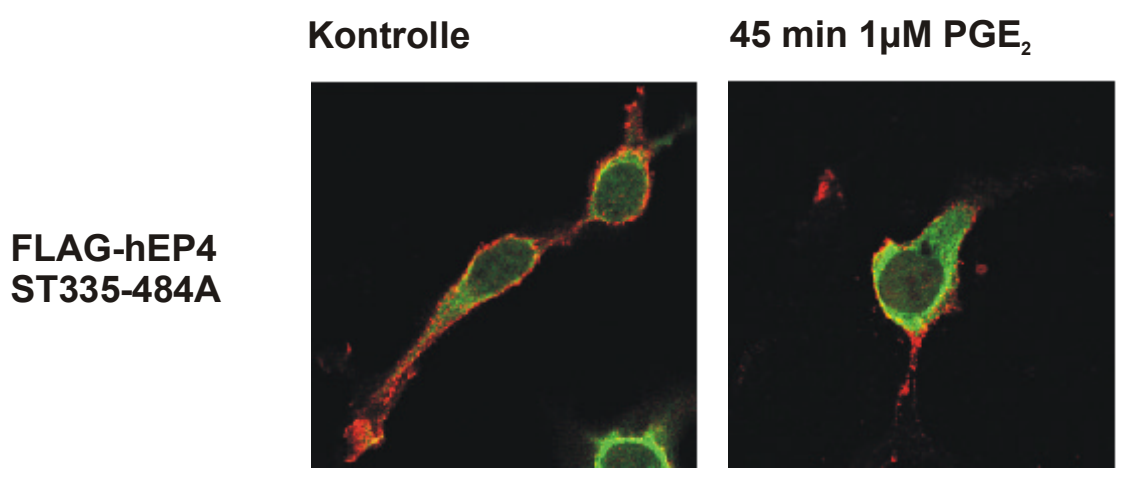

FLAG-hEP4 ST335-405A

FLAG-hEP4 ST428-484A

FLAG-hEP4 ST335-354; 389-484A

FLAG-hEP4 ST335-377; 382-484A
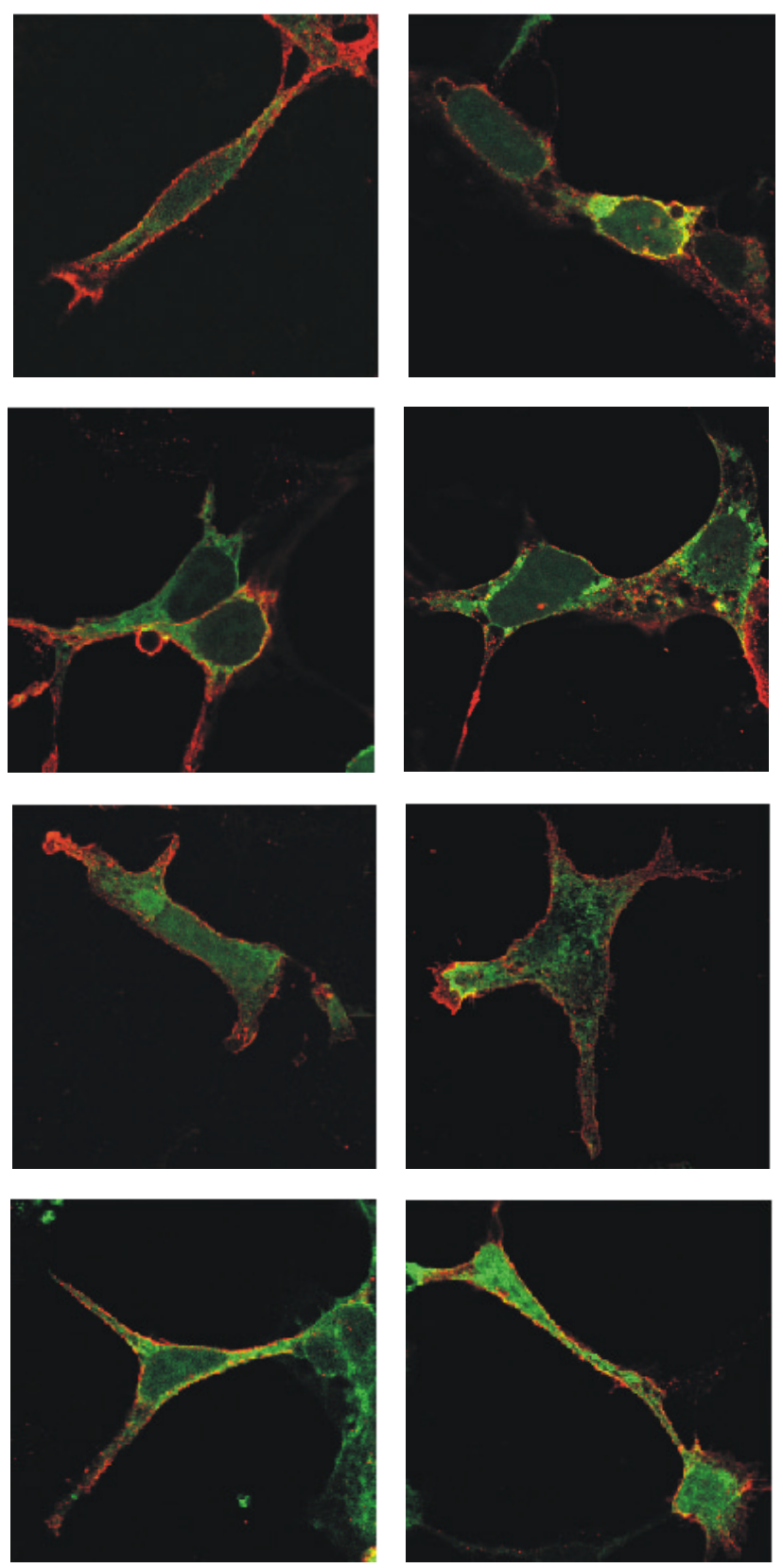

Abb. 42: Fehlende $\beta$ Arrestin-Translokation und -Colokalisation mit dem FLAG-hEP4 ST335484A-, $\quad$ FLAG-hEP4 S335-405A-, FLAG-hEP4 ST428-484A- FLAGhEP4 ST335-354; 389484A-Rezeptor und dem FLAG-hEP4 ST335-377; 382-484A-R nach $\mathrm{PGE}_{2}$ Stimulation dargestellt durch Immunfluoreszenz Mikroskopie. Die die Rezeptoren stabil exprimierenden HEK293 Zellen wurden, wie in Abb. 41 beschrieben, kultiviert, transfiziert und ohne Saccharosebehandlung stimuliert. Anschliessend wurden die Zellen, wie in Abb. 40 beschrieben, präpariert und die Aufnahmen, wie in Abb. 41 beschrieben, durchgeführt. In den Rezeptorexprimierenden HEK293Zellen war $\beta$-Arrestin/GFP ubiquitär im Zellinneren verteilt (linke Spalte). Nach Agonisten-Stimulation zeigte sich keine Umverteilung des $\beta$ Arrestin/GFP und keine Colokalisation mit den verschiedenen Rezeptoren (fehlende Gelbfärbung, rechte Spalte). 
Für den FLAG-hEP4 ST335-382A- und den FLAG-hEP4 S379A-Rezeptor zeigte sich in den Kontrollzellen keine Überlagerung von Rezeptor und $\beta$-Arrestin/GFP (Abb. 43, linke Spalte). Nach Ligand-Exposition der Rezeptor exprimierenden HEK293-Zellen internalisierten der FLAG-hEP4 ST335-382A- und der FLAG-hEP4 S379A-R, jedoch war keine eindeutige punktuelle Ansammlung des cytosolischen $\beta$-Arrestin/GFP sichtbar, woraus die geringe intrazelluläre Gelbfärbung in der Colokalisation beider Proteine resultierte (Abb. 43, mittlere Spalte).

Nach Inkubation der Zellen mit Saccharose und anschließender Stimulation konnte keine Umverteilung der Rezeptoren von der Plasmamembran ins Zellinnere mehr beobachtet werden, die hyperosmolare Saccharosekonzentration verhinderte eine Internalisierung der Rezeptorproteine (Abb. 43, rechte Spalte).

\section{Kontrolle}

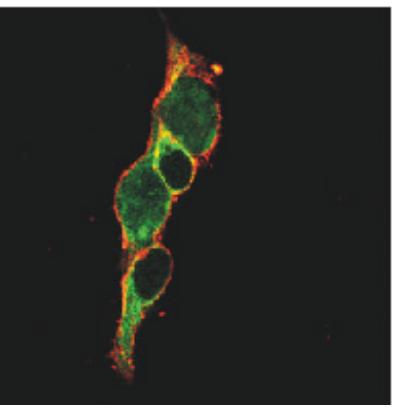

FLAG-hEP4

ST335-382A

FLAG-hEP4

S379A
$45 \min 1 \mu \mathrm{M} \mathrm{PGE}_{2}$
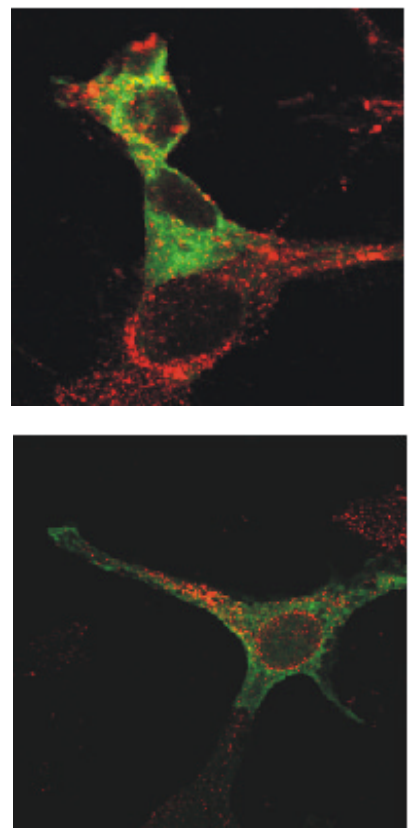

$30 \min 0,45 \mathrm{M}$ Sucrose $45 \min 1 \mu \mathrm{M} \mathrm{PGE}_{2}$
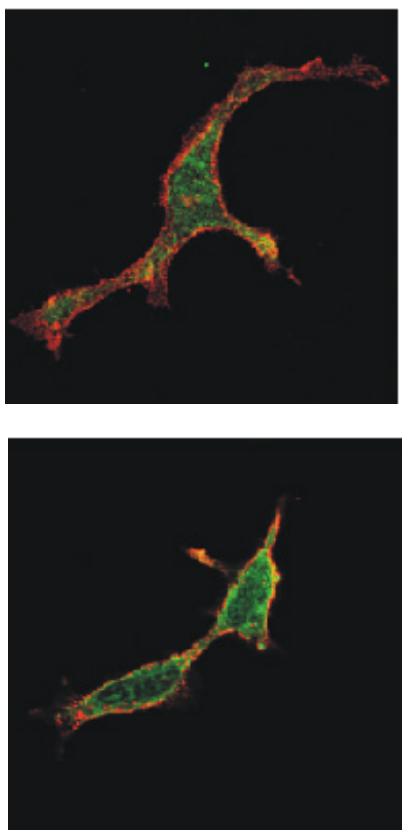

Abb. 43: $\beta$-Arrestin-Translokation und -Colokalisation mit dem FLAG-hEP4 ST335382A- und dem FLAG-hEP4 S379A-Rezeptor nach PGE $_{2}$-Stimulation ohne und nach Vorbehandlung der Zellen mit Saccharose. Die die verschiedenen Rezeptoren exprimierenden HEK293-Zellen wurden, wie in Abb. 41 beschrieben, kultiviert, transfiziert und in An- oder Abwesenheit von Saccharose stimuliert. Anschließend wurden die Zellen, wie in Abb. 40 beschrieben, präpariert und Aufnahmen mit einem konfokalen Laser-ScanMikroskop gemacht. Dargestellt sind die Überlagerungen aus den mit den einzelnen Lasern gemachten Aufnahmen. Der FLAG-hEP4 ST335-382A- und der FLAG-hEP4 S379A-R (rot) internalisierten nach Agonistenstimulation und zeigten eine schwache Colokalisation mit $\beta$ Arrestin/GFP (grün) (Gelbfärbung, mittlere Spalte), die durch Saccharose gehemmt werden konnte (rechte Spalte). 


\section{Diskussion}

Für Prostaglandin $\mathrm{E}_{2}\left(\mathrm{PGE}_{2}\right)$ wurden bisher die vier Rezeptorsubtypen EP1-, EP2-, EP3-, und EP4-R identifiziert, wobei für den EP1- und EP3-R in manchen Spezies Spleißvarianten nachgewiesen wurden. Der EP1-R ist an ein $\mathrm{G}_{\mathrm{q}}$-Protein gekoppelt und seine Aktivierung führt zu einer Erhöhung des intrazellulären $\mathrm{InsP}_{3}$ - und $\mathrm{Ca}^{2+}$-Spiegels, während der EP3-R an $\mathrm{G}_{i}$ gekoppelt ist und eine hormonstimulierte cAMP-Bildung hemmt. Dagegen sind der EP2und der EP4-R an $\mathrm{G}_{\mathrm{s}}$ gekoppelt und erhöhen nach $\mathrm{PGE}_{2}$-Bindung den intrazellulären cAMPSpiegel. Die Sequenzidentität der vier EP-R-Subtypen liegt unter $50 \%$, wobei die Sequenzen der Transmembrandomänen am höchsten konserviert sind.

Die beiden $\mathrm{G}_{\mathrm{s}}$-gekoppelten EP-R, EP2-R und EP4-R, unterscheiden sich in ihrer Agonisteninduzierten Rezeptordesensitisierung. Der in CHO-Zellen exprimierte murine EP4-R wurde nach Agonisten-Exposition schnell desensitisiert, der murine EP2-R nicht (Nishigaki et al. (1996)). Ein deutlicher struktureller Unterschied zwischen den beiden Rezeptoren EP2-R und EP4-R besteht in der Größe ihrer C-terminalen Domänen. Die C-terminale Domäne des humanen EP4-R umfaßt 156 Aminosäuren, innerhalb derer sich 38 Serine und Threonine befinden, denen als potentielle Phosphorylierungsstellen eine Rolle in der Rezeptordesensitisierung und Internalisierung zukommen könnte. Im Gegensatz dazu ist die C-terminale Domäne des humanen EP2-R, der eine höhere Sequenzidentität zum DP- und IP-R als zum EP4-R aufweist (Breyer et al. (2001)), mit 40 Aminosäuren deutlich kleiner und beinhaltet nur 10 Serine und Threonine. Weiterhin verfügt der EP4-R auch über eine sehr große dritte cytoplasmatische Schleife, in der weitere potentielle Phosphorylierungsstellen lokalisiert sind.

Für die Agonisten-induzierte Desensitisierung und Internalisierung vieler G Proteingekoppelter Rezeptoren ist deren Phosphorylierung an intrazellulären Serin- oder Threoninresten notwendig, wie für den $\beta 2$-adrenergen Rezeptor als Modellsystem gezeigt wurde (Bouvier et al. (1988); Hausdorff et al. (1989)). Nach Phosphorylierung kommt es zu einer Interaktion des Rezeptors mit dem Adaptorprotein $\beta$-Arrestin, die zur Entkopplung des Rezeptors von der intrazellulären Signalkaskade führt. In vielen Fällen ist die Bindung von $\beta$-Arrestin gleichzeitig für die Clathrin-vermittelte Internalisierung des Ligand-besetzten, phosphorylierten Rezeptors in intrazelluläre Kompartimente, die auf die Entkopplung folgt, notwendig. Die Agonisten-induzierte Desensitisierung des EP4-R wurde zuerst anhand der reduzierten maximalen Aktivierung der Adenylatcyclase nach $\mathrm{PGE}_{2}$-Vorstimulation der Rezeptor-exprimierenden Zellen durch Nishigaki et al. (1996) beschrieben. Der von innen parallel untersuchte EP2-R zeigte diese reduzierte $\mathrm{PGE}_{2}$-vermittelte AdenylatcyclaseAktivität nach Vorstimulation mit dem Agonisten nicht. Die Relevanz der C-terminalen Domäne des hEP4-R für die Agonisten-induzierte Desensitisierung wurde von Bastepe und 
Ashby (1996) anhand einer nicht mehr desensitisierbaren Rezeptormutante gezeigt, der durch Trunkierung des Rezeptors ab Aminosäure 350 große Teile der C-terminalen Domäne fehlten. Die Bedeutung der C-terminalen Domäne für die Agonisten-induzierte Desensitisierung wurde weiterhin dadurch belegt, daß ein Hybridrezeptor, in dem die C-terminale Domäne des nicht desensitisierbaren Ratten-EP3 $\beta-R$ gegen die des hEP4-R ausgetauscht war, nach Agonisten-Stimulation desensitisiert wurde (Neuschäfer-Rube et al. (1997)). Die Bindung des Agonisten führte beim EP4-R und beim Hybridrezeptor, aber nicht beim EP3 $\beta-R$ zu einer Phosphorylierung in der C-terminalen Domäne. Dadurch konnte gezeigt werden, daß die C-terminale Domäne des EP4-R sowohl hinreichend wie notwendig für die Agonisten-induzierte Phosphorylierung war (Neuschäfer-Rube et al. (1999)). Diese Schlußfolgerung wurde dadurch weiter gestützt, daß ein EP4-R, in dem große Teile der dritten cytoplasmatischen Schleife deletiert waren (Slipetz et al. (2001)), nach AgonistenExposition noch phosphorylierbar war.

Aufgrund dieser Befunde sollten in dieser Arbeit die potentiellen Phosphorylierungsstellen in der C-terminalen Domäne des humanen EP4-Rezeptors durch sequenzgerichtete Mutagenese teilweise oder komplett eliminiert und die Auswirkung dieser Mutationen auf die Phosphorylierung, Desensitisierung und Internalisierung untersucht werden. Weiterhin wurde der Einfluß der Mutationen auf die Bindungs- und Signaltransduktionseigenschaften, sowie den Transport des Rezeptors zur Plasmamembran untersucht.

\subsection{Eliminierung potentieller Phosphorylierungsstellen in der C-terminalen Domäne des hEP4-R durch sequenzgerichtete Mutagenese}

Für die Elimierung der potentiellen Phosphorylierungsstellen in der C-terminalen Domäne des hEP4-R existieren zwei prinzipiell unterschiedliche Verfahren, die Trunkierung der Cterminalen Domäne oder der Austausch einzelner Serine/Threonine durch sequenzgerichtete Mutagenese.

Zur Synthese einer trunkierten Rezeptormutante, in der die potentiellen Phosphorylierungsstellen eliminiert sind, wird an einer definierten Position der Rezeptor-cDNA ein Stop-Codon durch PCR-Reaktionen eingefügt, was nach heterologer Expression zu einem verkürzten Rezeptorprotein führt. Dieses Verfahren wurde jedoch nicht gewählt, da durch den Verlust großer Teile der C-terminalen Rezeptordomäne auch Elemente entfernt werden können, denen eine strukturelle Bedeutung bei der Phosphorylierung, Desensitisierung oder Internalisierung zukommen kann, ohne selbst jedoch relevante Phosphorylierungsstellen zu beinhalten. Für Trunkierungsmutanten kann daher nicht eindeutig bestimmt werden, ob der Verlust der potentiellen Phosphorylierungsstellen oder der Verlust anderer Strukturelemente für eine Modulation der Agonisten-induzierte Phosphorylierung verantwortlich sind. 
Darüber hinaus können durch die Trunkierung die funktionellen Eigenschaften des Rezeptors verändert werden. Für den bovinen EP3-R konnte gezeigt werden, daß Spleißvarianten des Rezeptors, die sich nur in der Sequenz ihrer C-terminalen Domäne unterschieden, an unterschiedliche G-Proteine koppelten und damit unterschiedliche Signalketten aktivierten (Namba et al. (1993)). Weiterhin wurde von Irie et al. (1994) für den EP3-R nachgewiesen, daß die C-terminale Domäne essentiell für die Agonisten-abhängige Kontrolle der Aktivierung des G-Proteins ist. Die Trunkierung der C-terminalen Domäne führte zu einer konstitutiven Aktivität des Rezeptors (Hasegawa et al. (1996); Jin et al. (1997)).

Aus diesen Gründen wurde für die Eliminierung potentieller Phosphorylierungsstellen in der C-terminalen Domäne des hEP4-R nicht die Trunkierung sondern die Substitution der Serine und Threonine durch die nicht mehr phosphorylierbare Aminosäure Alanin gewählt. Als Substituent wurde Alanin gewählt, da Alanin etwa die gleiche Größe wie Serin oder Threonin hat. Eine allein durch den Größenunterschied der Seitenkette hervorgerufene Änderung der räumlichen Anordnung des Proteins sollte so minimiert werden. Allerdings unterschieden sich Alanin einerseits und Serin und Threonin andererseits trotzdem nicht unerheblich in der relativen Häufigkeit, mit der sie in $\alpha$-helikalen-, $\beta$-Faltblatt- oder $\beta$-Turn-Strukturen gefunden werden können. Auch gehen durch den Austausch von Serinen und Threoninen nach Alanin Wasserstoffbrücken-Donoren und -Akzeptoren verloren, die potentiell relevant für die Stabilisierung der Sekundär- oder Tertiärstruktur sein könnten. Aus diesem Grund wurde bei der Identifikation relevanter Phosphorylierungsstellen des C5a-Rezeptors (Giannini et al. (1995) oder des Parathyroidhormon-Rezeptors (Malecz et al. (1998)) eine noch konservativere Substitutionsstrategie gewählt. Durch Phosphoraminosäureanalyse konnte ermittelt werden, daß eine Agonisten-induzierte Phosphorylierung des Rezeptors ausschließlich an Serinen und nicht an Threoninen, die ebenfalls z. B. durch GRKs phosphoryliert werden können, stattfand. Durch Substitution von Serinen durch Threonine konnten dann diejenigen Serine identifiziert werden, durch deren Substitution es zu einer Phosphorylierung des Rezeptors an Threoninresten kam.

Der Nachteil dieser Strategie besteht darin, daß nicht davon ausgegangen werden kann, daß sich Serin und Threonin unabhängig vom umgebenden Sequenzmotiv als Substrat für die GRKs in jedem Fall identisch verhalten. Threonine könnten phosphoryliert werden, obwohl Serine in identischer Position nicht phosphoryliert werden und umgekehrt. Dieses Problem erscheint weniger relevant, wenn es nur einen oder wenige Bereiche mit potentiellen Phosphorylierungsstellen gibt und nicht, wie im hEP4-R, etliche Cluster von Serinen und Threoninen, die als potentielle Phosphorylierungsstellen in Frage kommen.

Die Synthese der verschiedenen mutierten hEP4-R-cDNAs wurde mit der Methode der PCR mit überlappenden Extensionen („site directed mutagenesis“) (Ho et al. (1989)) durchgeführt. 
Die sequenzgerichtete Mutagenese ist eine schnelle und effiziente Methode, bei der die gewünschten Mutationen durch spezifisch mutierte Primer in die cDNA eingefügt oder diese um spezifische Sequenzen verlängert werden. Zusätzlich bietet sie durch Kombination verschiedener Primer die Möglichkeit zur Synthese unterschiedlicher mutierter Fragmente, welche durch die die Primer flankierenden Restriktionsschnittstellen in unterschiedlicher Weise kombiniert werden können.

Zusätzlich zum Einfügen der Mutationen diente die PCR-Technik auch zum Verlängern des 5 -Endes der hEP4-R-cDNA um eine für das FLAG-Epitop codierenden Sequenz, welches zur Immunpräzipitation der in HEK293-Zellen exprimierten Rezeptorproteine mit dem FLAGM2-Antikörper diente.

\subsection{Stabile Expression der verschiedenen FLAG-hEP4-Rezeptorproteine in HEK293- Zellen und Überprüfung der Funktionalität der verschiedenen FLAG-hEP4- Rezeptorproteine}

Die cDNAs für die hEP4-Rezeptormutanten, in denen die potentiellen Phosphorylierungsstellen durch Substitution eliminiert worden waren, wurden in den eukaryonten Expressionsvektor pcDNA3 kloniert, die Rezeptorproteine in HEK293-Zellen stabil exprimiert und die Rezeptorexpression immunologisch untersucht.

Von den 156 Aminosäuren der C-terminale Domäne des hEP4-R sind insgesamt 38 Serine und Threonine. Diese Serine und Threonine wurden teilweise oder vollständig gegen Alanine ausgetauscht, so daß bis zu 25\% (hEP4-ST335-484A-R) der Aminosäuren der C-terminalen Domäne durch eine fremde Aminosäure ersetzt wurden. Obwohl es sich um eine relativ konservative Substitution handelte, war nicht auszuschließen, daß hierdurch die Gesamtstruktur des Rezeptorproteins gestört wurde. Deshalb wurde überprüft, ob durch die Einführung der Mutationen die Rezeptoreigenschaften, wie der korrekte Transport zur Plasmamembran, Ligandbindung und Signaltransduktion beeinflußt wurden.

\subsubsection{Expression der hEP4-Rezeptoren in HEK293-Zellen}

Durch Immunpräzipitation mit dem FLAG-M2-Antikörper und nachfolgende WesternblotAnalyse konnte die Expression der verschiedenen hEP4-Rezeptorproteine wie erwartet in HEK293-Zellen nachgewiesen werden (Abb. 22). Alle Rezeptorproteine stellten sich als breite Bande mit einem Molekulargewicht von 70-100 kDa dar, was auf eine komplexe Glykosylierung der Rezeptoren und damit eine korrekte Prozessierung der Proteine im GolgiApparat rückschließen lies. Der Molekulargewichtsbereich, in dem die Rezeptorproteine nachgewiesen wurden, stimmte mit dem in Untersuchungen zur Phosphorylierung des hEP4-R in transient transfizierten COS-7-Zellen überein, bei der nur die im Bereich von 
70-110 kDa wandernde Form des Rezeptors Agonisten-abhängig phosphoryliert wurde (Neuschäfer-Rube et. al. 1999)

\subsubsection{Subzelluläre Lokalisation der hEP4-Rezeptoren in HEK293-Zellen}

Für den Vasopressin $V_{2}$-Rezeptor ist gezeigt worden, daß Mutationen, die Aminosäureaustausche in der C-terminalen Domäne des Rezeptor verursachten, dazu führten, daß der Transport des Rezeptors zur Plasmamembran gestört war (Schülein et al. (1998)). Deshalb sollte sichergestellt werden, daß die Serin/Threonin nach Alanin-Substitutionen in der C-terminalen Domäne des EP4-R keinen Einfluß auf den Transport der Rezeptorproteine zur Plasmamembran hatten. Dazu wurde die subzelluläre Verteilung der Rezeptoren mit Hilfe des FLAG-M2-Antikörpers durch indirekte Immunfluoreszenz-Mikroskopie mit einem konfokalen Laserscanmikroskop untersucht.

Der hEP4-R wie auch alle mutierten Rezeptorproteine waren korrekt in der Plasmamembran lokalisiert (Abb. 23). Die Mutationen hatten also keinen Einfluß auf den intrazellulären Transport der Rezeptorproteine. Lediglich für den hEP4-S379A-Rezeptor konnte neben der Lokalisation an der Plasmamembran zusätzlich noch eine geringe perinukleäre Lokalisation und damit intrazelluläre Retention festgestellt werden (Abb.23). Dies war am ehesten auf die hohe Expressionrate dieses Rezeptors zurückzuführen, der dadurch nicht vollständig prozessiert werden konnte.

\subsubsection{Bedeutung der eingefügten Mutationen für die Ligandbindung}

In früheren Studien wurde gezeigt, daß die Ligandbindungstasche der Prostanoidrezeptoren wahrscheinlich, wie z. B. auch bei den Catecholaminrezeptoren (Probst et al. (1992)) durch die Transmembrandomänen gebildet wird, wobei der hoch konservierten VII. Transmembrandomäne eine besondere Bedeutung bei der Ligandbindung zukommt. (Funk et al. (1993) Huang et al. (1995); Audoly und Breyer (1997a); Rehwald et al. (1999); Neuschäfer-Rube et al. (2003)). Weitere für die Ligandbindung relevante Aminosäuren sind unter Umständen in den extrazellulären Domänen lokalisiert. (Huang et al. (1996); Audoly und Breyer (1997b); Tai et al. (1997), Kedzie et al. (1998); Stillman et al. (1998); Stillman et al. (1999)). Da sich alle eingefügten Mutationen in der intrazellulären C-terminalen Domäne des hEP4-Rezeptors befanden, wurde angenommen, daß diese Mutationen keinen Einfluß auf die Ligandbindung haben. Es gibt aber auch Beispiele dafür, daß auch Veränderungen in der C-terminalen Domäne einen Einfluß auf die Ligandbindung haben können. So wurde gezeigt, daß eine C-terminale Trunkation des Angiotensin II-Rezeptors zu einer veränderten Affinität des Rezeptors zum Liganden führte (Pulakat et al. (2002)). Daher war nicht auszuschließen, daß ein solcher Effekt auch für die mutierten hEP4-Rezeptorproteine 
zutreffen könnte, zumal die C-terminale Domäne des hEP4-R direkt an die hochkonservierte VII. Transmembrandomäne anschließt und mögliche, durch die Mutationen bedingte Strukturveränderungen dieser Domäne direkt auf die VII. Transmembrandomäne übertragen werden könnten.

Die Affinität der verschiedenen FLAG-hEP4-Rezeptorproteine für $\mathrm{PGE}_{2}$ wurden durch Sättigungsbindungsstudien mit $\left[{ }^{3} \mathrm{H}\right]$-markiertem- $\mathrm{PGE}_{2}$ untersucht. Die $\mathrm{K}_{d}$ für den Liganden betrug für den Wildtyprezeptor 1,31 nM (Tab. 7). Da die Affinität aller mutierten Rezeptorproteine für $\mathrm{PGE}_{2}$ gleich hoch war wie die des Wildtyps (Tab. 7), ließ sich ein Einfluß der Mutationen auf die Ligandbindung der Rezeptorproteine ausschließen. Die Bindungskapazitäten der die unterschiedlichen Rezeptorproteine exprimierenden HEK293Zellklone (Tab. 7) waren mit Ausnahme des den hEP4-S379A-R exprimierenden Zellklons, etwa gleich, so daß sich Unterschiede in der Rezeptorsignaltransduktion, Rezeptorphosphorylierung, Desensitisierung und Internalisierung nicht auf eine unterschiedliche Rezeptorexpression zurückführen lassen. Ähnlich wie beim EP4-R hatte auch beim Thromboxan $A_{2}$-Rezeptor (Spurney et al. (1998)) und den Gastrin-releasingpeptide-Rezeptor (Benya et al. (1993)) die Substitution verschiedener Serine und Threonine in der C-terminalen Domäne keinen Einfluß auf die Bindungseigenschaften des Rezeptors. Die Affinität des hEP4-wt-Rezeptors und der hEP4-Rezeptormutanten für $\mathrm{PGE}_{2}$ war annähernd gleich wie die in anderen Untersuchungen gefundene (Bastepe und Ashby (1997); Neuschäfer-Rube et al. (1998)). Weiterhin konnten Bastepe und Ashby (1997) für einen in CHO-K1-Zellen exprimierten trunkierten EP4-R, dem die C-terminale Domäne ab Aminosäure 350 fehlte, eine dem Wildtyp vergleichbare Affinität für $\mathrm{PGE}_{2}$ bestimmen. Diese Ergebnisse bestätigen, daß die Mutationen in der C-terminalen Domäne des EP4-R keinen Einfluß auf die Bindungseigenschaften des Rezeptors haben.

\subsubsection{Einfluß der Mutationen in der C-terminalen Domäne des hEP4-R für die Signaltransduktion des Rezeptors}

\section{Kopplungsspezifität}

Für den bovinen EP3-R konnte eine Funktion der C-terminalen Domäne für die Spezifität der Kopplung des Rezeptors an unterschiedliche G Proteine gezeigt werden. Spleißvarianten des Rezeptors, welche sich nur in der Sequenz ihrer C-terminalen Domäne unterschieden, koppelten an unterschiedliche G-Proteine (Namba et al. (1993)). Im Gegensatz dazu koppelte ein Hybridrezeptor aus dem $\mathrm{G}_{\mathrm{i}}$-gekoppelten Ratten-EP3 $\beta-\mathrm{R}$, in dem die C-terminale Domäne gegen die des $G_{s}$-gekoppelten EP4-R ausgetauscht war, weiterhin an $G_{i}$ (Neuschäfer-Rube et al. (1997)). Es war dennoch nicht auszuschließen, daß sich die Kopplungsspezifität des hEP4-R aufgrund der eingefügten Mutationen in der C-terminalen Domäne ändern könnte. 
Durch $\mathrm{PGE}_{2}$-Stimulation konnte in allen Rezeptor-exprimierenden Zellen die cAMP-Bildung gesteigert werden, woraus sich schließen ließ, daß in HEK293-Zellen sowohl der hEP4 wt-R wie auch alle mutierten Rezeptorproteine an $G_{s}$ koppelten (Abb. 24). Die PGE $E_{2}$-induzierte cAMP-Bildung in Membranen von Zellen, die die mutierten hEP4-R exprimierten unterschied sich nicht von der $\mathrm{PGE}_{2}$-induzierten cAMP-Bildung in Membranen hEP4 wt-Rexprimierender HEK293-Zellen. Weiterhin war das Verhältnis der spezifischen, PGE ${ }_{2}^{-}$ induzierten cAMP-Bildung und der unspezifischen, direkt die Adenylatcyclase aktivierenden Forskolin-stimulierten cAMP-Bildung in allen Zellen annährend gleich. Daher konnte davon ausgegangen werden, daß alle mutierten Rezeptorproteine funktionell waren und mit der gleichen Effizienz an das $\mathrm{G}_{\mathrm{s}}$-Protein und die Adenylatcyclase-Signalkette koppelten (Abb. 24).

\section{Kopplungskontrolle}

Die C-terminale Domäne von G-Protein-gekoppelten Rezeptoren kann auch einen Einfluß auf die G-Protein-Kopplungskontrolle haben. So führte die Trunkierung der C-terminalen Domäne des EP3-R (Hasegawa et al. (1996); Jin et al. (1997)), oder die Substitution eines Leucin unmittelbar zu Beginn der C-terminalen Domäne des $\mathrm{AT}_{1 \mathrm{~A}}$-Rezeptors (Parnot et al. (2000)) zu einer konstitutiven, Ligand-unabhängigen Aktivität dieser Rezeptoren. Dagegen zeigte der IP-R nach Substitution verschiedener Aminosäuren in der C-terminalen Domäne ein normales Kopplungsverhalten (Smyth et al. (1998)) und Sustitutionen in der C-terminalen Domäne des PTH-Rezeptors hatten keinen Einfluß auf dessen Signaltransduktion (Malecz et al. (1998)). Weiterhin führte die Trunkierung der C-terminalen Domäne des EP4-Rezeptors (Bastepe und Ashby (1997); Slipetz et al. (2000)) zu keiner Veränderung in der G-ProteinKopplung. Um dennoch einen möglichen Einfluß der Mutationen in der C-terminalen Domäne des hEP4-R auf die Liganden-unabhängige G-Protein-Aktivierung auszuschließen, wurde die basale und Agonisten-induzierte cAMP-Bildung der verschiedenen Rezeptor-exprimierenden Zellen bestimmt. Die verschiedenen Rezeptor-exprimierenden HEK293-Zellen zeigten ohne Agonisten-Stimulation einen vergleichbar geringen basalen cAMP-Spiegel, was zeigt, daß die Mutationen keine konstitutive Aktivität der verschiedenen Rezeptoren hervorrief. Ebenso hatten die Mutationen keinen Einfluß auf die G-Protein-Kopplung, da die $\mathrm{PGE}_{2}$-induzierte cAMP-Bildung der mutierten Rezeptorproteine sich nicht von der des Wildtyprezeptors unterschied (Abb. 24).

\subsection{Agonisten-induzierte Phosphorylierung des FLAG-hEP4-wt-Rezeptors und der verschiedenen mutierten Rezeptorproteine}

Eine allgemein gültige, auf der Primärstruktur basierende Vorraussage, welche der Serine und Threonine nach Agonisten-Exposition in den intrazellulären Domänen von GPCR 
phosphoryliert werden, ist nicht möglich, da es nur für die „second-messenger“-abhängigen Kinasen PKA und PKC, nicht aber für die GRKs Konsensus-Sequenzen gibt. Bisher wurden relevante Phosphorylierungsstellen hauptsächlich in der C-terminalen Domäne verschiedener GPCRs identifiziert, jedoch wurden auch Phosphorylierungen in den intrazellulären Schleifen nach Stimulation mit dem Agonisten beschrieben (Hosey et al. (1999); Celver et al. (2001)).

Da eine ab Aminosäure 350 deletierte Trunkierungsmutante des EP4-Rezeptors nicht mehr desensitisierte (Bastepe und Ashby (1996)), wurden die relevanten Phosphorylierungsstellen des hEP4-R in der C-terminalen Domäne des Rezeptors vermutet. Dies konnte anhand von Untersuchungen mit einem Hybridrezeptor, der aus dem nicht desensitisierbaren EP3 $\beta-R$ bis einschließlich der VII. Transmembrandomäne und der C-terminalen Domäne des EP4-R bestand, bestätigt werden. Der Hybridrezeptor wurde, wie der hEP4-R, nach AgonistenExposition phosphoryliert während der rEP3 $\beta-R$ nicht phosporyliert wurde. Damit konnte gezeigt werden, daß die C-terminale Domäne des hEP4-R nicht nur notwendig, sondern auch hinreichend war, die Agonisten-induzierte Phosphorylierung zu vermitteln (NeuschäferRube et al. (1999)). Während der Arbeiten zu der vorliegenden Untersuchung konnte eine Agonisten-induzierte Phosphorylierung des EP4-R ebenfalls von Slipetz et al. (2001) gezeigt werden. In dieser Untersuchung wurde eine nach Aminosäure 355-deletierte Rezeptormutante nicht mehr Agonisten-induziert phosphoryliert, wodurch der Bereich der potentiell relevanten Phosphorylierungsstellen mit gewissen Vorbehalten (siehe 5.1) auf die Serine und Threonine zwischen 359 und 484 eingrenzt werden konnte.

\subsubsection{Identifizierung der an der $\mathrm{PGE}_{2}$-induzierten Phosphorylierung des FLAG-hEP4- wt-Rezeptors beteiligten Kinasen}

Der FLAG-hEP4-wt-Rezeptor zeigte eine basale Phosphorylierung, die nach $\mathrm{PGE}_{2^{-}}$ Stimulation deutlich gesteigert werden konnte (Abb. 25). Dagegen war nach Stimulation der Zellen mit Forskolin, welches die Adenylatcyclase und damit PKA aktiviert, keine Phosphorylierung und durch den PKC-Aktivator PMA nur eine schwache Phosphorylierung zu beobachten. Die basale und PMA-induzierte Phosphorylierung, nicht jedoch die $\mathrm{PGE}_{2^{-}}$ induzierte Phosphorylierung konnte durch Vorbehandlung der Zellen mit dem PKA/PKCInhibitor Staurosporin gehemmt werden. Diese Befunde ließen auf eine GRK- und nicht PKAoder PKC-vermittelte Phosphorylierung des Rezeptors durch Ligand-Exposition schließen, obwohl der Rezeptor über mehrere PKA- und PKC-Konsensus-Sequenzen verfügt. Dieses Ergebnis wurde durch Behandlung der FLAG-hEP4-wt-R exprimierenden HEK293-Zellen mit GRK-Antisense-Nukleotiden unterstützt, durch welche die PGE $_{2}$-induzierte Phosphorylierung reduziert werden konnte (nicht gezeigt). Weiterhin führte die Überexpression von GRK2, 3 und $5 \mathrm{zu}$ einer Steigerung der Agonisten-induzierten Phosphorylierung des hEP4-R 
(Neuschäfer-Rube et al. (1999)). Auch konnte die Agonisten-abhängige Desensitisierung des hEP4-Rezeptors durch Heparin, einem Inhibitor der GRK-vermittelten Phosphorylierung, gehemmt werden (Nishigaki et al. (1996)), was auf eine Beteiligung von GRKs bei der Agonisten-induzierten hEP4-R-Phosphorylierung hindeutete.

\subsubsection{PGE $_{2}$-induzierte Phosphorylierung der verschiedenen mutierten FLAG-hEP4- Rezeptorproteine}

Die Substitution aller in der C-terminalen Domäne lokalisierten Serine und Threonine durch Alanin führte zu einem vollständigen Verlust der Agonisten-induzierten Phosphorylierung (Abb. 26), was die Lokalisation der für die $\mathrm{PGE}_{2}$-induzierten Phosphorylierung relevanten Phosphorylierungsstellen des Rezeptors in der C-terminalen Domäne bestätigte. Desweiteren konnte eine Phosphorylierung an Tyrosinresten ausgeschlossen werden. Die noch vorhandene basale Phosphorylierung könnte auf eine nicht Agonisten-abhängige unspezifische Phosphorylierung in einer cytoplasmatischen Schleife hinweisen.

$\mathrm{PGE}_{2}$-Stimulation von HEK293-Zellen, die den hEP4 ST428-484A-R oder den hEP4 ST335354; 389-484A-R stabil exprimierten, führte zu einer mit dem hEP4 wt-R vergleichbaren

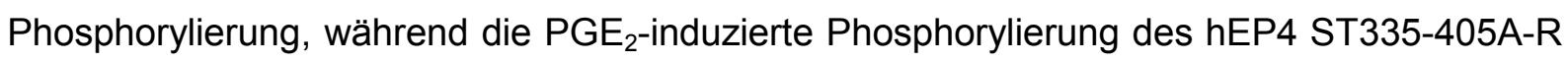
und des hEP4 ST335-382A-R im Vergleich zu dem hEP4 wt-R um 75\% reduziert war. Hierdurch konnte gezeigt werden, daß der hEP4-R nach $\mathrm{PGE}_{2}$-Stimulation zum überwiegenden Teil an Serinen und Threoninen im proximalen Teil der C-terminale Domäne phosphoryliert wurde und daß die Serine und Threonine zwischen Aminosäure 359 und 382 für eine dem hEP4 wt-R vergleichbaren Phosphorylierung hinreichend, und zum überwiegenden Teil auch notwendig waren. Diese Ergebnisse stehen im Einklang mit Experimenten zur $\mathrm{PGE}_{2}$-induzierten Desensitisierung des hEP4-R, die während der laufenden Arbeiten publiziert wurden. In diesen Experimenten wurde gezeigt, daß Substitution der Serine und Threonine zwischen Aminosäure 370 und 382 durch Alanin zu einem Verlust der Agonisten-induzierten Desensitisierung des hEP4-R führte (Bastepe und Ashby (1999)). Dies konnte weiterhin durch Untersuchungen bestätigt werden, in denen ein nach Aminosäure 355 trunkierter hEP4-R nicht mehr Agonisten-abhängig phosphoryliert wurde (Slipetz et al. (2001)).

Vorläufige Experimente zur Identifizierung der nach Agonisten-Stimulation im hEP4 wt-R phosphorylierten Serine/Threonine durch Phosphopeptidsequenzierung hatten ergeben, daß unter Umständen dem Serin 379 eine besondere Bedeutung bei der Phosphorylierung des Rezeptors zukommt. Dies konnte jedoch in den in dieser Arbeit durchgeführten Experimente nicht bestätigt werden. Einerseits reduzierte die alleinige Substitution des Serin 379 die $\mathrm{PGE}_{2}$-induzierte Phosphorylierung des hEP4-R nicht und andererseits führte die Reinsertion von Serin 379 in den FLAG-hEP4 ST335-484A-R zu keiner Agonisten-induzierten 
Rezeptorphosphorylierung. Eine Phosphorylierung von Serin 379 im hEP4 wt-R konnte jedoch hierdurch nicht ausgeschlossen werden. Es ist zu vermuten, daß der Verlust einer einzigen Phosphorylierungsstelle durch die Phosphorylierung residualer Phosphorylierungsstellen kompensiert werden kann und eine einzige verbleibende Phosphorylierungsstelle nicht für eine effektive Initiation der Rezeptorphosphorylierung ausreichend ist.

Anhand der durchgeführten Experimente konnte neben der überwiegenden Phosphorylierung proximaler Serine und Threonine auch eine geringe Agonisten-induzierte Phosphorylierung im distalen Bereich der C-terminalen Domäne nachgewiesen werden, die mit großer Wahrscheinlichkeit im Bereich der Serine und Threonine zwischen Aminosäure 428 und 484 lokalisiert war. Die durchgeführte Untersuchung reichte jedoch nicht aus, um entscheiden zu können, ob die $\mathrm{PGE}_{2}$-induzierte Phosphorylierung distaler Serine und Threonine auch im hEP4 wt-R stattfand, oder ob es sich hierbei um eine kompensatorische Phosphorylierung in den Rezeptormutanten handelte, bei denen die „Hauptphosphorylierungssstelle" nicht mehr vorhanden war.

\subsection{Desensitisierung des FLAG-hEP4 wt-Rezeptors und des FLAG-hEP4 ST335- 484A-Rezeptors}

Nach einem, für den $\beta 2$-adrenergen Rezeptor als Modell-Rezeptor entwickelten Konzept, kommt es nach der Bindung eines Liganden an G-Protein-gekoppelte Rezeptoren zur Rekrutierung des Adaptoproteins $\beta$-Arrestin an den Ligand-besetzten Rezeptor, was eine, wahrscheinlich sterische, Entkopplung des Rezeptors von seinem G-Protein und seiner nachgeschalteten Signalkette zur Folge hat. Dieses Phänomen wird als Desensitisierung bezeichnet. Eine der $\beta$-Arrestin-Bindung vorausgehende Phosphorylierung des Rezeptors durch G-Protein-gekoppelter-Rezeptor-Kinasen oder PKA/PKC erhöht dabei die Affinität von $\beta$-Arrestin für den Rezeptor und ist in den meisten untersuchten Rezeptorsystemen Vorraussetzung für eine effektive Desensitisierung des Rezeptors. Eine der Desensitisierung vorausgehende Phosphorylierung wurde für den $\beta 2$-adrenergen Rezeptor (Palmer et al. (1995)), den Angiotensin II-Rezeptor (Oppermann et al. (1996)), den $\mu$-opioid-Rezeptor (Yu et al. (1997)), den Endothelin-Rezeptor (Freedman et al. (1997)), den ß1-adrenergenRezeptor (Freedman et al. (1995)) oder den Thrombin-Rezeptor (Ishii et al. (1994)) sowie viele andere Rezeptoren beschrieben.

Die Agonisten-induzierte Desensitisierung des EP4-R wurde zuerst von Nishigaki et al. (1996) beschrieben. Im Gegensatz zu CHO-Zellen, welche den ebenfalls $\mathrm{G}_{\mathrm{s}}$-gekoppelten EP2-R der Maus exprimierten, führte eine primäre $\mathrm{PGE}_{2}$-Exposition von $\mathrm{CHO}$-Zellen, welche den Maus EP4-R exprimierten, zu einer Reduktion der cAMP-Bildung durch einen sekundären $\mathrm{PGE}_{2}$-Stimulus. Dabei verringerte der erste Stimulus die maximale durch die 
zweite $\mathrm{PGE}_{2}$-Exposition induzierte cAMP-Bildung ohne die EC50 für die $\mathrm{PGE}_{2}$-induzierte cAMP-Bildung zu beeinflussen. Die Desensitisierung des EP4-R war nach 5 min zu beobachten und erreichte ihr Maximum nach $10 \mathrm{~min}$.

Die Bedeutung der C-terminalen Domäne für die Agonisten-induzierte Desensitisierung konnte durch Untersuchungen mit einem Hybridrezeptor aus dem Ratten EP3 $\beta$-Rezeptor, dessen C-terminale Domäne durch die des humanen EP4-R ausgetauscht war, gezeigt werden. Im Gegensatz zu dem Ratten EP3 $\beta-R$ führte die Agonisten-Exposition zu einer Desensitisierung des Hybridrezeptor, wodurch gezeigt werden konnte, daß die C-terminale Domäne des hEP4-R ausreichend war, um eine Agonisten-induzierte Desensitisierung zu vermitteln.

Dieser Befund wurde dadurch unterstützt, daß eine C-terminal ab Aminosäure 350 trunkierte Mutante des hEP4-R nicht mehr Agonisten-abhängig desensitisierte (Bastepe und Asby (1997)).

Um die Relevanz der in der C-terminalen Domäne hEP4 wt-R lokalisierten Serine und Threonine für die Desensitisierung zu ermitteln, wurde zunächst die Agonisten-induzierte Desensitierung des hEP4 wt-R im Vergleich mit dem hEP4 ST335-484A-R, in dem keine der potentiellen Phosphorylierungsstellen mehr vorhanden waren, untersucht. Dabei wurde die $\mathrm{PGE}_{2}$-stimulierte cAMP-Bildung der beiden Rezeptoren als Meßparameter für die nachgeschaltete Signalkette verwendet.

\subsubsection{Desensitisierung des hEP4 wt-Rezeptors und des hEP4 ST335-484A-Rezeptors nach Vorstimulation mit $\mathrm{PGE}_{2}$}

Die Agonisten-induzierte Entkopplung des FLAG-hEP4 wt-R und des FLAG-hEP4 ST335484A-R wurde zunächst in einem Verfahren untersucht, bei dem die Desensitisierung der Rezeptoren durch einen ersten $\mathrm{PGE}_{2}$-Stimulus (Vorstimulation) initiert, der gebundene Ligand vom Rezeptor entfernt und die cAMP-Bildung auf eine direkt anschließende zweite $\mathrm{PGE}_{2}$-Exposition (Restimulation) gemessen wurde (Abb. 27). Dabei wurde eine intrazelluläre cAMP-Akkumulation erst in der zweiten Stimulationsphase durch Zugabe des Phosphodiesteraseinhibitors IBMX ermöglicht. Der deutlich erhöhte cAMP-Spiegel der vorstimulierten, aber nicht restimulierten hEP4 wt-R oder hEP4 ST335-484A-R exprimierenden HEK293-Zellen ließ auf ein Verbleiben eines Großteils des Liganden am Rezeptor schließen. Weder in den hEP4 wt-R noch in den hEP4 ST335-484-R exprimierenden HEK293-Zellen ließ sich der erhöhte intrazelluläre cAMP-Spiegel durch einen zweiten Stimulus steigern. Eine durch den ersten Stimulus induzierte verringerte Signaltransduktion ließ sich daher nicht messen. Jedoch war der basale, durch den nach Vorstimulation am Rezeptor verbleibenden Liganden induzierte Anstieg des CAMP in vorstimulierten hEP4 wt-R exprimierenden Zellen, nicht aber in hEP4 ST335-484A-R 
exprimierenden Zellen geringer als der durch $\mathrm{PGE}_{2}$ induzierte cAMP-Anstieg in nichtvorstimulierten Zellen. Dies konnte als ein Hinweis darauf gewertet werden, daß der hEP4 wt-R im Gegensatz zum hEP4-ST335-484A-R Agonisten-abhängig desensitisiert wurde. Wenn überhaupt, wurde jedoch nur ein so kleiner Teil der hEP4 wt-R Agonisten-abhängig desensitisiert, daß die Aktivierung der nachgeschalteten Signalkette davon kaum beeinträchtigt wurde. Dies könnte seine Ursachen in einem, in der hohen Expressionsrate der Rezeptoren in den HEK293-Zellen begründeten, Mißverhältniss zwischen Rezeptor und nachgeschalteter Signalkette haben. In diesem Fall würde ein geringer Anteil nicht von seinem G-Protein entkoppelter Rezeptoren ausreichend sein, um die intrazelluläre Signalkaskade maximal zu aktivieren („spare-receptor“-Hypothese). Zusammengefaßt war das gewählte Verfahren nicht geeignet, um eine Bedeutung einzelner Phosphorylierungsstellen für die $\mathrm{PGE}_{2}$-induzierte hEP4-R-Desensitisierung zu untersuchen.

\subsubsection{Fehlende Unterschiede in der Kinetik der $\mathrm{PGE}_{2}$-induzierten cAMP-Bildung in hEP4 wt-Rezeptor oder hEP4 ST335-484A-Rezeptor exprimierenden HEK293- Zellen nach Prästimulation mit $\mathrm{PGE}_{2}$}

Da nach $\mathrm{PGE}_{2}$-Vorstimulation der hEP4 wt-R exprimierenden Zellen im Gegensatz zu den hEP4 ST335-484A-R exprimierenden Zellen eine geringfügig reduzierte cAMP-Bildung gemessen werden konnte, wurde in beiden Zellinien die Kinetik der $\mathrm{PGE}_{2}$-induzierten $\mathrm{CAMP}$ Bildung nach Stimulation der Zellen mit $\mathrm{PGE}_{2}$ und nachfolgender Akkumulation des intrazellulären cAMPs durch den Phosphodiesteraseinhibitor IBMX untersucht. Die hEP4 wt$\mathrm{R}$ oder hEP4 ST335-484A-R exprimierenden Zellen zeigten nach IBMX-Zugabe einen vergleichbar schnellen Anstieg des intrazellulären cAMP-Spiegels, der nach ca. 10 min sein Maximum errreichte und über weitere 20 min konstant blieb (Abb. 28). Die Steigerung der cAMP-Bildung war in beiden Rezeptor exprimierenden Zellinien vergleichbar, was gegen eine Desensitisierung des EP4 wt-R und einer daraus resultierenden verminderten Steigerung des cAMP-Spiegel sprach. Dieses Ergebnis unterstützte die Annahme, daß der nach Agonisten-Exposition verbleibende, nicht entkoppelte Rezeptoranteil ausreichte, um die nachgeschaltete Signalkette maximal zu aktivieren (vgl. Abb. 27).

Die für den potentiell nicht mehr desensitisierbaren FLAG-hEP4 ST335-484A-R erwartete, kontinuierliche Agonisten-induzierte cAMP-Bildung konnte nicht beobachtet werden. Das Erreichen eines konstanten cAMP-Spiegels könnte bedeuteten, daß möglicherweise eine Komponente der dem Rezeptor nachgeschalteten Signalkette durch die starke intrazelluläre cAMP-Akkumulation desensitisiert wurde. Aus diesem Grund wurde die Kinetik der Rezeptor-unabhängigen cAMP-Bildung durch Stimulation mit Forskolin, einem direkten Aktivator der Adenylatcyclase untersucht. Forskolin stimulierte die cAMP-Bildung in hEP4 wt-R oder hEP4 ST335-484A-R exprimierenden Zellen mit der gleichen Kinetik wie 
$\mathrm{PGE}_{2}$, wobei ein Maximum ebenfalls nach 10 min erreicht wurde und der cAMP-Spiegel über weitere 20 min konstant blieb (Abb 29). Dies ließ vermuten, daß es unabhängig vom Rezeptor zu einer Desensitisierung der Adenylatcyclase, verursacht durch den hohen intrazellulären cAMP-Spiegel kam. Denkbar wäre auch, daß sich ein Gleichgewicht zwischen cAMP-Bildung und CAMP-Abbau nach ca. $10 \mathrm{~min}$ einstellte, bei dem, trotz des Phosphodiesteraseinhibitors IBMX, ein weiterer CAMP-Anstieg durch eine erhöhte Abbaurate kompensiert wurde.

In HEK293-Zellen wird in geringem Maße endogen der ebenfalls $\mathrm{G}_{\mathrm{s}}$-gekoppelte EP2Rezeptor exprimiert. Um eine mögliche Aktivierung dieses Rezeptors zu vermeiden, wodurch die Desensitisierung des EP4 wt-R überlagert werden könnte, wurde eine Kinetik der cAMPBildung in hEP4 wt-R oder hEP4 ST335-484A-R exprimierenden HEK293-Zellen mit dem EP4-Rezeptor-spezifischen, synthetischen Agonisten ONO604 durchgeführt (Abb. 30).

Die resultierende Kinetik entsprach der aus dem Versuch mit $\mathrm{PGE}_{2}$ (Abb. 28), was zeigte, daß der fehlende Nachweis der Desensitisierung des hEP4 wt-R nicht auf eine Aktivierung des intrinsisch in HEK293-Zellen exprimierten EP2-R zurückzuführen war.

Zusammenfassend konnte auch durch die kinetische Erfassung der $\mathrm{PGE}_{2}$-stimulierten cAMP-Bildung in hEP4 wt-R- oder hEP4 ST335-484A-R-exprimierenden Zellen die Agonisten-induzierte Desensitisierung des hEP4 wt-R nicht gezeigt werden.

\subsubsection{Fehlende Rechtsverschiebung der Dosis-Wirkungskurve des hEP4 wt-R}

Da in den Kinetiken die Desensitisierung des hEP4 wt-R nicht nachgewiesen werden konnte, sollte die Desensitisierung anhand einer Rechtsverschiebung der Dosis-Wirkungskurve für die $\mathrm{PGE}_{2}$-induzierte cAMP-Bildung in Membranen $\mathrm{PGE}_{2}$-vorstimulierter Zellen untersucht werden, wie dies für den $\beta 2$-adrenergen Rezeptor gezeigt worden war (Bouvier et al. (1988);

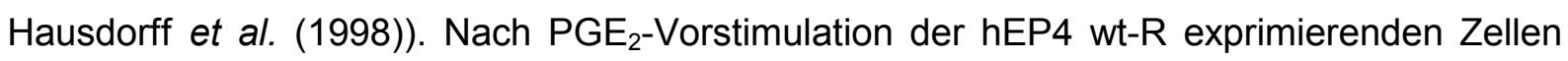
sollte in der Restimulation $\mathrm{PGE}_{2}$ ein gleich großes Signal erst mit höheren Konzentrationen auslösen. Ferner sollten sättigende Agonistenkonzentrationen in Zellen, in denen der Rezeptor desensitisiert ist, eine geringere maximale Signalstärke auslösen. Die Untersuchung der Dosis-Wirkungskurven-Verschiebung wurde in Membranen durchgeführt, um einen Einfluß des während der Vorstimulationsphase aufgebauten hohen intrazellulären cAMP-Spiegels auf die cAMP-Bildung in der zweiten Stimulationsphase auszuschließen. Auch mit diesem experimentellen Ansatz konnte eine Desensitisierung des hEP4 wt-R nicht nachgewiesen werden. Die Dosis-Wirkungskurven für die $\mathrm{PGE}_{2}$-stimulierte cAMP-Bildung waren in Membranen nicht-vorstimulierter und vorstimulierter Zellen nicht signifikant unterschiedlich (Abb. 31). 
Im Gegensatz zu diesem Befund konnten Slipetz et al. (2001) in ganzen Zellen eine Rechtsverschiebung der Dosis-Wirkungskurve für die $\mathrm{PGE}_{2}$-stimulierte cAMP-Bildung in HEK293-Zellen nachweisen, die den EP4-Rezeptors stabil exprimierten, allerdings wählten sie eine 30 minütige Vorstimulation. Bei solch langen Vorstimulationsphasen kann es neben der Rezeptordesensitisierung schon zu einer Internalisierung des Rezeptors kommen und die beobachtete Rechtsverschiebung der Dosis-Wirkungskurve könnte daher die Folge der Internalisierung und nicht der Desensitisierung des Rezeptorproteine sein.

Nishigaki et al. (1996) konnten eine Rechtsverschiebung der Dosis-Wirkungskurve nach $\mathrm{PGE}_{2}$-Vorstimulation in CHO-K1-Zellen, die den hEP4 wt-R exprimierten nicht nachweisen, allerdings fanden sie eine um 20\% reduzierte maximale Aktivierung der Adenylatcyclase nach Vorstimulation mit $\mathrm{PGE}_{2}$. Eine mögliche Erklärung dafür, daß in den $\mathrm{CHO}-\mathrm{K} 1-Z e l l e n$ eine Desensitisierung im Gegensatz zu den jetzt durchgeführten Experimenten nachweisbar war, ist der wahrscheinlich sehr viel niedrigere Expressionsspiegel der Rezeptorproteine. In den Arbeiten von Bastepe und Ashby (1997) und Castleberry et al. (2001) wurden Zellklone untersucht, in denen sättigende Kontentrationen $\mathrm{PGE}_{2}$ den cAMP-Spiegel ca. 2-fach über basal steigerten. In den in dieser Arbeit untersuchten Zellinien hob $\mathrm{PGE}_{2}$ dagegen den cAMP-Spiegel ca. 15-20-fach über basal.

Wahrscheinlich ist durch die sehr hohe Konzentration der Rezeptorproteine in der hier untersuchten HEK293-Zellinie die Desensitisierung des FLAG-hEP4 wt-Rezeptors nicht nachweisbar, da selbst bei einer Entkopplung eines großen Teils der vorhandenen Rezeptoren die Anzahl der verbleibenden, noch aktivierbaren Rezeptoren zur vollständigen Aktivierung der nachgeschalteten Signalkaskade ausreicht. Ein Unterschied zwischen dem hEP4 wt-R und dem mutmaßlich nicht mehr desensitisierbaren hEP4 ST335-484A-R konnte daher nicht nachgewiesen werden.

\subsection{Internalisierung und $\beta$-Arrestin-Rekrutierung des FLAG-hEP4 wt-Rezeptors und der verschiedenen mutierten Rezeptoren}

Zu Beginn dieser Arbeit lagen noch keine Daten über die Internalisierung des hEP4Rezeptors vor.

Desai et al. (2000) zeigten als erstes die Agonisten-induzierte Internalisierung des EP4-R. Ein ab Aminosäure 350 trunkierter EP4-Rezeptor wurde nach Agonisten-Stimulation nicht mehr internalisiert, was einen ersten Hinweis auf die Beteiligung der C-terminalen Domäne bei der Internalisierung gab. Eine weitere von innen untersuchte Rezeptormutante, in der die Serine und Threonine zwischen Aminosäure 354 und 382 durch Alanine substituiert waren, und ein ab Aminosäure 383 trunkierter Rezeptor internalisierten allerdings noch ähnlich wie der Wildtyprezeptor. Die Agonisten-abhängige Internalisierung des EP4-R wurde von Slipetz 
et al. (2001) bestätigt. Sie zeigten weiterhin anhand von zwei Deletionsmutanten, daß der Verlust großer Teile der dritten intrazellulären Schleife keinen Einfluß auf die Internalisierung hatte, während die Deletion der C-terminalen Domäne ab Aminosäure 355 zu einem Verlust der Internalisierung führte. Diese Ergebnisse bestätigten die Lokalisation der für die Internalisierung relevanten Elemente in der C-terminalen Domäne des EP4-R. Weiterhin wurde die Beteiligung von $\beta$-Arrestin und Dynamin an der Internalisierung des EP4-R durch Co-Expression mit dominant-negativem $\beta$-Arrestin (319-418), das konstitutiv an Clathrin bindet, und dominant-negativem Dynamin I (K44A), das GTP nicht mehr binden kann, gezeigt (Desai et al. (2001)). Die Co-Expression beider Proteine mit dem EP4-R hemmte die Agonisten-induzierte Internalisierung.

\subsubsection{Internalisierung der verschiedenen FLAG-hEP4-Rezeptoren}

Die Internalisierung des hEP4 wt-R wurde in dieser Arbeit durch drei experimentelle Ansätze untersucht: Die Reduktion der an der Zelloberfläche durch das FLAG-Epitop nachweisbaren Rezeptorproteine wurde im Cyto-ELISA nachgewiesen (Abb. 32), die Umverteilung der Rezeptorproteine von der Plasmamembran in ein intrazelluläres Kompartiment durch Immunfluoreszenz-Mikroskopie gezeigt (Abb. 36) und die Cointernalisierung des radioaktiv markierten Liganden mit dem Rezeptor quantifiziert (Abb. 34). In allen drei Verfahren konnte nachgewiesen werden, daß der Wildtyprezeptor Agonisten-abhängig internalisiert wurde, während keine Agonisten-induzierte Internalisierung der Mutante nachweisbar war, in der alle Serine und Threonine in der C-terminalen Domäne gegen Alanin substituiert waren. Offensichtlich war das Vorhandensein der Serine und Threonine für die Agonisten-induzierte Internalisierung notwendig.

Die Lokalisation der für die Internalisierung relevanten Serine und Threonine konnte anhand der Messung des mit den unterschiedlichen Rezeptormutanten internalisierten Liganden auf den Bereich zwischen Aminosäure 389-484 eingegrenzt werden (Abb. 35), da nur die Mutanten, in denen diese Serine und Threonine erhalten waren in diesem Assay im gleichen Umfang wie der Wildtyprezeptor Agonisten-abhängig internalisiert wurden, jedoch nicht die Mutanten, denen diese Serine und Threonine fehlten (Abb. 35).

Die Daten des Cyto-ELISAs unterstrichen die Notwendigkeit des Vorhandenseins der Serine und Threonine im distalen Teil der C-terminalen Domäne des hEP4-R ab dem Serin 428 für die Agonisten-induzierte Internalisierung. Die Mutante, der nur diese Serine und Threonine fehlten, wurde nicht mehr Agonisten-abhängig internalisiert. Im Gegensatz zum LigandInternalisierungsassay, der den Schluß nahelegte, daß auch noch die Serine und Threonine zwischen 389 und 405 für die Agonisten-induzierte Internalisierung essentiell waren, deutete der Cyto-ELISA darauf hin, daß dieser Cluster nicht essentiell war, da die Mutante, in der diese Serine und Threonine erhalten war (hEP4 ST335-382A-R) nicht besser internalisiert 
wurde als die Mutante, der diese Serine und Threonine fehlten (hEP4-ST335-405A-R). Beide Mutanten wurden im gleichen Umfang wie der Wildtyp-Rezeptor internalisiert.

Die Unterschiede in der durch Cyto-ELISA und Ligand-Internalisierung nachgewiesenen Rezeptorinternalisierungen könnten unter Umständen darauf zurückzuführen sein, daß der Cyto-ELISA nur die zu einem bestimmten Zeitpunkt an der Oberfläche zugänglichen Epitope erfaßt, während die Internalisierung des an den Rezeptor gebunden Liganden den gesamten über einen längeren Zeitraum in die Zelle aufgenommenen Liganden erfaßt. Die Menge des internalisierten Liganden könnte die Menge an internalisiertem Rezeptor übersteigen, wenn man annimmt, daß im Beobachtungszeitraum Rezeptorproteine an die Zelloberfläche rezirkulieren und neuen Liganden binden und internalisieren können, während der Ligand intrazellulär verbleibt.

Die Ergebnisse der Immunfluoreszenz-mikroskopischen Untersuchung zur Internalisierung sind eher mit denen des Ligand-Internalisierungsassays vereinbar, da nur bei solchen Rezeptormutanten eine Internalisierung morphologisch eindeutig nachweisbar war, bei denen alle Serine und Threonine ab Serin 389 erhalten waren. Die Mutante, der zusätzlich zu den Serinen und Threoninen bis Serin 382 auch die Serine und Threonine 389-405 fehlten, wurde nicht mehr internalisiert, allerdings war eine Agonisten-abhängige Clusterung der Rezeptorproteine an oder unmittelbar unterhalb der Plasmamembran nachweisbar. Zusammengenommen sprechen die Versuche eher dafür, daß die Serine und Threonine ab 389 bis 484 für die Agonisten-induzierte Internalisierung essentiell sind.

Für den Neurotensin 1-, Oxyticin- und Angiotensin II Typ 1A-Rezeptor wurde gezeigt (Oakley et al. (2001)), daß für die Agonisten-induzierte Internalisierung Cluster von Serinen und Threoninen notwendig sind, um nach Agonisten-Exposition einen stabilen Komplex von $\beta$-Arrestin und Rezeptor zu bilden. Innerhalb des Bereichs der C-terminalen Domäne des hEP4-R, der für die Internalisierung relevant war, befinden sich drei Serin/Threonin-Cluster (ST389-392, ST428-431 und ST439-443), die für die Ausbildung eines solchen, möglicherweise für die Internalisierung relevanten, stabilen $\beta$-Arrestin-Rezeptor-Komplexes dienen könnten. Die vorliegenden Ergebnisse erlauben nicht zu unterschieden, welchem dieser drei Cluster eine besondere Bedeutung für die Agonisten-induzierte Internalisierung des hEP4-R zukommt.

Dagegen war die Agonisten-induzierte Internalisierung des Substanz P-Rezeptors im Gegensatz zum Neurotensin 1-, Oxytocin- und Angiotensin II Typ 1A-Rezeptor unabhängig von solchen Ser/Thr-Clustern (Oakley et al. (2001)). Eine solche, von solchen Ser/ThrClustern unabhängige Internalisierung ist für den hEP4-R unwahrscheinlich, da die EP4Rezeptormutante, in der alle Serine und Threonine in der C-terminalen Domäne durch Alanine ersetzt waren, nicht mehr internalisiert wurde. 
Die stark verminderte, residuale, nur im Ligand-Interalisierungsassay nachweisbare Internalisierung der Mutante, in der alle distalen Serine und Threonine gegen Alanine getauscht waren, könnte dafür sprechen, daß die im proximalen Teil der C-terminalen Domäne gelegenen Phosphorylierungsstellen allein eine Agonisten-induzierte Internalisierung auslösen könnten, die durch die distal gelegenen Strukturen weiter reguliert wird. Die Trunkierung würde eine solche komplexe Regulierung zerstören.

In Übereinstimmung mit den hier erhobenen Daten fanden Desai et al. (2000), daß die Substitution der Serine und Threonine proximal des Serin 389 mit Alanin nicht mit der Agonisten-induzierten Internalisierung interferierte. Im extremen Widerspruch zu den hier gefunden Ergebnissen steht aber, daß bei ihren Untersuchungen ein Rezeptor, der distal der Aminosäure 383 trunkiert war, genau so gut internalisierte wie der Wildtyprezeptor. Erst wenn die Trunkierung weiter proximal erfolgte, war die Internalisierung gestört. Eine Bedeutung distal der Aminosäure 383 gelegener Strukturen in der C-terminalen Domäne des hEP4-R für die Internalisierung schien damit ausgeschlossen.

Der Unterschied ist möglicherweise auch auf zelluläre Unterschiede zurückzuführen. So zeigten Zhang et al. (1996), daß die Internalisierung des $\beta 2$-adrenergen Rezeptors in COS 7Zellen wesentlich schwächer war als in HEK293-Zellen, wohingegen sich die Internalisierung des Angiotensin 1A-Rezeptors in den beiden Zellinien nicht unterschied. Dies läßt vermuten, daß wahrscheinlich schon geringe Expressionsunterschiede in den verwendeten Zellinien ausreichten, um divergierenden Ergebnisse zu erhalten.

\subsubsection{Untersuchung der Rezeptor/ $\beta$-Arrestin-Colokalisation der verschiedenen Rezeptorproteine durch Immunfluoreszenz-Mikroskopie}

Durch Immunfluoreszenz-mikroskopische Untersuchung in den transient mit $\beta$-Arrestin/GFPcotransfizierten Rezeptor exprimierenden HEK293-Zellen wurde gezeigt, daß $\beta$-Arrestin nach Agonisten-Stimulation von dem EP4 wt-R rekrutiert und internalisiert wurde. Rezeptorprotein und $\beta$-Arrestin waren nach Agonisten-Exposition intrazellulär colokalisiert. Dies legte nahe, daß eine Interaktion von $\beta$-Arrestin mit dem Rezeptor für die Internalisierung des hEP4-R notwendig ist. Die Rezeptormutante, in der alle Serine und Threonine in der C-terminalen Domäne durch Alanine substituiert waren, rekrutierte $\beta$-Arrestin nicht mehr an die Plasmamembran, daher ist eine Phosphorylierung des Rezeptors für die $\beta$-ArrestinRekrutierung wahrscheinlich notwendig. $\beta$-Arrestin wurde nach Agonisten-Exposition, wenn auch nur in geringerem Umfang als bei dem Wildtyprezeptor, von der Mutante rekrutiert, in der alle proximalen Serine und Threonine bis einschließlich Serin 382 durch Alanine ersetzt waren und der damit die mutmaßliche Hauptphosphorylierungsstelle im Rezeptor fehlte. Dies 
legte nahe, daß die für die zur Internalisierung notwendige stabile Rezeptor- $\beta$-ArrestinInteraktion relevanten Serine und Threonine distal von Serin 382 lokalisiert waren.

Durch Inkubation der den hEP4-R-exprimierenden Zellen mit einer hyperosmolaren Saccharosekonzentration wurde die $\beta$-Arrestin-Rekrutierung nicht beeinflußt, jedoch war die Clathrin-vermittelte Internalisierung gehemmt. Die durch Saccharose inhibierbare Internalisierung des EP4-R wurde auch von Desai et al. (2001) beschrieben. Die Hemmung der Agonisten-induzierten Internalisierung durch eine hyperosmolare Saccharosekonzentration (Abb. 33, Abb. 35, Abb. 41 Abb. 43) bestätigte die Clathrin-vermittelte Internalisierung der verschiedenen noch internalisierenden Rezeptoren, da durch eine hyperosmolare Saccharosekonzentration nur die Clathrin-vermittelte Internalisierung gehemmt wird (Heuser und Anderson (1989); Okamoto et al. (2000)).

Die durch die Phosphorylierungsstudien erhaltenen Ergebnisse zeigten die Hauptphosphorylierung des EP4-Rezeptors im proximalen Teil der C-terminalen Domäne zwischen Aminosäure 359 und 382, während die für die Internalisierung relevanten Serine und Threonine zwischen Aminosäure 389 und 484 lokalisiert waren. Dies könnte darauf hindeuten, daß zwei unterschiedliche Motive für die Phosphorylierung und Internalisierung des EP4-R notwendig sind. Allerdings war auch eine geringe Phosphorylierung nach Elimination der Serine und Threonin im proximalen Teil der C-terminalen Domäne feststellbar, was darauf hindeuten könnnte, daß die Phosphorylierung im proximalen Teil für die Entkopplung des Rezeptors von der intrazellulären Signalkette verantwortlich ist und die geringe Phosphorylierung im distalen Teil der C-terminalen Domäne an der Agonisteninduzierten Internalisierung beteiligt ist. Eine eindeutige Aussage über die Beteiligung der proximalen Phosphorylierungsstellen an der Desensitisierung ist anhand der in dieser Arbeit erhobenen Daten nicht möglich, da die Desensitisierung des Rezeptors in dem gewählten System nicht nachweisbar war. Allerdings wird diese Vermutung durch die Ergebnisse von Bastepe et al. (1999) unterstützt, die den Verlust der Desensitisierung nach Substitution der Serine und Threonine zwischen Aminosäure 369 und 382 in CHO-Zellen zeigen konnten.

Eine Beteiligung von Phosphorylierungsstellen an der Internalisierung in den intrazellulären Schleifen, wie sie für den M2-muscarinischen Acetylcholin-Rezeptor (Hosey et al. (1999)) gezeigt wurde, ist jedoch auszuschließen, da die Rezeptormutante, in der alle Serine und Threonine eliminiert waren, nicht mehr internalisierte. Weiterhin scheint die Phosphorylierung für die Internalisierung notwendig, da eine $\beta$-Arrestin und GRK-unabhängige Internalisierung, wie die des IP-Rezeptors (Smyth et al. 2000) nicht gezeigt werden konnte. 


\subsection{Schlußfolgerung}

Für die, wahrscheinlich GRK-vermittelte, Agonisten-induzierte Phosphorylierung sind die Serine und Threonine zwischen Serin 359 und Serin 382 in der C-terminalen Domäne des hEP4-R notwendig. Die Relevanz dieser Serine und Threonine für die Agonisten-induzierte Desensitisierung des hEP4-R konnte jedoch in dem gewählten System nicht nachgewiesen werden. Die für die Agonisten-induzierte Internalisierung des hEP4-R relevanten Serine und Threonine sind mit den für die Phosphorylierung und möglicherweise Desensitisierung notwendigen nicht identisch und sind distal des Serin 382 lokalisiert, wobei eine der Internalisierung vorausgehende Phosphorylierung der Rezeptoren an diesen Positionen nicht ausgeschlossen werden kann. Der hEP4-R wird im Komplex mit $\beta$-Arrestin internalisiert, jedoch scheinen die im distalen Teil der C-terminalen Domäne gelegenen Serine und Threonine möglicherweise eine $\beta$-Arrestin-unabhängige Clathrin-vermittelte Internalisierung zu ermöglichen. Die im proximalen Teil der C-terminalen Domäne lokalisierten Serine und Threonine des hEP4-R sind also wahrscheinlich für die Entkopplung des Rezeptors verantwortlich, während die im distalen Bereich lokalisierten Serine und Threonine für die Internalisierung relevant sind. 


\section{Literatur}

Abramovitz M, Adam M, Boie Y, Grygorczyk R, Rushmore TH, Nguyen T, Funk CD, Bastien L, Sawyer N, Rochette C et al. (1995): Human prostanoid receptors: cloning and characterization. Adv Prostaglandin Thromboxane Leukot Res 23: 499-504

Ahn S, Kim J, Lucaveche CL, Reedy MC, Luttrell LM, Lefkowitz RJ, Daaka Y (2002): Src-dependent tyrosine phosphorylation regulates dynamin self-assembly and ligandinduced endocytosis of the epidermal growth factor receptor. J Biol Chem 277: 2664226651

Armstrong RA, Lawrence RA, Jones RL, Wilson NH, Collier A (1989): Functional and ligand binding studies suggest heterogeneity of platelet prostacyclin receptors. $\mathrm{Br} \mathrm{J}$ Pharmacol 97: 657-668

Audoly L und Breyer RM (1997a): Substitution of charged amino acid residues in transmembrane regions 6 and 7 affect ligand binding and signal transduction of the prostaglandin EP3 receptor. Mol Pharmacol 51: 61-68

Audoly L und Breyer RM (1997b): The second extracellular loop of the prostaglandin EP3 receptor is an essential determinant of ligand selectivity. J Biol Chem 272: 13475-13478

Bastepe M und Ashby B (1997): The long cytoplasmic carboxyl terminus of the prostaglandin E2 receptor EP4 subtype is essential for agonist-induced desensitization. Mol Pharmacol 51: 343-349

Bastepe M und Ashby B (1999): Identification of a region of the C-terminal domain involved in short-term desensitization of the prostaglandin EP4 receptor. Br J Pharmacol 126: 365371

Baxter GS, Clayton JK, Coleman RA, Marshall K, Sangha R, Senior J (1995): Characterization of the prostanoid receptors mediating constriction and relaxation of human isolated uterine artery. Br J Pharmacol 116: 1692-1696

Belley A und Chadee K (1999): Prostaglandin E(2) stimulates rat and human colonic mucin exocytosis via the EP(4) receptor. Gastroenterology 117: 1352-1362

Bennett TA, Maestas DC, Prossnitz ER (2000): Arrestin binding to the G protein-coupled $\mathrm{N}$-formyl peptide receptor is regulated by the conserved "DRY" sequence. J Biol Chem 275: 24590-24594

Benya RV, Fathi Z, Battey JF, Jensen RT (1993): Serines and threonines in the gastrinreleasing peptide receptor carboxyl terminus mediate internalization. J Biol Chem 268: 20285-90

Boege F, Neumann E, Helmreich EJ (1991): Structural heterogeneity of membrane receptors and GTP-binding proteins and its functional consequences for signal transduction. Eur J Biochem 199: 1-15

Böer U, Neuschäfer-Rube F, Möller U, Püschel GP (2000): Requirement of Nglycosylation of the prostaglandin E2 receptor EP3beta for correct sorting to the plasma membrane but not for correct folding. Biochem J 350: 839-847

Böhm SK, Grady EF, Bunnett NW (1997): Regulatory mechanisms that modulate signalling by G-protein-coupled receptors. Biochem J 322: 1-18

Bouvier M, Hausdorff WP, De Blasi A, O'Dowd BF, Kobilka BK, Caron MG, Lefkowitz RJ (1988): Removal of phosphorylation sites from the beta 2-adrenergic receptor delays onset of agonist-promoted desensitization. Nature 333: 370-3 
Bouvier M, Loisel TP, Hebert T (1995): Dynamic regulation of G-protein coupled receptor palmitoylation: potential role in receptor function. Biochem Soc Trans 23: 577-581

Bradford MM (1976): A rapid and sensitive method for the quantitation of microgram quantities of protein utilizing the principle of protein-dye binding. Anal Biochem 72: 248254

Breyer MD und Breyer RM (2000): Prostaglandin receptors: their role in regulating renal function. Curr Opin Nephrol Hypertens 9: 23-29

Breyer RM, Bagdassarian CK, Myers SA, Breyer MD (2001): Prostanoid receptors: subtypes and signaling. Annu Rev Pharmacol Toxicol 41: 661-90

Celver JP, Lowe J, Kovoor A, Gurevich VV, Chavkin C (2001): Threonine 180 is required for G-protein-coupled receptor kinase 3- and beta-arrestin 2-mediated desensitization of the mu-opioid receptor in Xenopus oocytes. J Biol Chem 2001 276: 4894-900

Chan BS, Satriano JA, Pucci M, Schuster VL (1998): Mechanism of prostaglandin E2 transport across the plasma membrane of HeLa cells and Xenopus oocytes expressing the prostaglandin transporter "PGT". J Biol Chem 273: 6689-6697

Chang CS, Negishi M, Nishigaki N, Ichikawa A (1997): Characterization of functional interaction of carboxylic acid group of agonists and arginine of the seventh transmembrane domains of four prostaglandin E receptor subtypes. Prostaglandins 54: 437-446

Chen C und Okayama H (1987): High-efficiency transformation of mammalian cells by plasmid DNA. Mol Cell Biol 7: 2745-2752

Chiang N, Kan WM, Tai HH (1996): Site-directed mutagenesis of cysteinyl and serine residues of human thromboxane A2 receptor in insect cells. Arch Biochem Biophys 334: 9-17

Chiang $\mathbf{N}$ und Tai HH (1998): The role of $\mathrm{N}$-glycosylation of human thromboxane A2 receptor in ligand binding. Arch Biochem Biophys 352: 207-213

Claing A, Laporte SA, Caron MG, Lefkowitz RJ (2002): Endocytosis of G protein-coupled receptors: roles of $G$ protein-coupled receptor kinases and beta-arrestin proteins. Prog Neurobiol 66: 61-79

Clark JD, Lin LL, Kriz RW, Ramesha CS, Sultzman LA, Lin AY, Milona N, Knopf JL (1991): A novel arachidonic acid-selective cytosolic PLA2 contains a $\mathrm{Ca}(2+)$-dependent translocation domain with homology to PKC and GAP. Cell 65: 1043-1051

Coleman RA und Sheldrick RL (1989): Prostanoid-induced contraction of human bronchial smooth muscle is mediated by TP-receptors. Br J Pharmacol 96: 688-692

Coleman RA, Smith WL, Narumiya S (1994): International Union of Pharmacology classification of prostanoid receptors: properties, distribution, and structure of the receptors and their subtypes. Pharmacol Rev 46: 205-29

Csepli J und Csapo Al (1975): The effect of the prostaglandin F2alpha analogue ICI 81008 on uterine small arteries and on blood pressure. Prostaglandins 10: 689-697

D'Angelo DD, Eubank JJ, Davis MG, Dorn GW 2nd. (1996): Mutagenic analysis of platelet thromboxane receptor cysteines. Roles in ligand binding and receptor-effector coupling. J Biol Chem 271: 6233-6240

Desai S, April H, Nwaneshiudu C, Ashby B (2000): Comparison of agonist-induced internalization of the human EP2 and EP4 prostaglandin receptors: role of the carboxyl terminus in EP4 receptor sequestration. Mol Pharmacol 58: 1279-1286 
Desai S, Ashby B (2001): Agonist-induced internalization and mitogen-activated protein kinase activation of the human prostaglandin EP4 receptor. FEBS Lett 501: 156-160

Djellas Y, Manganello JM, Antonakis K, Le Breton GC (1999): Identification of Galpha13 as one of the G-proteins that couple to human platelet thromboxane A2 receptors. J Biol Chem 274: 14325-30

Dohlman HG, Thorner J, Caron MG, Lefkowitz RJ (1991): Model systems for the study of seven-transmembrane-segment receptors. Annu Rev Biochem 60: 653-688

Dorn GW 2nd, Davis MG, D'Angelo DD (1997): Structural determinants for agonist binding affinity to thromboxane/prostaglandin endoperoxide (TP) receptors, Analysis of chimeric rat/human TP receptors. J Biol Chem 272: 12399-12405

Eccleston JF, Binns DD, Davis CT, Albanesi JP, Jameson DM (2002): Oligomerization and kinetic mechanism of the dynamin GTPase. Eur Biophys J 31: 275-282

Eshet R, Peleg S, Laron Z (1984): Direct visualization of binding, aggregation and internalization of human growth hormone in cultured human lymphocytes. Acta Endocrinol 107: 9-15

Fan GH, Yang W, Wang XJ, Qian Q, Richmond A (2001): Identification of a motif in the carboxyl terminus of CXCR2 that is involved in adaptin 2 binding and receptor internalization. Biochemistry 40: 791-800

Fennekohl A, Lucas M, Püschel GP (2000): Induction by interleukin-6 of Gs-coupled prostaglandin E2 receptors in rat hepatocytes mediating a prostaglandin E2-dependent inhibition of the hepatocyte's acute phase response. Hepatology 31: 1128-1134

Ferguson SS (2001): Evolving concepts in G protein-coupled receptor endocytosis: the role in receptor desensitization and signaling. Pharmacol Rev 53: 1-24

Freedman NJ, Liggett SB, Drachman DE, Pei G, Caron MG, Lefkowitz RJ (1995): Phosphorylation and desensitization of the human beta 1-adrenergic receptor. Involvement of $\mathrm{G}$ protein-coupled receptor kinases and cAMP-dependent protein kinase. J Biol Chem 270: 17953-61

Freedman NJ, Ament AS, Oppermann M, Stoffel RH, Exum ST, Lefkowitz RJ (1997): Phosphorylation and desensitization of human endothelin A and B receptors. Evidence for G protein-coupled receptor kinase specificity. J Biol Chem 272: 17734-43

Funk CD, Furci L, Moran N, Fitzgerald GA (1993): Point mutation in the seventh hydrophobic domain of the human thromboxane A2 receptor allows discrimination between agonist and antagonist binding sites. Mol Pharmacol 44: 934-939

Gabilondo AM, Hegler J, Krasel C, Boivin-Jahns V, Hein L, Lohse MJ (1997): A dileucine motif in the $\mathrm{C}$ terminus of the beta2-adrenergic receptor is involved in receptor internalization. Proc Natl Acad Sci USA 94: 12285-12290

Gallusser A, Kirchhausen T. (1993): The beta 1 and beta 2 subunits of the AP complexes are the clathrin coat assembly components. EMBO J 12: 5237-5244

Giannini E, Brouchon L, Boulay F (1995): Identification of the major phosphorylation sites in human C5a anaphylatoxin receptor in vivo. J Biol Chem 270: 19166-72

Giles H, Bolofo ML, Lydford SJ, Martin GR (1991): A comparative study of the prostanoid receptor profile of 9 alpha 11 beta-prostaglandin $\mathrm{F} 2$ and prostaglandin $\mathrm{D} 2$. Br J Pharmacol 104: $541-549$

Gilbert JA, Strobel TR, Richelson E (1988): Desensitization of neurotensin receptormediated cyclic GMP formation in neuroblastoma clone N1E-115. Biochem Pharmacol 37: 2833-3838 
Grabs D, Slepnev VI, Songyang Z, David C, Lynch M, Cantley LC, De Camilli P (1997): The $\mathrm{SH} 3$ domain of amphiphysin binds the proline-rich domain of dynamin at a single site that defines a new SH3 binding consensus sequence. J Biol Chem 272: 13419-13425

Harden TK, Su YF, Perkins JP (1979): Catecholamine-induced desensitization involves an uncoupling of beta-adrenergic receptors and adenylate cyclase. J Cyclic Nucleotide Res 5: $99-106$

Hausdorff WP, Bouvier M, O'Dowd BF, Irons GP, Caron MG, Lefkowitz RJ (1989): Phosphorylation sites on two domains of the beta 2-adrenergic receptor are involved in distinct pathways of receptor desensitization. J Biol Chem 264: 12657-65

Hasegawa H, Negishi M, Ichikawa A (1996): Two isoforms of the prostaglandin E receptor EP3 subtype different in agonist-independent constitutive activity. J Biol Chem 271: 18571860

Hasegawa H, Negishi M, Katoh H, Ichikawa A (1997): Two isoforms of prostaglandin EP3 receptor exhibiting constitutive activity and agonist-dependent activity in Rho-mediated stress fiber formation. Biochem Biophys Res Commun 234: 631-636

Hatae T, Wada M, Yokoyama C, Shimonishi M, Tanabe T (2001): Prostacyclin-dependent apoptosis mediated by PPAR delta. J Biol Chem 276: 46260-46267

Hayaishi O (1991): Molecular mechanisms of sleep-wake regulation: roles of prostaglandins D2 and E2. FASEB J 5: 2575-81

Hayes JS, Lawler OA, Walsh MT, Kinsella BT (1999): The prostacyclin receptor is isoprenylated. Isoprenylation is required for efficient receptor-effector coupling. J Biol Chem 274: 23707-23718

Heuser JE, Anderson RG (1989): Hypertonic media inhibit receptor-mediated endocytosis by blocking clathrin-coated pit formation. J Cell Biol 108: 389-400

Hille A, Klumperman J, Geuze HJ, Peters C, Brodsky FM, von Figura K (1992): Lysosomal acid phosphatase is internalized via clathrin-coated pits. Eur J Cell Biol 59: 106-115

Hinshaw JE und Schmid SL (1995): Dynamin self-assembles into rings suggesting a mechanism for coated vesicle budding. Nature 374: 190-192

Hirata Y, Umemura K, Nakano M, Uematsu T, Nakashima M (1994): Enhancement of thrombotic arterial occlusion following cholesterol feeding in the guinea-pig: a role for thromboxane A2. Prostaglandins Leukot Essent Fatty Acids 51: 81-86

Ho SN, Hunt HD, Horton RM, Pullen JK, Pease LR (1989): Site-directed mutagenesis by overlap extension using the polymerase chain reaction. Gene 77: 51-59

Hosey MM, Pals-Rylaarsdam R, Lee KB, Roseberry AG, Benovic JL, Gurevich VV, Bunemann M (1999): Molecular events associated with the regulation of signaling by M2 muscarinic receptors. Life Sci 64: 363-8

Huang C und Tai HH (1995): Expression and site-directed mutagenesis of mouse prostaglandin E2 receptor EP3 subtype in insect cells. Biochem J 307: 493-498

Huang C und Tai HH (1996): Ser-268 plays an important role in ligand binding of prostaglandin E2 receptor EP3alpha subtype. Arch Biochem Biophys 327: 161-166

Hüttenrauch F, Nitzki A, Lin FT, Honing S, Oppermann M (2002): Beta-arrestin binding to CC chemokine receptor 5 requires multiple C-terminal receptor phosphorylation sites and involves a conserved Asp-Arg-Tyr sequence motif. J Biol Chem 277: 30769-30777 
Irie A, Sugimoto Y, Namba T, Asano T, Ichikawa A, Negishi M (1994): The C-terminus of the prostaglandin-E-receptor EP3 subtype is essential for activation of GTP-binding protein. Eur J Biochem 224: 161-166

Ishii K, Chen J, Ishii M, Koch WJ, Freedman NJ, Lefkowitz RJ, Coughlin SR (1994): Inhibition of thrombin receptor signaling by a G-protein coupled receptor kinase. Functional specificity among G-protein coupled receptor kinases. J Biol Chem 269: 112530

Itoh S, Lu R, Bao Y, Morrow JD, Roberts LJ, Schuster VL (1996): Structural determinants of substrates for the prostaglandin transporter PGT. Mol Pharmacol 50: 738-742

Jin J, Mao GF, Ashby B (1997): Constitutive activity of human prostaglandin E receptor EP3 isoforms. Br J Pharmacol 121: 317-323

Kanai N, Lu R, Satriano JA, Bao Y, Wolkoff AW, Schuster VL (1995): Identification and characterization of a prostaglandin transporter. Science 268: 866-869

Katoh H, Negishi M, Ichikawa A (1996): Prostaglandin E receptor EP3 subtype induces neurite retraction via small GTPase Rho. J Biol Chem 271: 29780-29784

Kedzie KM, Donello JE, Krauss HA, Regan JW, Gil DW (1998): A single amino-acid substitution in the EP2 prostaglandin receptor confers responsiveness to prostacyclin analogs. Mol Pharmacol 54: 584-590

Kempson SA, Helmle C, Abraham MI, Murer H (1990): Parathyroid hormone action on phosphate transport is inhibited by high osmolality. Am J Physiol 258: 1336-1344

Kitanaka J, Hamano T, Gotoh M, Hashimoto H, Baba A (1994): Tunicamycin inhibits prostaglandin F2 alpha receptor-mediated phosphoinositide hydrolysis in cultured rat astrocytes. Neurochem Res 19: 1545-1550

Kobayashi T, Kiriyama M, Hirata T, Hirata M, Ushikubi F, Narumiya S (1997): Identification of domains conferring ligand binding specificity to the prostanoid receptor. Studies on chimeric prostacyclin/prostaglandin D receptors. J Biol Chem 272: 1515415160

Kraft K, Olbrich H, Majoul I, Mack M, Proudfoot A, Oppermann M (2001): Characterization of sequence determinants within the carboxyl-terminal domain of chemokine receptor CCR5 that regulate signaling and receptor internalization. J Biol Chem 276: 34408-34418

Krupnick JG und Benovic JL (1998): The role of receptor kinases and arrestins in G protein-coupled receptor regulation. Annu Rev Pharmacol Toxicol 38: 289-319

Laemmli UK (1970): Cleavage of structural proteins during assembly of the Head of Bacteriophage T4. Nature 227: 680-685

Laporte SA, Oakley RH, Zhang J, Holt JA, Ferguson SS, Caron MG, Barak LS (1999): The beta2-adrenergic receptor/betaarrestin complex recruits the clathrin adaptor AP-2 during endocytosis. Proc Natl Acad Sci USA 96: 3712-3717

Laporte SA, Miller WE, Kim KM, Caron MG (2002): beta-Arrestin/AP-2 interaction in G protein-coupled receptor internalization: identification of a beta-arrestin binging site in beta 2-adaptin. J Biol Chem 277: 9247-9254

Laporte SA, Miller WE, Kim KM, Caron MG (2002): $\beta$-arrestin/AP-2 interaction in G proteincoupled receptor internalization: identification of a $\beta$-arrestin binding site in $\beta_{2}$-adaptin. $J$ Biol Chem 277: 9247-9254

Lefkowitz RJ (1993): G protein-coupled receptor kinases. Cell 74: 409-412 
Lin HC und Gilman AG (1996): Regulation of dynamin I GTPase activity by G protein betagamma subunits and phosphatidylinositol 4,5-bisphosphate. J Biol Chem 271: 2797927982

Lin FT, Miller WE, Luttrell LM, Lefkowitz RJ (1999): Feedback regulation of beta-arrestin1 function by extracellular signal-regulated kinases. J Biol Chem 274: 15971-15974

Lohse MJ, Andexinger S, Pitcher J, Trukawinski S, Codina J, Faure JP, Caron MG, Lefkowitz RJ (1992): Receptor-specific desensitization with purified proteins. Kinase dependence and receptor specificity of beta-arrestin and arrestin in the beta 2-adrenergic receptor and rhodopsin systems. J Biol Chem 267: 8558-8564

Lu R, Kanai N, Bao Y, Schuster VL (1996): Cloning, in vitro expression, and tissue distribution of a human prostaglandin transporter cDNA(hPGT). J Clin Invest 98: 11421149

Luttrell LM, Roudabush FL, Choy EW, Miller WE, Field ME, Pierce KL, Lefkowitz RJ (2001): Activation and targeting of extracellular signal-regulated kinases by $\beta$-arrestin scaffolds. Proc Natl Acad Sci USA 98: 2449-2454

Luttrell LM und Lefkowitz RJ (2002): The role of beta-arrestins in the termination and transduction of G-protein-coupled receptor signals. J Cell Sci 115: 455-465

Machwate M, Harada S, Leu CT, Seedor G, Labelle M, Gallant M, Hutchins S, Lachance N, Sawyer N, Slipetz D, Metters KM, Rodan SB, Young R, Rodan GA (2001): Prostaglandin receptor EP(4) mediates the bone anabolic effects of PGE2. Mol Pharmacol 60: $36-41$

Malecz N, Bambino T, Bencsik M, Nissenson RA (1998): Identification of phosphorylation sites in the $\mathrm{G}$ protein-coupled receptor for parathyroid hormone. Receptor phosphorylation is not required for agonist-induced internalization. Mol Endocrinol 12: 1846-56

Morello JP und Bouvier M (1996): Palmitoylation: a post-translational modification that regulates signalling from G-protein coupled receptors. Biochem Cell Biol 74: 449-457

Morita T, Ando M, Kihara K, Kitahara S, Ishizaka K, Matsumura T, Oshima H (1994): Effects of prostaglandins E1, E2 and F2 alpha on contractility and cAMP and cGMP contents in lower urinary tract smooth muscle. Urol Int 52: 200-203

Munson PJ und Rodbard D (1980): Ligand a versatil computerized approach for characterization of ligand-binding systems. Anal Biochem 107: 220-239

Namba T, Sugimoto Y, Negishi M, Irie A, Ushikubi F, Kakizuka A, Ito S, Ichikawa A, Narumiya S (1993): Alternative splicing of C-terminal tail of prostaglandin E receptor subtype EP3 determines G-protein specificity. Nature 365: 166-170

Narumiya S, Hirata N, Namba T, Hayashi Y, Ushikubi F, Sugimoto Y, Negishi M, Ichikawa A (1993): Structure and function of prostanoid receptors. J Lipid Mediat 6: 155161

Narumiya S, Sugimoto Y, Ushikubi F (1999): Prostanoid receptors: structures, properties, and functions. Physiol Rev 79: 1193-1226

Negishi M, Sugimoto Y, Irie A, Narumiya S, Ichikawa A (1993): Two isoforms of prostaglandin E receptor EP3 subtype. Different $\mathrm{COOH}$-terminal domains determine sensitivity to agonist-induced desensitization. J Biol Chem 268: 9517-9521

Negishi M, Sugimoto Y, Ichikawa A (1995): Molecular mechanisms of diverse actions of prostanoid receptors. Biochim Biophys Acta 1259: 109-119 
Neuschäfer-Rube F, Hänecke K, Blaschke V, Jungermann K, Püschel GP (1997a): The C-terminal domain of the Gs-coupled EP4 receptor confers agonist-dependent coupling control to $\mathrm{Gi}$ but no coupling to $\mathrm{Gs}$ in a receptor hybrid with the $\mathrm{Gi}$-coupled EP3 receptor. FEBS Lett 401: 185-190

Neuschäfer-Rube F, Hänecke K, Püschel GP (1997b): The C-terminal domain of the human EP4 receptor confers agonist-induced receptor desensitization in a receptor hybrid with the rat EP3 $\beta$ receptor. FEBS Lett 415: 119-124

Neuschäfer-Rube F, Oppermann M, Möller U, Böer U, Püschel GP (1999): Agonistinduced phosphorylation by $\mathrm{G}$ protein-coupled receptor kinases of the EP4 receptor carboxyl-terminal domain in an EP3/EP4 prostaglandin $E(2)$ receptor hybrid. Mol Pharmacol 56: 419-428

Neuschäfer-Rube F, Engemaier E, Koch S, Böer U, Püschel GP (2003): Identification by site directed mutagenesis of amino acids contributing to ligand binding specificity or signal transduction properties of the human FP prostanoid receptor. Biochem J, [epub ahead of print]

Nishigaki N, Negishi M, Ichikawa A (1996): Two Gs-coupled prostaglandin E receptor subtypes, EP2 and EP4, differ in desensitization and sensitivity to the metabolic inactivation of the agonist Mol Pharmacol 50:1031-1037

Oakley RH, Laporte SA, Holt JA, Barak LS, Caron MG (2001): Molecular determinants underlying the formation of stable intracellular $G$ protein-coupled receptor-beta-arrestin complexes after receptor endocytosis. J Biol Chem 276: 19452-19460

Offermanns S, Laugwitz KL, Spicher K, Schultz G (1994): G proteins of the G12 family are activated via thromboxane $A 2$ and thrombin receptors in human platelets. Proc Natl Acad Sci USA 91: 504-508

Okamoto Y, Ninomiya H, Miwa S, Masaki T (2000): Cholesterol oxidation switches the internalization pathway of endothelin receptor type A from caveolae to clathrin-coated pits in Chinese hamster ovary cells. J Biol Chem 275: 6439-46

Okuma M, Hirata T, Ushikubi F, Kakizuka A, Narumiya S (1996): Molecular characterization of a dominantly inherited bleeding disorder with impaired platelet responses to thromboxane A2. Pol J Pharmacol 48: 77-82

Oppermann M, Freedman NJ, Alexander RW, Lefkowitz RJ (1996): Phosphorylation of the type $1 \mathrm{~A}$ angiotensin II receptor by $\mathrm{G}$ protein-coupled receptor kinases and protein kinase C. J Biol Chem 271: 13266-72

Parnot C, Bardin S, Miserey-Lenkei S, Guedin D, Corvol P, Clauser E. (2000): Systematic identification of mutations that constitutively activate the angiotensin II type $1 \mathrm{~A}$ receptor by screening a randomly mutated cDNA library with an original pharmacological bioassay. Proc Natl Acad Sci USA 97:7615-7620

Parruti G, Peracchia F, Sallese M, Ambrosini G, Masini M, Rotilio D, De Blasi A (1993): Molecular analysis of human beta-arrestin-1: cloning, tissue distribution, and regulation of expression. Identification of two isoforms generated by alternative splicing. J Biol Chem 268: $9753-9761$

Penn RB, Pronin AN, Benovic JL (2000): Regulation of G protein-coupled receptor kinases. Trends Cardiovasc Med 10: 81-89

Peters T, Gaillard T, Decker K (1990): Tumor necrosis factor alpha stimulates prostaglandin but not superoxide synthesis in rat Kupffer cells. Eicosanoids 3: 115-120

Pierce KL und Regan JW (1998): Prostanoid receptor heterogeneity through alternative mRNA splicing. Life Sci 62: 1479-1483 
Pierce KL, Fujino H, Srinivasan D, Regan JW (1999): Activation of FP prostanoid receptor isoforms leads to Rho-mediated changes in cell morphology and in the cell cytoskeleton. $\mathrm{J}$ Biol Chem 274: 35944-35949

Probst WC, Snyder LA, Schuster DI, Brosius J, Sealfon SC (1992): Sequence alignment of the G-protein coupled receptor superfamily. DNA Cell Biol 11: 1-20

Pulakat L, Gray A, Johnson J, KnowleD, Burns V, Gavini N (2002): Role of C-erminal cytoplasmatic domain of the AT2 receptor in ligand binding and signaling. FEBS Lett 524: 73-78

Rasmussen SG, Jensen AD, Liapakis G, Ghanouni P, Javitch JA, Gether U (1999): Mutation of a highly conserved aspartic acid in the beta2 adrenergic receptor: constitutive activation, structural instability, and conformational rearrangement of transmembrane segment 6. Mol Pharmacol 56: 175-184

Reginato MJ, Krakow SL, Bailey ST, Lazar MA (1998): Prostaglandins promote and block adipogenesis through opposing effects on peroxisome proliferator-activated receptor gamma. J Biol Chem 273: 1855-1858

Rehwald M, Neuschäfer-Rube F, de Vries C, Püschel GP (1999): Possible role for ligand binding of histidine 81 in the second transmembrane domain of the rat prostaglandin F2alpha receptor. FEBS Lett 443: 357-62

Samuelsson B (1978): Prostaglandins and thromboxanes. Recent Prog Horm Res 34: 239258

Satoh S, Chang C, Katoh H, Hasegawa H, Nakamura K, Aoki J, Fujita H, Ichikawa A, Negishi M (1999): The key amino acid residue of prostaglandin EP3 receptor for governing $G$ protein association and activation steps. Biochem Biophys Res Commun 255: $164-168$

Schülein R, Hermosilla R, Oksche A, Dehe M, Wiesner B, Krause G, Rosenthal W (1998): A dileucine sequence and an upstream glutamate residue in the intracellular carboxyl terminus of the vasopressin V2 receptor are essential for cell surface transport in COS.M6 cells. Mol Pharmacol 54: 525-35

Segi E, Sugimoto Y, Yamasaki A, Aze Y, Oida H, Nishimura T, Murata T, Matsuoka T, Ushikubi F, Hirose M, Tanaka T, Yoshida N, Narumiya S, Ichikawa A (1998): Patent ductus arteriosus and neonatal death in prostaglandin receptor EP4-deficient mice. Biochem Biophys Res Commun 246: 7-12

Slipetz D, Buchanan S, Mackereth C, Brewer N, Pellow V, Hao C, Adam M, Abramovitz M, Metters KM (2001): Sequestration and phosphorylation of the prostaglandin E2 EP4 receptor: dependence on the C-terminal tail. Biochem Pharmacol 62: 997-1012

Smith WL und Marnett LJ (1991): Prostaglandin endoperoxide synthase: structure and catalysis. Biochim Biophys Acta 1083: 1-17

Smyth EM, Li WH, FitzGerald GA (1998): Phosphorylation of the prostacyclin receptor during homologous desensitization. A critical role for protein kinase C. J Biol Chem 273: 23258-23266

Smyth EM, Austin SC, Reilly MP, FitzGerald GA (2000): Internalization and sequestration of the human prostacyclin receptor. J Biol Chem 275: 32037-32045

Spurney RF (1998): Role of C-terminal serines in desensitization and phosphorylation of the mouse thromboxane receptor. J Biol Chem 273: 28496-28503 
Sterne-Marr R, Gurevich VV, Goldsmith P, Bodine RC, Sanders C, Donoso LA, Benovic JL (1993): Protein Polypeptide variants of $\beta$-arrestin and arrestin3. J Biol Chem 268: 15640-15648

Stillman BA, Audoly L, Breyer RM (1998): A conserved threonine in the second extracellular loop of the human EP2 and EP4 receptors is required for ligand binding. Eur J Pharmacol 357: 73-82

Stillman BA, Breyer MD, Breyer RM (1999): Importance of the extracellular domain for prostaglandin EP(2) receptor function. Mol Pharmacol 56: 545-551

Stoffel RH 3rd, Pitcher JA, Lefkowitz RJ (1997): Targeting G protein-coupled receptor kinases to their receptor substrates. J Membr Bio 157: 1-8

Sugimoto Y, Negishi M, Hayashi Y, Namba T, Honda A, Watabe A, Hirata M, Narumiya S, Ichikawa A (1993): Two isoforms of the EP3 receptor with different carboxyl-terminal domains. Identical ligand binding properties and different coupling properties with $\mathrm{Gi}$ proteins. J Biol Chem 268: 2712-2718

Tai HH, Huang C, Chiang N (1997): Structure and function of prostanoid receptors as revealed by site-directed mutagenesis. Adv Exp Med Biol 407: 205-209

Urade Y und Hayaishi O (1999): Prostaglandin D2 and sleep regulation. Biochim Biophys Acta 1436: 606-15

Walsh MT, Foley JF, Kinsella BT (1998): Characterization of the role of N-linked glycosylation on the cell signaling and expression of the human thromboxane A2 receptor alpha and beta isoforms. J Pharmacol Exp Ther 286: 1026-1036

Warnock DE, Hinshaw JE, Schmid SL (1996): Dynamin self-assembly stimulates its GTPase activity. J Biol Chem 271: 22310-22314

White JG, Amos WB, Fordham M (1987): An evaluation of confocal versus conventional imaging of biological structures by fluorescence light microscopy. J Cell Biol 105: 41-48

Williams SP, Dorn GW 2nd, Rapoport RM (1994): Prostaglandin 12 mediates contraction and relaxation of vascular smooth muscle. Am J Physiol 267: H796-803

Yu Y, Zhang L, Yin X, Sun H, Uhl GR, Wang JB (1997): Mu opioid receptor phosphorylation, desensitization, and ligand efficacy. J Biol Chem 272: 28869-74

Zhang J, Ferguson SS, Barak LS, Menard L, Caron MG (1996): Dynamin and betaarrestin reveal distinct mechanisms for $G$ protein-coupled receptor internalization. Biol Chem 271: 18302-18305

Zhang Z, Austin SC, Smyth EM (2001): Glycosylation of the human prostacyclin receptor: role in ligand binding and signal transduction. Mol Pharmacol 60: 480-487

Zhu BT (1993): The competitive and non-competitive antagonism of receptor mediated drug actions in the presence of spare receptors. J Pharmacol Toxicol Methods 29: 85-91 
Danksagung

Mein besonderer Dank gilt Herrn Professor Dr. Kurt Jungermann für die Überlassung des Dissertationsthemas und die zahlreichen anregenden und hilfreichen Diskussionen. Leider konnte er aufgrund einer schweren Krankheit, an der er im Mai 2002 verstarb, meine Arbeit nicht mehr bis zum Ende betreuen.

Mein Dank gilt auch Herrn Prof. Dr. Kurt von Figura, der meine Dissertation übernommen hat und zur problemlosen Beendigung der Arbeit einen großen Teil beigetragen hat.

Ich möchte auch Prof. Dr. Gerhard P. Püschel, dem Betreuer dieser Arbeit, besonders danken, da er mir stets mit Rat und Tat zur Seite stand und dessen Hilfsbereitschaft und die vielen hilfreichen Diskussionen zum Gelingen dieser Arbeit beigetragen haben.

Herrn Prof. Dr R. Hardeland möchte ich meinen Dank für die Übernahme des Korreferats aussprechen.

Für die vielen hilfreichen Ratschläge und die Unterstütztung und für all das, was ich von ihm gelernt habe, möchte ich mich bei Dr. Frank Neuschäfer-Rube bedanken.

Mein Dank geht auch an Dr. Alexandra Fennekohl, Dr. Ulrike Böer, Ulrike Möller, Christiane Spillner, Manuela Kuna, Eva Engemeier, Sina Koch, Nadine Priemer und all die anderen, die mit ihrer Unterstützung für ein freundliches Arbeitsklima und für viel Spaß im Labor gesorgt haben.

Den Mitarbeitern der Abteilung von Prof. Dr. Kurt Jungermann und den Mitgliedern der Werksatt möchte ich für das schöne Arbeitsklima, und daß sie mir immer behilflich waren, danken.

Nicht zuletzt möchte ich auch meiner Familie, meinen Freunden, und besonders Yvonne für die Unterstützung, ihr Verständnis und aufmunterenden Worte, die zum Gelingen dieser beigetragen haben, danken. 
LEBENSLAUF

Angaben zur Person:

Name:

Rehwald

Vorname:

Matthias

Geburtsdatum:

02. 08.1973

Geburtsort:

Homberg

Staatsangehörigkeit:

Deutsch

Schulbildung:

1980-1986

Grundschule Altmorschen

1986-1990

Gesamtschule Spangenberg

1990-1993

Oberstufengymnasium Melsungen mit Abschluß Abitur

Studium:

Oktober 1993

Immatrikulation an der Georg-August Universität zu Göttingen im Studiengang Biologie

Oktober 1995

Vordiplom in den Fächern: Zoologie, Mikrobiologie, Chemie und Physikalische Chemie

Oktober 1997 Hauptdiplomprüfung in den Fächern: Zoologie, Biochemie und Physikalische Chemie

November 1997-August 1998

Anfertigung der Diplomarbeit am Institut für Biochemie und Molekulare Zellbiologie der Georg-August-Universität mit dem Titel: „Vergleich der Bindungseigenschaften einer durch sequenzgerichtete Mutagenese des His81 in der zweiten Transmembrandomäne gewonnenen Prostaglandin $F_{2 \alpha}$ Rezeptormutante mit denen des Wildtyps“

September 1998

Beginn der experimentellen Arbeit zur vorliegenden Dissertation

März 2003

Abgabe der vorliegenden Dissertation 